\title{
Paleomagnetic Rotation Study of Woodlark-Australia plate motions in the Woodlark Rift, SE Papua New Guinea
}

by

Elizabeth Ann Cairns

A thesis

submitted to Victoria University of Wellington

In fulfilment of the requirements of

Master of Science In Geology

Victoria University of Wellington

2014 


\section{Acknowledgements}

I am grateful for the opportunity to be involved in such an exciting place as SE Papua New Guinea, so first thanks go to Tim Little, Laura Wallace, and Susan Ellis for being involved in research on PNG tectonics, and for having me join them on an unforgettable journey. This project has been both a challenging, and extremely fulfilling Introduction to an amazing place to study and visit - best trip of my life!!

I am especially grateful to my primary supervisor Prof. T.A. Little who has been integral to the progression of this study, not least for being half of the paleomagnetic sampling team in PNG. For being committed and encouraging; for useful critiques; and for being patient and sweet every time I cried in his office, my sincere thanks go to Tim.

I also would like to thank my secondary supervisor Dr Gillian Turner for teaching me the principles of Paleomagnetism and lending her expertise. I am very grateful to have the benefit of Gillian's experience, in terms of understanding the principles of the discipline, in the practical foundation that are the systems in the Paleomagnetism lab at VUW, and for direct assistance in reaching the results presented in this thesis.

Additional thanks go to Laura Wallace for providing me with GPS solutions that have informed the interpretation of my paleomagnetic results, and for enthusiastic and encouraging response to the outcomes of this research.

Susan Ellis also helped with paleomagnetic sampling in PNG, and her thoughts regarding the implications of certain results were very constructive to the final interpretations presented in this thesis.

I would like to thank lan Smith for lending me his personal copies of out of print geological maps that have been very useful to me through the course of this thesis, as well as for taking the time to meet with me in the planning stages to share his personal experience from working in PNG, towards identifying suitable paleomagnetic sampling targets for my project.

I owe great thanks to Martin Chadima for help with Remasoft software, in rewriting/altering the program especially to read in the specific data file format of my corrected LongCore output files.

Claudio Tapia provided me with warm introduction to and assistance in the paleomagnetic facilities at Otago University.

To the many friends and family who have provided support through the course of my study, thanks to you too!

Last but not least, I would like to acknowledge the many people in Papua New Guinea who helped us to find our way around the bush, and who carried heavy sampling gear all the while helping me over slippery rocks, and made the Papuan experience a joyful one. 


\section{Abstract}

The Woodlark Rift in SE Papua New Guinea is a continental rift to the west of active oceanic spreading in the Woodlark Basin, which separates the Australian Plate to the south from the relatively anticlockwise rotating Woodlark Plate to the north. During Pliocene to Recent times the Woodlark Rift has been the setting for rapid exhumation of the world's youngest UHP rocks (Baldwin et al., 2004, 2008; Gordon et al, 2012; Little et al., 2011), and is currently one of few places on the globe where active continental breakup is occurring ahead of a propagating oceanic spreading centre. While the Woodlark Basin contains a record of oceanic spreading since $6 \mathrm{Ma}$ (Taylor et al., 1999), and GPS data describe present-day crustal motions (Wallace et al., manuscript in review), the Neogene temporal and kinematic evolution of continental extension in the Woodlark Rift is less well constrained. We compare Characteristic magnetization directions for six formations, Early Miocene $(\sim 20 \mathrm{Ma})$ to Late Pliocene $(3 \pm 0.5)$, with contemporaneous expected field directions corresponding to Australian Plate paleomagnetic pole locations. We interpret declination anomalies (at $95 \%$ confidence) to estimate finite vertical-axis rotations of crustal blocks with respect to a fixed Australian Plate. Temporal and spatial relationships between declination anomalies for six formation mean directions, across four paleomagnetic localities, provide new evidence to constrain aspects of the Miocene to Recent history of the Woodlark Rift.

We obtained 250 oriented core samples from Miocene to Pliocene aged rocks at four localities in the Woodlark Rift. Components of Characteristic Remanent Magnetization (ChRM) have been determined from step-wise thermal and alternating field demagnetization profiles of $>300$ individual specimens. A total of 157 ChRM components contribute to the calculation of representative paleomagnetic directions for six formations, which have undergone vertical-axis rotations with respect to the Australian Plate associated with development of the Woodlark Rift.

Pliocene volcanic rocks at two key localities near the northern extent of the rift record that: 1) The Amphlett Islands has experienced $10.1 \pm 7.6^{\circ}$ of anticlockwise rotation since $3 \pm 0.5 \mathrm{Ma} ; 2$ ) NW Normanby Island has undergone a $16.3 \pm 9.5^{\circ}$ clockwise rotation during the same time interval. Sedimentary rocks at Cape Vogel Peninsula on the northern coast of the mainland Papuan Peninsula, record variable anticlockwise finite rotations of $28.4 \pm 10.9^{\circ}$ and $12.4 \pm 5.5^{\circ}$ for Early and Middle Miocene rocks respectively, in contrast to a younger clockwise rotation of $6.5 \pm 11.2^{\circ}$ for Late Miocene rocks. At the Suau Coast locality, on the south eastern coast of the Papuan Peninsula, Late Miocene dikes record $22.7 \pm 13.3^{\circ}$ of anticlockwise rotation.

At the Amphlett Islands and NW Normanby localities paleomagnetic data are consistent with current GPS plate motions, suggesting the current kinematics in the rift were established by at least $\sim 3 \mathrm{Ma}$. The Amphlett Islands result is consistent with the rate of Pliocene sea floor spreading in the Woodlark Basin, suggesting that locality can be considered as fully on the Woodlark Plate. The clockwise rotation indicated at NW Normanby Island may record development of an incipient dextral transfer fault within an active part of the Woodlark Rift.

Time-varying declination anomalies from the Cape Vogel Peninsula suggest that rifting began there by $\sim 15 \mathrm{Ma}, 7 \mathrm{Ma}$ earlier than previously inferred based on stratigraphic evidence. Furthermore, paleomagnetic data from the south coast of the Papuan Peninsula suggests that early rifting extended further south, and has since contracted to where continental extension is currently accommodated north of the Papuan Peninsula. 
Contents

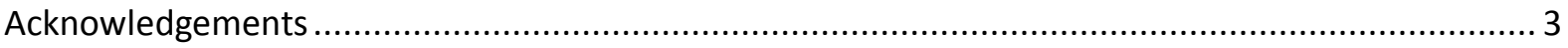

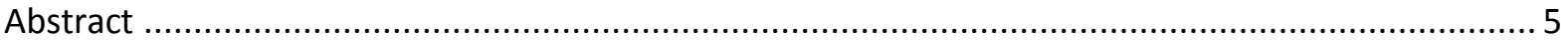

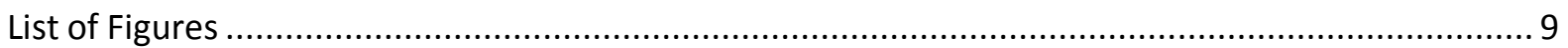

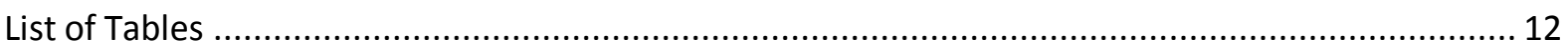

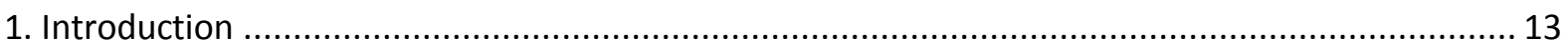

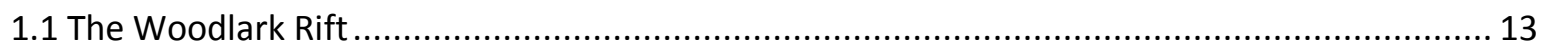

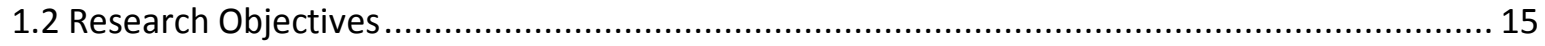

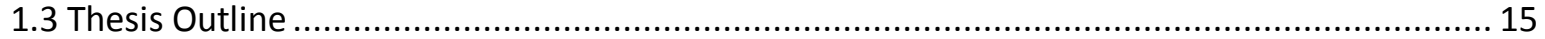

1.4 Regional Geological Setting, and a Cenozoic Tectonic History of the SE Papua New Guinea Region from the Literature .......................................................................... 19

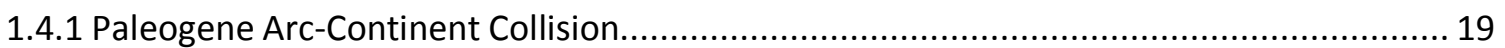

1.4.2 Miocene Basin Stratigraphy and Tectonic Implications Thereof ................................. 19

1.4.3 Pliocene to Recent Plate Motions, Rift Development, MCC exhumation, and Volcanism. . 21

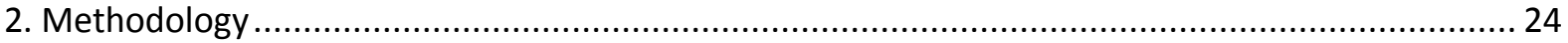

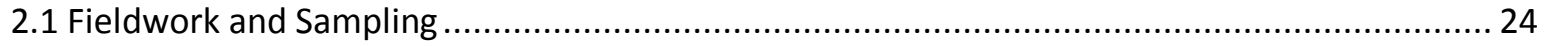

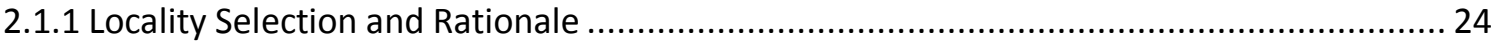

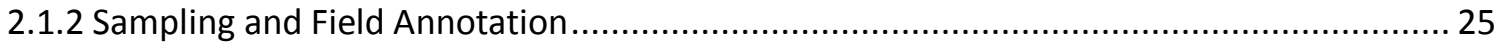

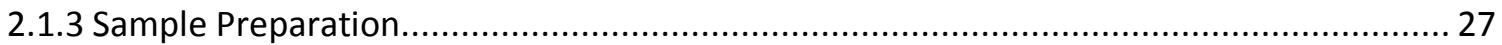

2.2 Natural Magnetization Processes and Magnetic Mineralogy ........................................... 28

2.2.1 Thin Section Petrology and Petrography.......................................................... 28

2.2.2 Temperature Dependent Susceptibility .......................................................... 29

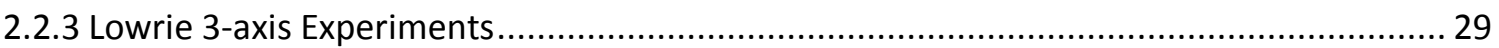

2.3 Measurement of NRM and Progressive Demagnetization....................................... 31

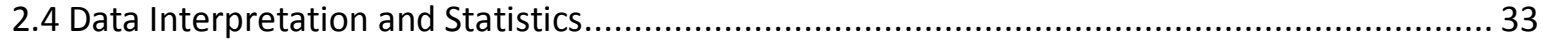

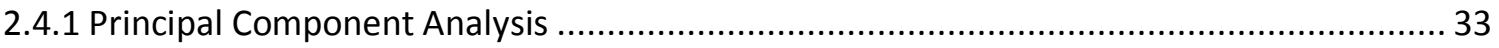

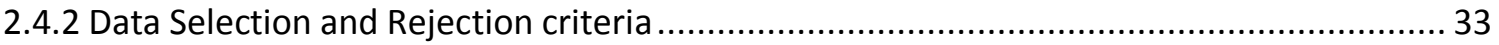

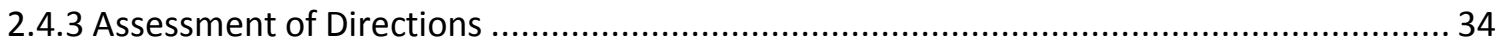

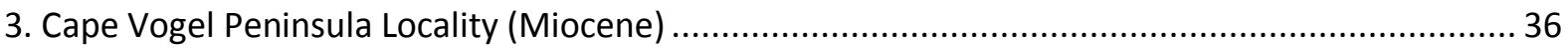

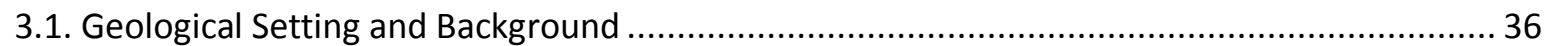

3.2 Field Relationships, Thin Section Petrography, and Applying a Structural Correction to

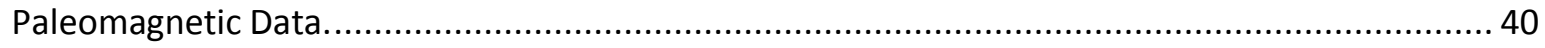

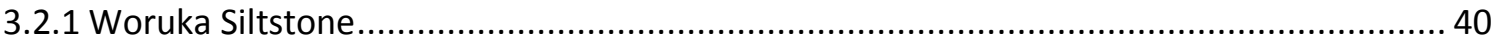

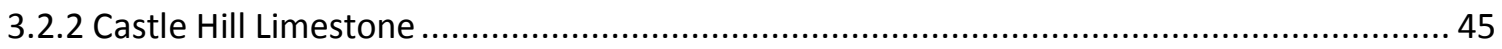


3.2.3 Tapio Marl.

3.3. Demagnetization Behaviour of Cape Vogel Peninsula Samples ...................................... 50

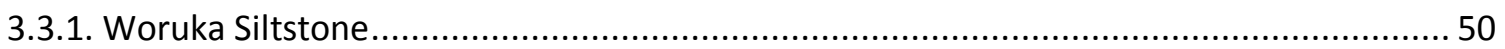

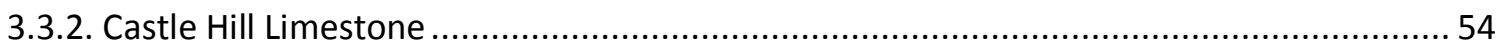

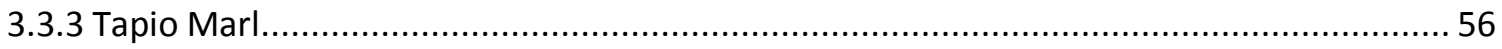

3.4 Group Statistics, Interpretation and Tectonic Implications ........................................60

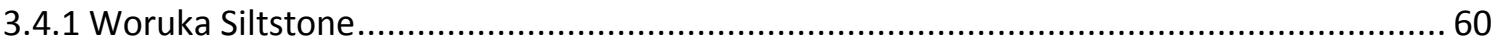

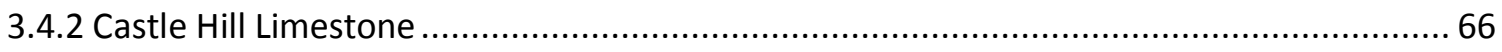

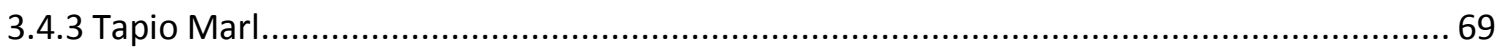

3.4.4 Synthesis and Tectonic Implications ....................................................... 74

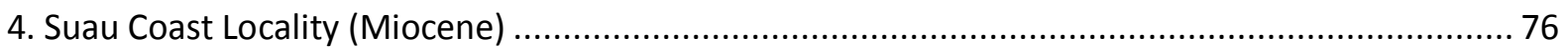

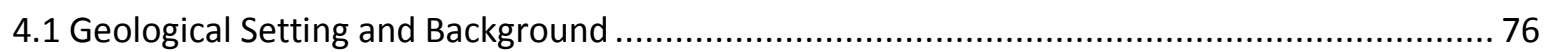

4.2 Field Relationships, Thin Section Petrography, and Structural Corrections to Paleomagnetic

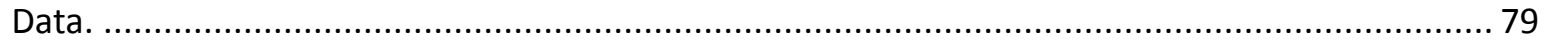

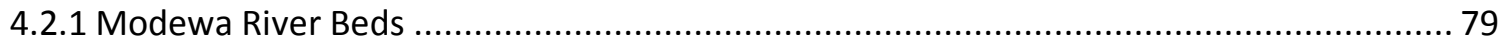

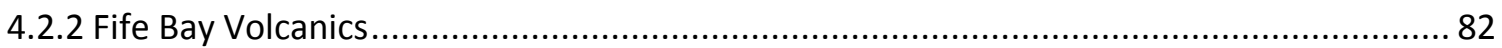

Demagnetization Behaviour and Data Selection................................................... 85

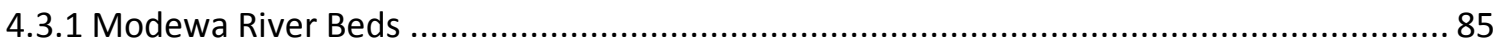

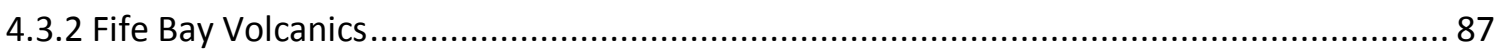

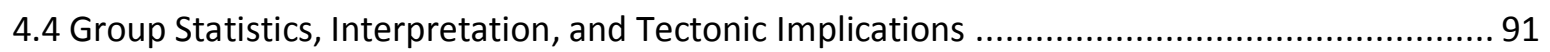

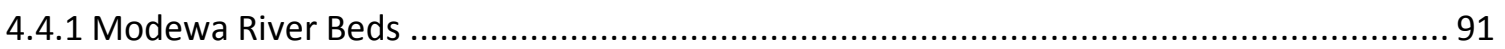

4.4.2 Fife Bay Volcanics............................................................................. 94

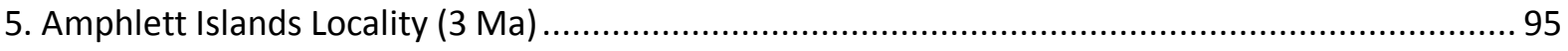

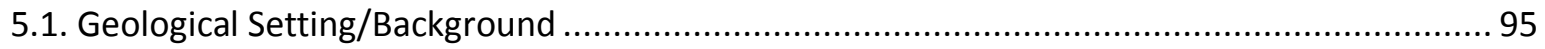

5.2. Sample Rocks - field relationships, petrography, and inferred structural correction............99

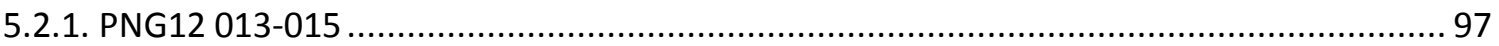

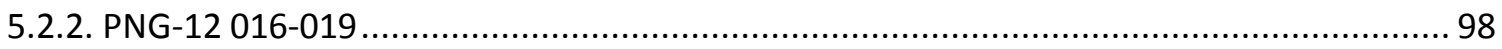

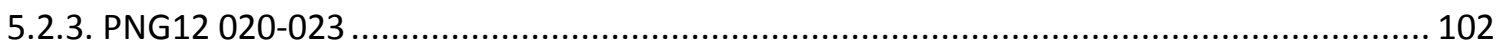

5.3 Magnetic Susceptibilty Experiments and Inferred Magnetic Mineralogy......................... 106

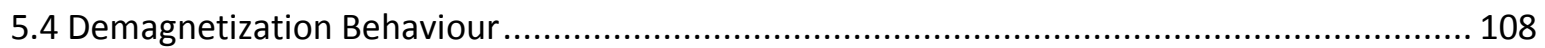

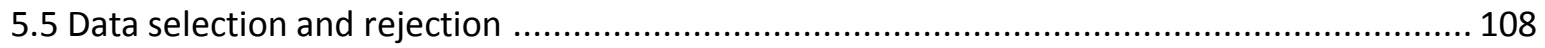

5.6 Group Statistics and Interpretation of Woodlark Plate Vertical Axis Rotation ................... 110

6. NW Normanby Island Locality (3 Ma) .............................................................. 114

6.1. Geological Setting and Background ......................................................... 114 
6.2 Sample Rocks - field relationships, petrography, and inferred structural correction. 119

6.3. Susceptibility Experiments and Inferred Magnetic Mineralogy . 121

6.4. Demagnetization Behaviour. 122

6.5 Group Statistics, Interpretation, and Tectonic Implications 126

7. Discussion \& Conclusions. 132

7.2 An Early Stage of Rifting. 135

7.3 Reorganisation of the Rift to the Pliocene Configuration 136

7.4 Pliocene to Recent Rotations of Crustal Blocks in the Woodlark Rift. 136

7.5 Possible avenues for further study. 140

7.6 Conclusions 141

References 142

APPENDIX A: Demagnetization Data 150

APPENDIX B: Sample Catalogue 150

APPENDIX C: Orientation Conventions. 151

APPENDIX D: Equations 152 


\section{List of Figures}

Introduction

Figure 1: Geological map of the Woodlark Rift study area......

Figure 2: Regional tectonic map of the SE Papua New Guinea region.

Figure 3: Miocene to recent stratigraphy and N-S cross section through the Trobriand and

Goodenough Basins.

Cape Vogel Peninsula Locality

Figure 4: Index map for the Cape Vogel Peninsula sample locality

Figure 5: Field photographs of the Woruka siltstone at sampling sites PNG-12-04 and PNG-12-

06

Figure 6: Photomicrographs of Claystone samples from the Woruka siltstone

Figure 7: Photomicrographs of basalt samples from the Woruka Siltstone.

Figure 8: Field photograph of the Castle Hill Limestone at sampling site PNG-12-08, and photomicrographs of Castle Hill Limestone samples.

Figure 9: Field photograph of the Tapio Marl at sampling site PNG-12-10, and photomicrographs of

Tapio Marl samples

Figure 10: Demagnetization plots for Woruka siltstone specimens. .52

Figure 11: Lowrie experiment and Temperature Dependent Magnetic Susceptibility plots for Woruka

Siltstone samples.

Figure 12: Demagnetization plots for Castle Hill Limestone specimens.

Figure 13: Lowrie experiment plots for Castle Hill Limestone samples. .55

Figure 14: Demagnetization plots for Tapio Marl specimens. .58

Figure 15: Lowrie experiment plots for Tapio Marl samples. . .59

Figure 16: Mean direction stereoplots for the Woruka Siltstone. .63

Figure 17: Mean direction stereoplots for the Castle Hill Limestone

Figure 18: Mean direction stereoplots for the Tapio Marl. .71

\section{Suau Coast Locality}

Figure 19: Index map for the Suau Coast sample locality. 
Figure 20: Photomicrographs of Modewa River Beds samples

Figure 21: Photomicrographs of Fife Bay Volcanics samples............................................................83

Figure 22: Demagnetization plots for Modewa River Beds specimens...............................................86

Figure 23: Demagnetization plots for Fife Bay Volcanics specimens................................................. 88

Figure 24: Temperature Dependent Magnetic Susceptibility plots for Fife Bay Volcanics samples

Figure 25: Mean direction stereoplots for the Modewa River Beds.

Figure 26: Mean direction stereoplots for the Fife Bay Volcanics

Amphlett Islands locality

Figure 27: Index map for the Amphlett Islands sample locality.........................................................96

Figure 28: Field photographs for sampling sites PNG-12-14 and PNG-12-15 ....................................98

Figure 29: Field photographs for sampling sites PNG-12-16 to PNG-12-19.......................................100

Figure 30: Photomicrographs of andesite samples from sampling sites PNG-12-16 to PNG-1219

Figure 31: Field photographs for sampling sites PNG-12-20 to PNG-12-23.

Figure 32: Photomicrographs for andesite samples from sampling sites PNG-12-20 to PNG-12-

23

Figure 33: Temperature Dependent Magnetic Susceptibility plots for andesite samples from the Amphlett Islands

Figure 34: Demagnetization plots for Amphlett Islands specimens .109

Figure 35: Mean direction stereoplots for the Amphlett Islands Andesite

NW Normanby Island locality

Figure 36: Index map for the NW Normanby Island sample locality

Figure 37: Field photographs for the NW Normanby Island sample locality

Figure 38: Photomicrographs of dike samples from NW Normanby Island

Figure 39: Temperature Dependent Magnetic Susceptibility plots for dike samples from the NW Normanby Island.

Figure 40: Demagnetization plots for NW Normanby Island dike specimens. 123 
Figure 41: Demagnetization plots for duplicate AF \& TH treated specimens from the NW Normanby

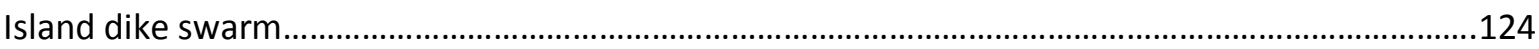

Figure 42: Interpretation of baked contacts in the NW Normanby Island dike swarm...................125

Figure 43: Mean direction stereoplots for the NW Normanby Island dike swarm..........................128

Figure 44: Interpretive map of the Dawson Strait area to show the proposed location of the Dobu Transfer Fault (this study)

\section{Discussion and Conclusions}

Figure 45: Summary map to show rotations relative to a fixed Australian Plate derived from mean ChRM and SRM directions from sampled formations

Figure 46: Schematic map representation of the inferred tectonic setting in the SE Papua New Guinea region and changes during the Late Cenozoic. 


\section{List of Tables}

Methodology

Table 1: Summary of sample sites

Cape Vogel Peninsula Locality

Table 2: Australian Plate GAD field expected directions for the Cape Vogel Peninsula locality 60

Table 3: Low blocking-temperature, and low coercivity (SRM) components for specimens from the Woruka Siltstone.

Table 4: ChRM components for specimens from the Woruka Siltstone. .65

Table 5: Low coercivity (SRM) components for specimens from the Castle Hill Limestone. 68

Table 6: High coercivity, and low temperature (ChRM) components for specimens from the Castle Hill Limestone.

Table 7: Low blocking-temperature, and low coercivity (SRM) components for specimens from the Tapio Marl.

Table 8: High blocking-temperature, and high coercivity (ChRM) components for specimens from the Tapio Marl.

\section{Suau Coast Locality}

Table 9: Australian Plate GAD field expected directions for the Suau Coast locality

Table 10: Low blocking-temperature, and low coercivity (SRM) components for specimens from the Modewa River Beds.

Table 11: ChRM components retained for calculation of the Fife Bay Volcanics mean direction.

\section{Amphlett Islands locality}

Table 12: Australian Plate GAD field expected directions for the Amphlett Islands locality......

Table 13: ChRM components retained for calculation of the Amphlett Islands locality mean direction

\section{NW Normanby Island locality}

Table 14: Australian Plate GAD field expected directions for the NW Normanby Island locality......127

Table 15: ChRM components retained for calculation of the NW Normanby Dike Swarm mean direction. 


\section{Introduction}

\subsection{The Woodlark Rift}

In this thesis I present the results of a vertical-axis rotation study using new paleomagnetic data from Miocene to Pliocene aged rocks sampled across the Woodlark Rift, SE Papua New Guinea. The approximately $100 \mathrm{~km}$ wide Woodlark Rift is currently situated to the north of the Papuan Peninsula in SE Papua New Guinea, and is a zone of active continental extension that lies to the west along strike from the Woodlark Basin Oceanic spreading centre that separates the Woodlark Plate to the north from the Australian Plate to the south (Fig. 1).The Woodlark Rift is known to have accommodated an estimated $\sim 50 \mathrm{~km}$ of north-south crustal extension since 8.4 Ma (Fitz \& Mann, 2013). During Pliocene to Recent times the active extensional setting of the Woodlark Rift has hosted several metamorphic core complexes, some of which contain the world's youngest known Ultra-High Pressure (UHP) rocks (Baldwin et al., 2004, 2008; Gordon et al, 2012; Little et al., 2007, 2011). It is also one of only few places in the world where continental breakup is known to be occurring today (Coffin et al., 2006; Sawyer et al., 2007). In order to fully understand the tectonic evolution of the SE Papua New Guinea setting it is necessary to constrain the temporal and kinematic evolution of the Woodlark Rift.

In this study I have used paleomagnetic data from six Miocene to Pliocene formations in the Woodlark Rift to constrain finite vertical-axis rotations with respect to an Australian Plate reference frame, towards better understanding the temporal and kinematic evolution of the Woodlark Rift since the Early Miocene.

Papua New Guinea is located between the major Australian and Pacific Plates, whose oblique convergence of about $110 \mathrm{~mm} / \mathrm{yr}$ is accommodated across the Papua New Guinea region (Wallace et al., 2004). That plate boundary zone is fragmented into several micro-plates that rotate rapidly with respect to each other about nearby Euler poles, and that are bounded by a diversity of plate boundary types (Tregoning et al., 1998; Wallace et al., 2004). One of those plate boundaries separates the Woodlark Plate to the north from the Australian Plate to the south. That boundary coincides with a west-to-east transition from continental extension in the Woodlark Rift to active sea floor spreading in the Woodlark Basin. In the area of the oceanic Woodlark Basin in the Solomon Sea, sea floor spreading rates between the Woodlark and Australian Plates are well constrained, both by Global Positioning Systems (GPS) data, and by sea floor magnetic anomalies (Taylor et al., 1999). Both indicate that the Woodlark Plate is currently rotating anticlockwise with respect to Australia. The most recent GPS data derive a contemporary Woodlark Plate rotation rate of $2.1 \pm 0.3$ $\% / \mathrm{Ma}$, about a pole located to the west of the study area at $11^{\circ} \mathrm{S}, 147^{\circ} \mathrm{E}$ (Fig.2) (Wallace et al., 2012, manuscript in review). Today the eastern part of the Woodlark Rift is undergoing north-south crustal extension at a rate of up to $3.8 \mathrm{~cm} / \mathrm{yr}$ (Wallace et al., manuscript in progress). That extension is chiefly accommodated by slip on several major active normal faults (Fig.2; Little et al., 2007). These faults bound several blocks that rotate differentially with respect to one another within a zone to the north of the Papuan Peninsula, encompassing Goodenough Bay and the D'Entrecasteaux Islands (Wallace et al., manuscript in review). Known active-slip transfer faults that also contribute to the rift kinematics include the Trobriand Transfer Fault (Little et al., 2007), the Normanby Island Transfer Fault, as well as the active Nubara Transfer (Taylor et al., 1999; Taylor \& Huchon, 2002; Wallace et al., manuscript in review). GPS data for sites on the SE Papuan Peninsula indicate little motion 
relative to the Australian Plate farther south (Wallace et al., manuscript in review), so the southern extent of the currently active Woodlark Rift appears to lie to the north of those GPS stations on the Papuan Peninsula. While GPS measurements can be very useful in modelling contemporary patterns of crustal deformation, such data have limited applications for understanding the evolution of plate boundary zones on the timescale of millions of years to tens of millions of years.

The onset of rifting in the Woodlark Rift is generally accepted to be around $8 \mathrm{Ma}$ based on stratigraphic analysis of cores from ODP leg 180 in the Western Woodlark Basin (Fig. 1). There, and elsewhere in the Woodlark Rift, a regional unconformity is age constrained to be $8.4 \mathrm{Ma}$ based on foraminiferal content of underlying and overlying sedimentary rocks. It has been interpreted as a syn-rift-onset paleo-sea-level erosion surface based on on-lapping depositional facies (Taylor and Huchon 2002). The sedimentary rocks that overly this unconformity record an increase in accommodation space, most likely predominantly due to rift related subsidence, but surely with some contribution from eustatic sea level rise and thermal subsidence (Taylor and Huchon 2002). The correlation of seismic horizons dated in leg 180 drill cores, through a grid of reflection profiles into the Moresby Rift (a submarine graben complex to the north of Moresby Seamount; Fig. 1) , show that the earliest graben in-fill sediments there are older than $5.5 \mathrm{Ma}$, but younger than the 8.4Ma unconformity (Taylor and Huchon 2002). Taylor and Huchon (2002) suggest extensional faulting began there $\sim 8 \mathrm{Ma}$.

Sea floor spreading certainly was underway in the eastern Woodlark Basin by $6 \mathrm{Ma}$, as evidenced by magnetic anomaly 3A.1 being recorded there (Taylor et al., 1999). However young oceanic crust is currently being subducted to the east at the San Christobal Trench, and it is clear that some even older ocean floor has been subducted there (Taylor et al., 1999). The oceanic spreading centre in the Woodlark Basin initiated towards the east, and has propagated approximately $500 \mathrm{~km}$ west in the past 6 Myr (Taylor et al., 1999). Importantly for this thesis, one cannot assume that the kinematics of sea floor spreading in the Woodlark Basin during the Pliocene (Kington \& Goodliffe, 2008; Taylor et al., 1999) is a template for the kinematics of the continental Woodlark Rift farther to the west.

The paleomagnetic approach employed in this thesis is an attempt to provide an entirely new data set aimed at resolving the kinematics and timing of rifting in the Woodlark Rift zone since the Miocene. Paleomagnetic samples were collected in the Woodlark Rift during May-June 2012, as part of a Marsden funded project (Grant 08-VUW-02, awarded to T.A. Little., L. Wallace. \& S. Ellis) on active deformation and UHP exhumation in the Woodlark Rift. Characteristic magnetization directions were determined for seven formations sampled, ranging in age from Early Miocene ( $\sim 20$ $\mathrm{Ma})$ to Late Pliocene ( $3 \pm 0.5 \mathrm{Ma}$ ). Declination anomalies were calculated for each of those characteristic directions by comparison with a Geocentric Axial Dipole (GAD) expected field direction corresponding to the contemporaneous Australian Plate paleomagnetic pole location for the Late Cenozoic (Idnurm, 1985; Turner, 2007; Veevers \& Li, 1991). Those declination anomalies are interpreted to be estimates of vertical-axis rotations of fault-bounded blocks in the Woodlark Rift, with respect to a fixed Australian Plate. These data were compiled and interpreted in order to constrain a new tectonic history of the Woodlark Rift since the Early Miocene. 


\subsection{Research Objectives}

This study aims to contribute paleomagnetic constraints on the temporal and spatial development of the Woodlark Rift since the Miocene. The key objectives of this study are as follows:

1) I aim to constrain the age of rift onset in the Woodlark Rift. Rocks deposited at different times through the history of rifting should have experienced different finite vertical-axis rotations associated with extension relative to the Australian Plate. Rocks dating prior to the onset of rifting should however have uniformly experienced the full finite rotation associated with extension to date. At two localities on the Papuan Peninsula (Cape Vogel Peninsula and Suau Coast) we sampled more than one formation of Miocene age. At two localities in the D'Entrecasteaux Islands area (NW Normanby Island and the Amphlett Islands) we sampled Pliocene age volcanic rocks. Within the span of those formation ages we aim to constrain the age of rift onset to within a few million years.

2) I aim to constrain the spatial extent of the Woodlark Rift through its history. Paleomagnetic pole locations determined for the Australian Plate through the Cenozoic (Idnurm, 1985; Turner, 2007; Veevers \& Li, 1991) provide a reference frame for the paleomagnetic data of this study. The southern extent of the Woodlark Rift forms part of the north-eastern boundary of the Australian Plate. Paleomagnetic directions from locations that have remained moving as part of the Australian Plate, to the south of the Woodlark Rift, should yield directions corresponding to Geocentric Axial Dipole field directions corresponding to Australian Plate paleomagnetic pole locations. The northern extent of the Woodlark Rift coincides with the southern boundary of the Woodlark Plate. The Woodlark Plate is considered as a stable lithospheric block to the north of the E-W striking Woodlark Rift to oceanic spreading transition, which has been rotating anticlockwise with respect to the Australian Plate, about the Euler pole that describes sea floor spreading in the Woodlark Basin. Thus If a paleomagnetic locality is located on the Woodlark Plate, it should yield a direction with declination that is anticlockwise rotated from an Australian Plate expected direction, to a degree consistent with the record of sea floor spreading since formation of the sample rocks. Localities within the rift should yield variable finite vertical-axis rotations corresponding to the crustal motions that have occurred in the continental rift zone.

3) I aim to provide constraints on the motion of crustal blocks in the Woodlark Rift, relative to Australia, during the Miocene to Recent history of rift development. The sense and magnitude of deflection of ChRM directions from an expected direction for the Australian Plate, at sites that are on a rotated crustal block, should reflect the sense and rate of slip on tectonic structures that bound them.

\subsection{Thesis Outline}

This thesis is organised into 7 chapters. The following sections of this introductory chapter will summarise what is known about the tectonic history of the SE Papua New Guinea region through the Cenozoic, to set the scene of this study. Chapter 2 describes the paleomagnetic analytical methods employed in this study. The subsequent four chapters (Chapter 3: Cape Vogel Peninsula, Chapter 4: Suau Coast, Chapter 5: Amphlett Islands Group, and Chapter 6: NW Normanby Island Dike Swarm) describe the geology, sampling and paleomagnetic analysis of the four chief localities investigated in the Woodlark Rift (Fig. 1). For each locality I begin by outlining the geological history and context of that locality, including the depositional environment and the style and degree of deformation of the rocks sampled there. Each of those chief localities includes up to twelve paleomagnetic sample sites 
distributed across an area of up to $75 \mathrm{~km}^{2}$, and embraces one to three formations of sedimentary and igneous rocks. The sampled rocks range in age from Early Miocene ( $20 \mathrm{Ma}$ ) to Late Pliocene ( 3 $\pm 0.5 \mathrm{Ma}$ ), and consist of marine clastic and carbonate strata, as well as basaltic to andesitic flows and dikes. After describing each formation and the way in which it was sampled, I present paleomagnetic data for that formation, and interpret the various components of magnetic remanence that can be identified. Finally, I calculate and then interpret any vertical-axis rotations of the locality with respect to the Australian Plate. The final chapter of this thesis (Chapter 7: Discussion \& Conclusions) summarises and integrates these data, and presents a new interpretation of the Neogene tectonic history of the SE Papua New Guinea region.

Figure 1 (next page). Regional map to show active tectonic structures, as well as estimates of Pliocene to Recent plate motions derived from (Euler pole in blue) magnetic anomalies in the Woodlark Basin sea floor spreading centre (Taylor et al., 1999), and from (Euler pole in red) inversion of GPS data and slip vectors (Wallace et al., 2004). Orange arrows depict a best fit velocity field describing Woodlark plate motion relative to Australia between 0.5 Ma to recent (Wallace et al., 2004). Eastward subduction of Woodlark Basin oceanic lithosphere is occurring at the San Christobal Trench. Northward subduction of Solomon Sea lithosphere is occurring at New Britain trench. The Nubara Transfer Fault(, and the Trobriand Transfer Fault (Little et al., 2007) accommodate transfer of differential rates of extension that is predominantly localized on the active Mai'iu Normal Fault, the Gneiss dome bounding D'Entrecasteaux Islands faults, and the Moresby Detachment Fault in the western Woodlark Basin 


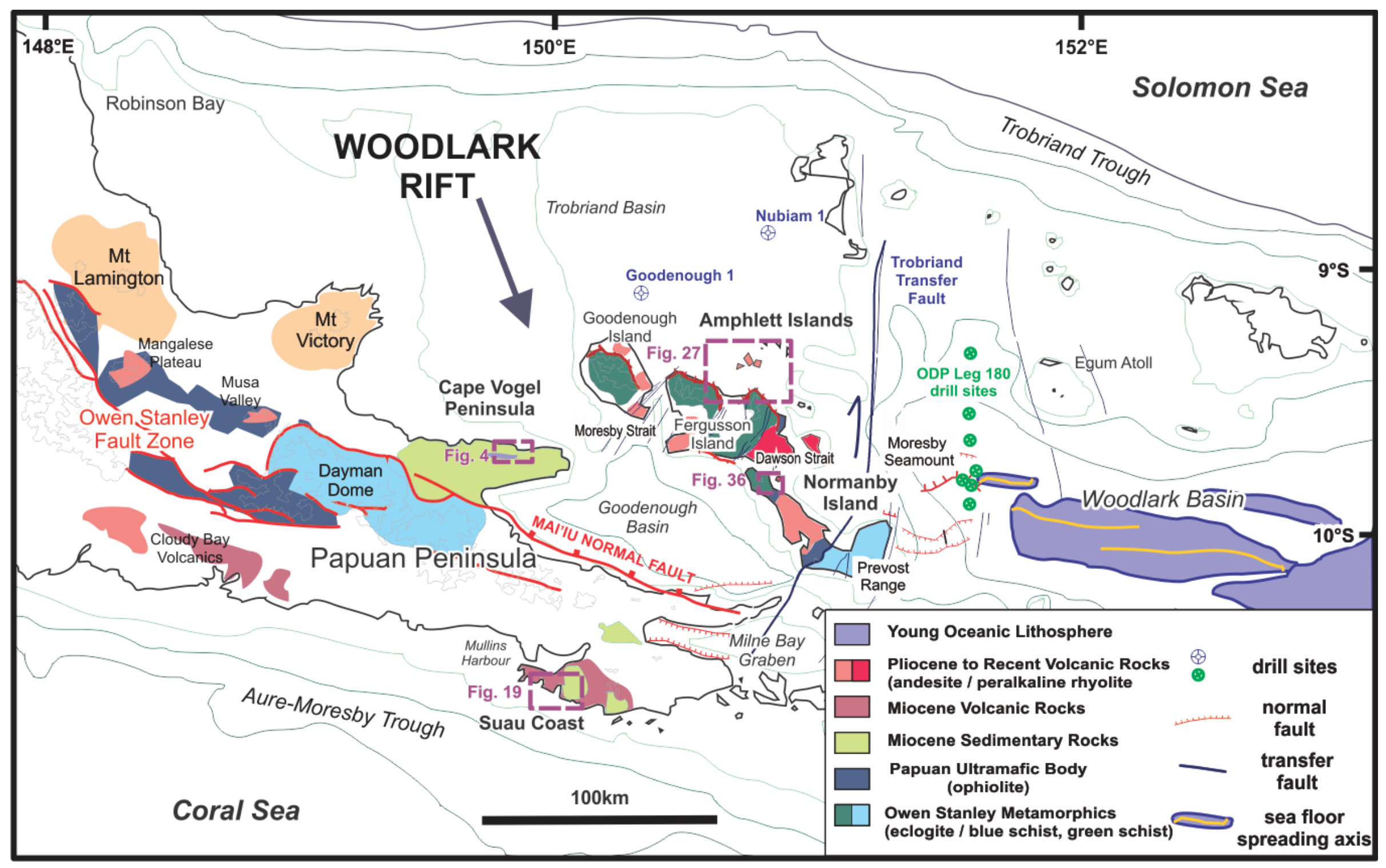




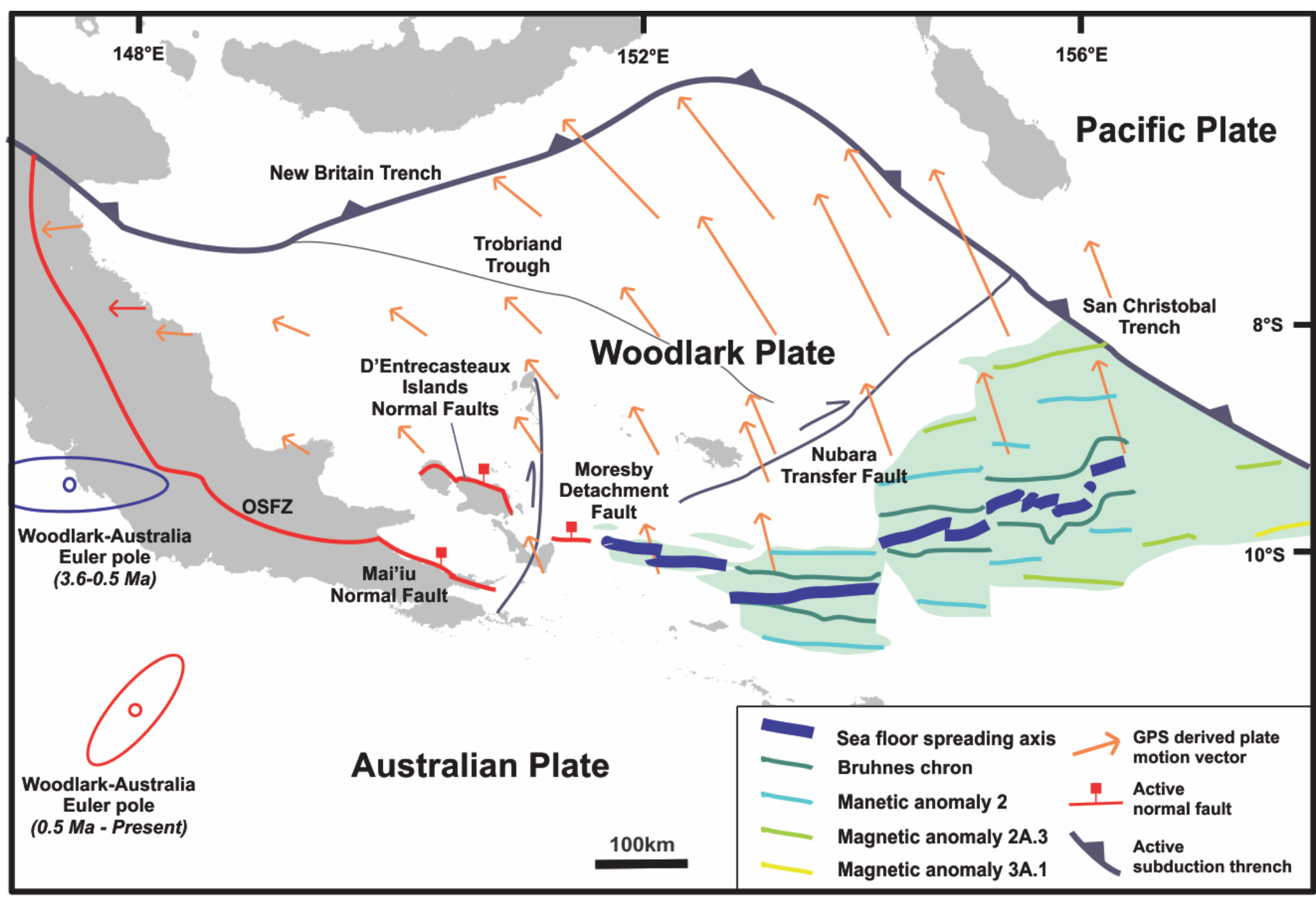

Figure 2. Regional map to show active tectonic structures, as well as estimates of Pliocene to Recent plate motions derived from (Euler pole in blue) magnetic anomalies in the Woodlark Basin sea floor spreading centre (Taylor et al., 1999), and from (Euler pole in red) inversion of GPS data and slip vectors (Wallace et al., 2004). Orange arrows depict a best fit velocity field describing Woodlark plate motion relative to Australia between $0.5 \mathrm{Ma}$ to recent (Wallace et al., 2004). Eastward subduction of Woodlark Basin oceanic lithosphere is occurring at the San Christobal Trench. Northward subduction of Solomon Sea lithosphere is occurring at New Britain trench. The Nubara Transfer Fault, and the Trobriand Transfer Fault (Little et al., 2007) accommodate transfer of differential rates of extension that is predominantly localized on the active Mai'iu Normal Fault, the Gneiss dome bounding D'Entrecasteaux Islands faults, and the Moresby Detachment Fault in the western Woodlark Basin. 


\subsection{Regional Geological Setting, and a Cenozoic Tectonic History of the SE}

\section{Papua New Guinea Region from the Literature}

\subsubsection{Paleogene Arc-Continent Collision}

Basement terranes of the Papuan Peninsula are mainly comprised of low and high grade metamorphosed sedimentary and volcanic protoliths derived from continental crust of Australian Plate proto-affinity (Owen Stanley Metamorphics) (Davies \& Jaques, 1984), and an obducted ophiolite Papuan Ultramafic Body (PUB) (Davies \& Jaques, 1984). These metamorphic rocks were accreted during the Paleogene Papuan Orogeny as a result of Northward subduction of Australian Plate lithosphere beneath oceanic lithosphere of the Melanesian Arc (Davies \& Jaques, 1984; Quarles van Ufford \& Cloos, 2005). During that orogeny a previously thinned part of the Australian continent collided with an ocean-arc terrane to its north, represented by the Papuan Ultramafic Body ophiolite which was obducted southward during that collision (Davies \& Jaques, 1984; Quarles van Ufford \& Cloos, 2005). The obduction took place along a northwest-southeast suture dipping north, called the Owen Stanley Fault Zone (OSFZ), the near $600 \mathrm{~km}$ trace of which runs the length of the Papuan Peninsula (Fig. 1). Submarine volcanism in the collided arc is associated with the Papuan Ophiolite, and includes the Paleocene Dabi Volcanics (Walker \& McDougall, 1982). These volcanic rocks are the oldest exposed unit at our Cape Vogel Peninsula sample locality, where they are unconformably overlain by Miocene sedimentary rocks (Fig. 1). South of the arc-continental collision in the Paleocene, the Coral Sea Basin began to form by rifting of continental crust that now forms the Papuan Plateau away from the Queensland Plateau on the northeast margin of the Australian Continent (Mutter, 1977). Sea floor spreading was underway there in the Late Paleocene to Early Eocene, between $\sim 62-56 \mathrm{Ma}$ (Weissel \& Watts, 1979). Eocene sedimentary rocks deposited in the newly formed ocean basin were sampled by Deep Sea Drilling Project (DSDP) leg 21 (Burns et al., 1973). The clastic component of those strata has an Australian Continental source (Burns et al., 1973; Mutter, 1977), an observation that suggests that the Papuan Peninsula may not yet have been exposed to erosion. The Eocene Kutu Volcanics found on the southeast Papuan Peninsula today, are submarine basalts up to $3 \mathrm{~km}$ thick in places and represent widespread submarine volcanism coeval with the Papuan Orogeny (Smith \& Davies, 1976). These may have formed by spreading processes in the Coral Sea Basin prior to their subduction and imbrication. Ar/Ar dating of amphibole from the metamorphic sole of the PUB suggests that ophiolite obduction was underway by $58 \mathrm{Ma}$ (Lus et al., 2004). Younger (45-22 Ma) K/Ar and Ar/Ar amphibole and mica ages in the Owen Stanley Metamorphics on the Papuan Peninsula (Davies \& Williamson, 1998), suggest that the Papuan orogeny continued through to the Oligocene but was probably over by the Early Miocene (Davies \& Jaques, 1984; Quarles van Ufford \& Cloos, 2005). By the Early Oligocene, uplift and exposure of the collisional fold thrust belt had shed a $7 \mathrm{~km}$ thickness of clastic material into the frontal Aure Trough or foredeep (Quarles van Ufford \& Cloos, 2005).

\subsubsection{Miocene Basin Stratigraphy and Tectonic Implications Thereof}

The Miocene to Recent history of the Woodlark Rift has largely been inferred by analysis of the stratigraphic and seismic data in the Trobriand Basin, including from the Goodenough-1 and Nubiam-1 exploration wells (Fig. 1) and ODP leg 180 in the western Woodlark Basin (Fig. 1) (Robertson et al., 2001; Taylor \& Huchon, 2002), as well as of Miocene aged sedimentary and volcanic rocks exposed on the Papuan mainland (Davies, 1971; Smith \& Davies, 1976). Those records can be correlated through Multi Channel Seismic (MCS) profiles across the offshore basins 
surrounding the Papuan Peninsula. Fitz and Mann (2013) have recently proposed a tectonic history of the Trobriand and Goodenough Basins in the Woodlark Rift, based on interpreted Multi Channel Seismic (MCS) reflection profiles. They follow Taylor \& Huchon (2002) in interpreting the Trobriand Basin as initiating as an asymmetric forearc basin in the Early Miocene, that was bounded by south dipping normal faults to the southwest of the Trobriand Trough which they infer to have been an active north facing subduction zone in the Miocene (Fitz \& Mann, 2013). This interpretation posits that oceanic lithosphere of the Solomon Sea was subducted southward at the Trobriand Trough (Davies et al., 1987; Fitz \& Mann, 2013; Smith \& Milsom, 1984; Quarles van Ufford \& Cloos, 2005; Taylor et al., 1999; Taylor \& Huchon, 2002). While high-K Miocene volcanic rocks in the SE Papua New Guinea region have been attributed to subduction related volcanism based on trace element signatures, there may be other explanations for those melt compositions through interaction with, or melting of arc-continental rocks (Catalano, 2012; Smith, 1982; Taylor et al., 1995). Presently there is little evidence for subduction at the Trobriand Trough, and no obvious southward dipping subducted slab has been imaged beneath the Trobriand Basin (Abers et al. 2002; Abers \& Roecker, 1991; Hall \& Spakman 2002; Wallace et al. 2004).

During the Early Miocene, the SE Papuan Peninsula was fringed by relatively starved marginal plateaux to the north and south, and with subsiding basins to the north and south of carbonate platforms. While clastic wedges were shedding into the Trobriand Basin to the north and the Papuan Gulf to the southwest at that time (Fitz \& Mann, 2013; Taylor \& Huchon, 2002; Wang \& Stein, 1992), carbonaceous silty claystone and limestone were respectively deposited near the current Cape Vogel Peninsula to the north of the Papuan Peninsula, and the Suau Coast to the south of it (Fig. 1) (Smith \& Davies, 1976). The limestones were deposited in shallow water (Bickel, 1974; Smith \& Davies, 1976) and the sparsity of clastic material that they contain suggest those areas were located on marginal plateaux isolated from the dominant clastic sedimentation that was taking place in the surrounding deep water basins. Carbonate deposition on those marginal plateaux was locally accompanied by submarine volcanism (e.g. basaltic interbeds in the Woruka Siltstone on the Cape Vogel Peninsula, see Chapter 3, section 2.1, as well as the lauga Formation near Robinson Bay further NW, Fig. 1) (Bickel, 1974).

Reef growth and isolated volcanism continued during the Middle Miocene both on the northern margin of the current Papuan Peninsula (Bickel, 1974; Smith \& Davies, 1976) and to the south (Davies \& Smith, 1971). During that time the main part of the Trobriand basin further north was subsiding as a symmetrical sag basin (Fitz \& Mann, 2013). South of that basin, Middle to Late Miocene volcanic rocks occur on the Papuan Peninsula, which are predominantly andesitic in composition and exhibit a trend of apparent younging to the west (Johnson, 1978; Smith, 1982; Smith \& Compston, 1982; Smith \& Milsom, 1984). That Middle Miocene volcanism, interpreted as subduction related, became increasingly subaerial with uplift and exposure of the Papuan Peninsula (Smith, 1982). South of the Papuan Peninsula, an increased rate of subsidence during the Miocene is evidenced by an increase in accommodation space drowning coral platforms on the Queensland and Marion Plateaux (DiCaprio et al., 2010; Wilson \& Hall, 2010), and in the Coral Sea Basin there was a change from carbonate sedimentation to deposition of abyssal clay or non-deposition below compensation depth (Mutter, 1977). Rapid subsidence also took place during the Miocene in the Gulf of Papua to the west of the study area (Mutter, 1977; Wang \& Stein, 1992). 
Deposition in the Coral Sea Basin renewed in the late Middle to Late Miocene with an influx of graded silt and clay turbidites, and the clastic component of those sediments suggests erosion of a New Guinea Source to the north (Mutter, 1977). This suggests a period of uplift, and exposure of the SE Papuan Peninsula by the Late Miocene. Following Taylor \& Huchon (2002), Fitz \& Mann (2013) proposed a phase of compression caused the reactivation and inversion of pre-existing normal faults in the Late Miocene, followed by renewed extension in the Woodlark Rift during the Pliocene to Recent. The terrigenous component in the Late Miocene Tapio Marl at Cape Vogel, overlying reefal limestone of the Castle Hill Limestone, suggests the arrival of siliclastic input there around the Late Miocene (see Chapter 3, section 2.3).

\subsubsection{Pliocene to Recent Plate Motions, Rift Development, MCC exhumation, and Volcanism.}

The Woodlark Basin sea floor preserves a record of sea floor spreading since at least $6 \mathrm{Ma}$ (Taylor et al., 1999). The spreading ridge has propagated approximately $500 \mathrm{~km}$ westward in the past $6 \mathrm{Ma}$ (Kington \& Goodliffe, 2008; Taylor et al., 1999). Westward propagation of the Woodlark Basin spreading axis has been accomplished at a discontinuous rate by a combination of propagation, and periodic westward jumps to form discrete cells of sea floor spreading (Martinez et al., 1999; Taylor et al., 1999). The Euler pole for Woodlark Australia Plate motion derived from magnetic anomalies between $3.6-0.5 \mathrm{Ma}$ is located at $9.3^{\circ} \mathrm{S}, 147^{\circ} \mathrm{E}$ with a $4.2^{\circ} / \mathrm{Myr}$ rate anticlockwise Woodlark Plate rotation relative to Australia (Fig.2; Taylor et al., 1999). A GPS derived best fit plate motion pole for $0.5 \mathrm{Ma}$ to present is located further south at $11.3^{\circ} \mathrm{S}, 147.6^{\circ} \mathrm{E}$, with a slower anticlockwise rotation of $2.8^{\circ}$ Myr (Fig.2; Wallace et al., 2004).

Fitz \& Mann (2013) propose that the current Woodlark Rift developed during extension that began in the Late Miocene. On-going extension was associated with exhumation of the UHP bearing gneiss domes of the D'Entrecasteaux Islands, and with subsidence and faulting in the Goodenough Basin. At the same time, the Trobriand Basin continued to subside as a symmetrical sag basin. The young UHP terranes of the D'Entrecasteaux Islands preserve petrologic and petrographic evidence for a rapid Pliocene exhumation history that followed eclogite facies metamorphism of Late Miocene to Early Pliocene age (Baldwin et al., 2004, 2008; Gordon et al., 2012; Little et al., 2007, 2011, 2012; Monteleone, 2007). Rapid vertical motions during Pliocene to Recent rifting are expressed by the contrast in lithology between rocks of Pliocene age in the D'Entrecasteaux Islands and on Cape Vogel Peninsula, as well as by rapid subsidence and accumulation of sediment in the nearby Goodenough Basin. Pliocene eclogite facies bearing gneisses are found at $2.5 \mathrm{~km}$ elevation on Goodenough Island (Little et al., 2011), yet less than $30 \mathrm{~km}$ to the southeast, relatively undeformed un-metamorphosed Pliocene sedimentary rocks occur near sea level on the Cape Vogel Peninsula (Bickel, 1974; Smith \& Davies, 1976). To the southeast of these sites, the Goodenough Basin has subsided at least $5 \mathrm{~km}$ since the formation of an 8.4 Ma regional unconformity at sea level (Fitz \& Mann, 2013; Taylor et al., 1999; Taylor \& Huchon, 2002). This dramatic juxtaposition is the result of gneiss dome emplacement, a process that Fitz \& Mann (2013) suggest was accommodated by lower crustal flow and extension off to the flanks of the domes. That inference is based on geophysical observations of other workers that indicate the Woodlark Rift continental crust is thinned, with elevated Moho and geotherm (Abers, 2002; Kington \& Goodliffe, 2008; Martinez et al., 2001).

One of the major extension accommodating structures in the Woodlark Rift today, and probably also in the past, is the Mai'iu Fault. Located along the southwest margin of the rift, the fault appears to reactivate (or cross cut) the older Owen Stanley Fault Zone (OSFZ) (Fig. 1), along which suture the 
Papuan Ultramafic Body was obducted southward in the Paleogene (Davies \& Jaques, 1984; Quarles van Ufford \& Cloos, 2005). The Mai'iu Fault bounds the northern flank of the south-eastern Owen Stanley Ranges, separating ophiolitic rocks of the Papuan Ultramafic Body (PUB) and metamorphic rocks of Australian Plate proto-affinity to the south from Plio-Pleistocene sedimentary rocks to the north (Fig. 1). To the NW of the study area, the Mai'iu Fault bounds the northern front of the Dayman Dome, an active metamorphic core complex (Daczko, 2011; Davies, 1980a; Spencer, 2010). The hanging wall includes the Goodenough Basin, where southward tilting and $\sim 5 \mathrm{~km}$ of subsidence have taken place against the Mai'iu Fault since 8Ma (Fitz \& Mann, 2013).

The Woodlark Rift also hosts several active to inactive (Plio-Pleistocene) volcanic centres. On the Papuan Peninsula high-K basalts dated between 5.5 and $0.1 \mathrm{Ma}$ are locally exposed at the Mangalese Plateau and Musa Valley (Smith \& Davies, 1976). Monzonite exposed at Mt Suckling, also on the Papuan Peninsula, yielded K/Ar hornblende ages between 6.3-4.4 (Smith \& Davies, 1976). Andesitic volcanic rocks of $\sim 3 \mathrm{Ma}$ are exposed to the north of the Papuan Peninsula in the Amphlett Islands, as well as on Fergusson Island, Normanby Island, and at Egum Harbour (Smith \& Compston, 1982; Smith \& Milsom, 1984). Andesitic to basaltic dikes of similar age ( 3Ma) occur at the NW end of Normanby Island (Baldwin et al., unpublished data, 1993; Davies, 1971; DesOrmeau, 2013; Little et al., 2011) are coeval with continued deformation in an especially active part of the rift. During the Pleistocene to Recent, andesitic volcanism occurred on the Papuan Peninsula near Mt Lamington (Fig. 1) and in the Moresby Strait area (Fig.1) of the D'Entrecasteaux Islands (Smith \& Davies, 1976; Smith \& Milsom, 1984). The Dawson Strait area of the D'Entrecasteaux Islands is host to Pleistocene to Recent peralkaline volcanic rocks, and active volcanic craters occur at Dobu Island and Dei Dei caldera (Smith et al., 1977). Active volcanic craters are found on the Papuan Peninsula (e.g. andesitic cones at Mt Victory and Mt Lamington), as well as in the D'Entrecasteaux Islands (e.g. Dobu Island and Dei Dei Caldera). The Peralkaline rhyolite volcanic rocks are similar in composition to other magmas generated in continental rift settings (Smith, 1982), and they occur in an especially active part of the rift. 


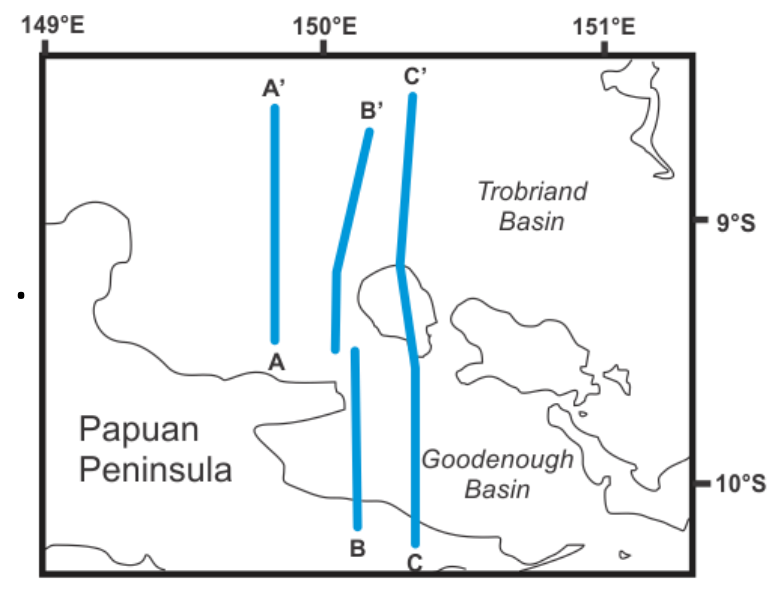

Late Miocane to Recent Strata $(<8.4 \mathrm{Ma})$

8.4 Ma unconformity

Middl to Late e Miocene Strata

Early Miocene Strata (>16.3 Ma)
Figure 3. Interpreted MCS reflection profiles across the Trobriand and Goodenough Basins, redrawn from Fitz \& Mann (2013), to show subsurface sediment packages for the Early Miocene, Middle to Late Miocene, and 8.4 Ma to Recent. Early Miocene stata thicken asymmetrically to the north against, and are offset by, south dipping normal faults in the Trobriand Basin. Middle Miocene strata thicken symmetrically towards the centre of the Trobriand Basin. The 8.4 Ma regional unconformity shown in yellow is generally inferred to mark the onset of extension in the Woodlark Rift. The unconformity is relatively undeformed in the Trobriand Basin north of the D'Entrecasteaux Islands, but has been significantly tilted southward in Goodenough Bay, in the hanging wall of the Mai'iu Normal Fault

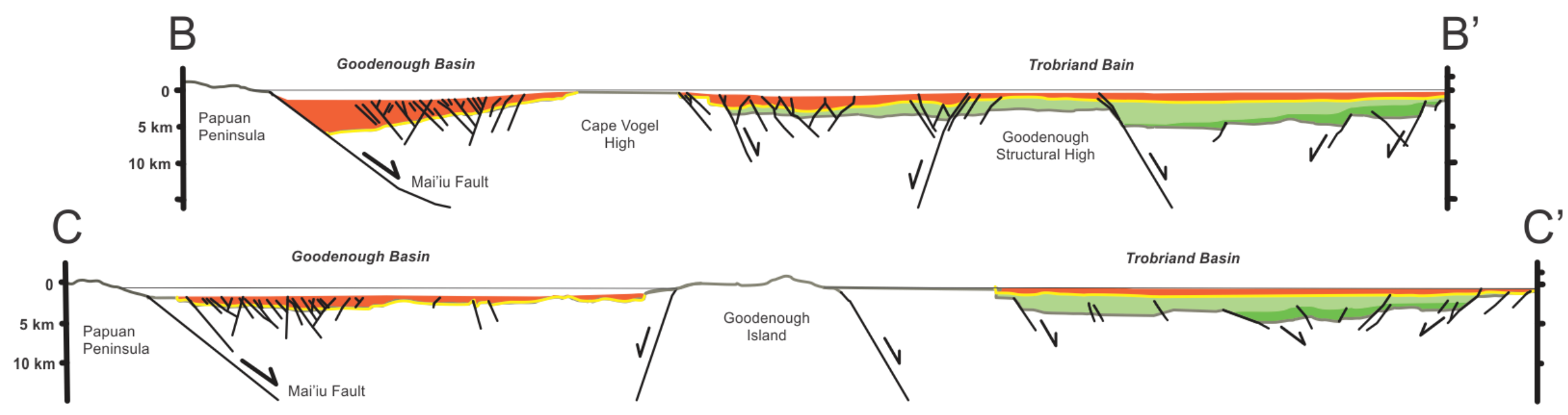

Page 23 of 152 


\section{Methodology}

\subsection{Fieldwork and Sampling}

Fieldwork for this study was carried out in conjunction with leg 1 of the 2012 (final) GPS campaign by boat, for Marsden Fund grant 08-VUW-020 to T.A. Little, L. Wallace. \& S. Ellis. All paleomagnetic sampling was carried out by E.A. Cairns and T.A. Little, with help from S. Ellis., during May-June 2012.

\subsubsection{Locality Selection and Rationale}

Potential localities for paleomagnetic sampling were identified in the Woodlark Rift where suitable outcrops would be accessible from the coast, and contribute to some temporal or spatial constraint on the evolution of rifting. Where a sequence of suitable rocks is deposited coevally with the development and evolution of the Woodlark Rift, their paleomagnetic remanence records a rift related rotational history for that location. By determining declination anomalies for each locality with respect to an Australian Plate reference frame, we can interpret apparent vertical axis rotations as due to rift related crustal motions with respect to Australia.

In order to gain temporal constraints on the history of rifting we looked for areas where rocks of different ages are exposed in close proximity to each other. Paleomagnetic directions from a sequence of rocks that predate the onset of rifting should be uniformly rotated from their corresponding Australian Plate GAD expected field direction; and the ages of the two oldest directions that differ in the magnitude of their rotation should bracket the timing of rift onset.

To gain spatial constraints on the zone of lithospheric extension at different times through the history of rifting, we aimed to sample rocks of the same or similar age at different locations in the Woodlark Rift region. Where localities have moved as part of the Woodlark Plate, paleomagnetic directions should be rotated anticlockwise from contemporaneous GAD expected directions for the Australian Plate, and vertical-axis rotated by an angle consistent with the record of sea floor spreading. Where localities have moved as part of the Australian Plate, paleomagnetic directions should be consistent with GAD expected field directions for the Australian Plate. Any other result can be interpreted as crustal block rotations associated with extensional deformation within the zone of the Woodlark Rift.

Target areas on the Papuan Peninsula were identified mainly on the basis of descriptions and dating of Smith and Davies (1976), and Australian Bureau of Mineral Resources geological maps (1:250,000 BMR Geological Series, 1972; 1974).

The Cape Vogel Peninsula was selected as a priority sample area because a semi-continuous sequence of Early Miocene (Woruka Siltstone $20 \pm 3 \mathrm{Ma}$ ), Middle Miocene (Castle Hill Limestone 15 $\pm 3 \mathrm{Ma}$ ) and Late Miocene (Tapio Marl $10 \pm 2 \mathrm{Ma}$ ) sedimentary rocks are exposed there (Bickel, 1974; Smith \& Davies, 1976). The three formations sampled there predate the traditionally accepted onset of rifting at $8 \mathrm{Ma}$ (Taylor \& Huchon, 2002). If that age assignment is accurate, then the mean remanence directions for each formation sampled at Cape Vogel Peninsula should be uniformly deflected anticlockwise from their corresponding Australian Plate GAD expected field directions.

The Suau Coast was identified as a potential sample locality corresponding temporally to that of the Cape Vogel Peninsula, but separated geographically by more than $100 \mathrm{~km}$. The formations targeted 
there are the Modewa River Beds (Early Miocene) and the Fife Bay Volcanics (Late Miocene 12 Ma), which cover a similar range of ages to the rocks sampled at Cape Vogel Peninsula. The Suau Coast, on the southern side of the SE Papuan Peninsula was considered as a potential "Australian Plate locality", as GPS velocities suggest that region is moving very similarly to the Australian Plate at present. If that has been the case through the history of the rift, then paleomagnetic directions derived from rocks sampled there should approximate their corresponding Australian Plate GAD expected field directions.

The Amphlett Islands and NW Normanby Island localities were selected to sample younger rocks of Pliocene age ( $3 \pm 0.5 \mathrm{Ma})$, based on the mapping and isotopic dating of Smith et al. $(1976,1982)$, more recent K/Ar and Ar/Ar dating of andesitic flow lavas in the Amphlett Islands by Baldwin et al. (1993). The dike swarm sampled at NW Normanby Island is located within a field area familiar to Little et al. (2011), and the andesitic-basaltic hypabyssal dikes have been Ar/Ar dated by Baldwin et al. (1993) and more recently U/Pb zircon dated by Gordon et al. (2012). The rocks sampled at those localities were deposited coevally with active continental rifting. The sense of deflection from contemporaneous GAD expected field directions for the Australian Plate, as well as the magnitude of rotation may be interpreted in terms of vertical axis rotations of crustal blocks since the Late Pliocene in the zone of continental rifting.

\subsubsection{Sampling and Field Annotation}

We obtained 250 oriented core samples from 40 sample sites between the four localities mentioned above. A sample "site" refers to a single field station or outcrop, while paleomagnetic "localities" consist of several sites where certain formations are sampled. Core samples were obtained from outcrop at each sample site using a Pomeroy rock drill, and oriented in situ according to VUW conventions (see Appendix B) using a Brunton compass and custom aluminium sheath clinometer. Attitudes to bedding were measured using a Brunton compass (mostly courtesy of T.A. Little), for the application of structural corrections to paleomagnetic data. All structural measurements and core orientations are corrected for $7^{\circ}$ local magnetic declination (IGRF-11, IAGA website).

Table 1 (below) provides a summary of samples by site and locality. For a full catalogue of specimens see Appendix C.

The annotation of sample site names and sample names presented in this thesis are as follows:

Sample sites referred to in the text and shown on index maps follow the annotation used by Little et al. in previous field seasons in the Woodlark Rift region. That annotation follows the format of PNG$x x-y y$. " $x x^{\prime \prime}$ refers to the year in which that field station was visited, and " $y y$ " refers to the sample site or station number of that field season corresponding to a point location with GPS coordinates. The names of oriented core samples and individual specimens differ from that annotation, and follow the format of XX-yy-Z.n. " $X X$ " is a two letter prefix corresponding to the area of the sample location (CV= Cape Vogel Peninsula, SW= Suwen River, FF= Fife Bay, AM= Amphlett Islands, NB= Normanby Island), " $y y$ " refers to the same station/sample site number corresponding to a point location, " $Z$ " is an alphabetic character corresponding to individual hand samples or oriented cores from each sample site, and " $\mathrm{n}$ " is a numeral corresponding to an individual specimen from an oriented core (1 being the innermost specimen); i.e. CV05C.1 is the name for the innermost specimen from core C, collected at site PNG-12-05, on the Cape Vogel Peninsula. 
Table 1 Summary of sample sites by locality, with tilt corrections applied to paleomagnetic data, and number of oriented cores and specimens for each site. The "ChRM" column indicates whether $(\mathrm{Y} / \mathrm{N})$ samples yield a representative remanence direction, and are thus included in calculation of a formation mean direction.

\begin{tabular}{|c|c|c|c|c|c|c|c|}
\hline Sites & $\begin{array}{c}\text { Longitude } \\
\left({ }^{\circ} \mathrm{E}\right)\end{array}$ & $\begin{array}{c}\text { Latitude } \\
\left({ }^{\circ} \mathrm{S}\right)\end{array}$ & $\begin{array}{c}\text { Formation } \\
\text { sampled }\end{array}$ & $\begin{array}{l}\text { Average tilt } \\
\text { correction }\end{array}$ & $\begin{array}{c}\mathrm{N} \text { cores } \\
\text { /specimens }\end{array}$ & $\begin{array}{c}\text { ChR } \\
M\end{array}$ & $\mathrm{~T} / \mathrm{S}$ \\
\hline PNG-12-04 & 149.8448 & -9.663 & \multirow{4}{*}{$\begin{array}{l}\text { Woruka } \\
\text { Siltstone }\end{array}$} & $327 / \mathrm{NE} / 13^{\circ}$ & $3 / 5$ & $\mathrm{Y}$ & $\mathrm{Y}$ \\
\hline PNG-12-05 & 149.8446 & -9.660 & & $339 / \mathrm{NE} / 36^{\circ}$ & $15 / 13$ & $\mathrm{Y}$ & $\mathrm{Y}$ \\
\hline PNG-12-06 & 149.8445 & -9.660 & & $327 / \mathrm{NE} / 26^{\circ}$ & $8 / 11$ & $\mathrm{Y}$ & $\mathrm{Y}$ \\
\hline PNG-12-07 & 149.8446 & -9.659 & & $334 / \mathrm{NE} / 41^{\circ}$ & $12 / 14$ & $\mathrm{Y}$ & $\mathrm{Y}$ \\
\hline \multicolumn{8}{|c|}{ Total demagnetization experiments: 43} \\
\hline PNG-12-08 & 149.8574 & -9.659 & \multirow{2}{*}{$\begin{array}{l}\text { Castle Hill } \\
\text { Limestone }\end{array}$} & $015 / \mathrm{E} / 8^{\circ}$ & $32 / 42$ & $\mathrm{Y}$ & $\mathrm{Y}$ \\
\hline PNG-12-09 & 149.8829 & -9.651 & & $038 / \mathrm{SE} / 13^{\circ}$ & $17 / 19$ & $\mathrm{Y}$ & $\mathrm{Y}$ \\
\hline \multicolumn{8}{|c|}{ Total demagnetization experiments: 61} \\
\hline PNG-12-10 & 149.8822 & -9.654 & \multirow{3}{*}{ Tapio Marl } & $064 / \mathrm{SE} / 10^{\circ}$ & $22 / 28$ & $\mathrm{Y}$ & $\mathrm{Y}$ \\
\hline PNG-12-11 & 149.8822 & -9.652 & & $251 / \mathrm{NE} / 6^{\circ}$ & $4 / 5$ & $\mathrm{Y}$ & $\mathrm{N}$ \\
\hline PNG-12-12 & 149.8823 & -9.652 & & $308 / \mathrm{NE} / 7^{\circ}$ & $11 / 13$ & $\mathrm{Y}$ & $\mathrm{Y}$ \\
\hline \multicolumn{8}{|c|}{ Total demagnetization experiments: 46} \\
\hline PNG-12-101 & 150.1448 & -10.614 & \multirow{2}{*}{$\begin{array}{c}\text { Modewa } \\
\text { River Beds }\end{array}$} & $36 / \mathrm{SE} / 33^{\circ}$ & $6 / 10$ & $\mathrm{~N}$ & $\mathrm{Y}$ \\
\hline PNG-12-102 & 150.1448 & -10.613 & & $356 / E / 16^{\circ}$ & $5 / 7$ & $\mathrm{~N}$ & $\mathrm{~N}$ \\
\hline \multicolumn{8}{|c|}{ Total demagnetization experiments: 17} \\
\hline PNG-12-103 & 150.1266 & -10.641 & \multirow{6}{*}{$\begin{array}{c}\text { Fife Bay } \\
\text { Volcanics }\end{array}$} & $177 / \mathrm{W} / 33^{\circ}$ & $10 / 12$ & $\mathrm{Y}$ & $\mathrm{Y}$ \\
\hline PNG-12-104 & 150.0189 & -10.587 & & \multirow{5}{*}{$\mathrm{N} / \mathrm{A}$} & $5 / 7$ & $\mathrm{Y}$ & $\mathrm{Y}$ \\
\hline PNG-12-105 & 150.0196 & -10.587 & & & $2 / 4$ & $\mathrm{Y}$ & $\mathrm{Y}$ \\
\hline PNG-12-106 & 150.0211 & -10.587 & & & $1 / 2$ & $\mathrm{Y}$ & $\mathrm{N}$ \\
\hline PNG-12-107 & 149.9986 & -10.598 & & & $4 / 4$ & $\mathrm{Y}$ & $\mathrm{Y}$ \\
\hline PNG-12-108 & 150.0187 & -10.612 & & & $3 / 5$ & $\mathrm{Y}$ & $\mathrm{Y}$ \\
\hline \multicolumn{8}{|c|}{ Total demagnetization experiments: 34} \\
\hline PNG-12-13 & 150.7821 & -9.242 & \multirow{11}{*}{$\begin{array}{l}\text { Amphlett } \\
\text { Islands } \\
\text { Andesite }\end{array}$} & \multirow{11}{*}{ N/A } & $3 / 3$ & $\mathrm{Y}$ & $\mathrm{Y}$ \\
\hline PNG-12-14 & 150.7875 & -9.239 & & & $2 / 3$ & $\mathrm{~N}$ & $\mathrm{Y}$ \\
\hline PNG-12-15 & 150.7868 & -9.234 & & & $3 / 4$ & $\mathrm{Y}$ & $\mathrm{Y}$ \\
\hline PNG-12-16 & 150.7104 & -9.311 & & & $2 / 3$ & $\mathrm{Y}$ & $\mathrm{Y}$ \\
\hline PNG-12-17 & 150.7106 & -9.312 & & & $3 / 3$ & $\mathrm{Y}$ & $\mathrm{Y}$ \\
\hline PNG-12-18 & 150.7105 & -9.312 & & & $3 / 5$ & $\mathrm{Y}$ & $\mathrm{Y}$ \\
\hline PNG-12-19 & 150.7122 & -9.313 & & & $3 / 6$ & $\mathrm{Y}$ & $\mathrm{Y}$ \\
\hline PNG-12-20 & 150.7397 & -9.326 & & & $3 / 5$ & $\mathrm{Y}$ & $\mathrm{Y}$ \\
\hline PNG-12-21 & 150.7125 & -9.333 & & & $3 / 6$ & $\mathrm{~N}$ & $Y$ \\
\hline PNG-12-22 & 150.6872 & -9.334 & & & $7 / 10$ & $\mathrm{Y}$ & $\mathrm{Y}$ \\
\hline PNG-12-23 & 150.6846 & -9.338 & & & $3 / 4$ & $\mathrm{Y}$ & $\mathrm{Y}$ \\
\hline \multicolumn{8}{|c|}{ Total demagnetization experiments: 52} \\
\hline PNG-12-31 & 150.8194 & -9.784 & \multirow{12}{*}{$\begin{array}{c}\text { NW } \\
\text { Normanby } \\
\text { Dike Swarm }\end{array}$} & \multirow{3}{*}{$315 / \mathrm{NE} / 15^{\circ}$} & $4 / 5$ & $\mathrm{Y}$ & $\mathrm{N}$ \\
\hline PNG-12-32 & 150.8137 & -9.764 & & & $2 / 2$ & $\mathrm{Y}$ & $Y$ \\
\hline PNG-12-33 & 150.8132 & -9.766 & & & $3 / 4$ & $Y$ & $\mathrm{~N}$ \\
\hline PNG-12-34 & 150.8128 & -9.767 & & \multirow{2}{*}{$315 / \mathrm{NE} / 5^{\circ}$} & $1 / 1$ & $\mathrm{Y}$ & $Y$ \\
\hline PNG-12-35 & 150.8127 & -9.768 & & & $3 / 4$ & $\mathrm{Y}$ & $\mathrm{Y}$ \\
\hline PNG-12-36 & 150.8127 & -9.769 & & \multirow{2}{*}{$315 / \mathrm{NE} / 20^{\circ}$} & $1 / 1$ & $Y$ & $\mathrm{~N}$ \\
\hline PNG-12-37 & 150.8124 & -9.769 & & & $2 / 2$ & $\mathrm{Y}$ & $\mathrm{N}$ \\
\hline PNG-12-38 & 150.8107 & -9.768 & & \multirow{3}{*}{$315 / \mathrm{NE} / 5^{\circ}$} & $1 / 1$ & $Y$ & $Y$ \\
\hline PNG-12-39 & 150.8107 & -9.769 & & & $3 / 3$ & $\mathrm{Y}$ & $\mathrm{Y}$ \\
\hline PNG-12-40 & 150.8102 & -9.768 & & & $4 / 5$ & $\mathrm{Y}$ & $Y$ \\
\hline PNG-12-41 & 150.8097 & -9.769 & & $315 / \mathrm{NE} / 20^{\circ}$ & $2 / 4$ & $Y$ & $\mathrm{Y}$ \\
\hline PNG-12-42 & 150.8091 & -9.770 & & $315 / \mathrm{NE} / 10^{\circ}$ & $2 / 2$ & $Y$ & $\mathrm{Y}$ \\
\hline \multicolumn{8}{|c|}{ Total demagnetization experiments: 34} \\
\hline
\end{tabular}




\subsubsection{Sample Preparation}

Samples were housed in mu-metal shielding for a number of months whilst in transit between the SE Papua New Guinea field area and Victoria University of Wellington (VUW). Those samples remained housed in mu-metal shielding at all times outside of demagnetization and measurement procedures. Months spent in magnetically shielded housing prior to analyses likely provided an opportunity for viscous magnetizations acquired by samples in the present day magnetic field to relax in zero field, effectively randomizing and removing low strength viscous components of magnetization and reducing noise and error in measurements.

Specimens were trimmed to $2.2 \mathrm{~cm}$ maximum length using a diamond blade rock saw and diamond lap. Those dimensions are optimal for measurement using the JR6 spinner magnetometer, to fit the automatic sample holder, and to minimise shape and volume discrepancies with the calibration standard (see Section 2.3). Some of the sample rocks are fractured, and so fragments were restored to core samples using UHU glue, prior to the sawing of specimens. 


\subsection{Natural Magnetization Processes and Magnetic Mineralogy}

\subsubsection{Thin Section Petrology and Petrography}

Thin sections were cut from selected hand samples and core specimens for each formation (see Appendix C). Optical light microscopy was employed as a first order tool to infer the suitability of sample rocks for paleomagnetic analysis, and their likely ferromagnetic mineralogy. Understanding of the likely ferromagnetic mineralogy of samples is useful for the interpretation of complex demagnetization behaviour.

A major requirement for paleomagnetic studies is that sample rocks were deposited or emplaced in conditions conducive to the acquisition of a primary and stable Natural Remanent Magnetization (NRM). Two main processes of primary NRM acquisition pertain respectively to the igneous and sedimentary rocks sampled for this study, and they are described below.

A Thermo-remanent Magnetization (TRM) is acquired by the alignment of the magnetic moments of individual mineral grains with an ambient magnetic field direction, on cooling through their individual blocking temperatures (Butler, 1992; Neel, 1955). Those mineral grains may be present in lavas as magmatic or inherited crystals. Deuteric oxidation during cooling also may result in the exsolution of ferromagnetic minerals within larger phenocrysts, capable of retaining a stable TRM (Butler, 1992). Mafic rocks are more likely to retain a stable TRM because of higher Fe and Ti contents, resulting in exsolution of titano-magnetite from other mineral grains (Butler, 1992). A representative TRM requires that sample rocks were in situ while cooling through at least a portion of the blocking temperature range of their primary ferromagnetic mineral grain constituents. We look for vitreous flow textures to indicate the sample rocks were rapidly cooled from high temperatures, probably as a cohesive unit. Volcaniclastic textures suggest that discrete clasts may have been cooled and magnetized before being reoriented prior to deposition, i.e., through ballistic transport or autobrecciation. Additionally, the textural variations observed in thin sections of volcanic rocks have been used in conjunction with field observations to infer a distinction between discrete lava flows where depositional contacts were ambiguous.

A Detrital Remanent Magnetization (DRM) is acquired by the alignment of magnetic mineral grains through deposition and lithification of sediments (Verosub, 1977). Acquisition of a representative DRM requires that grains are settled slowly out of a water column to allow for alignment with the ambient geomagnetic field (Butler, 1992). We look for grain size and fossil evidence to indicate sedimentary rocks were deposited in a low energy environment, conducive to slow sedimentation and acquisition of a representative DRM.

Many secondary processes may result in the acquisition of new remanence components, e.g., through reheating of rocks to remagnetize a portion of the blocking temperature spectrum with a partial Thermal Remanent Magnetization (pTRM), or through the growth of new minerals to grow Chemical Remanent Magnetizations (CRM). A CRM may be grown through the alteration of preexisting minerals to new ferromagnetic phases, or by precipitation of ferromagnetic minerals from solution (Butler, 1992). Those secondary components may replace, obscure, or alter the characteristic magnetization of samples. We look for petrographic evidence of secondary alteration in order to identify potential sources of secondary remanence. 


\subsubsection{Temperature Dependent Susceptibility}

Temperature dependent susceptibility experiments were conducted for selected samples using a Bartington MS2 furnace system at in the Paleomagnetism Laboratory at VUW, Wellington. The magnetic susceptibility of a rock sample is measured periodically, at intervals of $10^{\circ} \mathrm{C}$, as it is heated to $700^{\circ} \mathrm{C}$ and cooled back to room temperature. As the rock sample is heated through the blocking temperature of progressively more grains, they become superparamagnetic, resulting in a slight increase in susceptibility until grains are brought past their Curie temperature. As the sample is brought to temperatures above the Curie temperature of a mineral present, there will be a significant drop in susceptibility as thermal energy overcomes magnetic exchange forces, and that mineral cannot sustain a magnetization in those conditions (Tauxe 2011). On heating past the Curie temperatures of all the minerals present, magnetic susceptibility will drop to un-measurable levels. As grains are cooled back through their Curie temperature, magnetic susceptibility is restored to the sample. During cooling back to room temperature, a slight decrease in magnetic susceptibility accompanies re-blocking of mineral grains. The most favourable result of these experiments is a reversible curve, indicating that the ferromagnetic mineral grain population is resistant to thermal alteration.

Curie (and Néel) temperatures are known for a wide range of naturally occurring magnetic minerals which are known to grow in different conditions and processes. By using temperature dependent susceptibility curves to determine Curie temperatures for the ferromagnetic minerals in sample rocks, as well as their thermal alteration behaviour, we can infer their likely origins and contribution to NRM.

\subsubsection{Lowrie 3-axis Experiments}

Lowrie experiments (1990) involve using a pulse magnetizer to grow Isothermal Remanent Magnetizations (IRM) in low, intermediate and high fields aligned respectively with the $\mathrm{X}, \mathrm{Y}$ and $\mathrm{Z}$ axes of specimens, and then measuring their decreasing vectors through stepwise thermal demagnetization. IRM is the name for a remanent magnetization acquired as a result of exposure to a magnetic field at constant temperature (Butler, 1992; Tauxe, 2011). By exposing samples to a field of given strength, the grains with coercivities lower than that field strength are magnetized in the direction of the applied field. By viewing the thermal demagnetization behaviour of IRM components within different coercivity ranges we can approximate the blocking temperature spectrum and Curie temperature of different grain populations, and correlate components between the coercivity and blocking-temperature spectra.

Lowrie experiment procedures were carried out on a few specimens of Miocene Siltstone, Marl and Limestone, courtesy of G.M. Turner. Specimens were subjected to a magnetic field of $850 \mathrm{mT}$ aligned with the $Z$ axis, then reoriented and subjected to a field of $150 \mathrm{mT}$ aligned with the $Y$ axis, and $80 \mathrm{mT}$ aligned with the $X$ specimen axis. This process results in the growth of three orthogonal IRM components. The magnetization in the $Z$ direction is carried by grains with coercivities of $150-$ $850 \mathrm{mT}$, the $Y$ component is carried by grains with coercivities of $80-150 \mathrm{mT}$, and grains with coercivities $<80 \mathrm{mT}$ are magnetized in the $X$ direction. The resulting IRM is then step-wise thermally demagnetized until all three IRM components are completely removed. The resultant magnetic moment decay plot for each specimen depicts the thermal demagnetization behaviour of three grain populations in different coercivity ranges. Experimentally determined Curie temperature and 
coercivities for a range of ferromagnetic minerals (Tauxe, 2011), inform the interpretation of Lowrie plots in terms of the ferromagnetic grain populations of samples. 


\subsection{Measurement of NRM and Progressive Demagnetization}

The NRM of a sample is the vector sum of all the magnetic moments of its ferromagnetic grain constituents. Those grains probably have a range of blocking temperatures and coercivities, and hence magnetic stabilities (see below). Furthermore, those grains may include some diagenetic and secondary precipitated minerals in addition to the primary igneous or detrital minerals. Different components of magnetization are held in different portions of the blocking temperature $\left(T_{b}\right)$ and coercivity $\left(h_{c}\right)$ spectra of sample rocks based on the mineralogy, size and shape of ferromagnetic grains that carry them. Progressive demagnetization experiments are designed to isolate the Characteristic Remanent Magnetization (CHRM) component that is acquired the time of rock formation from other secondary remanence.

The relaxation time of individual grains is synonymous with magnetic stability. It is an exponential function of grain volume, microscopic coercive force, and the inverse of thermal energy (Néel, 1955). A consequence of that relationship is that grains with high blocking temperatures and coercivity are more magnetically stable, and more likely to carry a Characteristic Remanent Magnetization (ChRM). Another consequence is that magnetically stable grains are exponentially more likely to retain a remanent magnetization at high temperature than magnetically softer grains.

Thermal demagnetization procedures involve heating samples to a given temperature $\left(T_{\max }\right)$, and cooling to room temperature in zero magnetic field. By doing so the portion of remanent magnetization held by grains with blocking temperatures $<T_{\text {max }}$ is removed. By heating samples stepwise to successively higher temperatures we demagnetize successively more stable portions of NRM, held within successive blocking temperature intervals.

Alternating field demagnetization procedures involve exposing samples to an alternating field of decaying amplitude that oscillates between antipodal field directions. To accomplish a directionally uniform demagnetization, specimens are exposed to the same field in three different orientations, i.e., with $X, Y$ and $Z$ axes parallel to the direction of the applied field. The result of that treatment is that the magnetic moments of grains with coercivities less than the strength of the peak field amplitude are effectively randomized (Butler, 1992). In rocks with titano-magnetite as the dominant ferromagnetic mineralogy, secondary NRM may be carried predominantly by multi-domain grains with low coercivity (Butler, 1992). Multi-domain grains have low coercivity because their overall magnetic moments are able to align with an applied field by movement of domain walls that separate regions of uniform magnetization (Butler, 1992).

Step-wise measurements of remanence through thermal and alternating field demagnetization experiments were carried out using either the AGICO JR6 Spinner Magnetometer at VUW, Wellington, or using the $2 \mathrm{G}$ LongCore SQUID cryogenic magnetometer at Otago University, Dunedin. Analyses were split between VUW and Otago because the sedimentary rocks we sampled are generally more weakly magnetized than the $10^{-4}$ to $10^{-5} \mathrm{~A} / \mathrm{m}$ sensitivity of the JR6 spinner. The SQUID cryogenic magnetometer at Otago is more suitable for measuring those samples, being sensitive to $10^{-6} \mathrm{~A} / \mathrm{m}$, despite also being at its limit with some of the weaker limestone samples.

The $2 \mathrm{G}$ system at Otago University includes a 3 axis SQUID magnetometer, high field degausser and Bartington susceptibility bridge controlled by $2 \mathrm{G}$ LongCore software (Mills, 2000). Alternating field demagnetization was conducted by passing samples at constant speed through a bridge of constant 
field, by which the sample experiences a decrease in applied field as it moves through and away from the bridge. Step-wise thermal demagnetization procedures were undertaken using a singlechamber (heating and cooling) thermal demagnetizer, where samples are exposed to peak demagnetization temperature for 30 minutes and allowed to cool back to room temperature. After each demagnetization step the remaining remanent magnetization carried by specimens was measured individually on passing by the SQUID magnetometer.

The JR6 Spinner at VUW measures the AC voltage that is induced in a pair of coils surrounding a sample of defined size and shape, when it is rotated at a constant angular velocity. The spinner is run by Rema6W which uses Fourier analysis to calculate two vector components for each of three orthogonal sample orientations. I used an automatic cylindrical holder, on low speed (16 rev/s) and normal integration time settings, and calibrated using an $11.15 \mathrm{cc}$ cylindrical standard containing a $6.36 \mathrm{~A} / \mathrm{m}$ magnetic moment aligned with the specimen $\mathrm{Z}$ axis. Alternating Field demagnetization experiments at VUW were undertaken by manually rotating samples and demagnetizing three orthogonal orientations using a Molspin AF demagnetizer, with peak fields up to $90 \mathrm{mT}$, at slow to medium decay rate. Thermal demagnetization was undertaken by heating samples in a shielded chamber for a minimum of 30 minutes, and passing through to another shielded chamber to cool to room temperature, each time allowing 30 minutes for the specimen to equilibrate. 


\subsection{Data Interpretation and Statistics}

Remasoft 3.0 (Chadima, 2011) was used to view paleomagnetic data, apply structural corrections, perform principal component analysis, and Fisher statistics (1953) of individual specimen data, as well as of group data sets for each formation sampled.

\subsubsection{Principal Component Analysis}

Remasoft 3.0 (Chadima, 2007) is used to calculate the total magnetization vector sum from $X, Y$ and $Z$ measurements at each demagnetization step. Those data are displayed in Zijderveld (vector component) plots (Zijderveld, 1967) and stereoplots that can be interpreted in terms of the directional components of remanence removed through different stages of demagnetization. Remasoft 3.0 allows the user to calculate the direction of discrete remanence components by Principal Component Analysis (PCA) (Kirshvink, 1980). Components are mathematically determined for best line fits between individual NRM vectors for a series of demagnetization steps, to determine directions of remanence held in different portions of the demagnetization spectrum. PCA components were calculated for straight line sections of Zijdeveld curves, selected to achieve the lowest Maximum Angle of Deviation (MAD). MAD is a measure of directional scatter within a sequence of demagnetization points, which quantifies the precision of their sum eigenvector. Vector components were determined for a variety of blocking temperature and coercivity ranges, and recorded for inclusion in group analyses. The Remasoft 3.0 program also allows the user to fit a Fisher mean (Fisher, 1953) to a collection of demagnetization points to determine the mean direction of a component of remanence remaining.

\subsubsection{Data Selection and Rejection criteria}

Remanence components are primarily evaluated on the basis of the following criteria:

1) Components calculated by Principal Component Analysis (PCA) should have a Maximum Angle of Deviation (MAD) no larger than $10^{\circ}$ in order to be included in calculation of a mean direction.

2) Components calculated for different specimens from a given core should display directional agreement $\left(<10^{\circ}\right)$.

3) ChRMs from core samples of the same depositional unit should exhibit directional agreement $\left(<10-15^{\circ}\right)$.

4) ChRMs should be interpretable as a GAD field direction corresponding to either a normal or reverse polarity field that has undergone vertical-axis rotation and minor latitudinal movement (i.e., directions with declination $>270^{\circ}$ and $<90^{\circ}$ should have negative inclination, directions with declination $>90^{\circ}$ and $<270^{\circ}$ should have positive inclination).

Poor directional agreement between samples is often consistent with field and petrographic observations to suggest that sample rocks were probably magnetized prior to being reoriented by autobrecciation; or that they have been subject to chemical mineral alteration.

In some cases components have declinations $\sim 90 / 270^{\circ}$. Those anomalous directions may be the result of inclination flattening, which favours rotation of remanence to shallow inclinations as well deflecting components to E-W declinations (Tauxe, 2011). In other cases components have 
northward declinations but positive inclination, or vice versa, inconsistent with a GAD field direction. Those directions may be due to viscous rotation, or two non-antipodal normal and reverse polarity magnetizations of different magnitude, overlapping in the blocking temperature and/or coercivity spectrum. In any case, those anomalous directions are outliers, and cannot be accounted for by geomagnetic field directions having undergone tectonic rotation.

Curvilinear trajectories and scattered demagnetization plots may be indicative of multi domain grain behaviour. In rocks with titano-magnetite as the dominant ferromagnetic mineralogy, secondary NRM is carried predominantly by multi domain grains with low coercivity (Butler, 1992). Multi domain grains have low coercivity because their magnetic moments are able to align with an applied field by shifting of domain walls that separate regions of atomic interaction (Butler, 1992). Their ability to realign magnetic moment without being completely demagnetized means that multi domain grains remanence can obscure ChRM directions. Some demagnetization plots had sufficient directional scatter or visibly curvilinear trajectories to yield no PCA components to satisfy the above criteria, and those data are excluded from analyses.

All specimen data files can be found in Appendix A, and they include all calculated PCA components. The ChRM and SRM directions included in the calculation of mean directions, which satisfy the aforementioned criteria are presented in tables 2-11, with stereoplots of group data.

\subsubsection{Assessment of Directions}

Components are grouped and averaged according to the blocking temperature and coercivity ranges in which they are isolated. That rationale is adopted in order to infer the relative magnetic stability, as well as the likely carrier grain mineralogy of remanence. Blocking temperature and coercivity of ferromagnetic grains are indicative of magnetic stability (Neel, 1955), so components removed through high temperature and peak field demagnetization steps are the most magnetically stable. In some cases however, those grains may be carrying secondary magnetizations, while grains with lower blocking temperature or coercivity are part of the primary assemblage, and carry a ChRM.

A major assumption we utilise in inferring tectonic rotations from paleomagnetic directions is that a formation mean direction is representative of a time averaged Geocentric Axial Dipole (GAD) field. The geomagnetic field direction at any one location is subject to secular variation on timescales of hundreds to thousands of years. However, when averaged over $10^{4}-10^{5}$ years, the geomagnetic field of the earth approximates that of a Geocentric Axial Dipole (GAD) magnet oriented with the spin axis of the globe (Butler, 1992; Tauxe, 2011). In order to derive an average direction representative of that global reference frame, the data must sample enough of the field variation through sufficient time to average out secular variation. Analogous to the standard deviation of a normal scalar distribution, $\theta 63$ (see Appendix D) is an angular dispersion parameter, used to infer the degree to which secular variation has been sampled. The amplitude of secular variation differs as a function of latitude (Merrill \& McElhinny, 1983). If secular variation has been effectively sampled, then the angular dispersion should be consistent with amplitude as seen in the global compilation of secular variation for the past $5 \mathrm{Ma}$ (Butler, 1992; Merrill \& McElhinny, 1983). For the low latitudes of the study area $\left(9-11^{\circ} \mathrm{S}\right)$, the global compilation model of secular variation predicts angular dispersion of $\sim 13^{\circ}$ (Merrill \& McElhinny, 1983). I use this as a reference figure to assess the validity of assuming that formation mean directions represent a sufficiently time averaged field. 
Another major assumption is that characteristic magnetization directions are primary, and represent a geomagnetic field direction at the time of rock formation. This assumption can be justified by the observation of normal and reverse polarity directional components, as well as the directional and statistical effects of applying structural corrections to paleomagnetic data. The occurrence of antipodal normal and reverse polarity remanence components through a sequence of rocks is a powerful indicator of the primary nature of that remanence. Secondary magnetizations dating to an isolated secondary alteration or heating event are likely to uniformly magnetize rocks of different ages in either a normal or reverse polarity direction. Recent secondary magnetizations and viscous overprints are also expected to approximate the present day field direction of normal polarity. The retention of alternating polarity components through a sequence of rocks indicates that they were magnetized at different times, and over sufficient time to straddle at least one geomagnetic field reversal. Also, if normal and reverse polarity components are representative of a GAD field having undergone a polarity reversal, they should be of antipodal directions. That assumption provides the basis for a powerful test of the primary time averaged nature of a formation mean ChRM direction. The average direction from clusters of primary remanence directions of contrasting normal and reverse polarity should statistically overlap when one or other is rotated by $180^{\circ}$.

The fold test for formation mean directions is also a useful indicator of the age of ChRM data; i.e., whether it predates or postdates folding. When a structural correction is applied to ChRM component data, it should be improved rather than worsened both statistically and directionally (i.e., better representing a GAD expected direction for the sample location). In the latitudinal range of sample locations, and depending on the age of sample rocks, the inclination of expected directions for the Australian Plate is between $17^{\circ}$ and $45^{\circ}$. That range provides a range of expected inclinations for ChRM directions having undergone vertical axis tectonic rotations. The application of different structural corrections to paleomagnetic data from sites between which rocks have been variably tilted should result in a statistically and directionally improved average. If that is the case, the magnetization of those rocks predates deformation of those rocks and can reliably be inferred as a primary ChRM. 


\section{Cape Vogel Peninsula Locality (Miocene)}

\subsection{Geological Setting and Background}

I sampled three Miocene sedimentary formations on Cape Vogel Peninsula, and they are: 1) the Early Miocene Woruka Siltstone; 2) the Middle Miocene Castle Hill Limestone; and 3) the Late Miocene Tapio Marl (Bickel, 1974; Smith and Davies, 1976). Oriented cores were obtained at seven sites near the northern coast of the Cape Vogel Peninsula (Fig. 4). The sites are located $<5 \mathrm{~km}$ inland of Woruka and Tapio villages. The Cape Vogel Peninsula protrudes eastward $\sim 50 \mathrm{~km}$ from the main part of the Papuan Peninsula, and is located on the hanging wall of the Mai'iu detachment fault at $\sim 9.7^{\circ} \mathrm{S}$ (Fig. 1). The peninsula is the subaerially exposed portion of a more extensive, mostly submerged structural high that divides the Trobriand Basin to the north from the Goodenough Basin to the south. Submarine basalts of the Dabi Volcanics are Paleocene in age (Walker \& McDougall, 1982), are exposed at its deepest level in the core of the Cape Vogel Anticline.

The three Miocene formations sampled at Cape Vogel Peninsula were deposited in moderate shallow marine shelf environments on the south-western margin of an extensive marine basin that lay to the northeast of the emerging landmass that now includes the Papuan Peninsula (Bickel, 1974). The sequence of rocks sampled at Cape Vogel Peninsula correlates with other Miocene rocks exposed near Robinson Bay, located $>200 \mathrm{~km}$ to the NW (Bickel, 1974). The foraminifera found in the Miocene sections at Cape Vogel and at Robinson Bay similarly indicate connection of both regions with the open ocean (Bickel, 1974). Also, Miocene rocks correlative to those on the Cape Vogel Peninsula have been intersected and dated in Goodenough-1 and Nubiam-1 exploration wells in the Trobriand Basin (ref). Furthermore, these subsurface units have been correlated across the Trobriand Basin in Multi-Channel Seismic (MCS) reflection profiles (Fitz \& Mann, 2013; Francis, 1987). The Miocene section on the Cape Vogel Peninsula is $225 \mathrm{~m}$ thick (Smith \& Davies, 1976), which is very thin relative to the up to $4 \mathrm{~km}$ thickness of contemporaneous sediment packages shown in interpreted seismic profiles across the Trobriand Basin (Fitz \& Mann, 2013).

The moderate to shallow marine nature of the Miocene sediments that are now subaerially exposed on Cape Vogel Peninsula, as well as their unconformable contacts with older rocks, suggest that the peninsula has remained structurally elevated (near sea level) during both the Miocene development of the Trobriand Basin and the Pliocene development of the Goodenough Basin (Fitz \& Mann, 2013). All of the Miocene sedimentary formations sampled on the Cape Vogel Peninsula were deposited in moderate to shallow marine environments (Bickel, 1984). They are broadly concordant but with unconformable contacts, and all of the units sampled locally onlap the Paleocene Dabi Volcanics (Smith \& Davies, 1976). Younger stratigraphy of Late Miocene to Pliocene age consists of lithologies suggesting deposition in transitional shallow marine to terrestrial environments, periodically exposed to erosion (Bickel, 1974). The Cape Vogel Group formation covers more than half of the Cape Vogel Peninsula, and is characterised by lateral transitions between non-marine, marginal, deltaic, and open-marine depositional facies (Bickel, 1974). Those rocks are also locally unconformable with older rocks, including the Castle Hill Limestone and the basement Dabi Volcanics (Bickel, 1974). Those depositional relationships suggest that Cape Vogel has remained near sea level and has been periodically exposed to erosion during and since the Miocene, which may be due to transient periods of uplift and subsidence near the southern margin of the developing Trobriand Basin. 
Fitz and Mann (2013) propose that the Trobriand Basin developed as an asymmetric extensional forearc basin in the Early Miocene, followed by a period of contractional inversion, followed by a renewal of extension which has continued since $8.4 \mathrm{Ma}$. Early Miocene sediment packages, as interpreted in N-S seismic profiles across the Trobriand Basin (Fig. 3), thicken and form syn-growth wedges against predominantly south dipping normal faults towards the northern margin of the Trobriand Basin (Fitz \& Mann, 2013). Middle Miocene sedimentary rocks are also deformed by those faults, but thicken symmetrically towards the centre of the basin, and their upper surface is deformed into a westward plunging regional syncline (Fitz \& Mann, 2013). These relationships led Fitz \& Mann (2013) to infer a transition in the Trobriand Basin from asymmetric forearc extension to symmetric sag basin subsidence in the Middle Miocene. A short period of shortening is inferred to have inverted normal faults and formed anticlinal folds as seen in interpreted seismic profiles in the Trobriand Basin (Fitz \& Mann, 2013). That period of shortening is inferred by Taylor \& Huchon (2002) to have ceased by $\sim 8.4 \mathrm{Ma}$.

Backstripping reconstructions of the Trobriand Basin by Fitz and Mann (2013) suggest that at 8.4 Ma a shallow marine shelf contiguous with the Papuan Peninsula extended $\sim 50 \mathrm{~km}$ north of the Paleocene subduction front that forms the Owen Stanley Fault Zone (Fig. 1). Since 8.4 Ma the Goodenough Basin has subsided by up to $5 \mathrm{~km}$ in the hanging wall of the north dipping Mai'iu Fault (Fitz \& Mann, 2013). However, the Cape Vogel Peninsula part of the same hanging wall has remained structurally elevated relative to the subsiding Goodenough Basin further to the southeast (Fitz \& Mann, 2013). Also since 8.4 Ma the Cape Vogel Structural High has been further structurally elevated relative to the Trobriand Basin by uplift in the footwall of steep north dipping normal faults that formed between 8 and 1.8 $\mathrm{Ma}$ and developed into a graben complex directly to the north of the current Cape Vogel High (Fitz \& Mann, 2013).

The Cape Vogel Anticline plunges to both the east and west. The age of this gentle fold structure is uncertain, but spatial variation in the foraminiferal content of the Early Pliocene Awaitapu Claystone across the trace of the anticline may suggest a minimum age. The Awaitapu Claystone is exposed in parts of both the northern and southern coasts of Cape Vogel Peninsula, on either side of the eastto west- trending spine of the Cape Vogel Anticline, and in places onlaps against the Dabi Volcanics in the core of the anticline (Bickel, 1974; Smith \& Davies, 1974). The portion of the Awaitapu Claystone exposed on the southern side of the Cape Vogel Peninsula incorporates few fossils and is mostly non-marine, while the northern section is more calcareous and contains both planktonic and benthonic foraminifera indicating a greater connection with the open ocean to the north (Bickel, 1974). The onlapping depositional relationship of those rocks with basement volcanics exposed at the core of the Cape Vogel Anticline, as well as the aforementioned paleontological evidence suggest that the Cape Vogel Anticline had formed a divide between the open-marine Trobriand Basin and the Goodenough Basin developing to the south, by at least the early Pliocene. In both north and south exposures on the Cape Vogel Peninsula, the Awaitapu Claystone dips to the southwest at $\sim 20^{\circ}$ increasing to $43^{\circ}$ near the south coast (Smith \& Davies, 1974). That tilting is probably associated with the Late Miocene to recent development of the asymmetric Goodenough Basin, and post-dating formation of the Cape Vogel Anticline.

The Goodenough Basin has developed on the hanging wall of the north dipping Mai'iu detachment fault since $8 \mathrm{Ma}$ (Fitz \& Mann, 2013), contemporaneous with the ascent of eclogite facies bodies from mantle depths in the D'Entrecasteaux Island gneiss domes (Baldwin et al., 2004, 2008; Gordon 
et al, 2012; Little et al., 2011; Monteleone et al., 2007) to the north of the Goodenough Basin. Erosion of those domes provided source material for some of the Pliocene conglomerates in the Goodenough Basin (Davies \& Warren, 1988; Francis, 1987; Tjhin, 1976). These sediments in the Goodenough Basin are unlike any coeval rocks in the Trobriand Basin, and are thought to be locally derived by unroofing of the newly emergent D'Entrecasteaux Islands (Fitz \& Mann, 2013). The oldest package of rocks seen in interpreted seismic profiles across the Goodenough Basin thins and becomes absent towards the southwest of Goodenough Bay, which may indicate that this western end remained raised during the initial stage of basin subsidence (Fitz \& Mann, 2013). The pattern of uplift of Holocene marine terraces on the Papuan Peninsula suggest that normal dip-slip on the Mai'iu Fault increases to the northwest, to reach a maximum rate of footwall uplift (relative to sea level) estimated at $3.4 \mathrm{~mm} / \mathrm{yr}$ maximum near the southwest extent of Goodenough Bay (Mann \& Taylor, 2002). 


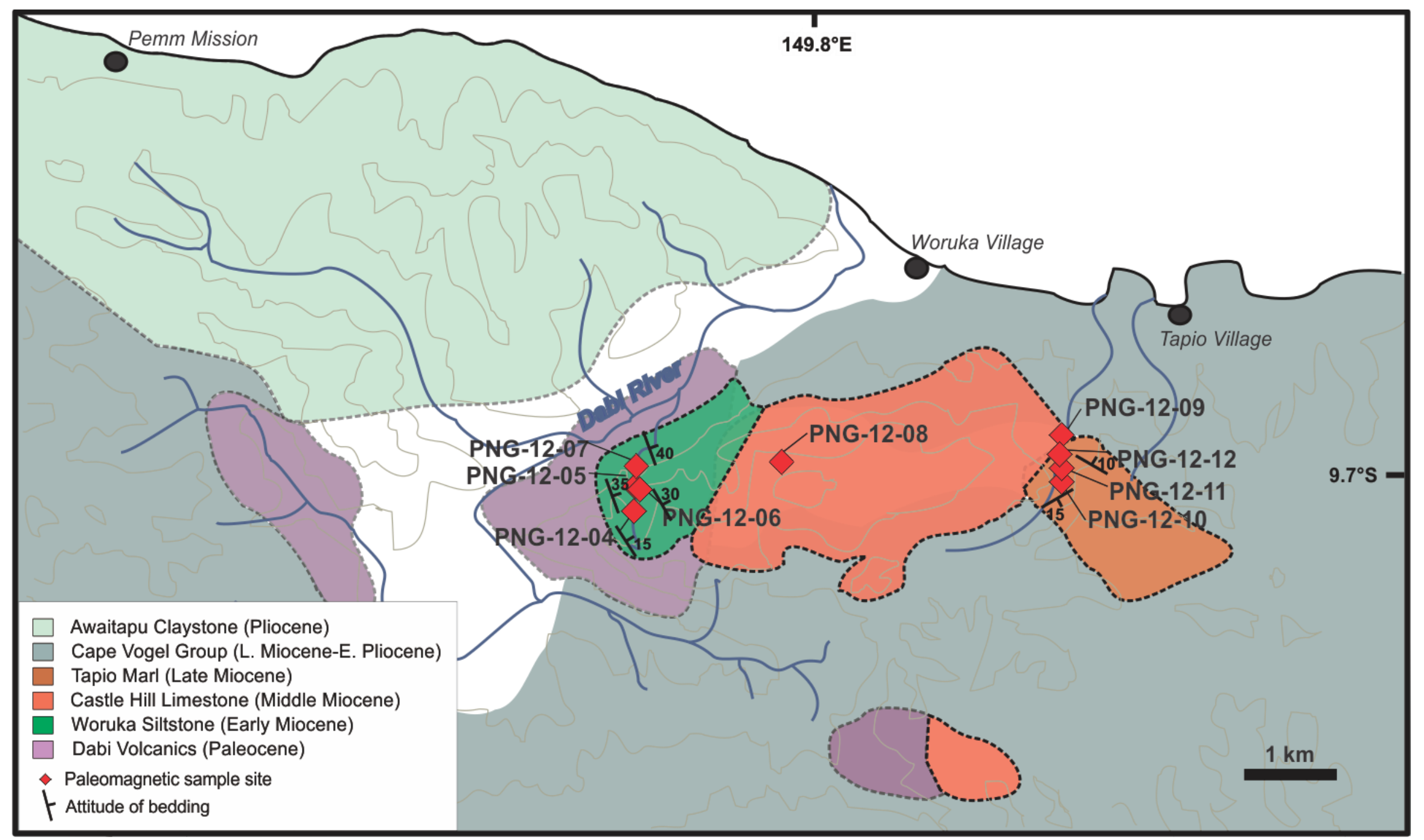

Figure 4. Map of the Cape Vogel Peninsula locality to show geology (after Smith \& Davies, 1976), representative bedding attitudes, and paleomagnetic sample locations inland from Woruka and Tapio Villages. Topographic contours are show at $80 \mathrm{~m}$ intervals up to $280 \mathrm{~m}$ peak elevation in the sample area, after the initial $40 \mathrm{~m}$ contour 


\subsection{Field Relationships, Thin Section Petrography, and Applying a Structural Correction to Paleomagnetic Data.}

\subsubsection{Woruka Siltstone}

The Woruka Siltstone samples consist of 38 oriented cores obtained at 4 sites (PNG-12-04 to PNG12-07). There, the formation crops out in a steep northwest flowing tributary on the true right of the Dabi River to the southwest of Woruka village (Fig. 4). The Woruka Siltstone dips to the NE between $15-40^{\circ}$ (Fig. 4), and the stream where it was sampled cuts down in such a way to expose different stratigraphic levels of the approximately $45 \mathrm{~m}$ thick Woruka Siltstone section on Cape Vogel Peninsula (Bickel, 1974; Smith \& Davies, 1976). Oriented cores were obtained at $10-15 \mathrm{~cm}$ stratigraphic intervals through four different sections of 0.5-2 $\mathrm{m}$ stratigraphic thickness. Those sites are at elevations between $50-120 \mathrm{~m}$, and I infer that they are located at lower, mid, and upper stratigraphic levels of the exposed $45 \mathrm{~m}$ section.

The rocks sampled are mainly fissile and platy dark-green to olive-grey laminated silty Claystone. They are finely bedded (green and red colour banded) on a $\mathrm{mm}$ to $\mathrm{cm}$ scale, and locally interbedded with discontinuous ( $<1 \mathrm{~m}$ thick) interbeds of basalt. The latter have not been described in this unit before. Thin section petrography reveals that the claystone is siliceous with spheroidal microfossils (probably radiolarian). A weak compaction fabric is defined by the bedding parallel alignment of elongate detrital grains (Fig. 6C-D). Some of the rocks appear chloritized, or contain cherty lenses that mildly deflect the surrounding bedding (Fig. 5). Abundant and undeformed spherical microfossils (probably radiolarian), as well as the extremely fine grained ferruginous nature of the claystone suggest a low energy environment starved of sediment, that would have had slow sedimentation rates. Based on the incorporation of upper Te stage foraminifera and a Middle Miocene age for the overlying Castle Hill Limestone, Smith \& Davies (1976) infer that the Woruka Siltstone at Cape Vogel Peninsula is probably Early Miocene in age.

Infiltration of the claystone by an opaque mineral with dendritic habit that emanates from fracture walls does not continue beyond fine grained glauconite rich laminations that are parallel to bedding. Those fine grained glauconite bearing layers in the claystone appear to enhance local alteration, perhaps by reducing permeability in cross cutting fractures. Such heterogeneous alteration may help to explain the variability of demagnetization behaviour of samples through the Woruka siltstone section sampled for this study (see section 3.3.1).

Throughout the sampled section of Woruka Siltstone sampled for this study siliceous claystone intervals are interlayered by $<1 \mathrm{~m}$ thick beds of basalt. These basalts (Fig. 7) have a fine grained, microlitic texture, with abundant phenocrysts of plagioclase and clinopyroxene. Brown glass is common in all samples, as well as less common occurrences of sparry calcite. These observations suggest that although they are pervasively altered now, those basalt layers were deposited as glassy, vesicular, and porphyritic lavas.

A structural correction has been applied to the raw paleomagnetic data from the Woruka Siltstone to account for dip changes observed on both map and outcrop scale. While bedding attitudes measured in the Woruka Siltstone at Cape Vogel Peninsula generally dip to the NE between $15-40^{\circ}$, and strike between $320^{\circ}$ and $340^{\circ}$, short wavelength dip changes and internally deformed beds were observed in outcrop. This variability of tilt may in part be due to slump folding as other units do not 
share this style of folding, but the temporal relationship of tilting to the acquisition of a ChRM is unclear. Bedding attitudes were measured at all sample sites, and structural corrections have been applied to paleomagnetic data consistent with returning bedding to horizontal. The structural correction applied varies between outcrops and is in some cases core specific, reflective of the level of bedding variation at each site (see individual .rs3 files, Appendix A). 

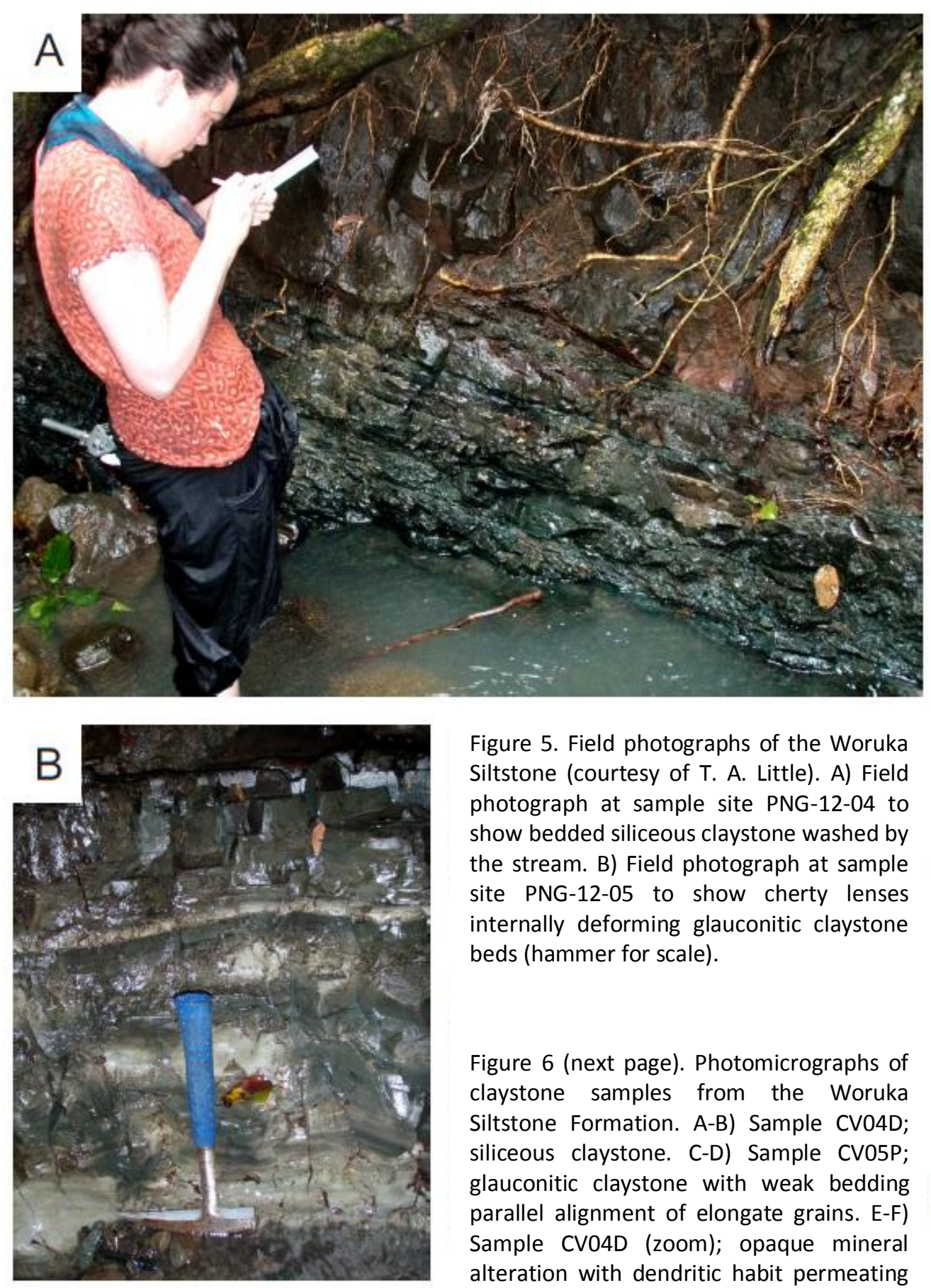

Figure 5. Field photographs of the Woruka Siltstone (courtesy of T. A. Little). A) Field photograph at sample site PNG-12-04 to show bedded siliceous claystone washed by the stream. B) Field photograph at sample site PNG-12-05 to show cherty lenses internally deforming glauconitic claystone beds (hammer for scale).

Figure 6 (next page). Photomicrographs of claystone samples from the Woruka Siltstone Formation. A-B) Sample CV04D; siliceous claystone. C-D) Sample CV05P; glauconitic claystone with weak bedding parallel alignment of elongate grains. E-F) Sample CVO4D (zoom); opaque mineral alteration with dendritic habit permeating from fracture walls. G-H) Sample CV05P1; red and green layering, where opaque mineral is confined within glauconite rich horizons. 

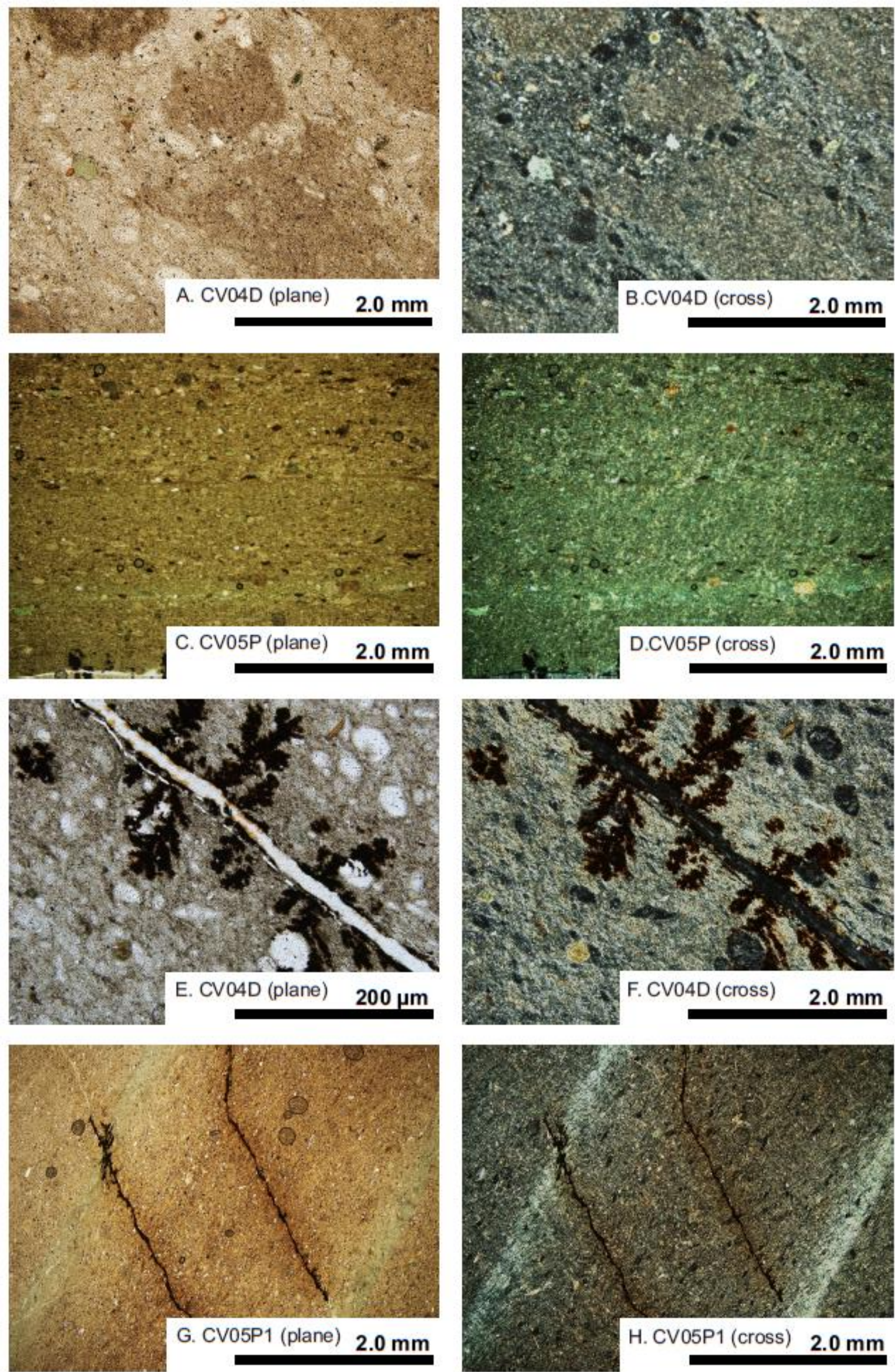

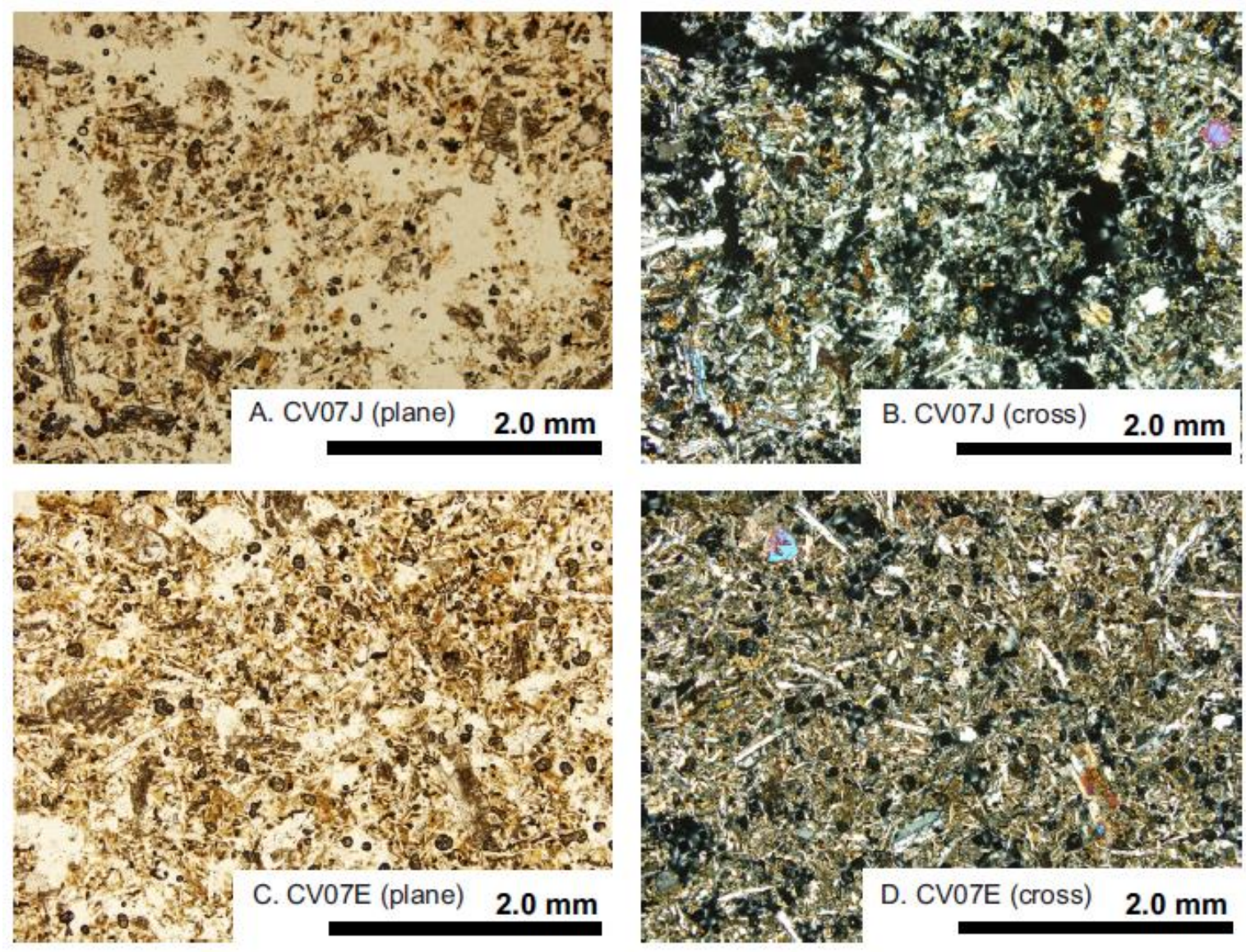

Figure 7. Photomicrographs of basalt samples from the Woruka Siltstone Formation. A-B) Sample CV07J; glassy and porphyritic, with abundant plagioclase phenocrysts as well as minor amphibole and pyroxene. C-D) Sample CV07E; glassy porphyritic basalt with sub-equigranular groundmass of intersertal feldspar and clinopyroxene. 


\subsubsection{Castle Hill Limestone}

The Castle Hill Limestone was sampled at 2 sites on the Cape Vogel Peninsula (PNG-12-08 and PNG12-09), which are located 2-3 km to the south of Woruka and Tapio villages (Fig. 5). A total of 49 oriented cores were retrieved at $0.5-1 \mathrm{~m}$ spacing. In total those cores sample 41 stratigraphic metres of the Castle Hill Limestone as exposed on Cape Vogel Peninsula.

The two sites where we sampled the Castle Hill Limestone are near the stratigraphically lower (PNG12-08) and upper (PNG-12-09) extents of the estimated $120 \mathrm{~m}$ thick sequence exposed on the Cape Vogel Peninsula (Smith \& Davies, 1976). At site PNG-12-08 (Fig. 8G), a sharp planar basal contact separates recessive friable sandy sediment (possibly Woruka Siltstone) from $>50 \mathrm{~m}$ of overlying Castle Hill Limestone, of which we sampled the lower $30 \mathrm{~m}$. At the base of the section sampled, the limestone is predominantly a coarse arenaceous grain supported biomicrite with some red colouration and laminated cross bedding internal to $5-10 \mathrm{~cm}$ rhythmic beds. These beds grade upward into more massive and well cemented cream coloured limestone. That sequence observed at site PNG-12-08 is similar to the one described by Bickel (1974) at the base of the Robinson Bay Limestone $>200 \mathrm{~km}$ to the NW. Because of the similarity of that Castle Hill Limestone sequence to the Robinson Bay Limestone, and the aforementioned correlation of those formations based on foraminiferal assemblages (Bickel, 1974); as well as the position of our samples in relation to the total thickness of exposed Limestone section, I infer that the limestone sampled at PNG-12-08 is near the base of the Castle Hill Limestone, and that it is of early Middle Miocene age. The Castle Hill Limestone was also sampled for paleomagnetic analysis at site PNG-12-09, where it is exposed in a stream to the south of Tapio Village. There, the gradient of that north draining stream is such with respect to shallow dipping sedimentary layers, that stratigraphically higher horizons are exposed with distance upstream. An outcrop of highly resistant $\mathrm{dm}$ bedded limestone forms a narrow gorge in the stream at site PNG-12-09. Other stratigraphically higher limestone beds found 50m upstream are also highly resistant and bedded on a $\mathrm{dm}$ scale, but increasingly incorporate brown-grey interbeds of marl that are 5-30 cm thickness in an up stream, up-section direction. I infer that the limestone sampled at PNG-12-09 is in the upper-most part of the Castle Hill Limestone. Where marl layers are distinguishable, I infer those rocks to be of the younger Tapio Marl Formation, gradationally overlying Castle Hill Limestone.

Most of the Castle Hill Limestone is composed of well defined $5-10 \mathrm{~cm}$ thick tabular beds that are organised in metre scale packages bounded by low-angle reactivation surfaces. The $\mathrm{cm}$-scale tabular layering is defined by alternating layers of cream coloured resistant calcareous limestone with less resistant layers of ruddy calcarenite. Castle Hill Limestone in thin section contains a well preserved framework of skeletal grains (Fig. 8), which suggests that those rocks have not been recrystallized. Those foraminifera and coral fragment grains are suspended in a matrix of un-recrystallized micrite ooze.

Repetitive bedding surfaces in the Castle Hill Limestone at site PNG-12-08 generally dip less than $10^{\circ}$, striking in many directions. Paleomagnetic data were corrected by rotating directions about strike of bedding consistent with returning bedding attitudes to horizontal. However, I recognise that the large variation in dip direction in the sampled section may at least in part reflect diverse primary dips of variably onlapping and downlapping bedding surfaces. The attitude of bedding at PNG-12-09 was determined both from direct measurements of bedding surfaces with a geologic compass and from constructing best fitting great circles to sets of related apparent dips of bedding traces measured on 
differently oriented outcrop faces. Those samples are corrected for bedding that strikes between 020-070 ${ }^{\circ}$, and dips between $13-27^{\circ}$ (see individual .rs3 files, Appendix C). 

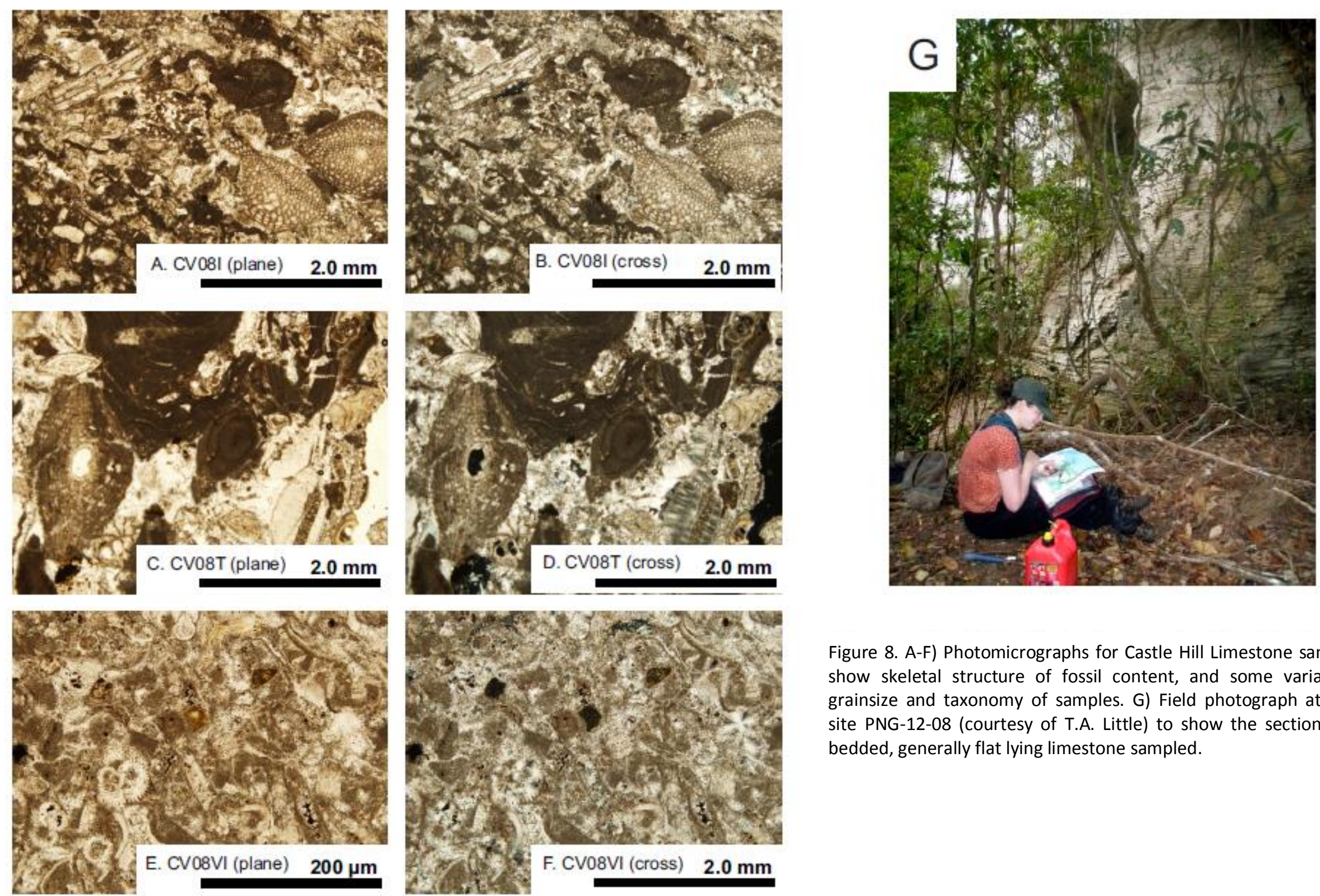

Figure 8. A-F) Photomicrographs for Castle Hill Limestone samples to show skeletal structure of fossil content, and some variability in grainsize and taxonomy of samples. G) Field photograph at sample site PNG-12-08 (courtesy of T.A. Little) to show the section of well bedded, generally flat lying limestone sampled. 


\subsubsection{Tapio Marl}

The Tapio Marl was sampled at 3 sites (PNG-12-10 to PNG-12-12) in the same stream as site PNG-1209, $2 \mathrm{~km}$ inland of Tapio Village. A total of 37 oriented cores were retrieved at $0.5 \mathrm{~m}$ spacing through 3 outcrops. We sampled approximately $18 \mathrm{~m}$ of section, in a semi-continuous fashion within the lower part of the $60 \mathrm{~m}$ thickness of Tapio Siltstone that is exposed on Cape Vogel Peninsula (Smith \& Davies, 1976).

The Tapio Marl rocks drilled for this study consist mainly of horizontally continuous planar beds of soft marl, with interbeds of resistant calcarenitic limestone and some thin seams of claystone and sandstone. The outcrops at the stratigraphically lower sample sites of the Tapio Marl (PNG-12-11 \& PNG-12-12) are mainly dm thick layers of arenaceous limestone that alternate with marl interbeds. This alternating limestone-marl sequence grades up section into predominantly brown-grey marl beds that are $\mathrm{dm}$ thick, and that are only locally interbedded with cream limestone. The aforementioned gradation from mostly limestone beds to increasingly terrigenous marl beds, as well as the proximity of the sample strata to the upper contact of the Castle Hill Limestone, at site PNG12-09, indicates that the sampled Tapio Marl section is located near the base of the formation. The Tapio Marl samples for this study are considered to be Late Miocene in age (Bickel, 1974).

Thin sections of the limestone in the Tapio Marl (Fig. 9D-E) are distinct from the Castle Hill Limestone (Fig. 8). Foraminiferal skeletons are smaller $(<0.5 \mathrm{~mm})$, and generally appear more spherical. Another feature of the Tapio Marl Limestone is the occurrence of rare detrital volcanogenic crystals. Foraminiferal tests are generally suspended in a variably plentiful micrite matrix. Marl samples (Fig. 9B-C) have an increased siliceous detrital component. The siliceous groundmass of Tapio Marl samples incorporates lithic fragments and opaque mineral grains (generally $<0.1 \mathrm{~mm}$ ) presumably of detrital origin. Tapio Marl samples do all incorporate fossil foraminifera, but they are relatively sparse and small in the brown-grey marl samples. The thin section petrography of Tapio Marl samples indicates an increased detrital component relative to the underlying Castle Hill Limestone, and at least some of that is from erosion of a crystalline rock source. Despite an influx of clastic material, the fine grained nature of detrital components and the micro fossil content remains suggestive (continuing from underlying units) of a depositional environment starved of sediment, probably with slow sedimentation rates.

Bedding surfaces are mostly planar and parallel to one another at the sampled Tapio Marl outcrops. The beds dip at $<10^{\circ}$ to the $N$ and NNE, and $<15^{\circ}$ to the SE (Fig. 4). Paleomagnetic data were tilt corrected by rotating directions about the strike of bedding consistent with restoring those beds to horizontal. 

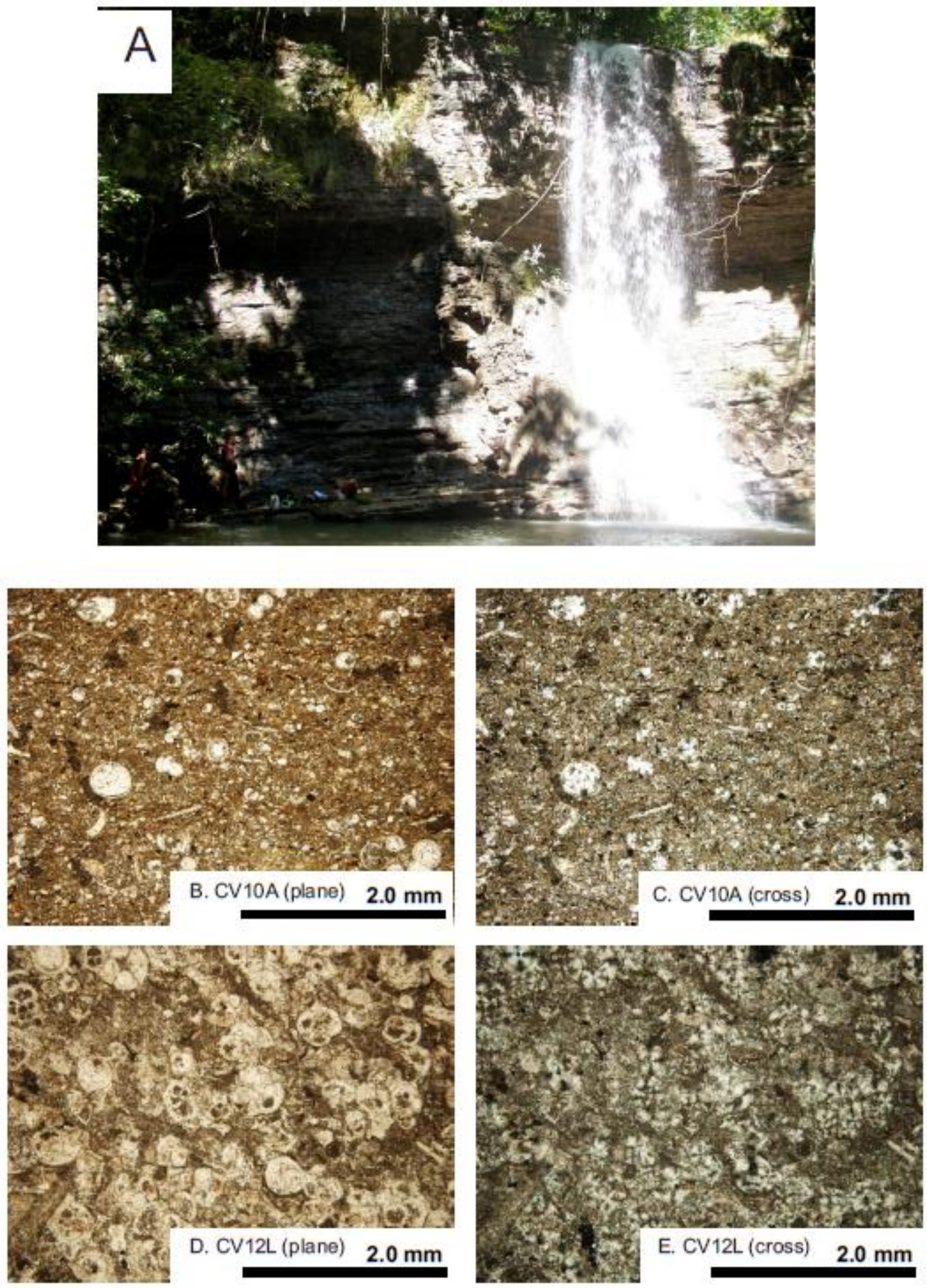

Figure 9. A) Field photograph (courtesy of T. A Little) at sample site PNG-12-10 to show well bedded shallow dipping section of brown-grey marl sampled. B-E) Photomicrographs to show marl (top) and limestone (bottom) samples from the Tapio Marl Formation. Marl samples are fine grained with $\sim 50 \%$ fossil content. Limestone samples are coarser grained consisting of $>90 \%$ foraminifera $\sim 0.2 \mathrm{~mm}$ diameter. Note the texture of this limestone is distinct from the Castle Hill Limestone shown in Fig. 8. 


\subsection{Demagnetization Behaviour of Cape Vogel Peninsula Samples}

\subsubsection{Woruka Siltstone}

A total of 45 specimens of Claystone and basalt from the Woruka Siltstone were demagnetized for this study. Most of those specimens retain a well-defined and origin-bound component of magnetization that can be interpreted as the ChRM, or primary remanence. There is also evidence however, for secondary alteration in the demagnetization profiles of many specimens. Some secondary magnetizations result in deflection of ChRM directions to anomalous declinations and curvilinear trajectories in Zijdeveld plots. In several cases those secondary magnetizations are well defined in distinct blocking temperature ranges, and are readily distinguishable from ChRM components in a single demagnetization plot.

The strength of NRM in Woruka Siltstone samples generally falls in two ranges which correlate to sample rock type. Silty claystone samples have NRM ranging between $10^{-5}$ to $10^{-2} \mathrm{~A} / \mathrm{m}$, and samples from altered basalt layers may retain maximum magnetizations up to $4.5 \mathrm{~A} / \mathrm{m}$ (Table 3; Appendix A).

ChRM directions for the Woruka Siltstone are defined as remanence components that persist through thermal demagnetization at temperatures of $300^{\circ} \mathrm{C}$ and above, and at peak alternating fields of greater than $30 \mathrm{mT}$. Those components are differentiated from others removed through low temperature $\left(<300^{\circ} \mathrm{C}\right)$ and peak field $(<25 \mathrm{mT})$ demagnetizing steps. CV04B.2 and CV04A.2 are examples of specimens that carry those two components, and where they are well defined in thermal demagnetization plots (Fig. 10). Zijdeveld plots from thermal demagnetization experiments generally have origin bound trajectories through high temperature steps, and remanence is generally removed completely by thermal demagnetization at $550-600^{\circ} \mathrm{C}$. However, some specimens (of which CV05N.1 is an example) carry ChRM components that are well defined through a wide blocking temperature range, but are not origin bound in Zijdeveld plot (Fig. 10). A high temperature remanence component sometimes remains after the maximum thermal demagnetization step of $520^{\circ} \mathrm{C}$ for these specimens, but remains undetermined. Alternating Field demagnetization profiles of Woruka Siltstone specimens also exhibit some well-defined components of magnetization through the $5<85 \mathrm{mT}$ coercivity range, though there is a higher frequency of curvilinear trajectories in those Zijdeveld plots, and GAD uninterpretable PCA component directions are more often determined from alternating field demagnetization plots than from thermal demagnetization plots. There is also often an undetermined component of remanence remaining after peak demagnetizing fields of 120 mT.

Specimens from altered basalt layers at the stratigraphically highest sample site for the Woruka Siltstone (PNG-12-07) retain three well defined remanence components of alternating normal and reverse polarity in low, intermediate, and high blocking temperature ranges. Though the intermediate blocking-temperature components are only well defined enough in a few experiments to determine PCA components with Maximum Angle of Deviation (MAD) less than $10^{\circ}$, the basalt specimens consistently produce decay curves with an inflection or hump at intermediate temperatures $\left(\sim 200-350^{\circ} \mathrm{C}\right)$. Temperature dependant susceptibility curves for basalt samples from the Woruka Siltstone are in some cases interrupted slightly at around $200-300^{\circ} \mathrm{C}$ (Fig. 11D), which may also be reflective of an intermediate Curie temperature mineralogy. 
Lowrie 3-axis experiments of two Woruka Siltstone specimens (Fig. 11A-B) show that the majority of ferromagnetic grains are within the $80-150 \mathrm{mT}$ coercivity range, and very few have coercivities above $150 \mathrm{mT}$. There appears to be a small grain population in the $<80 \mathrm{mT}$ coercivity range with a Curie temperature at approximately $300-350^{\circ} \mathrm{C}$, and all IRM components are completely removed by thermal demagnetization at $650^{\circ} \mathrm{C}$. 

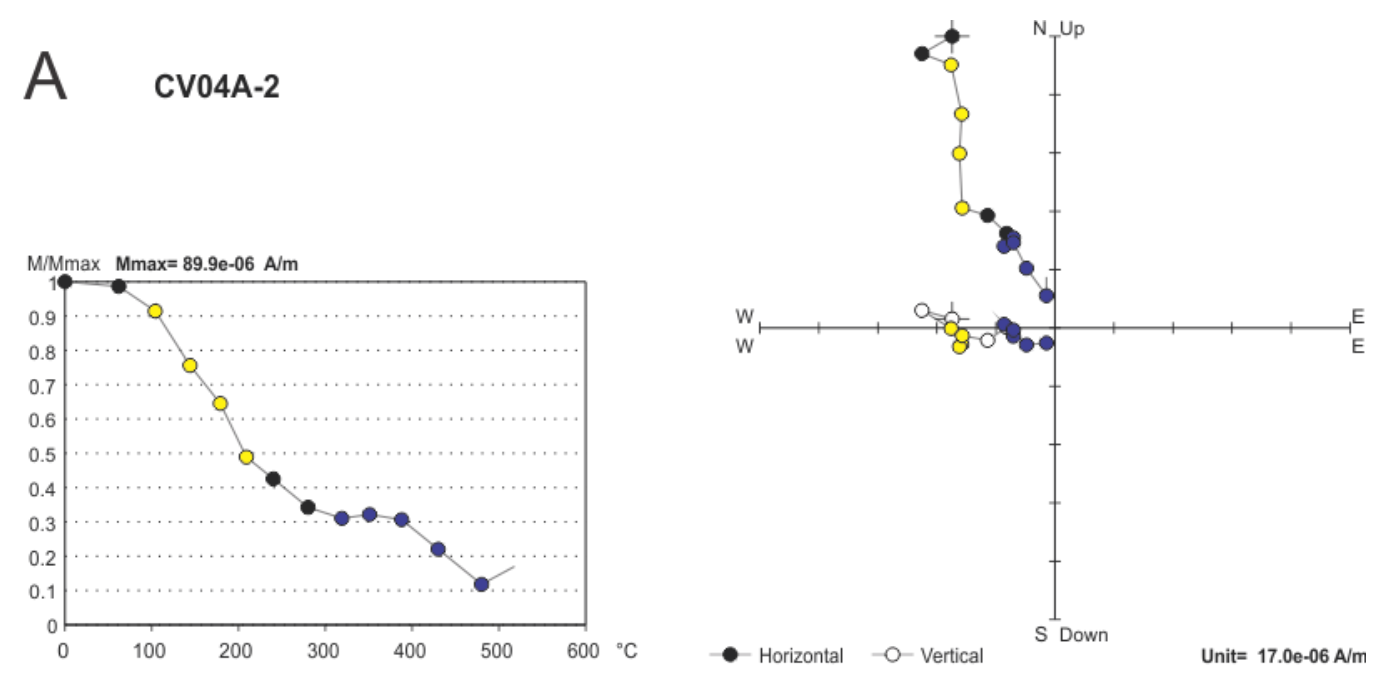

B $\quad$ cvo5N-1
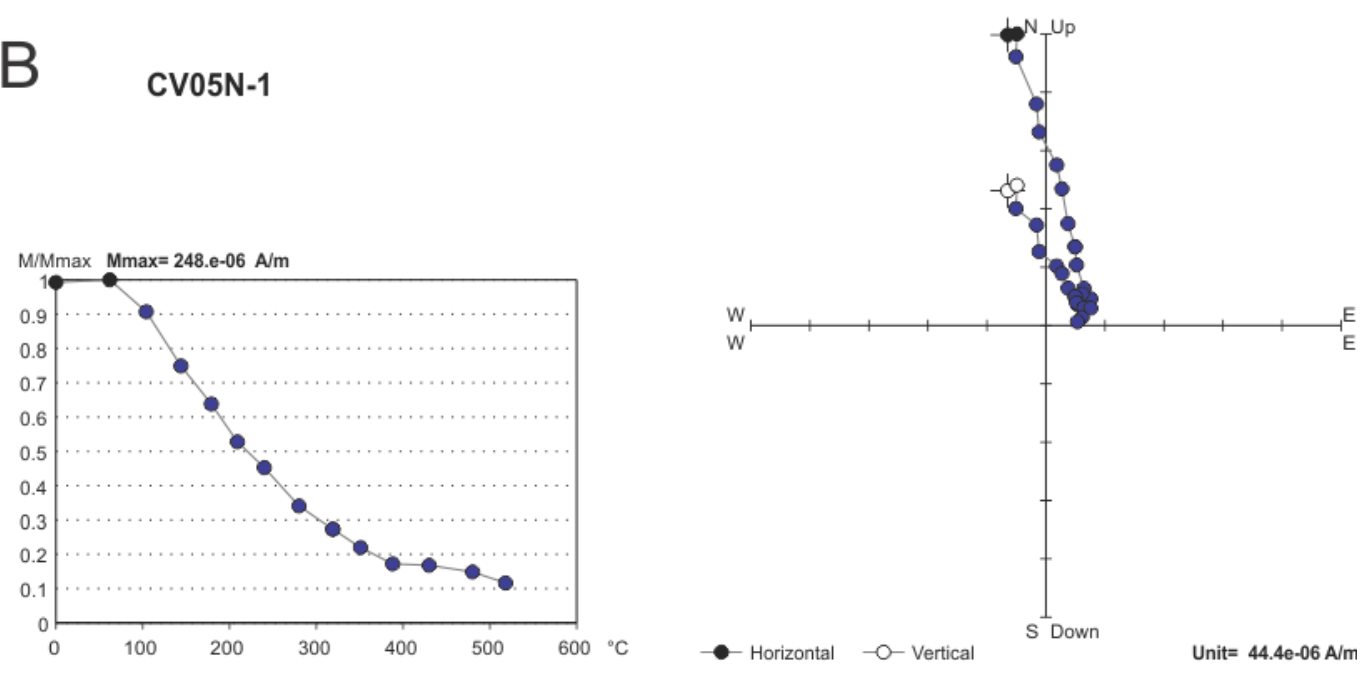

\section{CV07E1}
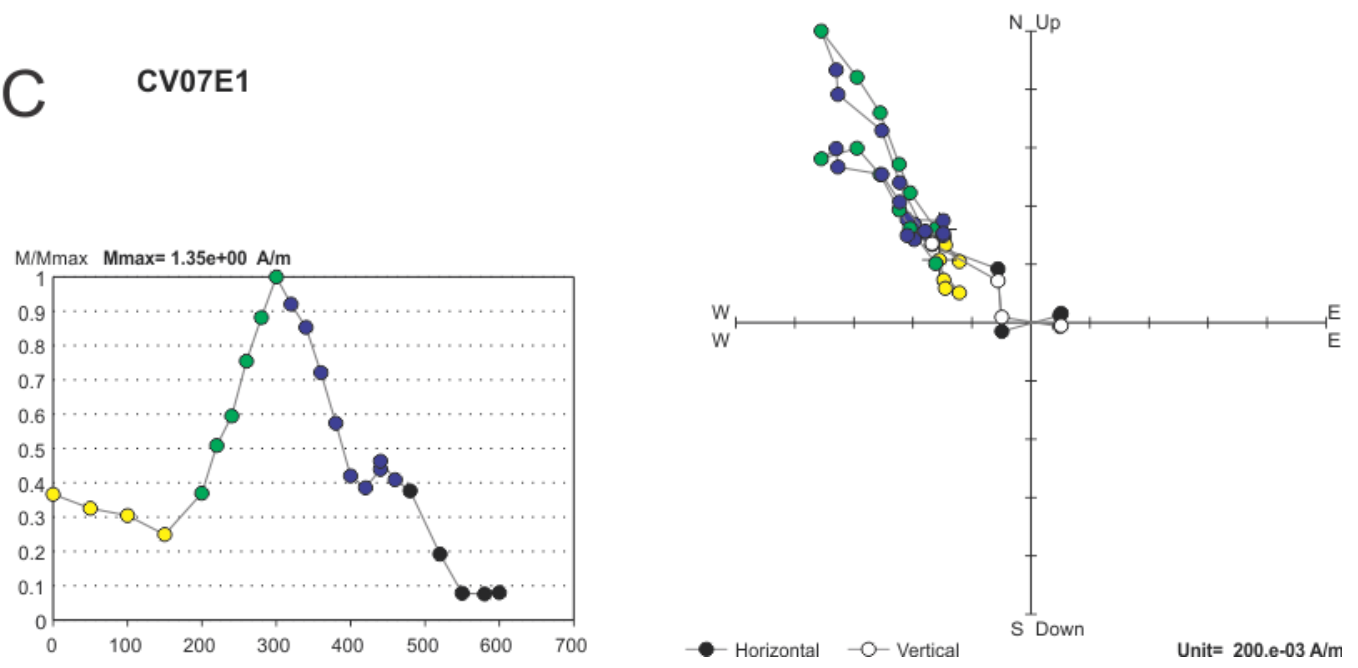

Figure 10. Module and Zijdeveld plots for selected specimens from the Woruka Siltstone to show a range of demagnetization behaviour. Components interpreted as secondary are shown in yellow, ChRM in blue, and intermediate in green. 

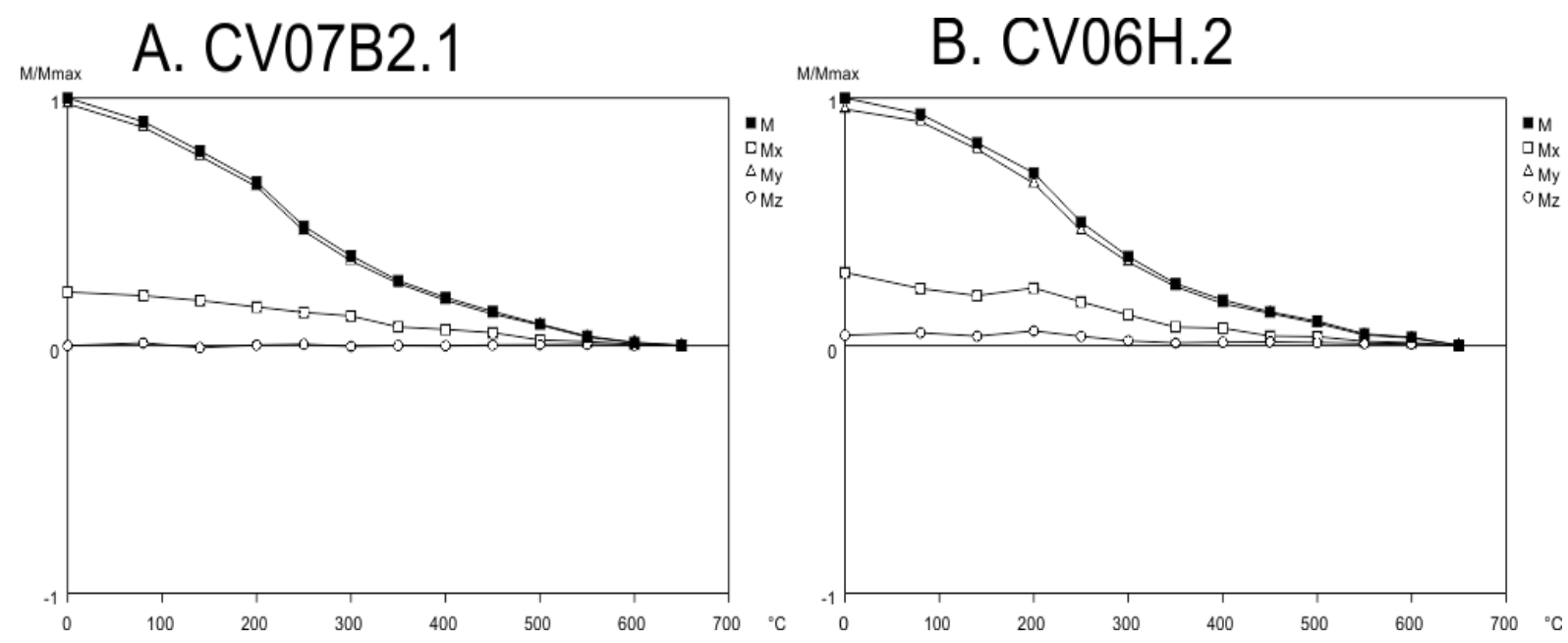

C. CV050

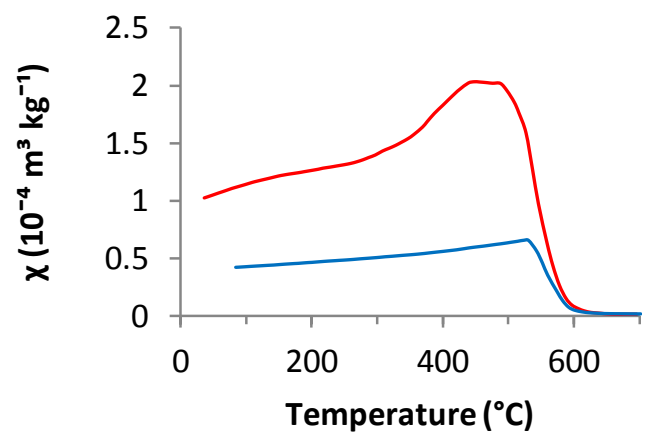

D. CV07J

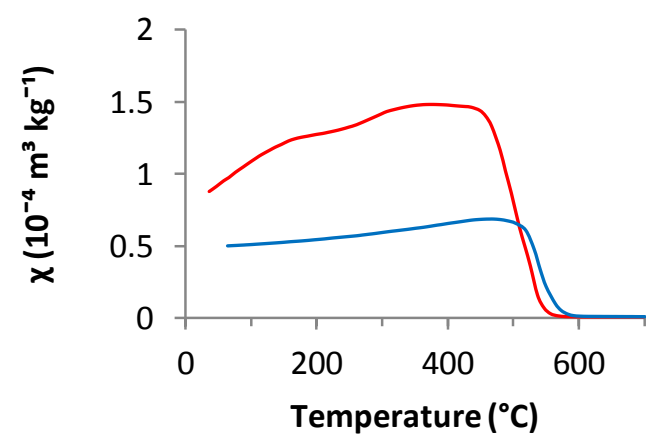

Figure 11. A-B) Lowrie experiment 3-component demagnetization plots for claystone samples of Woruka Siltstone samples. Grains with coercivity $<80 \mathrm{mT}$ are magnetized in the direction of X-axis, $80-150 \mathrm{mT}$ coercivity grains are magnetized in the direction of the $Y$-axis, and $>150 \mathrm{mT}$ coercivity grains are magnetized in the direction of the Z-axis. The relationship of the overall thermal decay plot to the $\mathrm{Y}$-axis demagnetization curve indicates that most grains have coercivity of $80-150 \mathrm{mT}$, and a range of blocking temperatures $<600^{\circ} \mathrm{C}$. C-D) Temperature dependent magnetic susceptibility curves for basalt samples from the Woruka Siltstone formation. 


\subsubsection{Castle Hill Limestone}

The Castle Hill Limestone data set includes PCA directions determined from 55 of a total 61 demagnetization profiles. Several components of magnetization can be identified in both Thermal and Alternating Field demagnetization plots of Castle Hill Limestone specimens.

Castle Hill Limestone samples are very weakly magnetized, on the order of $10^{-6}$ to $10^{-7} \mathrm{~A} / \mathrm{m}$. This is approaching the sensitivity of the SQUID magnetometer at Otago University in Dunedin, which was used to measure these specimens.

Two components of magnetization are distinguishable in Castle Hill Limestone demagnetization plots. Those are: 1) carried by low blocking temperature $\left(<250^{\circ} \mathrm{C}\right)$, high coercivity $(>120 \mathrm{mT})$ grains; and 2 ) removed by demagnetization of low coercivity $(<35 \mathrm{mT})$ grains. The directional agreement between low temperature and high coercivity components evident in the demagnetization plots of CV08M.1 and CV08M.2 (Fig. 12) provide a basis for correlating low temperature with high coercivity components through the data set. Furthermore, the Lowrie 3-axis experiment data for specimen CV08N.1 (Fig. 13) is highly indicative of a high coercivity mineral that has a low Curie temperature mineral (probably goethite) dominating the ferromagnetic mineral grain population in at least that one sample. In many other specimens the largest and only well-defined component of magnetization is removed through Alternating Field demagnetization steps $<35 \mathrm{mT}$. Remanence components removed below $500^{\circ} \mathrm{C}$ generally do not exhibit origin bound trajectories in Zijdeveld plot. The peak thermal demagnetization for Castle Hill Limestone specimens in this study was $520^{\circ} \mathrm{C}$, and it appears there may be a weak remanence carried by high blocking temperature grains that remains unremoved and undetermined by this study.

There may be some overlap of remanence components in the intermediate to high blocking temperature ranges. Determination of components in the intermediate blocking temperature and coercivity ranges yields directions that are highly scattered and appear deflected to $\sim 90^{\circ}$ declinations. Those directions are speculatively inferred to be the result of overlapping nonantipodal reverse and normal components, which results in directions considered GAD uninterpretable and those components have been rejected. 

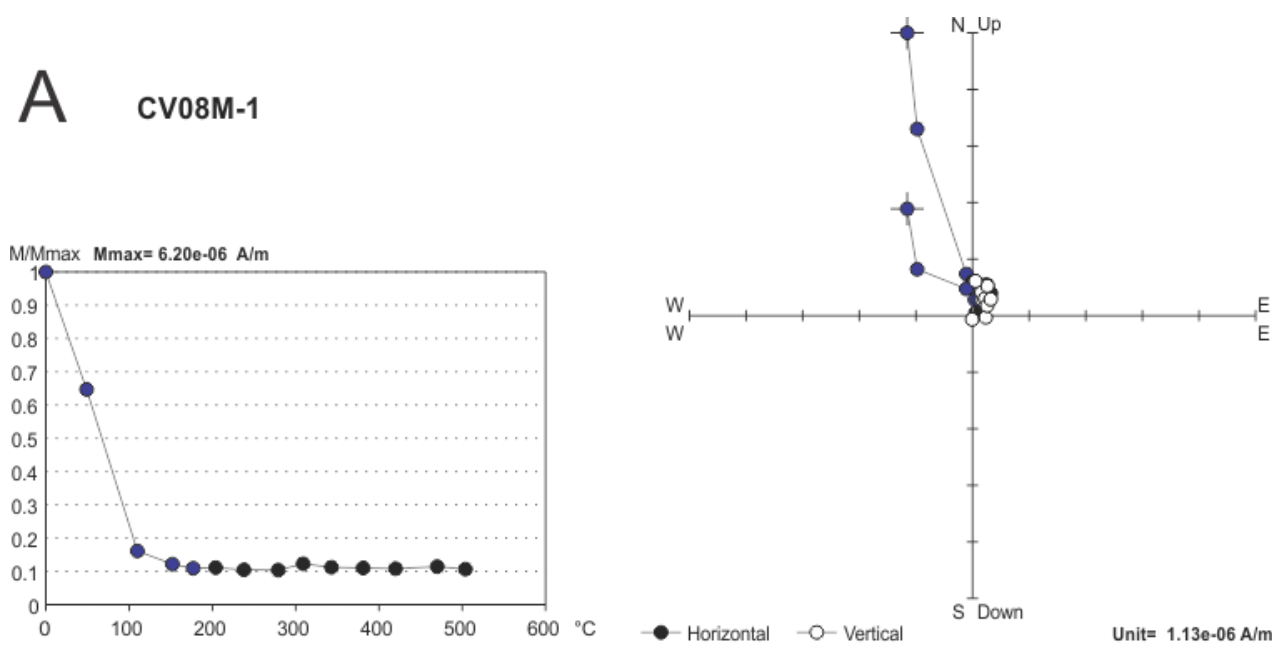

\section{B cvo8m-2}
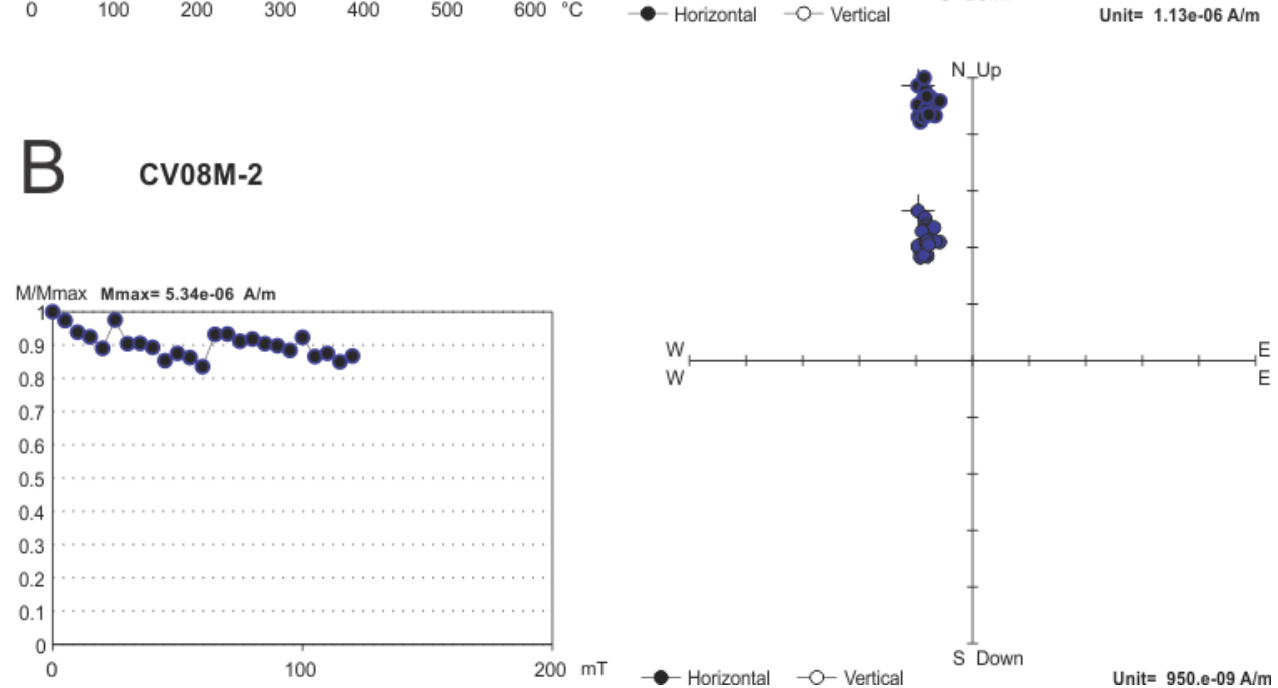

Figure 12. Demagnetization plots for selected specimens from the Castle Hill Limestone to show demagnetization behaviour through thermal (A), and alternating field (B) treatment, together indicative of goethite as a dominant carrier of remanence.

A CV08N-1

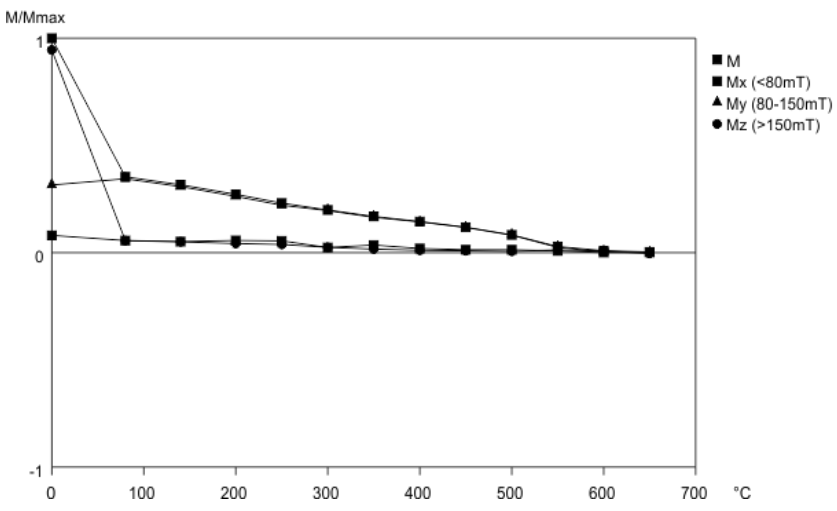

B cv08c2.1

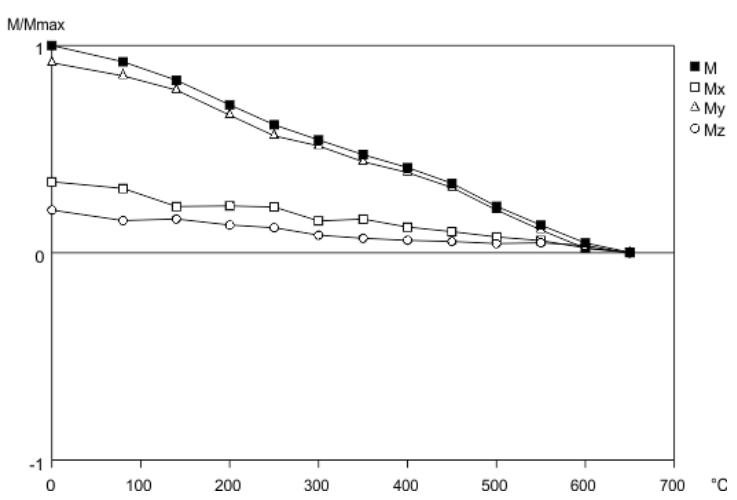

Figure 13. Lowrie experiment 3-component demagnetization plots for limestone samples of the Castle Hill Limestone. Grains with coercivity $<80 \mathrm{mT}$ are magnetized in the direction of $\mathrm{X}$-axis, $80-150 \mathrm{mT}$ coercivity grains are magnetized in the direction of the $Y$-axis, and $>150 \mathrm{mT}$ coercivity grains are magnetized in the direction of the Z-axis. The low blocking temperature range of high coercivity grains in A) is highly indicative of goethite. 


\subsubsection{Tapio Marl}

From 38 out of a total of 45 demagnetization experiments of Tapio Marl specimens, a combination of Principal Component Analysis (PCA) and Fisher statistics have been used to determine 45 components of magnetization.

The Tapio Marl samples are weakly magnetized, with NRM on the order of $10^{-5}$ to $10^{-6} \mathrm{~A} / \mathrm{m}$ (see Appendix A). All Tapio Marl specimens have normal polarity NRM in geographic coordinates, the only exception (specimen CV12D.1) being probably due to poor core orientation. The most well defined and consistent remanence component is carried by low coercivity $(<35 \mathrm{mT})$ and low blocking temperature $\left(<300^{\circ} \mathrm{C}\right)$ grains. That component usually constitutes the majority of NRM. There also appears to be a small population of grains carrying a weak remanence that persists through thermal demagnetization steps $350-620^{\circ} \mathrm{C}$, and the remanence carried by those grains is distinguished from the aforementioned pervasive component carried by low coercivity and blocking temperature grains. In the high blocking temperature range, stratigraphically high samples carry reverse polarity components, while older samples have normal polarity remanence. There is also often a weak remanence that remains after maximum AF demagnetization steps at peak fields of $120 \mathrm{mT}$.

While an instrument malfunction in the initial heating step of 24 specimens (see Appendix C) means that the temperature dependant demagnetization behaviour of those specimens is enigmatic. Some of those demagnetization profiles for the above mentioned 24 specimens were retained because the characteristic demagnetization behaviour correlates with that seen in the demagnetization profiles of other successful experiments. Faulty wiring meant that temperature control on the thermal demagnetizer was non-existent during the initial heating step of 24 Tapio Marl specimens. Those specimens were heated to an unknown temperature (probably $300-500^{\circ} \mathrm{C}$ based on behaviour during further treatment), and the majority of NRM was removed in one step. Specimens CV10C.1 and CV10G.1 (Fig. 13) are two examples of successful thermal demagnetization experiments (demagnetized at known temperatures) that provide a basis to interpret the inferior demagnetization plots of compromised thermal demagnetization experiments. The remanence direction of CV10C.1 changes gradually, along a great circle trajectory, from normal polarity NRM to reverse polarity at high temperatures. The normal polarity component is removed between $0-320^{\circ} \mathrm{C}$, after which measurements cluster around a reverse polarity direction, and a weak reverse polarity remanence remains after peak demagnetization step of $520^{\circ} \mathrm{C}$. Samples CV10B-P (in stratigraphic sequence, increasing in age alphabetically) appear to exhibit similar demagnetization behaviour, with normal polarity NRM heading towards reverse polarity directions through progressive thermal demagnetization. The 24 specimens involved in the compromised thermal demagnetization experiments produce demagnetization plots where the remanence direction changes rapidly, potentially removing that same low temperature normal polarity component entirely during the first heating step. I infer based on the demagnetization behaviour of the affected group of specimens that the instrument malfunction subjected those 24 specimens to temperatures $>300^{\circ} \mathrm{C}$, and that in some cases the remaining remanence may be tentatively interpreted as a ChRM retained by primary detrital grains with blocking temperatures greater than $300^{\circ} \mathrm{C}$.

The weak remanence of Tapio Marl samples produces a low signal to noise ratio of measurement, resulting in errors that contribute to the directional scatter between successive measurement points, and results in poor definition of magnetization components in Zijdeveld plots. Directional scatter in Tapio Marl demagnetization plots may also be due to post-depositional chemical alteration 
affecting remanence carrying mineral grains, as well as thermal alteration through demagnetization experiments.

Lowrie 3-axis experiments for Tapio Marl samples (Fig. 15) were largely undiagnostic, but indicate that ferromagnetic mineral grains are predominantly in the $80-150 \mathrm{mT}$ coercivity range, and distributed evenly through the blocking temperature spectrum $<600^{\circ} \mathrm{C}$. The largest Isothermal Remanent Magnetization (IRM) component acquired by all Tapio Marl samples is retained by intermediate coercivity $(80-150 \mathrm{mT})$ grains. An IRM up to $\sim 40 \%$ strength of the largest component is also acquired by low coercivity $(<80 \mathrm{mT})$ grains. The stratigraphically highest marl samples exhibit a small (Curie temperature) step at $\sim 250^{\circ} \mathrm{C}$ superimposed on a gradual decrease in all components through thermal demagnetization to where all remanence is removed by $600^{\circ} \mathrm{C}$. In all Lowrie threecomponent experiments for Tapio Marl specimens the largest component is acquired in the intermediate $(80-150 \mathrm{mT})$ coercivity range, followed by the low coercivity $(<80 \mathrm{mT})$ component. The proportion of high coercivity mineral grains appears to decrease with stratigraphic height, which is correlative with the silica/clastic content of sample rocks. 
A

CV10C-1
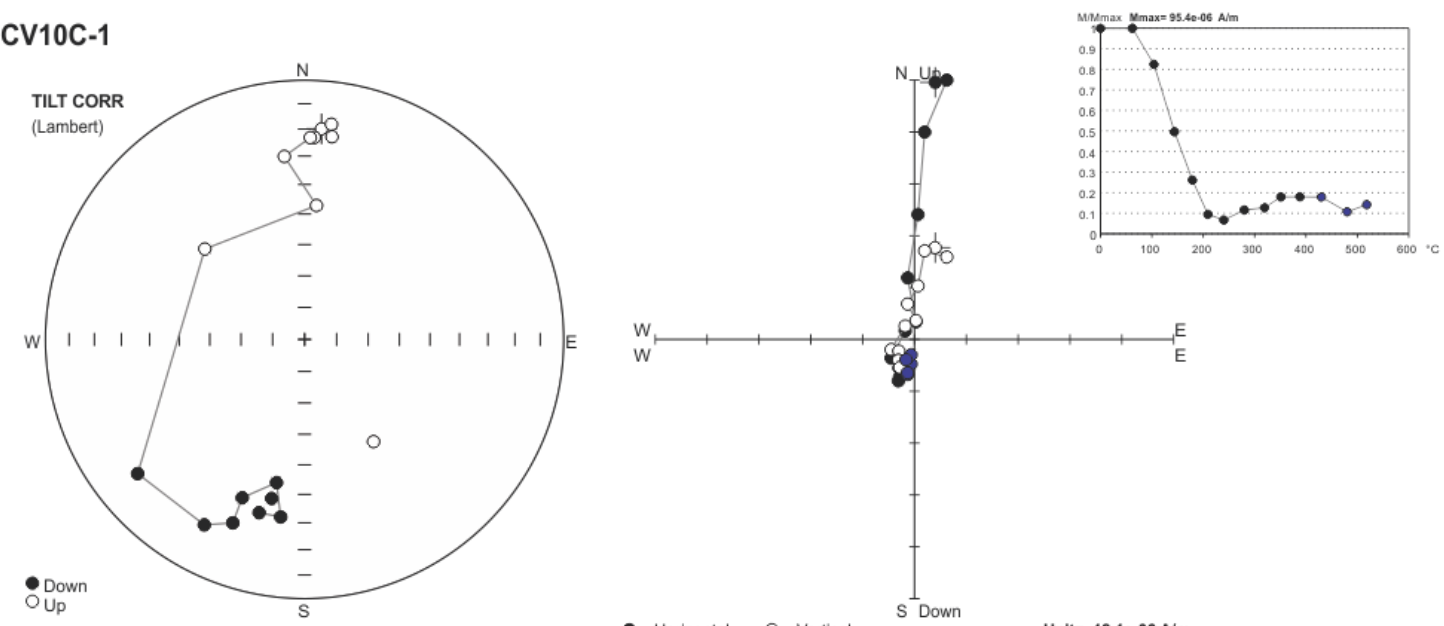

B

CV10B-1
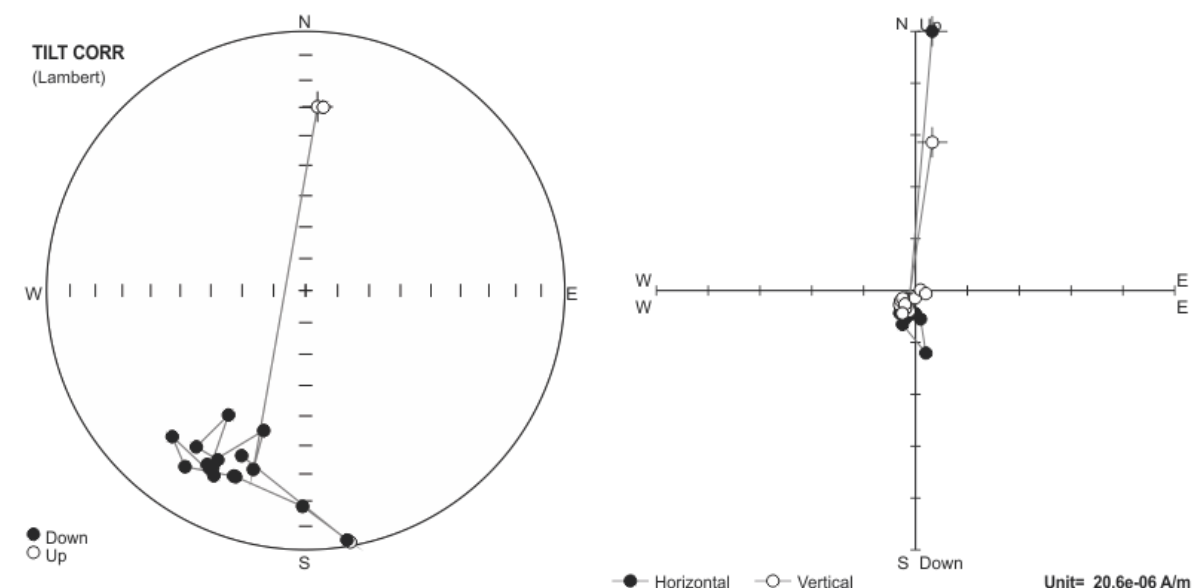

C
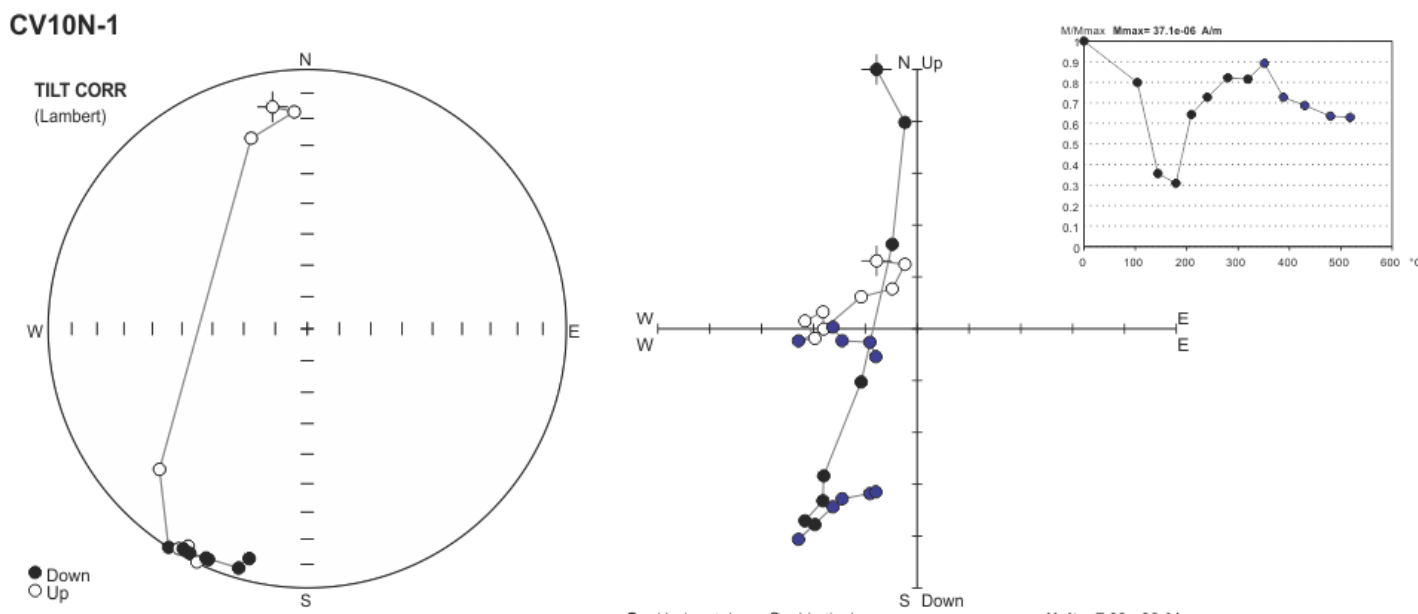

- Horizontal -O- Vertica

Unit= $7.09 \mathrm{e}-06 \mathrm{~A} / \mathrm{m}$

Figure14. Demagnetization plots for selected specimens from the Tapio Siltstone to show great circle trajectories through removal of a secondary remanence at low to intermediate temperatures. CV10B.1 (B) is one of 24 compromised demagnetization experiments discussed in text, but the correlation of the directions removed in those samples and in successful experiments lends confidence to the interpretation of compromised data. 
A. CV12F.1

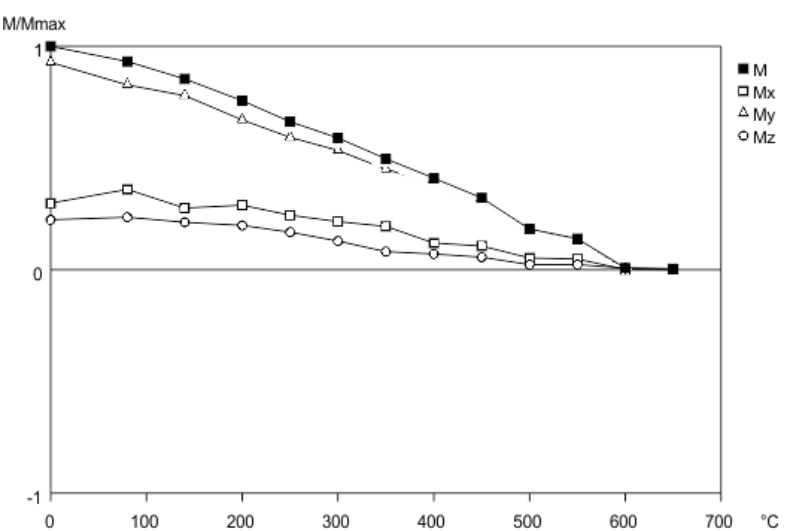

\section{CV19W.1}

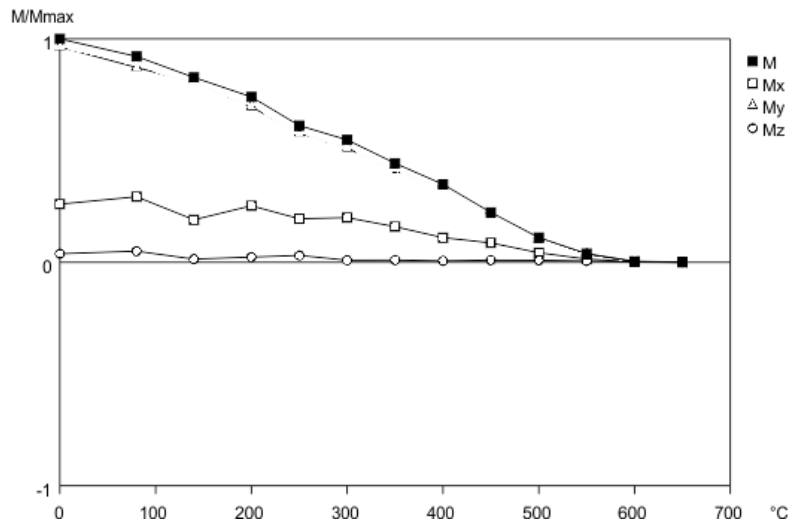

B. CV12G.1

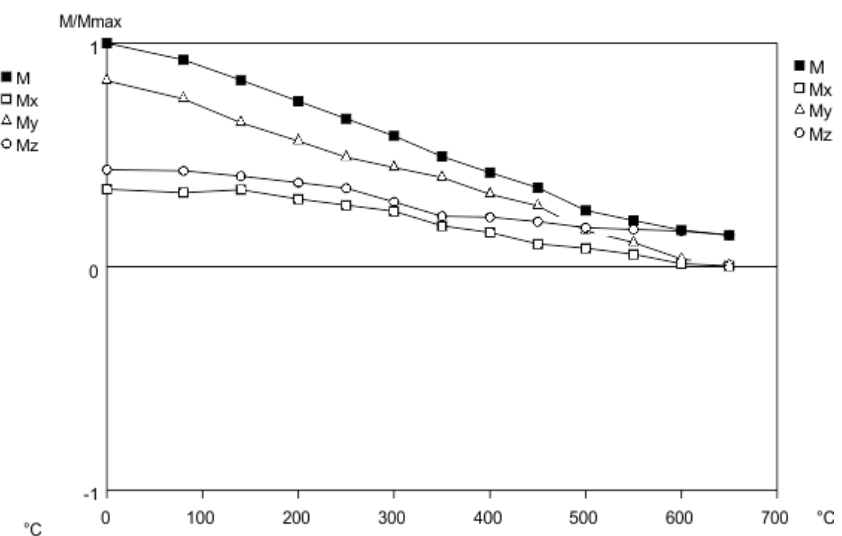

Figure 15. Lowrie experiment 3-component demagnetization plots for marl and limestone samples of the Tapio Marl Formation. Grains with coercivity $<80 \mathrm{mT}$ are magnetized in the direction of X-axis, $80-150 \mathrm{mT}$ coercivity grains are magnetized in the direction of the $Y$-axis, and $>150 \mathrm{mT}$ coercivity grains are magnetized in the direction of the Z-axis. Together the plots indicate variable proportions of low, intermediate and high coercivity grains, but the Curie temperature is in most cases $<600^{\circ} \mathrm{C}$ consistent with titano-magnetite. 


\subsection{Group Statistics, Interpretation and Tectonic Implications}

The Miocene sedimentary rocks sampled at Cape Vogel Peninsula are interpreted to carry both primary characteristic magnetizations and secondary overprints which complicate and contribute uncertainty to the interpretation of ChRM directions. However, those components are sufficiently well defined and consistent to be distinguished and interpreted with varying degrees of confidence. ChRM components in the data from all three formations can be separated from less stable remanence components, and can be used to calculate mean directions that are interpreted in terms of time averaged field directions for the Early, Middle, and Late Miocene. Though the foraminiferal based age constraint on those formations (Bickel, 1974; Smith \& Davies, 1976) is not precise beyond a few Myr, the results of this paleomagnetic analysis indicate statistically robust vertical-axis rotations of the Cape Vogel Peninsula relative to the Australian Plate.

Components of magnetization have been grouped according to blocking temperature and coercivity ranges correlated across specimens, and contribute to the calculation of two mean directions for each of the three sedimentary formations sampled at Cape Vogel Peninsula. For each of those formations, one direction is interpreted as a secondary overprint; distinguishable from a ChRM direction interpreted as a representative time averaged formation mean direction (those interpretations are discussed further in the following sections 3.4.1 to 3.4.3).

Individual PCA components and Fisher mean directions are assessed according to the data selection and rejection criteria outlined earlier in section 2.4.2: Data selection and rejection criteria.

The latitude and longitude at the Cape Vogel Locality is $9.7^{\circ} \mathrm{S}, 149.8^{\circ} \mathrm{E}$. The GAD field direction for those coordinates for the present day, and corresponding to Australian Plate pole locations in the Miocene (Turner et al., 2007; Veevers \& Li, 1991) are shown below.

Table 2. Expected Geomagnetic field directions for the Cape Vogel Peninsula location, corresponding to Australian Plate paleomagnetic pole positions during the Cenozoic.

\begin{tabular}{|c|c|c|}
\hline & Declination $\left(^{\circ}\right)$ & Inclination $\left(^{\circ}\right)$ \\
\hline Present & 0.0 & -18.9 \\
\hline $10 \mathrm{Ma}$ & $5.8 \pm 5.3$ & $-34.8 \pm 7.6$ \\
\hline $17.5 \mathrm{Ma}$ & $8.8 \pm 2.6$ & $-32.2 \pm 3.9$ \\
\hline $20 \mathrm{Ma}$ & $10.1 \pm 5.5$ & $-42.9 \pm 5.7$ \\
\hline
\end{tabular}

The group statistics and interpretation of each formation direction are first presented separately in the following sections (3.4.1 to 3.4.3) and compared to the Australian Plate expected field direction relevant to formation age. Those results are then discussed together in terms of tectonic implications for the Cape Vogel Locality in section 3.4.4.

\subsubsection{Woruka Siltstone}

The two remanence components identified in Woruka Siltstone demagnetization plots are interpreted as: 1$)$ a recent secondary remanence carried by low coercivity $(<15 \mathrm{mT})$ and low blocking 
temperature $\left(<300^{\circ} \mathrm{C}\right)$ grains; and 2$)$ a ChRM persisting between $300-600^{\circ} \mathrm{C}$ heating steps, and above $45 \mathrm{mT}$ peak alternating fields.

The low coercivity and blocking temperature remanence components of the Woruka Siltstone form a cluster of normal polarity directions, anticlockwise deflected from the GAD field direction for the Cape Vogel locality. The mean direction from those components (Fig. 16A; Dec: $349.3^{\circ}$, Inc: $-14.4^{\circ}$, $\alpha 95: 12.0 \mathrm{~N}=10$ ) is interpreted as a secondary magnetization for several reasons: 1 ) Those remanence components are carried by low stability grains; 2 ) there are no reverse polarity magnetizations; and 3) statistical precision is diminished by the application of a structural correction.

The mean of the more stable components, that persist past $300^{\circ} \mathrm{C}$ and $45 \mathrm{mT}$, is interpreted as a ChRM direction for the Woruka Siltstone. Those components removed in the intermediate blocking temperature and coercivity ranges are of both normal and reverse polarity, and are distributed in two antipodal clusters. The transposed mean direction of those components (Fig. 16E; Dec: $341.7^{\circ}$, Inc: $-25.2^{\circ}, \alpha 95: 8.5^{\circ} \mathrm{N}=31$ ) exhibits 1 ) a positive reversal test; 2)sufficient dispersion for a reliable time averaged field direction; and 3 ) improved statistical precision on application of a structural correction. For these reasons, I interpret that direction as a reliable time averaged direction recording an anticlockwise vertical axis rotation of the Cape Vogel locality with respect to the Australian Plate during the time since the Early Miocene. While there is relatively poor constraint on the reverse polarity direction in the Woruka Siltstone samples, the antipodes of mean directions derived from clusters of either normal or reverse polarity components have overlapping $95 \%$ confidence intervals (Fig. 16). A $\theta 63$ of $27.4^{\circ}$ for the transposed mean is sufficient to suggest that the data represent sufficient time to effectively average out secular variation. Also, if only slightly, the $\alpha 95$ of the transposed mean is reduced by application of a structural correction, suggesting magnetization was acquired prior to deformation of those rocks and represents a GAD field direction at the Cape Vogel locality for this study in the early Miocene.

Reverse polarity components are only found in the intermediate blocking temperature range of the stratigraphically highest volcanic samples. Stratigraphically lower samples do retain a component in the same blocking temperature range, distinct from higher temperature remanence, but those components are of normal polarity similar to the higher temperature remanence. In some specimens from basalt samples in the upper portion of the Woruka Siltstone there are up to 3 well defined components of alternating reverse and normal polarity found in different parts of the blocking temperature spectrum. I infer that two components carried by high and intermediate blocking temperature mineral grains represent a primary magnetization acquired on deposition, and followed by the acquisition of a CRM by partial alteration of the primary ferromagnetic mineralogy during progressive burial and diagenesis (probably to pyrrhotite or greigite based on Curie temperature). I infer that the deposition of the Woruka Siltstone sample rocks for this study took place entirely during an extended period of normal polarity, and that a geomagnetic polarity reversal took place shortly after the deposition and prior to diagenesis of the youngest rocks sampled. This scenario may allow for stratigraphically lower samples to have acquired normal polarity secondary magnetizations overlapping in time with the deposition of younger rocks. In this way, I suggest that the high temperature remanence components of those volcanic samples is a primary TRM, and that intermediate temperature remanence components date to the acquisition of a CRM during diagenetic alteration and growth of a new mineralogy with Curie temperature $\sim 300^{\circ} \mathrm{C}$. Based on this reasoning, and given that the age constraint on the Woruka Siltstone sample set is limited to the 
Early Miocene (Smith \& Davies, 1976), I propose that including both of these components in calculation of a ChRM direction for the Woruka Siltstone should serve to increase the density of time represented by components and further contribute to effectively averaging secular variation. If the secondary mineralogy does significantly postdate deposition of the Woruka Siltstone, then inclusion of these components will result in underestimation of vertical axis rotation.

The mean direction for the Woruka Siltstone has a shallow inclination $\left(25.2 \pm 8.5^{\circ}\right)$ with respect to the expected field direction, which for rocks of 20 Ma should be $42.9 \pm 5.7^{\circ}$. This may be the result of inclination-shallowing, common in sediments (Tauxe, 2011). Due to the age of these samples increasing the likelihood of viscous remanent magnetization, inclination shallowing, and chemical alteration which may affect directions through overlap of magnetizations in both blocking temperature and coercivity spectra, I consider the observed inclination anomaly of $17.7 \pm 10.2^{\circ}$ to be acceptable.

Comparison of the mean direction of the ChRM direction determined for the Woruka Siltstone at Cape Vogel with the expected Australian Plate field direction for the same location at $20 \mathrm{Ma}$ (Veevers \& Li, 1991) yields an anticlockwise declination anomaly of $28.4 \pm 10.9^{\circ}$. 

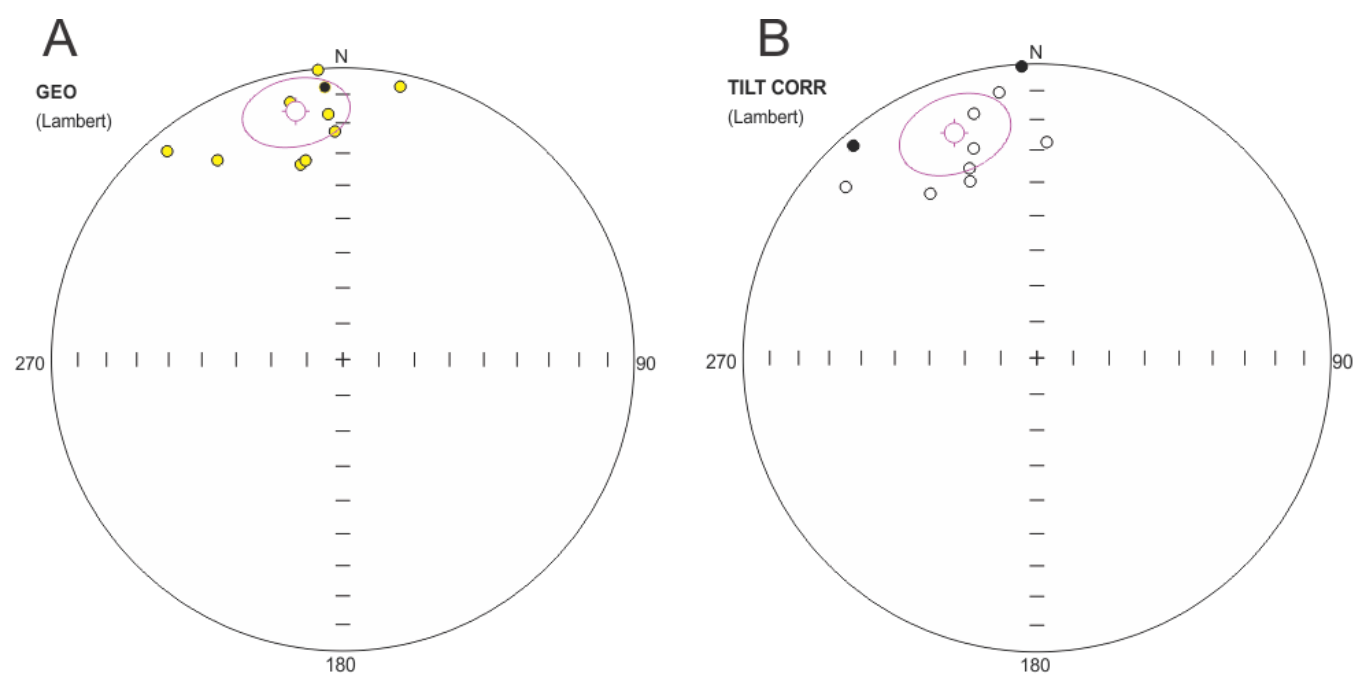

Figure 16. Equal area stereoplots to show distribution of PCA components, and mean directions (with $\alpha 95$ ellipse) for the Woruka Siltstone. A) SRM interpreted components in geographic coordinates; preferred mean SRM direction: $349.3^{\circ} /-14.4^{\circ}$ $\alpha 95=12.0^{\circ}$. B) SRM interpreted components corrected for bedding tilt; mean direction: $339.8^{\circ} \% 19.6^{\circ} \alpha 95=13.0^{\circ}$. C) ChRM interpreted components in geographic coordinates; normal mean: $355.5^{\circ} /-11.4^{\circ} \alpha 95=9.5^{\circ}$, reverse mean: $190.1^{\circ} / 41.4^{\circ}$ $\alpha 95=32.2^{\circ}$. D) ChRM interpreted components corrected for bedding tilt; normal mean: $342.7^{\circ} /-22.5^{\circ} \alpha 95=8.8^{\circ}$, reverse mean: $149.6^{\circ} / 48.5^{\circ} \alpha 95=26.5^{\circ}$. E) Transposed mean of ChRM components corrected for bedding tilt; preferred mean direction: $341 \cdot 7^{\circ} /-25 \cdot 2^{\circ} \alpha 95=8.5^{\circ}$. N(SRM) $=10, N($ ChRM $)=31$.
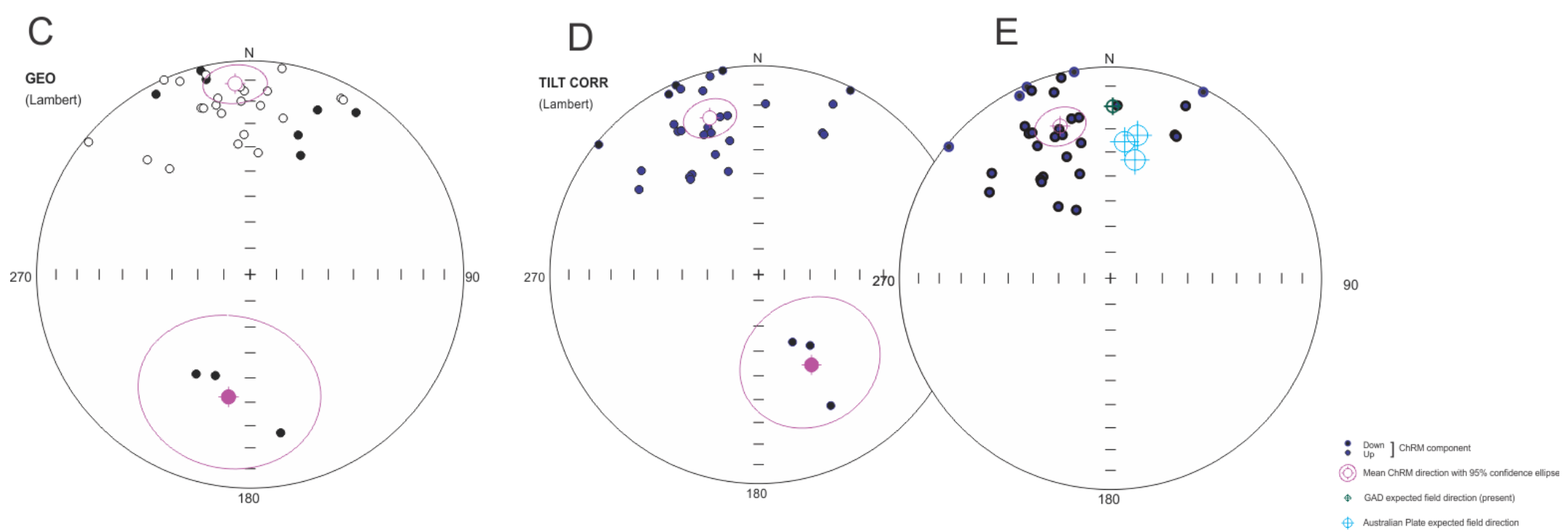
Table 3. Low blocking-temperature, and low coercivity (SRM) components for specimens from the Woruka Siltstone

\begin{tabular}{|c|c|c|c|c|c|c|c|}
\hline \multirow{3}{*}{$\begin{array}{l}\text { Specimen ID } \\
\text { CV04A.2 }\end{array}$} & \multirow{2}{*}{$\begin{array}{c}\text { NRM } \\
\left(10^{-3} \mathrm{~A} / \mathrm{m}\right)\end{array}$} & \multirow{2}{*}{\multicolumn{2}{|c|}{$\begin{array}{c}\mathrm{MDF} / \mathrm{MDT} \\
\left(\mathrm{Mt} /{ }^{\circ} \mathrm{C}\right)\end{array}$}} & \multicolumn{4}{|c|}{ ChRM calculated } \\
\hline & & & & PCA limits & $\operatorname{Dec}\left({ }^{\circ}\right)$ & $\operatorname{Inc}\left({ }^{\circ}\right)$ & $\operatorname{MAD}\left({ }^{\circ}\right)$ \\
\hline & 0.09 & & 206.9 & $100-200^{\circ} \mathrm{C}$ & 357.0 & 0.8 & 5.3 \\
\hline CV04B.2 & 0.09 & & 219.3 & $60-200^{\circ} \mathrm{C}$ & 345.5 & -15.3 & 6.3 \\
\hline CV04C.1 & 24.5 & & 236.7 & NRM $-200^{\circ} \mathrm{C}$ & 339.4 & -36.0 & 1.7 \\
\hline CV05B.1 & 3.26 & & 318.5 & $100-300^{\circ} \mathrm{C}$ & 319.1 & 5.1 & 4.5 \\
\hline CV05G.1 & & & & NRM- $250^{\circ} \mathrm{C}$ & 351.9 & -9.7 & 3.3 \\
\hline CV06F.2 & & & & $60-280^{\circ} \mathrm{C}$ & 2.6 & -27.4 & 7.0 \\
\hline CV07D.1 & 32.8 & 13.5 & & NRM-15mT & 311.8 & -13.8 & 3.9 \\
\hline CV07E.1 & & & & NRM- $150^{\circ} \mathrm{C}$ & 349.4 & -31.2 & 10.8 \\
\hline CV07F.1 & & & & NRM- $150^{\circ} \mathrm{C}$ & 343.2 & -26.5 & 9.2 \\
\hline CV07F.2 & & & & NRM $-150^{\circ} \mathrm{C}$ & 340.4 & -32.1 & 6.0 \\
\hline
\end{tabular}


Table 4. ChRMs (tilt corrected) for Woruka Siltstone specimens.

\begin{tabular}{|c|c|c|c|c|c|c|c|}
\hline \multirow{3}{*}{$\begin{array}{l}\text { Specimen ID } \\
\text { CV04A.2 }\end{array}$} & \multirow{3}{*}{$\begin{array}{c}\begin{array}{c}\mathrm{NRM} \\
\left(10^{-3} \mathrm{~A} / \mathrm{m}\right)\end{array} \\
0.09\end{array}$} & \multirow{2}{*}{\multicolumn{2}{|c|}{$\begin{array}{c}\mathrm{MDF} / \mathrm{MDT} \\
\left(\mathrm{Mt} /{ }^{\circ} \mathrm{C}\right)\end{array}$}} & \multicolumn{4}{|c|}{ ChRM calculated } \\
\hline & & & & \multirow{2}{*}{$\frac{\text { PCA limits }}{319-480^{\circ} \mathrm{C}}$} & \multirow{2}{*}{$\frac{\operatorname{Dec}\left({ }^{\circ}\right)}{333.5}$} & \multirow{2}{*}{$\frac{\operatorname{Inc}\left({ }^{\circ}\right)}{4.0}$} & \multirow{2}{*}{$\frac{\operatorname{MAD}\left({ }^{\circ}\right)}{7.5}$} \\
\hline & & & 206.9 & & & & \\
\hline CV04B.2 & 0.09 & & 219.3 & $430-518^{\circ} \mathrm{C}$ & 309.1 & 1.5 & 4.7 \\
\hline CV04C.1 & 24.5 & & 236.7 & $200-550^{\circ} \mathrm{C}$ & 311.0 & -23.6 & 6.2 \\
\hline CV05A.1 & 0.11 & & 324.9 & $104-518^{\circ} \mathrm{C}$ & 336.4 & 1.3 & 2.4 \\
\hline CV05B.1 & 3.26 & & 318.5 & $400-550^{\circ} \mathrm{C}$ & 330.6 & -18.6 & 7.6 \\
\hline CV05C.1 & 0.19 & & 232.4 & $62-518^{\circ} \mathrm{C}$ & 2.3 & -19.3 & 4.4 \\
\hline CV05D.1 & 0.04 & 12.0 & & $5-75 \mathrm{mT}$ & 350.0 & 1.0 & 6.5 \\
\hline CV05D.2 & 0.05 & 17.6 & & $5-85 \mathrm{mT}$ & 346.2 & -2.6 & 7.1 \\
\hline CV05E.1 & 3.89 & & 153.4 & $\mathrm{NRM}-350^{\circ} \mathrm{C}$ & 346.4 & -23.3 & 6.1 \\
\hline CV05F.1 & 0.03 & 24.0 & & $5-120 \mathrm{mT}$ & 337.2 & -4.1 & 3.9 \\
\hline CV05H.1 & 0.01 & & 266.4 & $209-518^{\circ} \mathrm{C}$ & 343.1 & -8.9 & 5.0 \\
\hline CV05I.1 & 7.32 & & 180.9 & $100-450^{\circ} \mathrm{C}$ & 305.4 & -30.4 & 4.4 \\
\hline CV05L.1 & 0.62 & 8.1 & & $15-55 \mathrm{mT}$ & 331.7 & 15.9 & 5.6 \\
\hline CV05N.1 & 0.25 & & 222.1 & $104-518^{\circ} \mathrm{C}$ & 348.9 & -23.5 & 4.1 \\
\hline CV06B.1 & 0.46 & & 253.3 & $280-518^{\circ} \mathrm{C}$ & 24.2 & -26.5 & 2.4 \\
\hline CV06B.2 & 0.38 & 13.0 & & $10-75 \mathrm{mT}$ & 25.0 & -26.9 & 4.9 \\
\hline CV06C.1 & & & & $\mathrm{NRM}-300^{\circ} \mathrm{C}$ & 326.4 & -41.9 & 7.3 \\
\hline CV06F.1 & 20.2 & 7.9 & & 5-50mT & 23.6 & -12.0 & 8.0 \\
\hline CV06F.2 & 0.19 & & 203.3 & $351-518^{\circ} \mathrm{C}$ & 26.5 & 1.7 & 3.4 \\
\hline CV06H.1 & 25.0 & & 228.8 & $\mathrm{NRM}-600^{\circ} \mathrm{C}$ & 338.6 & -28.9 & 5.7 \\
\hline CV06H.2 & 0.33 & 17.5 & & $5-75 \mathrm{mT}$ & 341.0 & -26.4 & 2.3 \\
\hline CV07B.1 & 0.64 & 16.7 & & $5-45 \mathrm{mT}$ & 340.2 & -38.8 & 2.6 \\
\hline CV07B2.1 & 0.58 & 15.0 & & $5-45 \mathrm{mT}$ & 347.8 & -34.8 & 8.3 \\
\hline CV07B2.2 & 0.45 & & 281.7 & $104-518^{\circ} \mathrm{C}$ & 343.6 & -47.3 & 4.3 \\
\hline CV07E.1 & 495 & & 522.3 & $150-300^{\circ} \mathrm{C}$ & 151.1 & 29.2 & 7.4 \\
\hline CV07E.1 & 495 & & 522.3 & $300-480^{\circ} \mathrm{C}$ & 330.6 & -22.4 & 8.0 \\
\hline CV07F.1 & 568 & & 367.8 & $300-480^{\circ} \mathrm{C}$ & 324.7 & -42.2 & 8.7 \\
\hline CV07G.1 & 20.9 & & 175.0 & $\mathrm{NRM}-420^{\circ} \mathrm{C}$ & 341.5 & -29.2 & 2.7 \\
\hline CV07H.1 & 1770 & & 535.4 & $300-600^{\circ} \mathrm{C}$ & 324.5 & -43.3 & 2.1 \\
\hline CV07H.1 & 1770 & & 535.4 & NRM-300 & 144.0 & 55.5 & 1.7 \\
\hline CV07I.1 & & & & $10-80 \mathrm{mT}$ & 153.4 & 60.4 & 8.7 \\
\hline CV07J.1 & 722 & & 442.5 & $250-500$ & 331.7 & -22.7 & 5.2 \\
\hline
\end{tabular}




\subsubsection{Castle Hill Limestone}

The two remanence components identified in Castle Hill Limestone samples are interpreted as: 1) A secondary viscous remanence carried by low coercivity ( $<35 \mathrm{mT}$ ) grains; and 2) a ChRM removed at low temperatures $\left(<250^{\circ} \mathrm{C}\right)$, and persisting through alternating field demagnetization past peak fields of $120 \mathrm{mT}$.

Low coercivity components carried by Castle Hill Limestone specimens are distributed in a cluster of normal polarity directions. The mean direction from those components (Fig. 17A; Dec: $359.3^{\circ}$, Inc: $29.8^{\circ}, \alpha 95: 9.5^{\circ} \mathrm{N}=11$ ) is interpreted as due to a recent viscous overprint because the mean direction approximates the present day GAD field direction. Also, those components are carried by low stability grains; there are no reversals in the group; and statistical precision is diminished by application of a structural correction.

A component of normal polarity is consistently removed through low temperature demagnetization steps (NRM $<250^{\circ} \mathrm{C}$ ) and often persists past peak alternating fields of $120 \mathrm{mT}$. A combination of PCA components and Fisher means determined for low blocking-temperature and high coercivity components are distributed in a cluster about a normal polarity mean direction (Fig. 17D; Dec: 356. $4^{\circ}$, Inc: $-20.4^{\circ}, \alpha 95: 4.5^{\circ} \mathrm{N}=27$ ), which is interpreted as a ChRM for the Castle Hill Limestone. Confidence in this direction is hindered because there are no reversals in the dataset; and the carrier mineralogy appears to be goethite, which is generally not favoured in paleomagnetic studies. A low temperature or high coercivity component can be identified in the demagnetization plots of most specimens, distinct from another low stability component; and those components yield a reasonable mean direction, which is statistically improved by the application of a structural correction.

The blocking temperature and coercivity ranges in which the interpreted characteristic magnetization is removed are indicative of goethite as the carrier mineralogy. I postulate that goethite may have formed in these rocks as a diagenetic mineral, by dehydration from limonite precipitated out of the water column. Because the foraminiferal based age constraint on the Castle Hill Limestone for this study is limited to the Middle Miocene (Bickel, 1974; Smith \& Davies, 1976) a diagenetic timeframe should not be significantly outside of the current age assignment. The incorporation of magnetizations postdating deposition should result in a minimum estimate of vertical-axis rotation.

Like those in the Woruka Siltstone, the Castle Hill Limestone samples appear to be affected by some inclination flattening. The inclination of the Castle Hill Limestone ChRM direction $\left(20.4 \pm 4.5^{\circ}\right)$ is shallow with respect to that of the GAD expected field direction for $17.5 \mathrm{Ma}\left(32.2 \pm 3.9^{\circ}\right)$ The resultant inclination anomaly is $11.8 \pm 6.0^{\circ}$.

A $\theta 63$ of $13.5^{\circ}$ for the mean direction interpreted as ChRM is sufficient to suggest that secular variation has been sampled and effectively averaged out.

Comparison of the ChRM direction for the Castle Hill Limestone with the expected Australian Plate field direction for the same location at 17.5 Ma (Turner et al., 2007) yields an anticlockwise declination anomaly of $12.4 \pm 5.5^{\circ}$. 

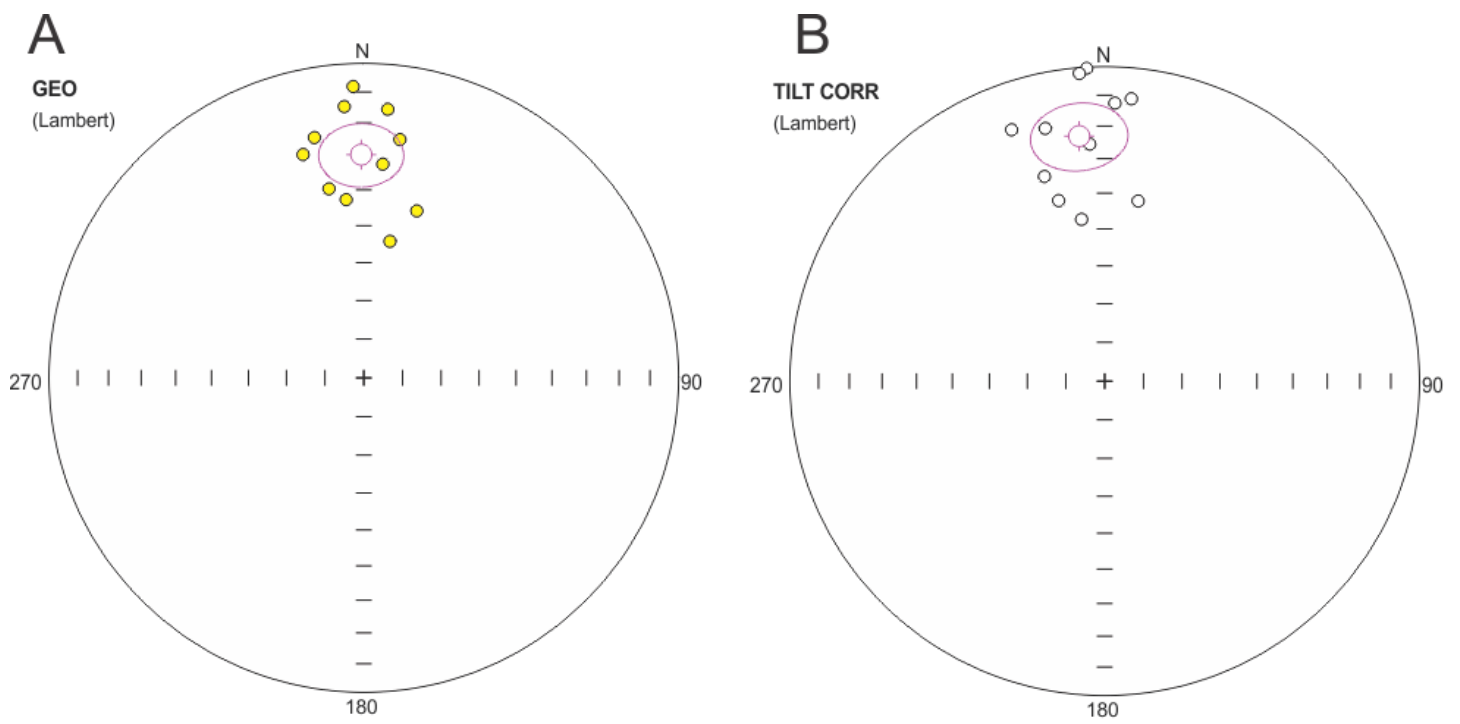

Figure 17. Equal area stereoplots to show distribution of PCA components, and mean directions (with $\alpha 95$ ellipse) for the Castle Hill Limestone. A) SRM interpreted components in geographic coordinates; preferred mean SRM direction: $359.3^{\circ} /-29.8^{\circ} \alpha 95=9.5^{\circ}$. B) SRM interpreted components corrected for bedding tilt; mean direction: $354.1^{\circ} /-22.7^{\circ} \alpha 95=10.5^{\circ}$. C) ChRM interpreted components in geographic coordinates; mean direction: $359.4^{\circ} \%-22.1^{\circ}$ $\alpha 95=4.7^{\circ}$. D) ChRM interpreted components corrected for bedding tilt; preferred mean direction: $356.4^{\circ} \%-20.4^{\circ}$ $\alpha 95=4.5^{\circ}$. $N($ SRM $)=11, N($ ChRM $)=27$.
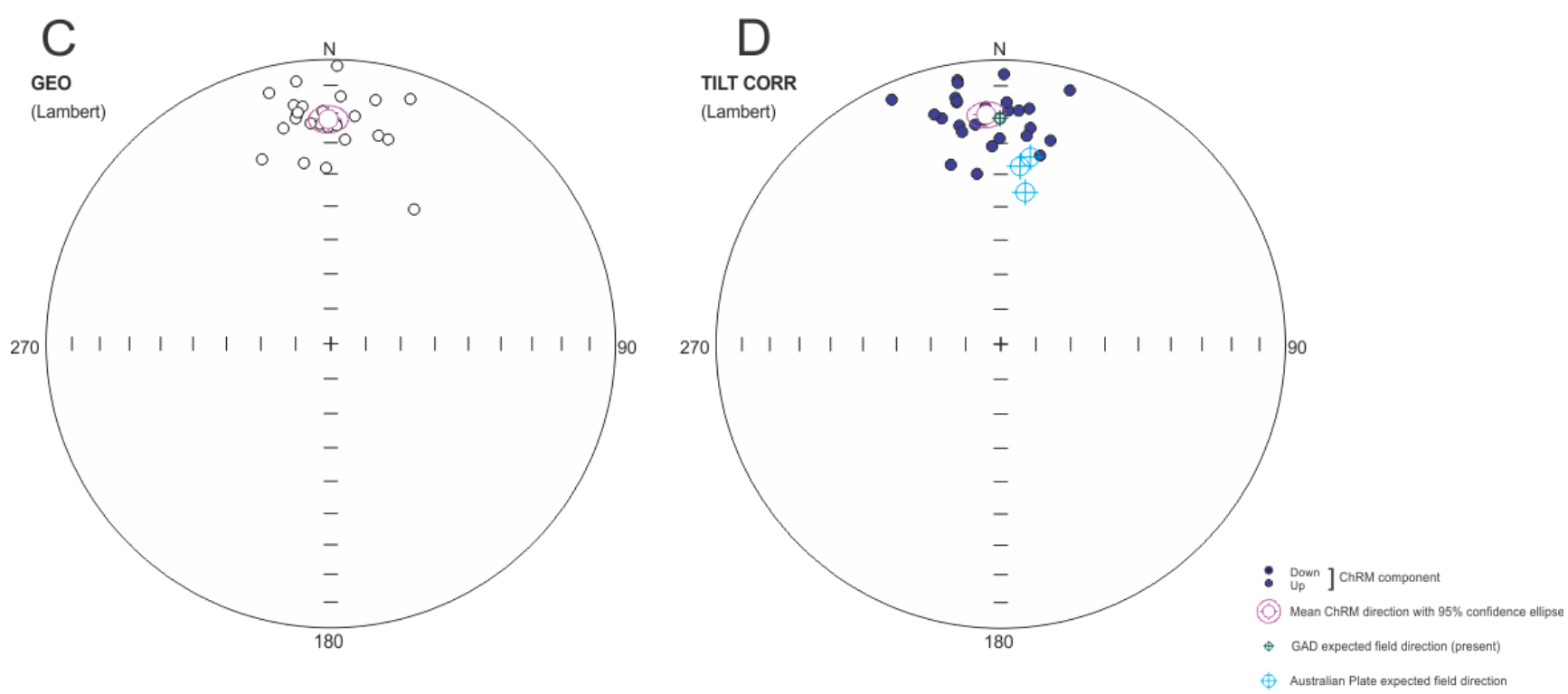
Table 5. Low coercivity components from the Castle Hill Limestone

\begin{tabular}{|l|c|c|c|c|c|c|}
\hline Specimen ID & \multirow{2}{*}{$\begin{array}{c}\text { NRM } \\
\end{array}$} & \multirow{2}{*}{$\begin{array}{c}\text { MDF } \\
\left(10^{-6} \mathrm{~A} / \mathrm{m}\right)\end{array}$} & $(\mathrm{mT})$ & \multicolumn{4}{|c|}{ ChRM calculated } \\
\cline { 4 - 7 } & 1.36 & 14.1 & PCA limits & Dec $\left({ }^{\circ}\right)$ & $\operatorname{Inc}\left({ }^{\circ}\right)$ & MAD $\left({ }^{\circ}\right)$ \\
\hline CV08D2.1 & 10.3 & 9.9 & NRM-35mT & 8.6 & -24.4 & 4.8 \\
\hline CV08V.1 & 9.7 & 9.5 & NRM-25mT & 5.1 & -15.4 & 8.3 \\
\hline CV08Y.1 & 8.22 & 16.7 & NRM-20mT & 349.6 & -38.8 & 8.6 \\
\hline CV08.II.2 & 1.74 & 18.6 & NRM-15mT & 348.4 & -23.1 & 9.1 \\
\hline CV08.VI.2 & 0.55 & 35.5 & NRM-15mT & 5.1 & -32.3 & 3.3 \\
\hline CV09D.1 & 1.06 & 24.3 & NRM-30mT & 354.4 & -42.5 & 2.5 \\
\hline CV09F.1 & 0.50 & 22.6 & NRM-10mT & 357.9 & -8.1 & 4.6 \\
\hline CV09G.1 & 0.38 & 43.2 & NRM-15mT & 344.8 & -27.3 & 5.2 \\
\hline CV09G.2 & 2.11 & 15.3 & NRM-15mT & 355.9 & -14.6 & 8.5 \\
\hline CV09R.1 & & & &
\end{tabular}

Table 6. High coercivity and low blocking-temperature components for the Castle Hill Limestone.

\begin{tabular}{|c|c|c|c|c|c|c|c|}
\hline \multirow{3}{*}{$\begin{array}{l}\text { Specimen ID } \\
\text { CV08S.1 }\end{array}$} & \multirow{3}{*}{$\begin{array}{c}\begin{array}{c}\mathrm{NRM} \\
\left(10^{-6} \mathrm{~A} / \mathrm{m}\right)\end{array} \\
2.51\end{array}$} & \multirow{2}{*}{\multicolumn{2}{|c|}{$\begin{array}{c}\mathrm{MDF} / \mathrm{MDT} \\
\left(\mathrm{mT} /{ }^{\circ} \mathrm{C}\right)\end{array}$}} & \multicolumn{4}{|c|}{ ChRM calculated } \\
\hline & & & & \multirow{2}{*}{$\begin{array}{l}\text { PCA limits } \\
N R M-120 m T\end{array}$} & \multirow{2}{*}{$\frac{\operatorname{Dec}\left({ }^{\circ}\right)}{0.7}$} & \multirow{2}{*}{$\frac{\operatorname{Inc}\left({ }^{\circ}\right)}{-5.6}$} & \multirow{2}{*}{$\frac{\operatorname{MAD}\left({ }^{\circ}\right)}{4.2}$} \\
\hline & & 27.7 & & & & & \\
\hline CV08R.1 & 4.90 & & 34.7 & $\mathrm{NRM}-152^{\circ} \mathrm{C}$ & 352.1 & -39.3 & 3.0 \\
\hline CV08P.1 & 5.94 & & 64.7 & $\mathrm{NRM}-152^{\circ} \mathrm{C}$ & 344.5 & -34.8 & 3.7 \\
\hline CV080.1 & 8.47 & $N A$ & & NRM-120mT & 1.4 & -16.0 & 1.3 \\
\hline CV08N.1 & 4.67 & $N A$ & & NRM-12OmT & 357.5 & -30.9 & 0.7 \\
\hline CV08M.1 & 6.20 & & 67.5 & NRM- $177^{\circ} \mathrm{C}$ & 343.9 & -17.0 & 6.2 \\
\hline CV08M.2 & 5.34 & $N A$ & & NRM-120mT & 349.7 & -25.1 & 0.8 \\
\hline CV08L.1 & 3.02 & & 78.0 & $\mathrm{NRM}-177^{\circ} \mathrm{C}$ & 350.7 & -7.6 & 5.2 \\
\hline CV08K.1 & 4.88 & & 68.2 & NRM- $177^{\circ} \mathrm{C}$ & 353.4 & -23.3 & 2.0 \\
\hline CV08J.1 & 3.31 & & 81.0 & NRM- $152^{\circ} \mathrm{C}$ & 357.5 & -18.8 & 3.9 \\
\hline CV08I.1 & 2.26 & $N A$ & & NRM-120mT & 1.9 & -18.9 & 1.3 \\
\hline CV08H.1 & 5.61 & & 75.7 & $49-204^{\circ} \mathrm{C}$ & 359.7 & -28.4 & 1.3 \\
\hline CV08G.1 & 3.15 & $N A$ & & NRM-120mT & 350.7 & -6.6 & 1.0 \\
\hline CV08F.1 & 4.54 & 22.3 & & NRM-120mT & 355.6 & -22.0 & 1.7 \\
\hline CV08E.1 & 0.50 & & 150.6 & $\mathrm{NRM}-152^{\circ} \mathrm{C}$ & 13.7 & -27.1 & 4.7 \\
\hline CV08D.1 & 0.93 & & 146.1 & $49-238^{\circ} \mathrm{C}$ & 349.7 & -14.6 & 8.8 \\
\hline CV08B.1 & 0.70 & & 308.2 & NRM $-152^{\circ} \mathrm{C}$ & 345.4 & -19.0 & 7.6 \\
\hline CV08A.1 & 2.46 & & 298.4 & $49-279^{\circ} \mathrm{C}$ & 7.4 & -28.5 & 9.1 \\
\hline CV08X.1 & 9.28 & & 175 & $\mathrm{NRM}-279^{\circ} \mathrm{C}$ & 6.7 & -28.0 & 3.0 \\
\hline CV08.II.1 & 2.28 & & 266.6 & $\mathrm{NRM}-238^{\circ} \mathrm{C}$ & 349.3 & -22.8 & 4.5 \\
\hline CV08.IV.2 & 1.67 & & 156.1 & NRM $-152^{\circ} \mathrm{C}$ & 4.4 & -18.7 & 3.5 \\
\hline CV08.V.2 & 1.91 & & 132.0 & $\mathrm{NRM}-204^{\circ} \mathrm{C}$ & 6.9 & -17.6 & 3.5 \\
\hline CV09G.1 & 0.50 & 22.6 & & $60-120 \mathrm{mT}$ & 15.2 & -8.2 & 9.5 \\
\hline CV09H.1 & 1.15 & $N A$ & & NRM-120mT & 349.8 & -14.2 & 2.7 \\
\hline CV09L.2 & 0.36 & 27.3 & & $35-120 \mathrm{mT}$ & 336.0 & -6.5 & 8.6 \\
\hline CV09M.1 & 0.23 & & 175.2 & $49-177^{\circ} \mathrm{C}$ & 11.8 & -32.7 & 9.1 \\
\hline
\end{tabular}




\subsubsection{Tapio Marl}

Two remanence components determined from demagnetization plots of Tapio Marl samples are interpreted as: 1) A pervasive overprint carried by low blocking temperature $\left(<350^{\circ} \mathrm{C}\right)$, and low coercivity ( $<35 \mathrm{mT}$ ) grains, which is distinct from 2 ) a ChRM removed through thermal demagnetization steps above $350^{\circ} \mathrm{C}$, or origin bound through alternating field demagnetization steps $<120 \mathrm{mT}$.

Low temperature and coercivity components are distributed in a cluster of normal polarity directions about a mean direction (Fig.18A; Dec: $4.5^{\circ}$, Inc: $-32.1^{\circ}$, a95: $4.4^{\circ} \mathrm{N}=29$ ) which is interpreted as resulting from secondary magnetization that largely obscures the primary ChRM. While this direction is in large part determined from the 24 compromised demagnetization plots (see section 3.3.3), the consistency of directions is compelling. I interpret this magnetization as a recent overprint because it is carried in the low stability portion of both blocking temperature and coercivity spectra, it well approximates the present day field direction, and statistical precision is diminished by the application of a structural correction. Pyrrhotite may, depending on lattice structure, have Curie temperatures between $270-325^{\circ} \mathrm{C}$, and coercivities may vary widely up to $100 \mathrm{~s}$ of $\mathrm{mT}$ (Tauxe, 2009). I speculate that a population of secondary pyrrhotite grains carry an overprinting magnetization that is removed during.

A more elusive weak component is carried by grains with intermediate to high blocking temperature and coercivities up to and above $120 \mathrm{mT}$. A combination of PCA components and Fisher means are distributed in two clusters of antipodal normal and reverse polarity, clockwise deflected from the GAD field direction. The transposed mean direction (Fig. 18D; Dec: 12.3, Inc: $-31.8^{\circ}, \alpha 95: 8.4^{\circ} \mathrm{N}=14$ ) is interpreted as a representative time averaged ChRM for the Tapio Siltstone. Despite having few reliable components to contribute to the calculation of this mean direction, it produces a directionally reasonable result (reasonable inclination with respect to GAD expected field directions), with a positive reversal test. The mean directions from each of the normal and reverse polarity clusters are very close to directly antipodal with overlapping 95\% confidence intervals (Fig. 18). Furthermore, there appears to be a correlation between stratigraphic height and polarity of the high temperature component. Reverse polarity components are carried by the stratigraphically highest and lowest of core samples at site PNG-12-010 respectively, and the stratigraphically lower sites PNG-12-011 and PNG-12-012 record normal polarity magnetizations at high temperature. That component is probably carried by a population of titano-magnetite or maghemite grains (based on blocking temperature range and Curie temperature), that are likely minerals to be present as detrital grains in the Tapio Marl given that the Dabi Volcanics represent a directly local source for potential erosion of volcanic rocks.

The two clusters of normal and reverse polarity produce mean directions with $-33.7^{\circ}$ and $28.2^{\circ}$ inclination, highly comparable with the $-34.8 \pm 7.6^{\circ}$ inclination expected for the locality coordinates being located on the Australian Plate at $10 \mathrm{Ma}$. The transposed mean direction yields an inclination anomaly of $3.0 \pm 11.3^{\circ}$ relative to the expected GAD field direction for the Cape Vogel locality at 10 Ma.

A $\theta 63$ of $18.2^{\circ}$ for the transposed mean direction is sufficient to suggest that sufficient time is represented by these components to effectively average secular variation. 
Comparison of the transposed mean direction interpreted as a ChRM direction for the Tapio Marl with the expected Australian Plate field direction for the same location at $10 \mathrm{Ma}$ (Veevers \& Li, 1991) yields a declination anomaly of $-6.5 \pm 11.2^{\circ}$, indicating a clockwise vertical-axis rotation of the Cape Vogel locality with respect to the Australian Plate has taken place since the late Miocene. That is a minimum estimate of the declination anomaly for the Tapio Marl, as it assumes that the direction interpreted as ChRM is primary; however, that direction does not pass a fold test, and so may have been acquired at a later date post deformation. If we assume that the folding of Tapio Marl beds is associated with the Cape Vogel Anticline, then the maximum age of a post deformation magnetization is $6 \mathrm{Ma}$ (see section 4.1). 

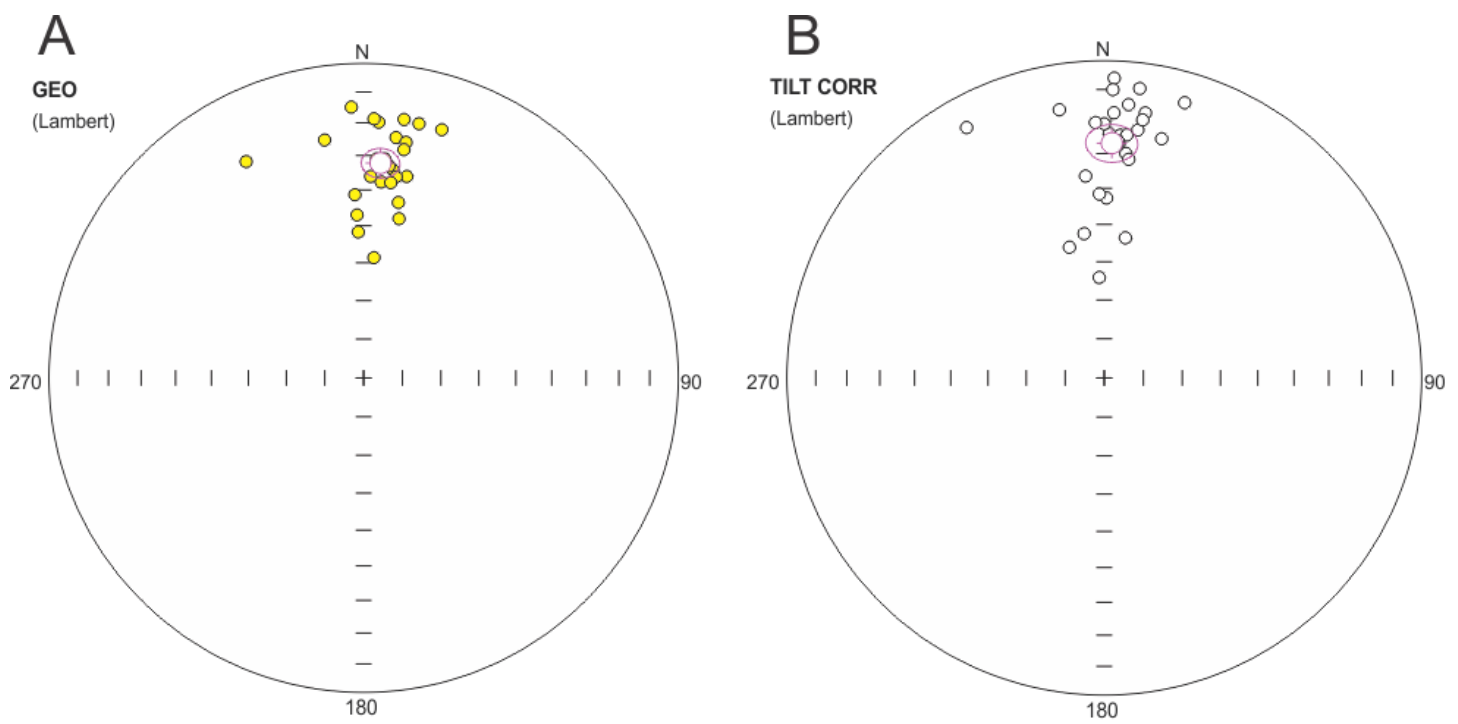

Figure 18. Equal area stereoplots to show distribution of PCA components, and mean directions (with $\alpha 95$ ellipse) for the Tapio Marl. A) SRM interpreted components in geographic coordinates; preferred mean SRM direction: $004.5^{\circ} /-32.1^{\circ} \alpha 95=4.4^{\circ}$. B) SRM interpreted components corrected for bedding tilt; mean direction: $001.8^{\circ} /-26.9^{\circ}$ $\alpha 95=5.7^{\circ}$. C) ChRM interpreted components in geographic coordinates; normal mean: $012.1^{\circ} /-33.7^{\circ} \alpha 95=10.0^{\circ}$, reverse mean: $192.8^{\circ} / 28.2^{\circ} \alpha 95=19.9^{\circ}$. D) Transposed mean of ChRM components in geographic coordinates; preferred mean direction: $012.3^{\circ} /-31.8^{\circ} \alpha 95=8.4^{\circ}$. E) ChRM interpreted components corrected for bedding tilt. normal mean: $009.3^{\circ} /-33.6^{\circ} \alpha 95=11.9$, reverse mean: $189.5^{\circ} / 19.2^{\circ} \alpha 95=18.0^{\circ} . \mathrm{N}(\mathrm{SRM})=29, \mathrm{~N}(\mathrm{ChRM})=14$.
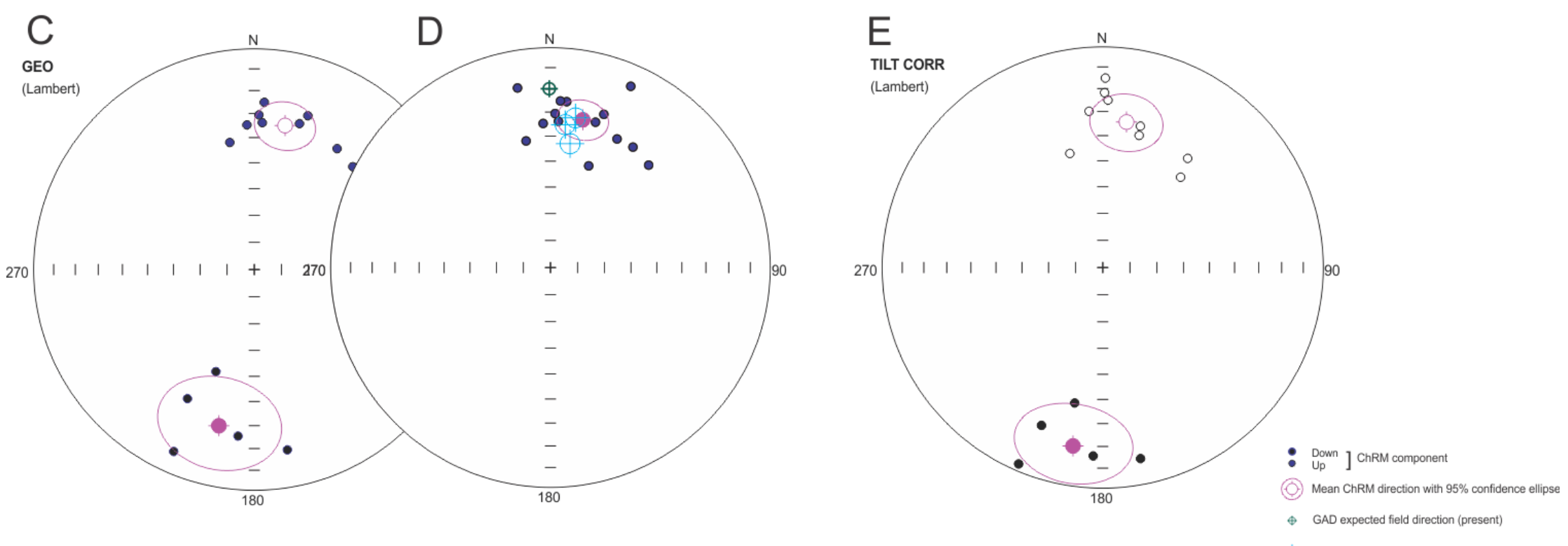
Table 7. ChRM \& High T (geographic coordinates) for Tapio Siltstone

\begin{tabular}{|c|c|c|c|c|c|c|c|}
\hline \multirow{3}{*}{$\begin{array}{l}\text { Specimen ID } \\
\text { CV10B.1 }\end{array}$} & \multirow{3}{*}{$\begin{array}{c}\begin{array}{c}\mathrm{NRM} \\
\left(10^{-6} \mathrm{~A} / \mathrm{m}\right)\end{array} \\
119\end{array}$} & \multirow{2}{*}{\multicolumn{2}{|c|}{$\begin{array}{c}\mathrm{MDF} / \mathrm{MDT} \\
\left(\mathrm{mT} /{ }^{\circ} \mathrm{C}\right)\end{array}$}} & \multicolumn{4}{|c|}{ ChRM calculated } \\
\hline & & & & \multirow{2}{*}{$\begin{array}{l}\text { PCA limits } \\
\text { (F) } 97-616^{\circ} \mathrm{C}\end{array}$} & \multirow{2}{*}{$\begin{array}{c}\operatorname{Dec}\left({ }^{\circ}\right) \\
207.4\end{array}$} & \multirow{2}{*}{$\begin{array}{c}\operatorname{Inc}\left({ }^{\circ}\right) \\
34.5\end{array}$} & \multirow{2}{*}{$\frac{\operatorname{MAD}\left({ }^{\circ}\right)}{9.1}$} \\
\hline & & & & & & & \\
\hline CV10C.1 & 95.4 & & 143.6 & $430-518^{\circ} \mathrm{C}$ & 200.6 & 49.1 & 6.1 \\
\hline CV10G.1 & 118 & & 151.3 & $(\mathrm{GC}) 62-518^{\circ} \mathrm{C}$ & $3.4 / 183.4$ & $-25.1 / 25.1$ & 4.5 \\
\hline CV10N.1 & 37.1 & & 131.0 & $351-518^{\circ} \mathrm{C}$ & 203.9 & 10.8 & 6.5 \\
\hline CV10P.1 & 421 & & 165.1 & (GC) $104-351^{\circ} \mathrm{C}$ & $4.6 / 184.6$ & $-33.0 / 33.0$ & 1.6 \\
\hline CV10P.2 & 371 & & 167.4 & $104-351^{\circ} \mathrm{C}$ & 0.8 & -32.3 & 2.5 \\
\hline CV10S.1 & 268 & & 174.3 & $104-351^{\circ} \mathrm{C}$ & 359.7 & -34.1 & 3.7 \\
\hline CV11C.1 & 2.41 & & & $532-616^{\circ} \mathrm{C}$ & 34.4 & -34.0 & 2.8 \\
\hline CV12C.1 & & & & (F) $330-620^{\circ} \mathrm{C}$ & 19.2 & -27.1 & 8.6 \\
\hline CV12C.2 & & & & (F) $330-620^{\circ} \mathrm{C}$ & 43.8 & -35.7 & 5.4 \\
\hline CV12I.2 & 1.23 & 12.9 & & NRM-120mT & 19.2 & -31.4 & 6.4 \\
\hline CV12J.2 & 4.54 & 27.4 & & NRM-120mT & 349.1 & -41.0 & 8.8 \\
\hline
\end{tabular}


Table 8. Low C \& low T components (geographic coordinates) for Tapio Siltstone.

\begin{tabular}{|c|c|c|c|c|c|c|c|}
\hline \multirow{2}{*}{$\begin{array}{l}\text { Specimen ID } \\
\text { CV10B.1 }\end{array}$} & \multirow{2}{*}{$\begin{array}{c}\begin{array}{c}\mathrm{NRM} \\
\left(10^{-6} \mathrm{~A} / \mathrm{m}\right)\end{array} \\
119\end{array}$} & \multirow{2}{*}{\multicolumn{2}{|c|}{$\begin{array}{c}\mathrm{MDF} / \mathrm{MDT} \\
\left(\mathrm{mT} /{ }^{\circ} \mathrm{C}\right)\end{array}$}} & \multicolumn{4}{|c|}{ ChRM calculated } \\
\hline & & & & PCA limits & $\frac{\operatorname{Dec}\left({ }^{\circ}\right)}{11.2}$ & $\frac{\operatorname{Inc}\left({ }^{\circ}\right)}{-42.6}$ & $\frac{\operatorname{MAD}\left(^{\circ}\right.}{3.4}$ \\
\hline CV10B.2 & 132 & & & & 5.1 & -37.5 & 4.2 \\
\hline CV10C.1 & 95.4 & & 143.6 & $62-350^{\circ} \mathrm{C}$ & 7.7 & -22.2 & 4.3 \\
\hline CV10D.1 & 153 & & & & 5.1 & -30.9 & 5.2 \\
\hline CV10D.2 & 137 & & & & 3.4 & -19.7 & 3.4 \\
\hline CV10E.1 & 98.0 & & & & 7.7 & -23.9 & 1.8 \\
\hline CV10E.2 & 91.3 & & & & 3.4 & -30.9 & 2.6 \\
\hline CV10H.1 & 246 & 7.1 & & NRM-30mT & 8.9 & -18.0 & 2.3 \\
\hline CV10I.1 & 138 & & & & 8.0 & -33.6 & 2.4 \\
\hline CV10J.1 & & & 190.7 & NRM $-250^{\circ} \mathrm{C}$ & 331.5 & -22.8 & 6.2 \\
\hline CV10L.1 & 171 & & & & 6.8 & -32.6 & 1.7 \\
\hline CV10M.1 & 138 & & & & 10.2 & -24.9 & 3.0 \\
\hline CV10N.1 & 37.1 & & 130.0 & $100-350^{\circ} \mathrm{C}$ & 17.5 & -18.4 & 4.2 \\
\hline CV100.1 & 60.5 & 7.7 & & $5-20 m T$ & 2.3 & -18.7 & 1.5 \\
\hline CV100.2 & 181 & & & & 10.0 & -27.2 & 2.7 \\
\hline CV10Q.2 & 285 & & & & 350.7 & -24.4 & 4.2 \\
\hline CV10R.1 & 337 & & & & 9.2 & -35.5 & 2.0 \\
\hline CV10T.1 & 338 & & & & 5.8 & -31.5 & 2.9 \\
\hline CV10T.2 & 272 & & & & 5.5 & -30.7 & 3.1 \\
\hline CV10V.1 & 282 & & & & 5.4 & -31.7 & 4.1 \\
\hline CV10W.2 & 180 & & & & 357.3 & -41.3 & 3.4 \\
\hline CV11C.1 & 2.41 & & & & 357.4 & -14.9 & 9.1 \\
\hline CV11C.2 & 2.76 & 20.1 & & NRM-30mT & 12.3 & -18.4 & 2.8 \\
\hline CV12C.1 & 3.57 & & & & 357.9 & -51.7 & 6.4 \\
\hline CV12C.2 & 3.44 & & & & 7.9 & -37.4 & 6.6 \\
\hline CV12E.1 & 1.61 & 24.2 & & NRM-30mT & 2.0 & -36.1 & 9.8 \\
\hline CV12F.1 & 6.90 & 16.1 & & NRM-30mT & 4.9 & -58.5 & 1.8 \\
\hline CV12F.2 & 5.70 & 18.3 & & NRM-35mT & 12.5 & -47.0 & 5.9 \\
\hline CV12H.1 & 6.67 & 18.3 & & NRM-35mT & 357.7 & -47.0 & 1.6 \\
\hline
\end{tabular}




\subsubsection{Synthesis and Tectonic Implications}

Declination anomalies of $28.8 \pm 14.0^{\circ}$ and $12.4 \pm 7.1^{\circ}$ respectively, for the Woruka Siltstone and Castle Hill Limestone sampled at Cape Vogel, suggest that $\sim 15^{\circ}$ of anticlockwise rotation relative to the Australian Plate occurred there between the Early and Middle Miocene. That vertical-axis rotation may have been accommodated by differential rates of normal faulting along or south of the Cape Vogel High during that time. There is a significant difference between that anticlockwise vertical-axis rotation in the Early to Middle Miocene, and a clockwise vertical-axis rotation of $-11.8 \pm$ $8.4^{\circ}$ since the deposition of the Late Miocene Tapio Marl.

If the Late Miocene Tapio Marl declination anomaly is truly recording a younger clockwise verticalaxis rotation relative to the Australian Plate, then the directions determined for the Woruka Siltstone and Castle Hill Limestone must have been deflected clockwise also, subsequent to larger finite anticlockwise vertical-axis rotation in the Early to Middle Miocene. When the clockwise rotation of the Tapio Marl ChRM mean direction is applied in reverse to the Woruka Siltstone and Castle Hill Limestone ChRM directions, they suggest vertical-axis rotations of $40.6 \pm 22.4^{\circ}$ and $24.2 \pm$ $15.5^{\circ}$ having occurred between the deposition of Early and Middle Miocene rocks respectively, and the onset of the $11.8 \pm 8.4^{\circ}$ clockwise vertical-axis rotation that has taken place since the Late Miocene. Those still are minimum estimates. They result from assuming that the declination anomaly for the Tapio Marl reflects the total clockwise vertical-axis rotation, and that rotation began prior to or at the time of Tapio Marl deposition.

The change in the sense of rotation at Cape Vogel Peninsula indicates a reorganisation, probably towards the current kinematic organisation of the Woodlark Rift. Today the Cape Vogel Peninsula is situated to the north of, and in the hanging wall of the Mai'iu Fault, which is part of the greater Owen Stanley Fault Zone (Fig. 1). The Owen Stanley Fault Zone has certainly been accommodating extension through the past $8 \mathrm{Ma}$, as evidenced by $<5 \mathrm{~km}$ of hanging wall subsidence in the Goodenough Basin (Fitz \& Mann, 2013), and footwall exhumation of the Dayman Dome metamorphic core complex (Daczko et al., 2011). It is possible that an along strike gradient in the extension rate on the Owen Stanley Fault Zone (decreasing to the east) (Mann \& Taylor, 2002) has resulted in a clockwise vertical-axis rotation of the Cape Vogel Peninsula relative to the Australian Plate since the Late Miocene.

A parallel complexity in the mode of deformation in the Woodlark Rift can be seen in the spatial pattern of starkly contrasting uplift and subsidence represented by exposure of eclogite facies rocks in the D'Entrecasteaux Islands and deepening of the Goodenough Basin). The Miocene sedimentary rocks exposed near sea level on the Cape Vogel Peninsula have remained isolated from up to $5 \mathrm{~km}$ of subsidence in the Goodenough Basin to the southeast. Even more remarkable is that those rocks remain only weakly deformed despite being located within $50 \mathrm{~km}$ of Pliocene aged gneiss domes at nearby Goodenough Island. Those gneiss domes host eclogite facies rocks that have been exhumed from mantle depths to where they are now found at $2.5 \mathrm{~km}$ elevation. Such dramatically contrasting localized vertical motions over short distances do not seem easily explained by horizontal plate motions. Thinned crust and an elevated Moho beneath the D'Entrecasteaux Islands suggests the high topography of the Goodenough and Fergusson Island gneiss domes may be isostatically supported by lithospheric mantle thinning and active asthenospheric upwelling (Abers et al., 2002). One speculative scenario is that the Cape Vogel Structural High is a less deeply exhumed continuation of the belt of metamorphic gneiss domes that form the D'Entrecasteaux Islands to the 
east, and that the structural high there is also supported by lithospheric mantle thinning and/or asthenospheric upwelling or underplated by a buoyant body of metamorphosed continental crust formerly of the Australian Plate, similar to that inferred to have ponded beneath the current D’Entrecasteaux Islands (Ellis et al, 2011; Gordon et al., 2012, Little et al., 2011). 


\section{Suau Coast Locality (Miocene)}

\subsection{Geological Setting and Background}

Two formations were sampled on the Suau Coast, in Fife Bay and in the Suwen River north of the Baxter Harbour. At 2 inland sites (PNG-12-101 and PNG12-102; Fig. 19) in the middle reaches on the Suwen River I sampled Limestone of the Modewa River Beds (Smith \& Davies, 1976). At one location $1.5 \mathrm{~km}$ northwest of Savaia on the Suwen River (PNG-12-103), and at five coastal sites in Fife Bay (PNG-12-104 to PNG-12-108; Fig. 19) I sampled basaltic-andesite dikes and flows of the Fife Bay Volcanics (Smith \& Davies, 1976).

The Modewa River Beds formation constitutes an unknown thickness of bedded limestone and younger tuffaceous sandstone that are gently folded (Smith \& Davies, 1976) and exposed $<15 \mathrm{~km}$ inland around Baxter Harbour (Fig. 19). The Modewa River Beds incorporate foraminifera of Late Oligocene to Middle Miocene age, and represent a period of shallow marine bioclastic sedimentation accompanied by volcanic activity towards the south of the current Papuan Peninsula (Smith \& Davies, 1976). The Limestone of the Modewa River Beds unconformably overlies the basement Kutu Volcanics (submarine basalt) and Badila Beds (limestone) of Late Cretaceous to Eocene age (Smith \& Davies, 1976).

The Fife Bay Volcanics overly the Modewa River Beds (Smith \& Davies, 1976), and comprise the dominant rock type coastally exposed in an area of $\sim 1800 \mathrm{~km}^{2}$ to the southeast of Mullins Harbour. The Fife Bay Volcanics consists mainly of flow and tuff deposits, as well as numerous dikes intruding underlying sediments (Smith \& Davies, 1976). The Fife Bay Volcanics have been assigned a lateMiddle to Late Miocene age, constrained by the Oligocene to Middle Miocene aged foraminiferal content of underlying sedimentary rocks, and a K/Ar age of $12.6 \mathrm{Ma}$ for dikes that intrude them (Smith \& Davies, 1976). Also, that age assignment is consistent with dating of geochemically equivalent high-K intrusive rocks which yield $\mathrm{K} / \mathrm{Ar}$ ages, from biotite and hornblende mineral separates, between 16-12 Ma (Smith, 1972).

The SE Papuan Peninsula and Papuan Plateau are separated from the Australian continent, and the adjoining Queensland Plateau, by the Coral Sea Ocean Basin. That basin formed during the Paleocene to Middle Eocene by continental rifting prior to the subsequent onset of sea floor spreading that occurred between 63-55 Ma (Veevers \& Li, 1991; Weissel \& Watts, 1979). Eocene to Oligocene strata drilled in the Coral Sea Basin record deposition in a deep marine basin, where detrital material was probably derived from the Australian Continent (Mutter, 1977). Early to Middle Miocene sediments in the same drill cores mark a change in detrital provenance, accompanied by a relative depth increase (Mutter, 1977). Those Miocene sediments incorporate crystalline terrigenous sediment most likely derived from a Papua New Guinea source (Mutter, 1977). Deposition in the Coral Sea Basin during the Late Miocene to Pleistocene was dominated by graded silt and clay turbidites also from a New Guinea source (Mutter, 1977). On both the SW and NW margins of the Coral Sea, continued and elevated subsidence during the Miocene to Pliocene has resulted in the drowning of coral reef platforms on the Queensland and Marion Plateaux, as well as in the Papuan Gulf (DiCaprio, 2010; Muller et al, 2000; Mutter, 1977; Wang \& Stein, 1992). 
GPS velocities on the Suau Coast of the SE Papuan Peninsula show very little motion relative to Australia, which indicates that area is moving as part of the Australian Plate (Wallace et al., manuscript in review). 


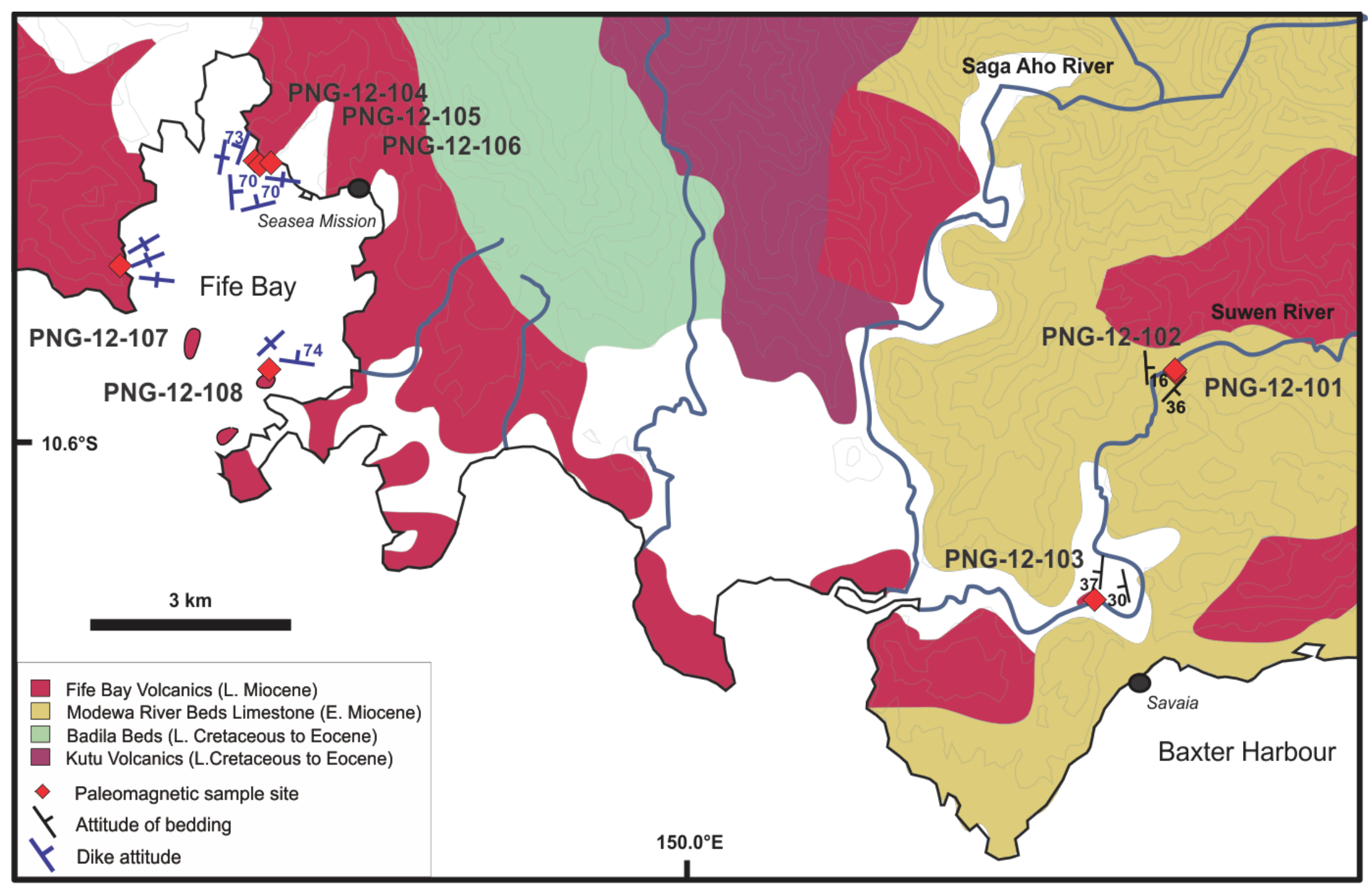

Figure 19. Map of the Suau coast locality to show the geology in the Fife Bay area (after Smith \& Davies, 1976). Representative bedding is shown for Limestone sampling sites in the Suwen River, and dike attitudes are shown where they were measured at sampling sites in Fife Bay. 


\subsection{Field Relationships, Thin Section Petrography, and Structural Corrections to Paleomagnetic Data.}

\subsubsection{Modewa River Beds}

The Modewa River Beds formation was sampled at two locations (PNG-12-101 and PNG-12-102) within 50-100m of each other, in the middle reaches of the Suwen River (Fig. 19). At each of those two sites $\sim 6 \mathrm{~m}$ sections of limestone are exposed dipping gently into the hills on the banks of the river. A total of 11 oriented cores were retrieved through the section exposed at those two outcrops, at $1 \mathrm{~m}$ stratigraphic intervals.

The Limestone sampled is cream to light-grey, very fine grained, and is well bedded in regular $\mathrm{dm}$ thick tabular packages. Intact foraminiferal skeletons can be seen in thin section, and are present in variable abundance suspended in a micritic matrix (Fig. 20). The stratigraphically lowest of the samples (Fig. 20C-D) viewed under a microscope appears to incorporate a greater abundance of foraminifera relative to younger samples (Fig. 20A-B). Abundant cross cutting veins, from microscopic to $\mathrm{mm}$ scale width, permeate the rock; and they are predominantly filled with sparry calcite (Fig. 20). Some veins appear brown in both plane and cross polarised light, and may be filled with some Fe-oxide precipitate (Fig. 20C-D). The abundance of fluid veins is evidence for likely recrystallization that may have affected the remanent magnetization of these rocks.

Bedding measurements were obtained at each sample site for applying a structural correction to the paleomagnetic data. The sampled beds dip gently to the east at $043 / \mathrm{SE} / 36^{\circ}$ and $356 / \mathrm{E} / 16^{\circ}$. 

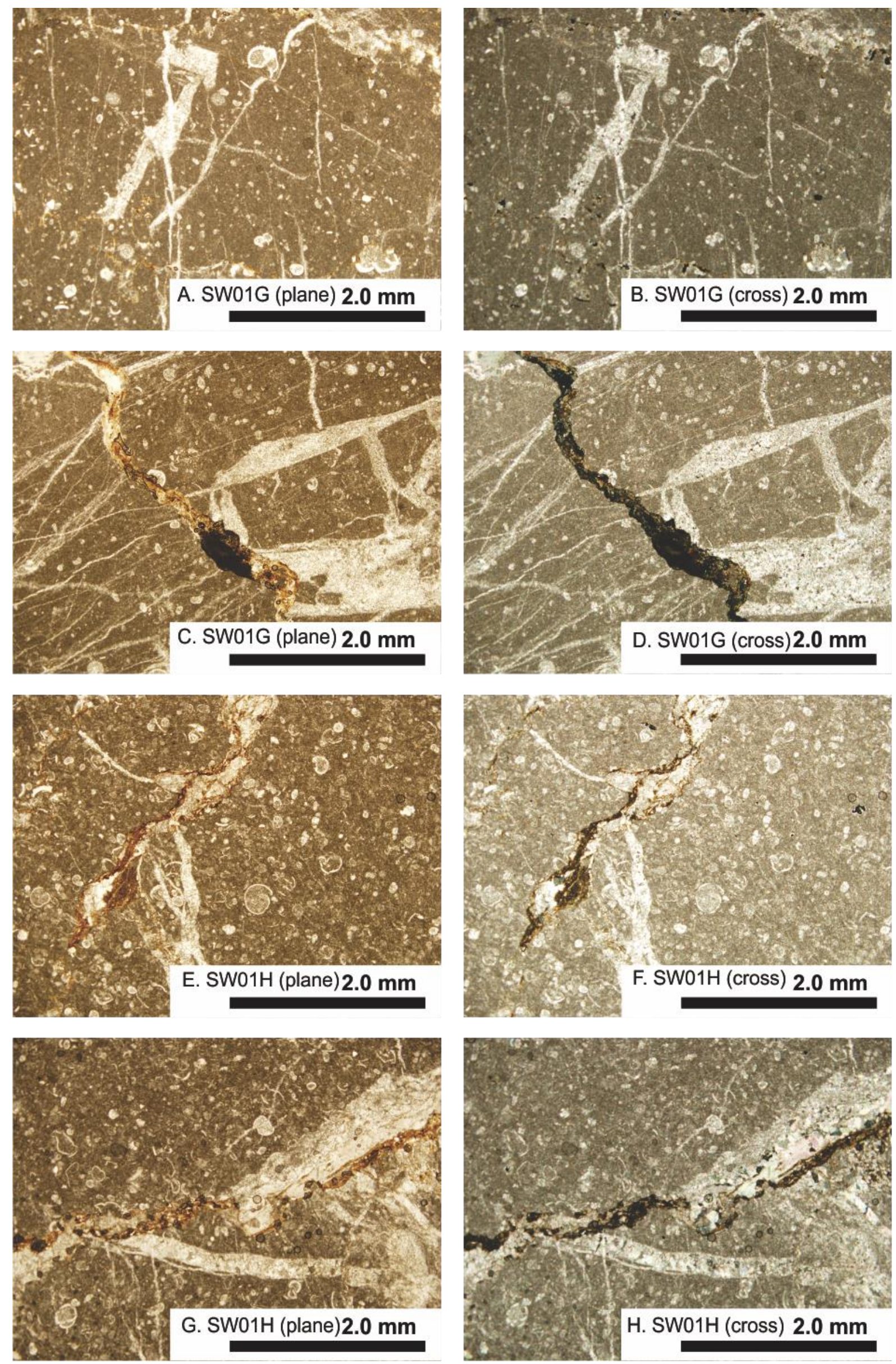

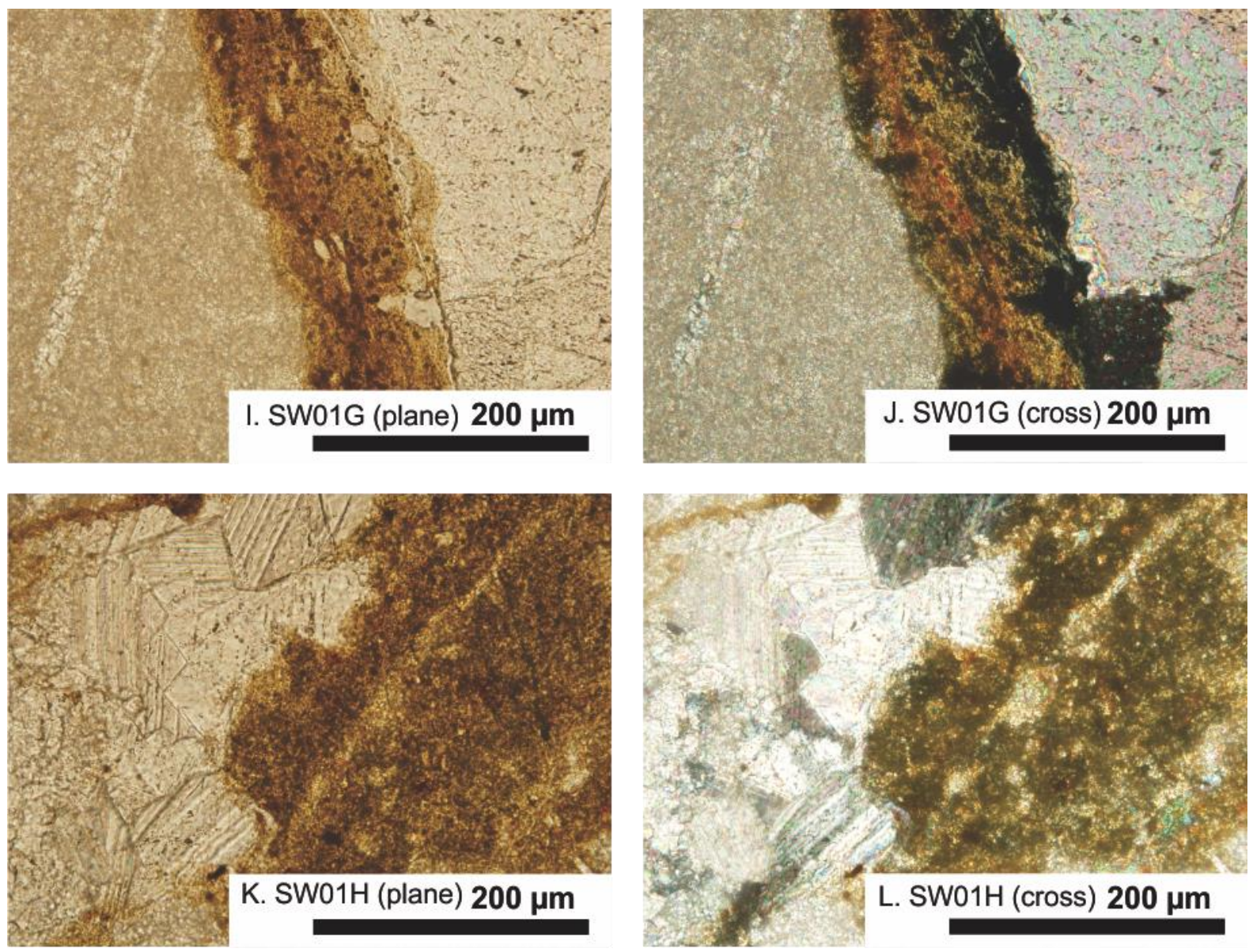

Figure 20. Photomicrographs of limestone samples from the Modewa River Beds. The limestones are very fine grained, with variable proportions of foraminifera $(<0.5 \mathrm{~mm}$ diameter) suspended in a micrite matrix. Comparison of stratigraphically separate samples A-D vs. E-H show small variation in the abundance and size of foraminifera. Abundant fractures filled with sparry calcite, are in places filled with a brown precipitate (probably Fe-oxide). Zoom images I-L illustrate the presence of sparry calcite interspersed with vein fill precipitate, and indicate these rocks are in places completely recrystallized. 


\subsubsection{Fife Bay Volcanics}

The sample set for the Fife Bay Volcanics consists of 25 oriented cores obtained between 5 locations in Fife Bay (PNG-12-104 to PNG-12-108), and one site on the Suwen River (PNG-12-103). In Fife Bay I sampled 10 separate dikes at 5 locations, with additional cores from volcaniclastic country rock at two of those locations.

The dikes sampled at sites PNG-12-104 to PNG-12-108 are between $1 \mathrm{~m}$ and $6 \mathrm{~m}$ wide, and well exposed as erosionally resistant walls that protrude from sea cut cliffs and sand flats. The dikes are generally dark grey and fine grained (some porphyritic), with some vesicles and all have well developed columnar jointing. They generally strike NE-SW, but strikes vary between $355^{\circ}$ and $095^{\circ}$, and are mostly vertical within measurement error, though some dip as shallow as $70^{\circ}$. There does not appear any systematic deflection of dike attitudes from the vertical that can be interpreted as due to tectonic deformation; the dikes that deviate from the vertical are deflected in all different directions, and appear to represent natural variability in the orientation of primary dike attitudes.

At PNG-12-103 I obtained 10 oriented cores from a hummocky mound of volcanic rock $20 \mathrm{~m}$ high, which is surrounded by flat lying fluvial silt. Those rocks are highly eroded, and determination of depositional contacts is problematic. However, I infer that this mound is formed by interlayered flows and pyroclastic deposits exposed in the river. The rocks sampled are generally dark browngrey, with abundant red xenoliths $<2 \mathrm{~cm}$. Localised areas viewed in thin section vary with respect to texture and mineralogy, and it is difficult to determine which is representative of the overall lithology. Some portions appear porphyritic and vesicular; and may demonstrate weak flow textures, while other parts appear crystalline (Fig. 21). I suspect that the paleomagnetic core samples from this site come from both flow lavas and from fragmental ballistic deposits incorporating xenolithic blocks.

A repetitive surface dips westward into the slope of the mound at 2-4m intervals, and coincides with subtle breaks in rock colour and texture. Those breaks are inferred to define contacts between 5 different layers. Core samples SW03A and SW03B are from the uppermost two layers of 1-2 m thickness. Core sample groups SW03C-D, SWO3E-G and SWO3H-J correspond to stratigraphically lower layers of $\sim 3 \mathrm{~m}$ thickness. I measured those repetitive surfaces for application of a structural correction to paleomagnetic data, though they are poorly defined due to erosion. Also, if those measured surfaces are depositional contacts their attitudes may equally reflect tectonic tilting or primary dips due to deposition on a slope.

Figure 21 (next page). Photomicrographs for a range of samples from the Fife Bay Volcanics. A-H are sampled from Dikes in Fife Bay. Those rocks demonstrate a range of textures within the dikes sampled. Generally those rocks are fine grained or hypocrystalline. Groundmass generally incorporates roughly equal proportions of equigranular plagioclase and pyroxene. In some cases (A-B, G-H) opaque grains are readily observed. Some dikes appear to be predominantly glassy, and possibly that glass is altered to brown mineraloid (E-F). I-J are photographed from volcaniclastic country rock intruded by the sampled dikes. The fragmental nature of it constituents are discouraging with regard to the suitability of those samples for paleomagnetic analysis. K-P are of samples from the Suwen River, and again show significant variation in rock texture. Some of those rocks demonstrate trachytic textures (M-N), while others appear holocrystalline (O-P). 

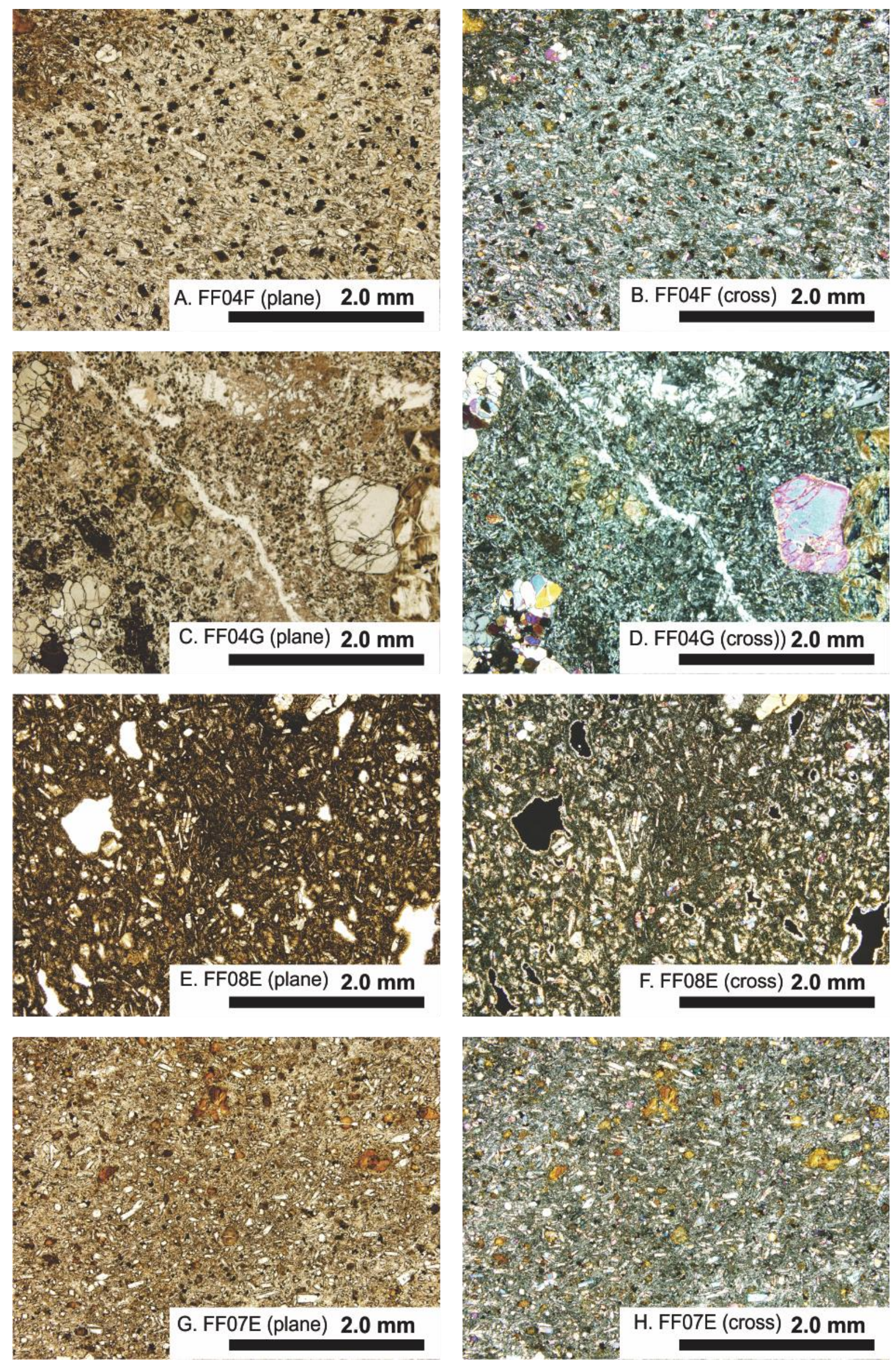

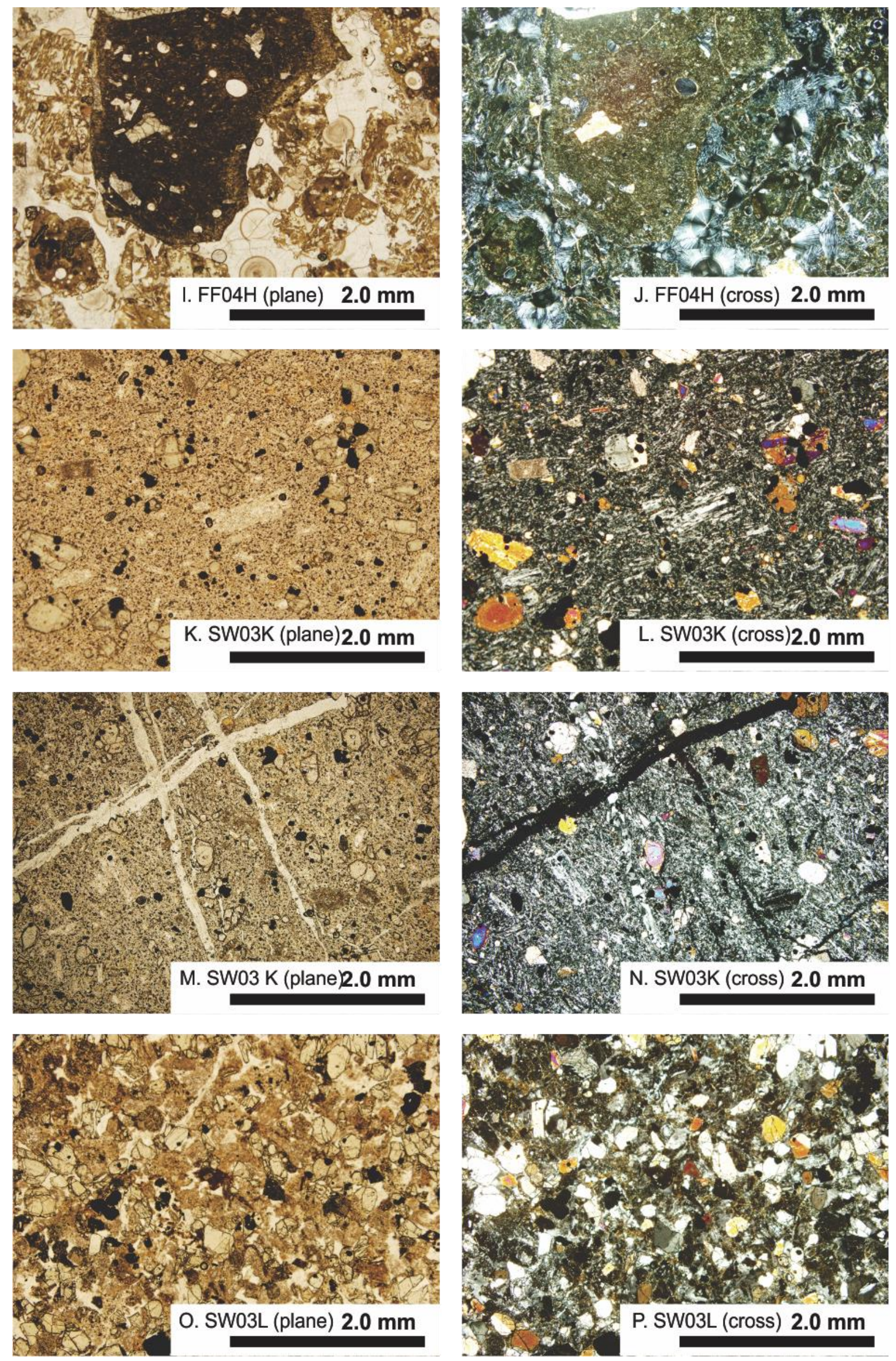


\section{Demagnetization Behaviour and Data Selection}

\subsubsection{Modewa River Beds}

A total of 17 specimens were demagnetized from the Modewa River Beds limestone. The Limestone is weakly magnetized $\left(<10^{-5} \mathrm{~A} / \mathrm{m}\right)$, often approaching the sensitivity of the $2 \mathrm{G}$ LongCore SQUID cryogenic magnetometer at Otago University, Dunedin.

All Modewa River Beds specimens carry a normal polarity remanence that is removed at low peak field $(<30 \mathrm{mT})$ and temperature $\left(<200^{\circ} \mathrm{C}\right)$ demagnetization steps (Fig. $\left.22 \mathrm{~A}-\mathrm{H}\right)$. Specimens from PNG12-101 also carry a normal polarity remanence component in the intermediate to high blocking temperature range (Fig. 22C \& F). In duplicate specimens, treated by alternating field demagnetization, other components in the intermediate to high coercivity range have declinations anticlockwise deflected from north (Fig. 22D \& C). The MDF of those specimens is between 10-15 $\mathrm{mT}$, which may be indicative of a multi-domain grain population. Specimens from sample site PNG12-102 are an order of magnitude more weakly magnetised than those from PNG-12-101. They carry a similar normal polarity component (Fig. 22B, G \& H) at low coercivity ( $<20 \mathrm{mT}$ ), and at low blocking temperature $\left(<200^{\circ} \mathrm{C}\right)$ (Fig. $\left.22 \mathrm{~A}\right)$ but a contrasting component of reverse polarity is removed through intermediate peak field $(15-50 \mathrm{mT})$ and temperature $\left(350-520^{\circ} \mathrm{C}\right)$ demagnetization steps (Fig. $22 \mathrm{~A}, \mathrm{G}$ \& H). Another component common to all Modewa River Beds specimens is a high temperature remanence, of undetermined direction, that remains past peak thermal demagnetization at $520^{\circ} \mathrm{C}$. 

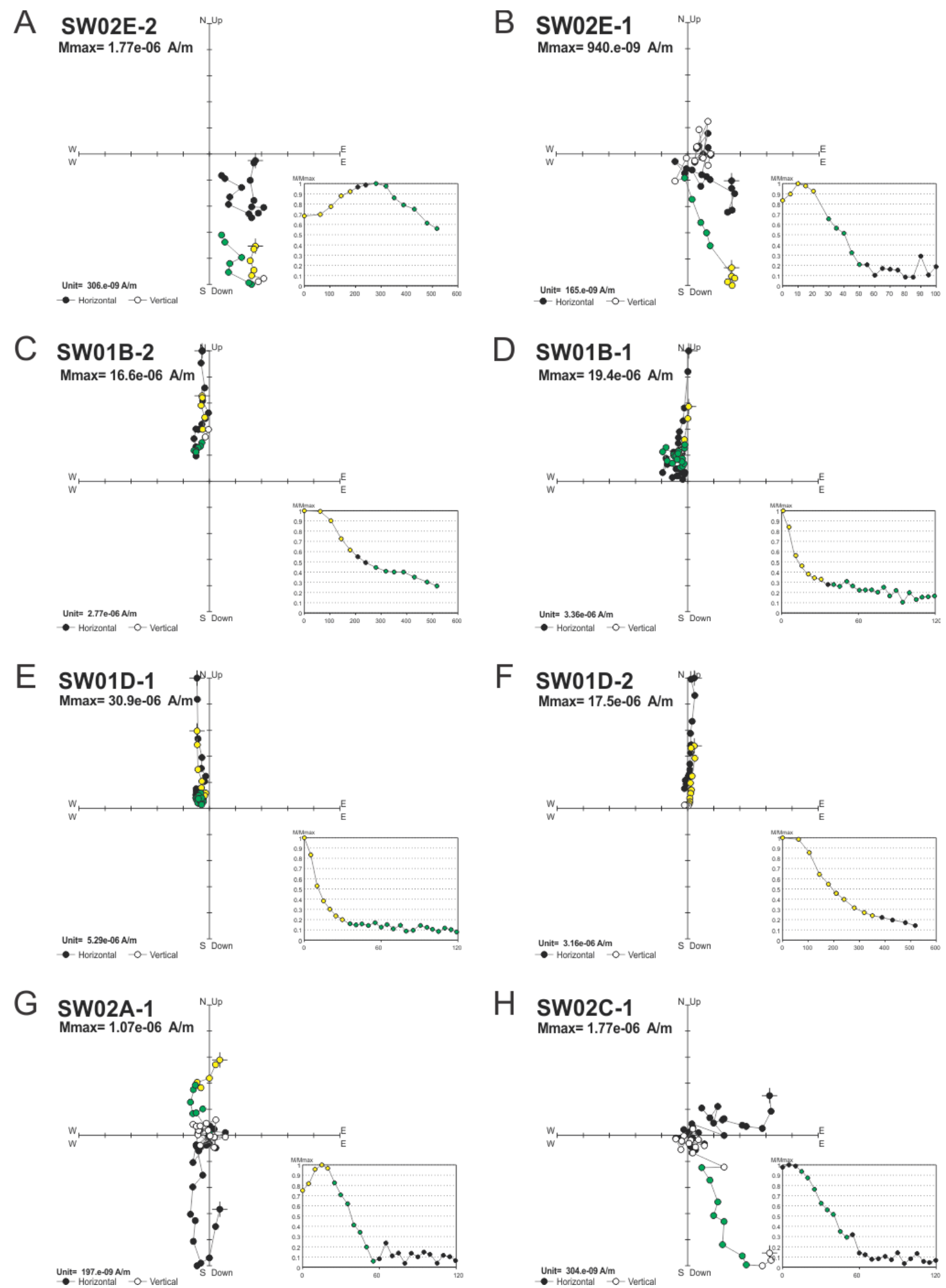

Figure 22. Zijdeveld and Module plots for demagnetization experiments of Modewa River Beds specimens showing a range of demagnetization behaviour. Some specimens carry one well defined and origin bound component of normal polarity $(F)$, while others may retain components of reverse polarity, but are not well isolated by demagnetization experiments. Specimens do generally agree directionally between $A F$ and $T H$ demagnetization treatments (A-B, C-D, E-F). 


\subsubsection{Fife Bay Volcanics}

A total of 34 specimens from the Fife Bay Volcanics were demagnetized using a combination of stepwise thermal and alternating field demagnetization treatments. Of the samples collected at Fife Bay, the dikes were strongly magnetized, with NRM between 0.2 and $12 \mathrm{~A} / \mathrm{m}$, while the volcaniclastic rock they intrude is two orders of magnitude more weakly magnetized, with NRM on the order of $10^{-3} \mathrm{~A} / \mathrm{m}$. The samples from PNG-12-103 in the Suwen River were also strongly magnetized, with NRM between 0.4 and $11 \mathrm{~A} / \mathrm{m}$.

Demagnetization plots of the Fife Bay Volcanics display a range of complex demagnetization behaviour. Most of the dike samples treated by alternating field demagnetization lost the majority of their remanence in the low coercivity grain range (Fig. 23C), and many have MDF values less than 10 $\mathrm{mT}$. In some cases alternating field and thermal demagnetization plots correlate well (Fig. 23G \& H). In other cases thermal demagnetization plots are scattered and/or Zijdeveld plots have curvilinear trajectories (Fig. 23C \& D). Those plots may result from demagnetization of a multi-domain ferromagnetic grain population. Multi-domain grains' magnetization is prone to viscous reorientation, so demagnetization data from those samples may be unreliable.

Some samples produce demagnetization plots with origin bound components removed through high temperature demagnetization steps (Fig. 23E-F), but yield anomalous ChRM directions with very high inclinations. In several cases apparently stable ChRM components with anomalous directions correspond to module plots with small humps at intermediate temperature (Fig. 23IK-M). I speculate that those plots are produced by the simultaneous removal of two overlapping components with opposing polarity.

Specimens of the Fife Bay Volcanics sampled in the Suwen River generally retain a single origin bound remanence component that is removed by demagnetization at $600^{\circ} \mathrm{C}$ (Fig. $23 \mathrm{I}, \mathrm{N} \& \mathrm{O}$ ). In some cases another component is removed at low temperature, and the remanence direction follows a predictable great circle trajectory (see Appendix A). Within each of the two stratigraphically lowest layers sampled at PNG-12-103 there is very poor directional agreement between specimens, and while those ChRM directions are well defined they often yield GAD uninterpretable directions (see Appendix A).

Figure 23 (next page). Zijdeveld and Module plots for demagnetization experiments of specimens from the Fife Bay Volcanics. Fife Bay samples demonstrate a wide range of demagnetization behaviour. Some specimens carry a single well defined component of normal polarity through their range of blocking temperatures $(F, N, O)$, others may carry a reverse polarity component at low temperatures but are not well defined $(E, K)$.In several cases low coercivity, and curvilinear trajectories in Zijdeveld plots are suggestive of multi-domain grain behaviour $(C, G, H)$. 

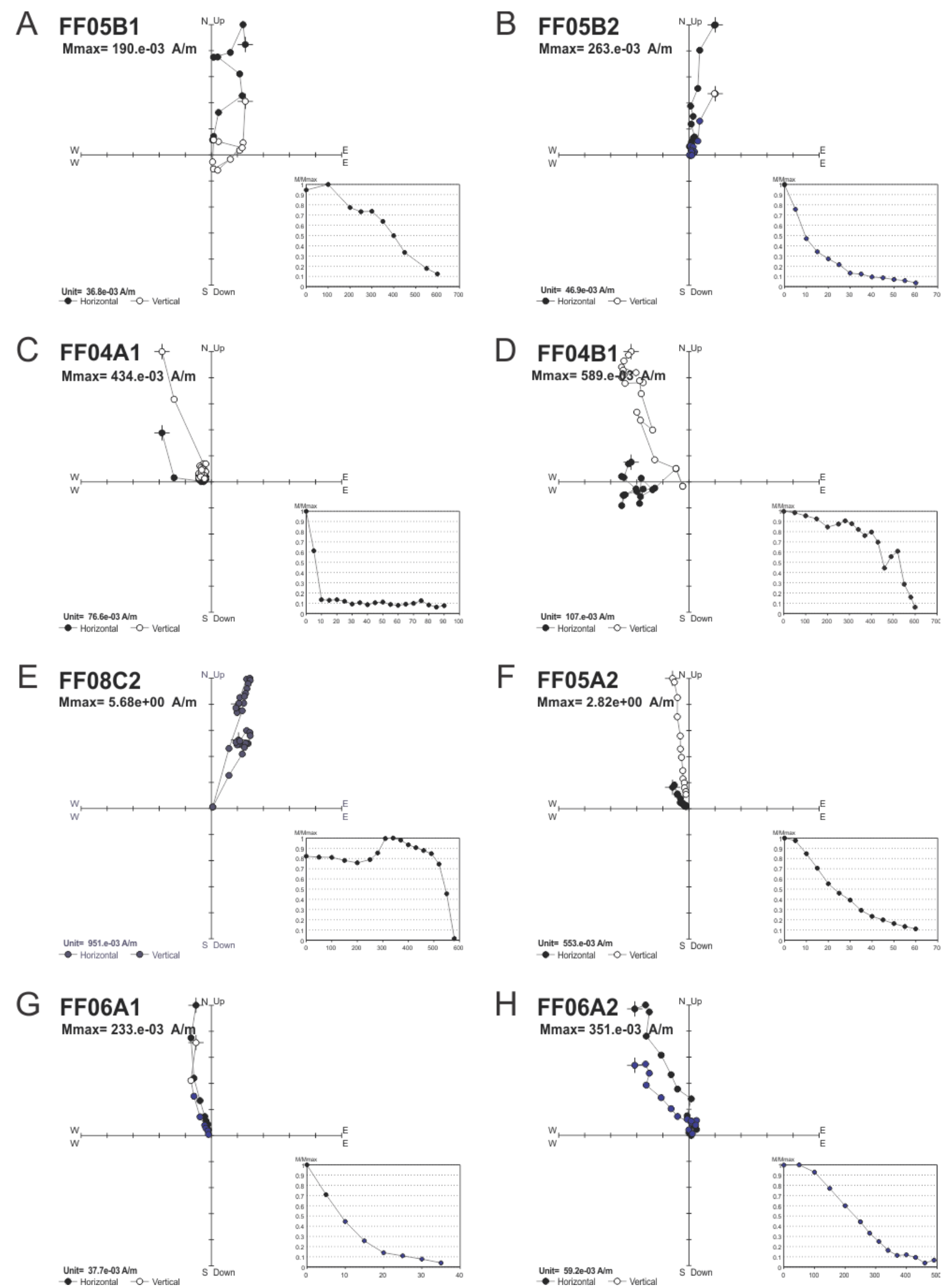

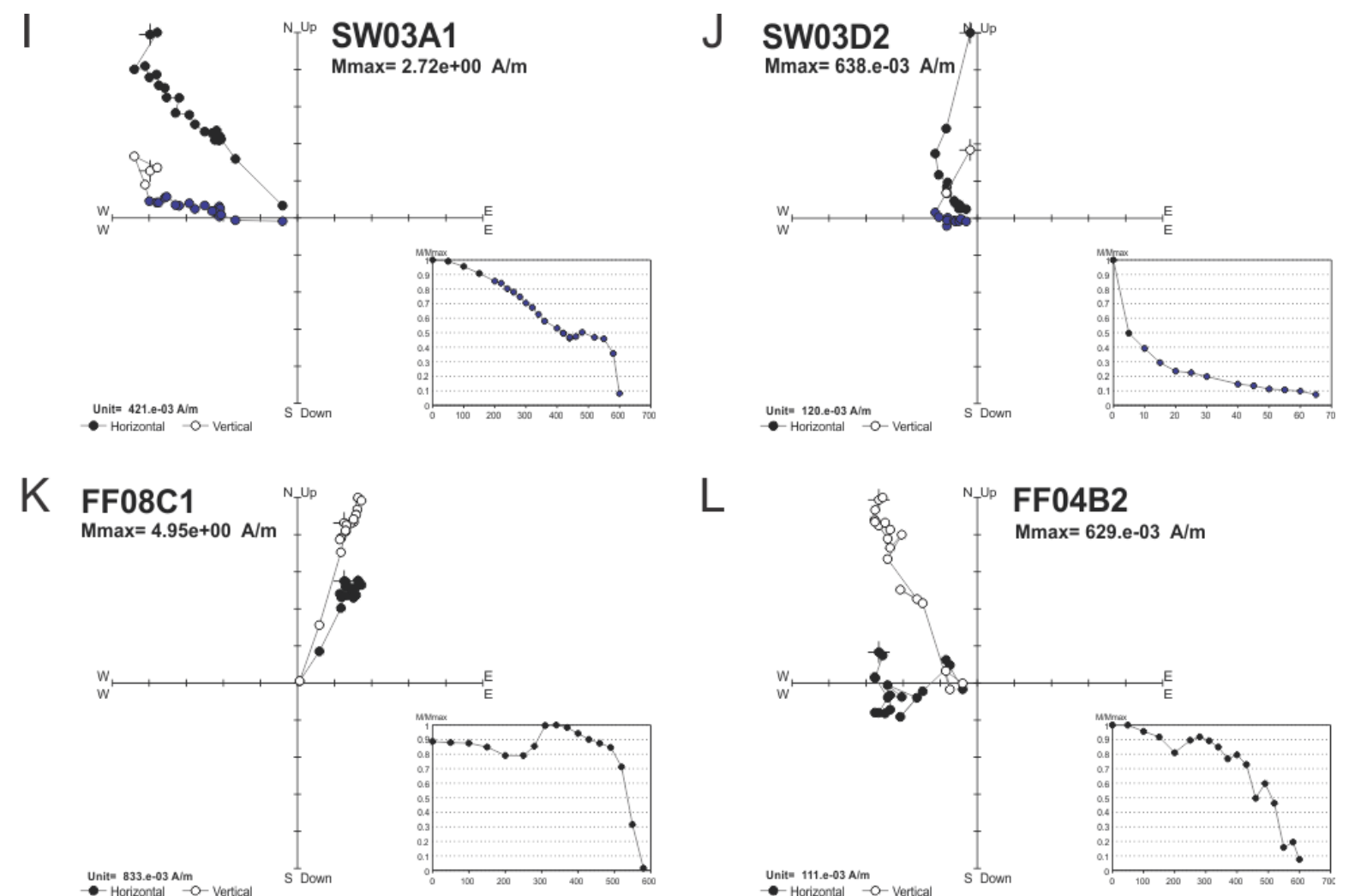

L
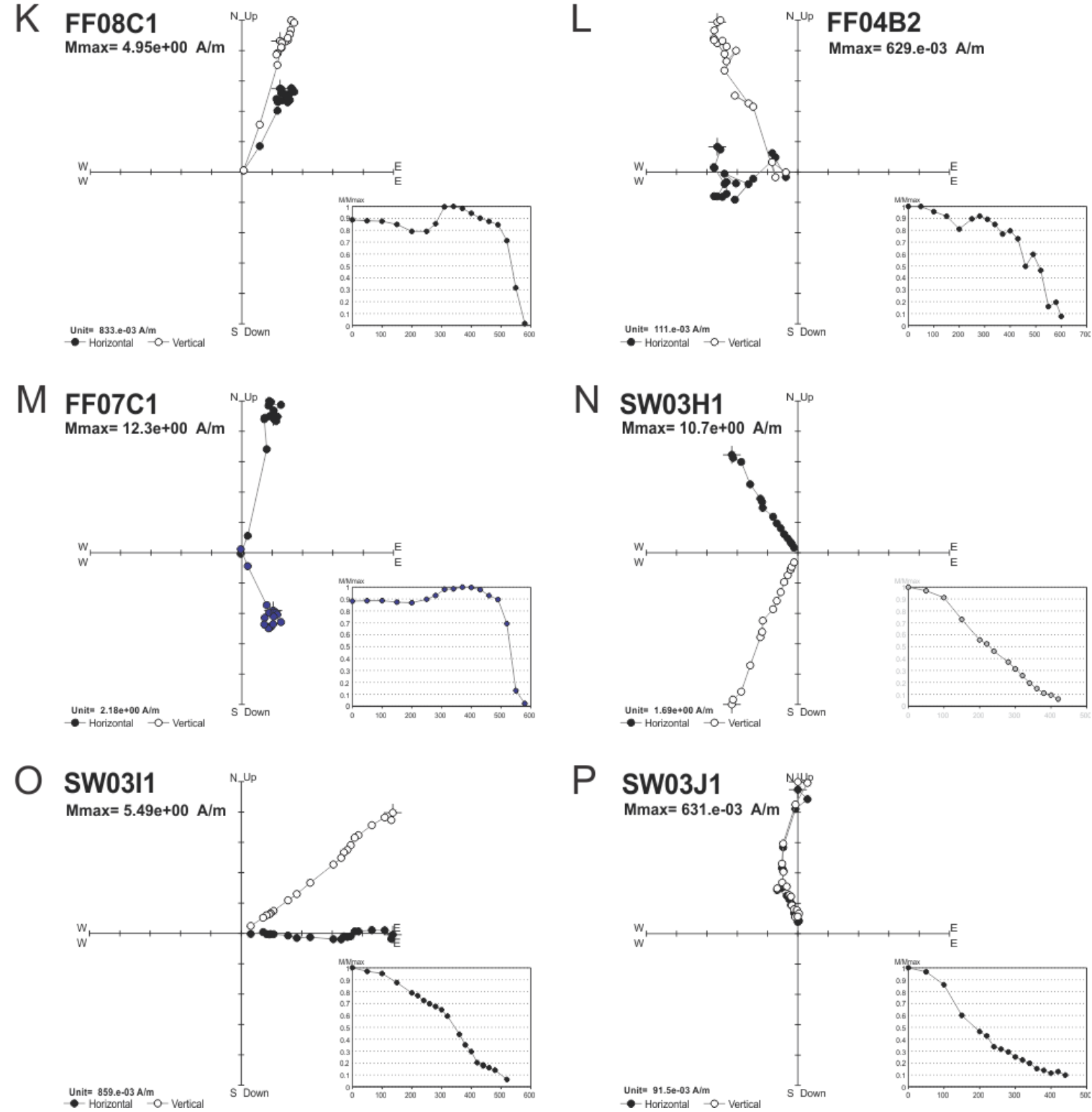

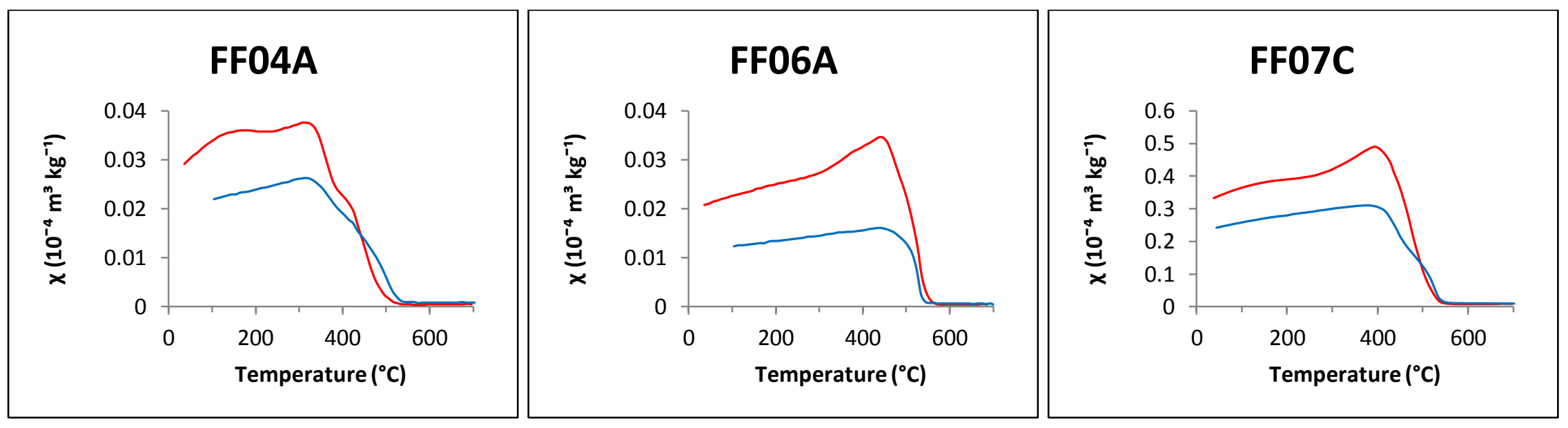

Figure 24. Temperature dependent magnetic susceptibility plots for Fife Bay Volcanics samples. 


\subsection{Group Statistics, Interpretation, and Tectonic Implications}

The Latitude and Longitude representative of the Suau Coast locality is $10.6^{\circ} \mathrm{S}, 150.0^{\circ} \mathrm{E}$. The GAD field direction for those coordinates for the present day, as well as the field directions corresponding to Australian Plate pole locations in the Miocene (Turner et al., 2007; Veevers \& Li, 1991) are shown below.

Table 9. Expected field directions for the Suau Coast locality, corresponding to Australian Plate pole locations in the Cenozoic

\begin{tabular}{|c|c|c|}
\hline & Declination $\left({ }^{\circ}\right)$ & Inclination $\left({ }^{\circ}\right)$ \\
\hline Present & 0.0 & -20.5 \\
\hline $10 \mathrm{Ma}$ & $5.8 \pm 5.3$ & $-36.1 \pm 7.4$ \\
\hline $17.5 \mathrm{Ma}$ & $8.9 \pm 2.6$ & $-33.6 \pm 3.9$ \\
\hline $20 \mathrm{Ma}$ & $10.2 \pm 5.6$ & $-44.0 \pm 6.4$ \\
\hline
\end{tabular}

The Group Statistics and mean direction for each formation sampled near the Suau Coast are presented separately, and interpreted relative to Australian Plate expected directions, followed by a discussion of the tectonic implications of those directions.

\subsubsection{Modewa River Beds}

The most consistent component seen in the demagnetization plots of Modewa River Beds specimens is in the low coercivity $(<30 \mathrm{mT})$ and low to intermediate temperature $\left(<350^{\circ} \mathrm{C}\right)$ ranges. The directions derived from those ranges in 14 specimens are distributed in a cluster about a normal polarity mean direction (Fig. 25A; Dec: $3.1^{\circ}$, Inc: $-31.4^{\circ}, \alpha 95: 4.0 \mathrm{~N}=12$ ). That direction is indistinguishable from the present day field direction in geographic coordinates, and it is statistically more precise prior to the application of a structural correction. That component is interpreted as a pervasive recent overprint, and does not allow for the determination of a reliable time averaged paleomagnetic mean direction.

The component interpreted as an overprint yields a smaller declination anomaly than data from the younger Fife Bay Volcanics which supports interpretation of that direction as a younger secondary overprint.

A few components retained in the intermediate to high coercivity, and high blocking temperature ranges may be reflective of a primary remanence. Those directions are few, and the MAD on most of those components does not fulfil the data selection criteria outlined in section 2.4.2, but they are distributed in clusters of both normal and reverse polarity anticlockwise deflected from the corresponding expected direction for the Australian Plate (Fig. 25). I do not suppose that the transposed mean of those directions (Dec: $311.0^{\circ}$, Inc: $-52.0^{\circ}, \alpha 95: 13.2^{\circ} \mathrm{N}=7$ ) is a representative time averaged GAD field direction, but it is worth mention for qualitative comparison with other more robust directions. The declination anomaly derived from that mean direction is $59.2 \pm 22.4^{\circ}$, with an anticlockwise sense of deflection. 

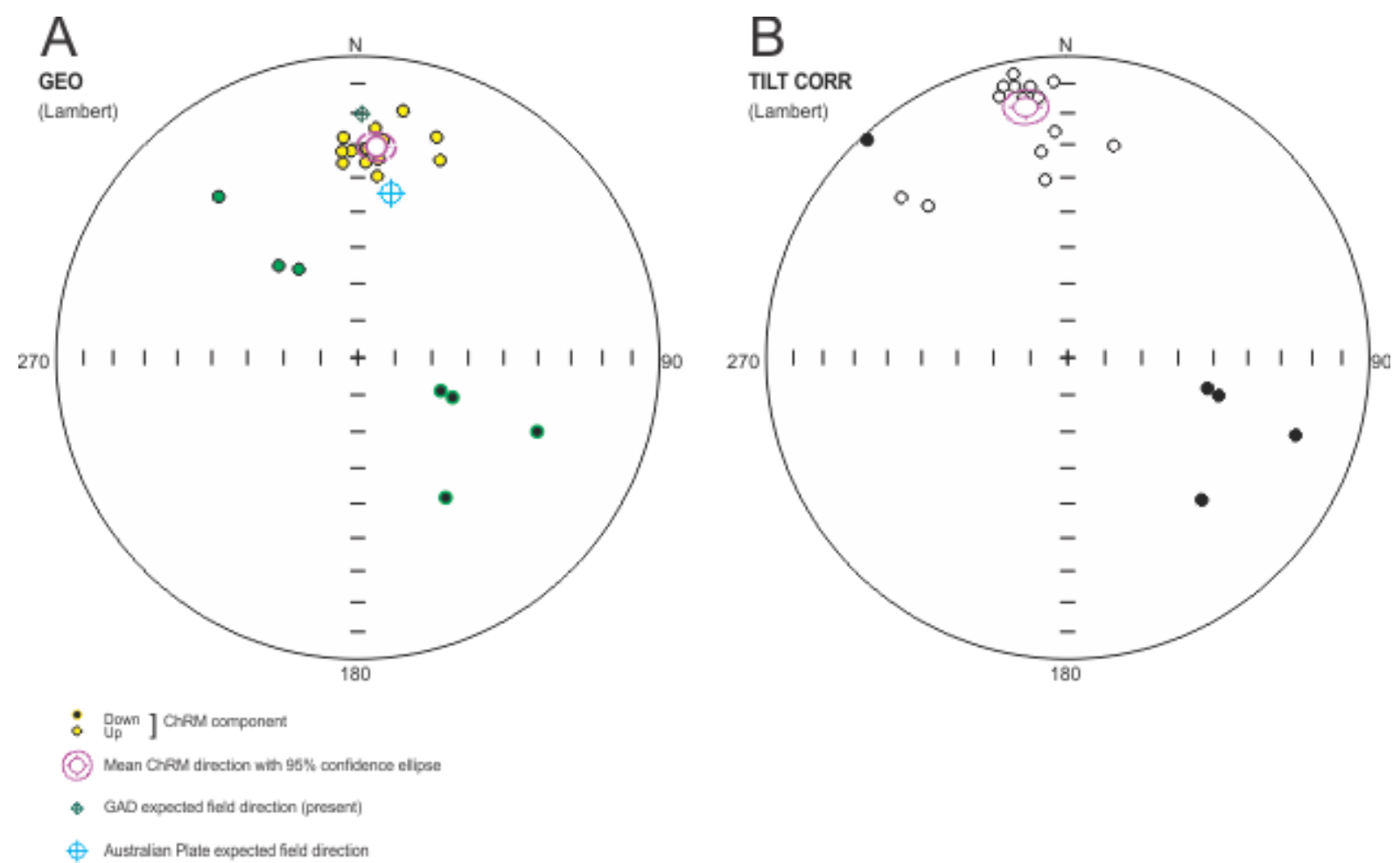

Figure 25. Equal area stereoplots to show distribution of PCA components from the Modewa River Beds, and mean direction (with $\alpha 95$ ellipse) for SRM interpreted components. A) No structural correction applied (preferred coordinate system). Directions shown in yellow are interpreted as SRM components, with resultant mean: $003.1^{\circ} /-31.4^{\circ} \alpha 95=4.0^{\circ}$. Directions shown in green are intermediate to high blockingtemperature and coercivity components tentatively interpreted as ChRM. Those directions do not meet the criteria for inclusion in calculation of a ChRM mean, but are conspicuously distributed in antipodal clusters anticlockwise deflected from the expected Australian Plate field direction. B) Tilt corrected coordinates. SRM mean direction: $352.9^{\circ} /-17.4^{\circ} \alpha 95=7.1^{\circ} . \mathrm{N}(\mathrm{SRM})=12$.

Table 10. Low blocking temperature and low coercivity components for specimens from the Modewa River Beds

\begin{tabular}{|c|c|c|c|c|c|c|c|}
\hline \multirow[t]{2}{*}{ Specimen ID } & \multirow{2}{*}{$\begin{array}{c}\text { NRM } \\
\left(10^{-6} \mathrm{~A} / \mathrm{m}\right)\end{array}$} & \multirow{2}{*}{\multicolumn{2}{|c|}{$\begin{array}{c}\text { MDF/MDT } \\
\left(\mathrm{mT} /{ }^{\circ} \mathrm{C}\right)\end{array}$}} & \multicolumn{4}{|c|}{ ChRM calculated } \\
\hline & & & & PCA limits & $\operatorname{Dec}\left({ }^{\circ}\right)$ & $\operatorname{Inc}\left({ }^{\circ}\right)$ & $\operatorname{MAD}\left({ }^{\circ}\right)$ \\
\hline SW01A.1 & 52.0 & & 233.5 & $209-518^{\circ} \mathrm{C}$ & 355.6 & -35.5 & 3.8 \\
\hline SW01B.1 & 19.4 & 13 & & $\mathrm{NRM}-30 \mathrm{mT}$ & 6.7 & -28.2 & 4.6 \\
\hline SW01B.2 & 16.6 & & 236.2 & NRM- $180^{\circ} \mathrm{C}$ & 358.3 & -32.0 & 4.0 \\
\hline SW01C.1 & 6.0 & & 182.3 & $\mathrm{NRM}-350^{\circ} \mathrm{C}$ & 6.0 & -34.2 & 2.5 \\
\hline SW01C.2 & 7.9 & 12.6 & & NRM-25 mT & 2.3 & -35.4 & 2.2 \\
\hline SW01D.1 & 30.9 & 11.0 & & NRM-30 mT & 355.6 & -32.0 & 2.0 \\
\hline SW01D.2 & 17.5 & & 194.8 & $\mathrm{NRM}-320^{\circ} \mathrm{C}$ & 2.2 & -31.3 & 2.4 \\
\hline SW01F.1 & 33.1 & 14.6 & & NRM-25 mT & 356.3 & -27.7 & 2.2 \\
\hline SW02A.1 & 0.8 & 42.6 & & $\mathrm{NRM}-20 \mathrm{mT}$ & 19.7 & -23.4 & 8.3 \\
\hline SW02B.1 & 1.55 & & & $\mathrm{NRM}-200^{\circ} \mathrm{C}$ & 6.2 & -39.3 & 7.5 \\
\hline SW02E.1 & 0.8 & 42.5 & & $\mathrm{NRM}-20 \mathrm{mT}$ & 4.4 & -24.6 & 12.3 \\
\hline SW02E. 2 & 1.21 & & & NRM-20 mT & 2.5 & -31.2 & 4.6 \\
\hline
\end{tabular}




\subsubsection{Fife Bay Volcanics}

A ChRM mean direction has been calculated from PCA components of 18 specimens from the Fife Bay Volcanics. Those data have been selected from an initial 34 demagnetization plots. There is significant directional scatter in the ChRM data for the Fife Bay Volcanics, and over half of the specimens have been disregarded on the basis of demagnetization behaviour and poor directional agreement between samples, so we approach the interpretation of these results with caution. However, these data are complimentary to paleomagnetic results from other Miocene rocks on the Papuan Peninsula at the Cape Vogel Peninsula locality.

Data have been rejected where directions are highly anomalous and GAD un-interpretable, as well as in the case of poor directional agreement between specimens from the same dike or depositional layer. Some data are retained that are potentially unreliable due to multi domain grains, but those data are treated with caution.

The distribution of ChRM directions retained for calculation of a mean direction for the Fife Bay Volcanics are shown in Figure 10. Those directions are for components that persist past demagnetization at peak fields of $>20 \mathrm{mT}$, and temperatures exceeding $>280^{\circ} \mathrm{C}$. They are distributed around a normal polarity direction (Fig. $26 \mathrm{~B}$; Dec: $343.5^{\circ}$, Inc: $-12.2^{\circ}, \alpha 95: 12.2 \mathrm{~N}=18$ ) that is anticlockwise deflected from north, and from the expected direction for the Australian Plate.

A structural correction to directional data from the Fife Bay Volcanics only affects that of PNG-12103 specimens, because all other data for the Fife Bay Volcanics come from dikes with vertical margins (presumably un-tilted). The structural correction applied involves rotating paleomagnetic directions consistent with returning the inferred bedding attitude measured at PNG-12-103 to horizontal, by rotation about the strike of that surface. That rotation results in directionally more favourable ChRM directions. Some directions that have anomalous positive inclinations for their declination in geographic coordinates are rotated to the upper hemisphere by application of a structural correction. Also, the mean ChRM direction is not significantly altered, but statistical precision is slightly improved by application of a structural correction to the data.

Comparison of the mean ChRM direction determined for the Fife Bay Volcanics with the expected field direction for the Australian plate at 10Ma (Dec: $5.8 \pm 5.3$, Inc: $-36.1 \pm 7.4$ ) yields an anticlockwise declination anomaly of $22.3 \pm 17.5^{\circ}$. That result suggests that an anticlockwise verticalaxis rotation relative to the Australian Plate has occurred at the Suau Coast locality on the Papuan Peninsula since the Middle to Late Miocene. It is possible that anticlockwise vertical-axis rotations at the Cape Vogel Peninsula and the Suau Coast are both expressions of the same Miocene phase of rifting, and that extension was distributed over a large area encompassing at least the present SE Papuan Peninsula. 

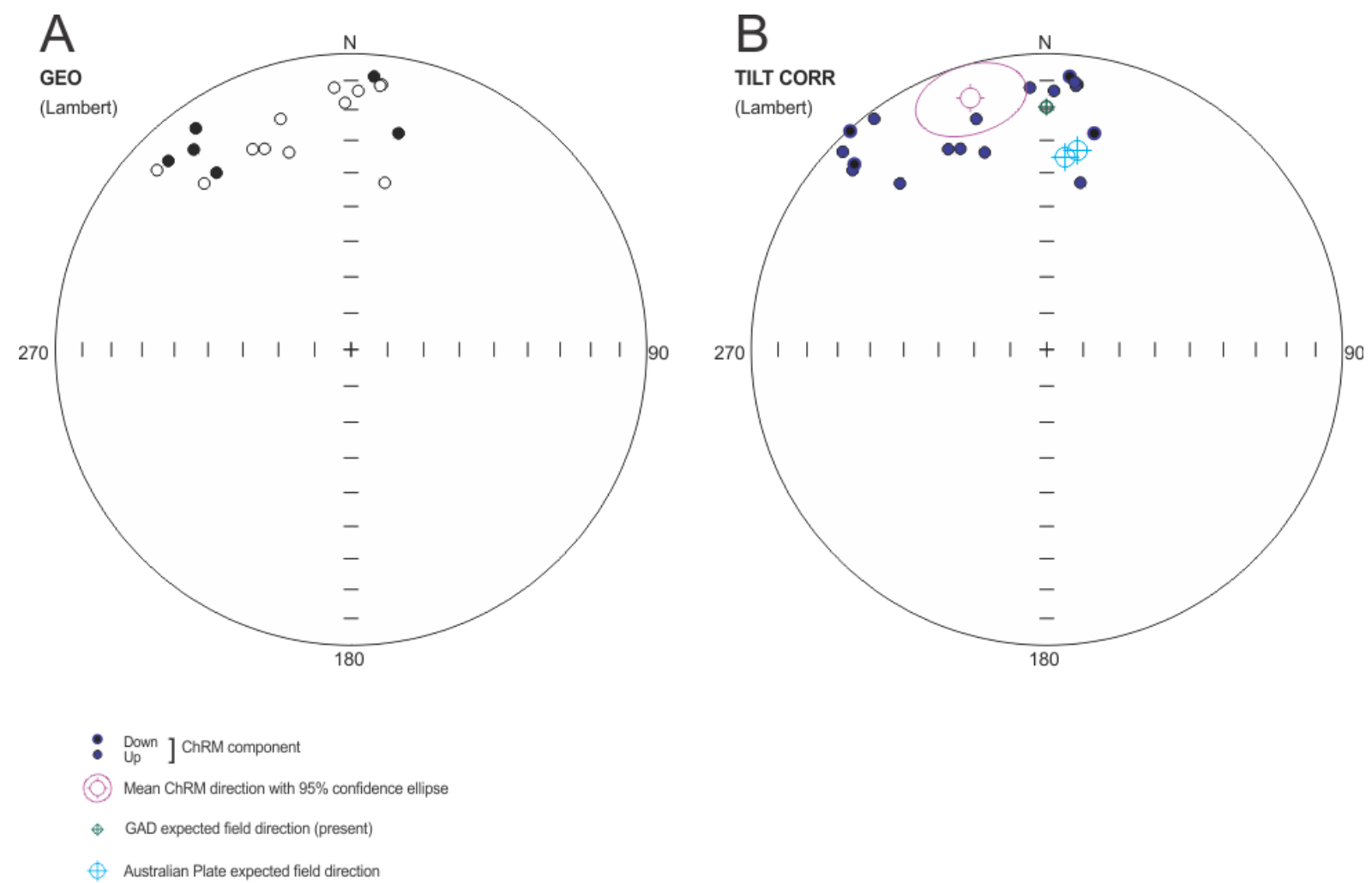

Figure 26. Equal area stereoplots to show distribution of ChRM components, and mean directions (with $\alpha 95$ ellipse) for the Fife Bay Volcanics A) No structural correction applied; mean direction: $343.7^{\circ} /-9.1^{\circ} \alpha 95=12.8^{\circ}$. B) Tilt corrected (preferred coordinate system); mean direction: $343.1^{\circ} /-11.0^{\circ} \alpha 95=12.4^{\circ} . \mathrm{N}=18$.

Table 11. ChRM components retain for calculation retained for calculation of the Fife Bay Volcanics mean direction.

\begin{tabular}{|c|c|c|c|c|c|c|c|}
\hline \multirow{3}{*}{$\begin{array}{l}\text { Specimen ID } \\
\text { FF04C.1 }\end{array}$} & \multirow{3}{*}{$\begin{array}{c}\begin{array}{c}\mathrm{NRM} \\
\left(10^{-6} \mathrm{~A} / \mathrm{m}\right)\end{array} \\
0.2\end{array}$} & \multirow{2}{*}{\multicolumn{2}{|c|}{$\begin{array}{c}\mathrm{MDF} / \mathrm{MDT} \\
\left(\mathrm{mT} /{ }^{\circ} \mathrm{C}\right)\end{array}$}} & \multicolumn{4}{|c|}{ ChRM calculated } \\
\hline & & & & \multirow{2}{*}{$\begin{array}{l}\text { PCA limits } \\
\text { NRM-45 mT }\end{array}$} & \multirow{2}{*}{$\frac{\operatorname{Dec}\left({ }^{\circ}\right)}{11.4}$} & \multirow{2}{*}{$\frac{\operatorname{Inc}\left({ }^{\circ}\right)}{-42.0}$} & \multirow{2}{*}{$\frac{\operatorname{MAD}\left({ }^{\circ}\right)}{5.0}$} \\
\hline & & 7.5 & & & & & \\
\hline FF04D.1 & 0.3 & & 292 & $\mathrm{NRM}-280^{\circ} \mathrm{C}$ & 333.8 & -25.5 & 3.4 \\
\hline FF04D.2 & 0.5 & & 277 & $100-340^{\circ} \mathrm{C}$ & 343.0 & -19.6 & 4.8 \\
\hline FF04E.1 & 2.3 & & 285 & NRM $-500^{\circ} \mathrm{C}$ & 356.3 & -12.3 & 4.8 \\
\hline FF05B.2 & 0.2 & 9.5 & & $10-60 \mathrm{mT}$ & 6.6 & -0.8 & 4.3 \\
\hline FF06A.1 & 0.2 & 9.0 & & $10-35 \mathrm{mT}$ & 342.5 & -30.8 & 3.7 \\
\hline FF06A.2 & 0.3 & & 232 & $\mathrm{NRM}-490^{\circ} \mathrm{C}$ & 336.7 & -27.0 & 5.9 \\
\hline FF07A.1 & 2.6 & & 244 & $50-520^{\circ} \mathrm{C}$ & 312.7 & -11.6 & 2.9 \\
\hline FF07B.1 & 1.4 & 4.4 & & $10-20 \mathrm{mT}$ & 318.5 & -26.0 & 4.0 \\
\hline FF07C.1 & 10.8 & & 533 & $\mathrm{NRM}-580^{\circ} \mathrm{C}$ & 12.4 & 26.4 & 2.3 \\
\hline FF07D.1 & 9.0 & & 454 & $400-600^{\circ} \mathrm{C}$ & 4.8 & 8.2 & 2.2 \\
\hline FF08A.1 & 0.7 & & 377 & $\mathrm{NRM}-550^{\circ} \mathrm{C}$ & 1.6 & -13.6 & 3.8 \\
\hline FF08A.2 & 0.7 & & 385 & $\mathrm{NRM}-600^{\circ} \mathrm{C}$ & 6.3 & -11.3 & 5.1 \\
\hline SW03A.1 & 2.7 & & 418 & $200-600^{\circ} \mathrm{C}$ & 314.4 & -4.4 & 2.2 \\
\hline SW03B.1 & 0.8 & & 185 & $200-580^{\circ} \mathrm{C}$ & 6.0 & -10.1 & 7.4 \\
\hline SW03C.1 & 2.13 & & 294 & $360-600^{\circ} \mathrm{C}$ & 323.2 & -2.9 & 4.6 \\
\hline SW03D.1 & 0.43 & & 191 & $300-600^{\circ} \mathrm{C}$ & 313.9 & 10.6 & 7.9 \\
\hline SW03D.2 & 0.64 & 5.0 & & $10-65 \mathrm{mT}$ & 318.0 & 0.7 & 9.5 \\
\hline
\end{tabular}




\section{Amphlett Islands Locality (3 Ma)}

\subsection{Geological Setting/Background}

The Amphlett Islands are a collection of volcanic islets, located 10-20 km north of Fergusson Island (Fig. 27). The predominantly high-K andesites that comprise the Amphlett Island Group are included in the Northern Volcanic Belt of Johnson et al. (1978). This belt consists of an east-west trending swath of volcanic rocks to the north of the Papuan Peninsula that form a curvilinear distribution of Miocene to recent andesitic volcanism (Johnson et al., 1978).

Smith \& Compston (1982) reported K/Ar hornblende, and Rb/Sr whole rock ages of $3.8 \pm 0.5 \mathrm{Ma}$ and $4.4 \pm 1.0$ Ma respectively, from two separate andesite samples from Wawiwa Island (Fig. 27) in the Amphlett Island Group. More recent, yet unpublished Ar/Ar ages have been determined by Suzanne Baldwin (pers. comm., 2013), and the ages of the rocks at her sample locations are shown in Fig. 27. The available range of dates for volcanic rocks from the Amphlett Islands volcanics suggests this volcanic complex was probably active between $\sim 2.5-3.5 \mathrm{Ma}$. For the purposes of this study, I treat the paleomagnetic data from the Amphlett Islands as $3 \pm 0.5 \mathrm{Ma}$.

Figure 27. Map of the Amphlett Islands locality to show paleomagnetic sample site locations, and attitudes of fissile flow fabrics in andesite flows, sampled at PNG-12-20 to PNG-12-23. Blue inverted triangles show sample locations, and are labelled with $\mathrm{Ar} / \mathrm{Ar}$ whole rock and hornblende radiometric age determinations of Baldwin et al. (pers. comm., 2013). Normal faults bounding Pliocene eclogite bearing gneiss is after Hill et al. (1994) and Little et al. (2011). 


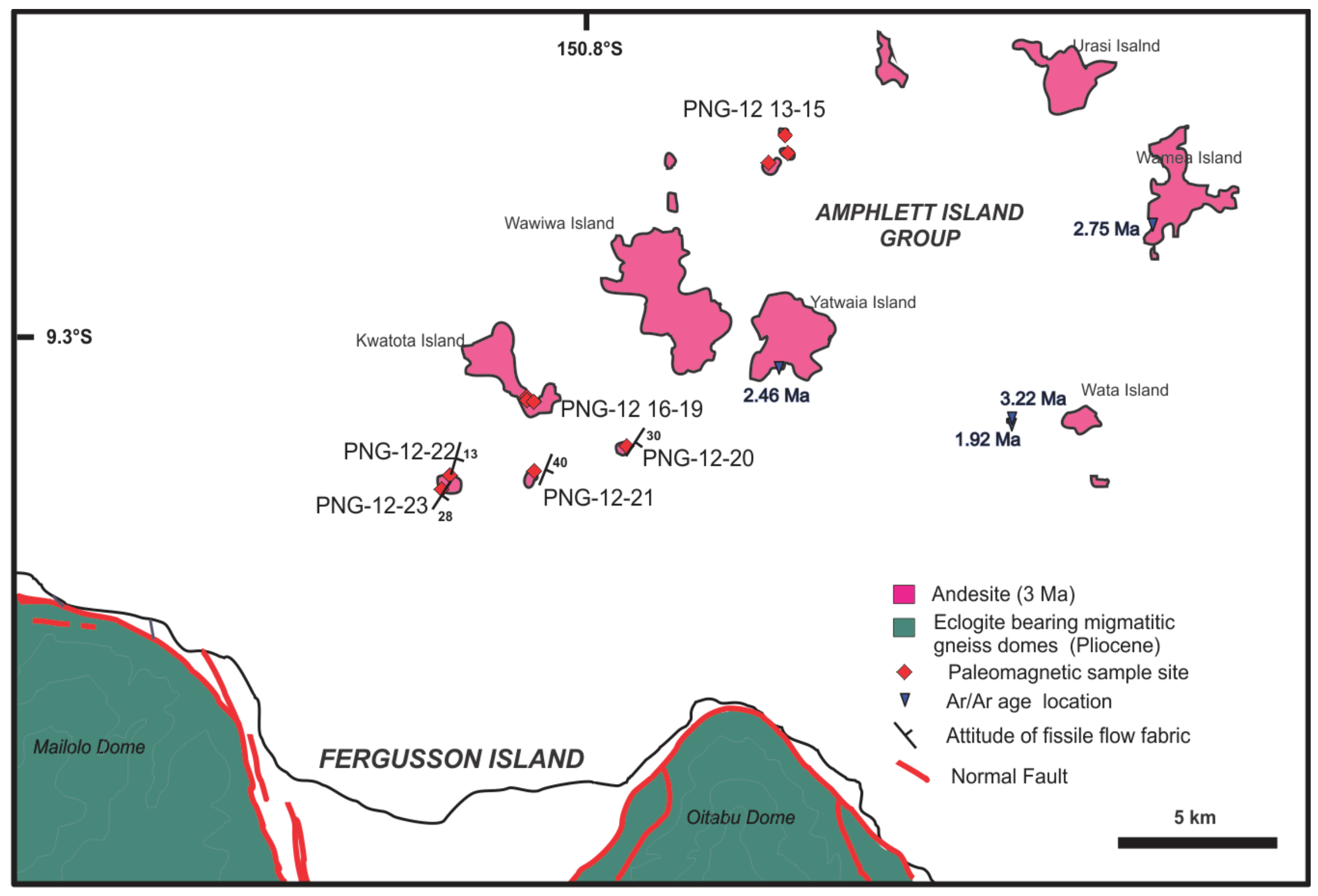




\subsection{Sample Rocks - field relationships, petrography, and inferred structural correction.}

At 11 different sample sites (PNG-12-013 to PNG-12-023), on 7 different islands, we collected 34 oriented cores from what we infer to be 13 depositional units. The rocks sampled consist of 9 massive flows (autobrecciated to varying degrees), 3 dikes and 1 internally brecciated megaclastic deposit. The sample sites are distributed over an area of $\sim 50 \mathrm{~km}^{2}$ in two main clusters, both toward the SW end of the Amphlett Island Group. Direct observation of original depositional contacts between sampled flows is difficult because of limited exposure. In several cases I have used geomorphology and/or petrography to infer that nearby samples were collected from different andesitic flows.

Where depositional contacts were not observed in the field, flow units have been distinguished from one another based on the following criteria:

1) Rocks from separate islands are considered to be of distinct depositional units.

2) Differential erosion of stacked rock layers may be interpreted to indicate different depositional units. Geomorphically such boundaries are expressed by topographic benches and bluffs, which I interpret to indicate preferential erosion at contacts between separate flow units.

3) Marked petrographic variations in texture and mineralogy, especially from layers of similar thickness, indicate that samples were collected from discrete flow units.

Using these criteria, I interpret that these samples were drilled from 13 separate depositional units in the Amphlett Island Group. The following sections (5.2.1 to 5.2.3) further discuss the sample rocks and field observations in terms of depositional units and deformation.

\subsubsection{PNG12 013-015}

Sample sites PNG-12-13, PNG-12-14 and PNG-12-15 are located on three different islands and are considered to sample distinct depositional units. Each of these sites is located at sea level, on one of three small islets that form a cluster towards the NE of the Amphlett Islands that were sample for this study (Fig. 27). Coastal outcrops on the islets typically expose several metre thick layers of massive to autobrecciated andesitic flow material (Fig. 28). The flow sampled at site PNG-12-13 is massive and plagiophyric with autobrecciated margins. The rocks sampled at PNG-12-014 come from two separate blocks in a coarsely autobrecciated flow. This flow contains massive blocks up to $1 \mathrm{~m}$ in diameter that are surrounded by a fine grained matrix of oxidized fragmental rock (Fig. 28). Samples from PNG-12-15 were retrieved from a $2 \mathrm{~m}$-thick massive andesite flow that overlies an $<1 \mathrm{~m}$ thick oxidised tuff deposit. Dipping basal contacts of the flow are presumed to be paleotopographical surfaces upon which the flows were extruded, but no tectonic tilting is obvious. 

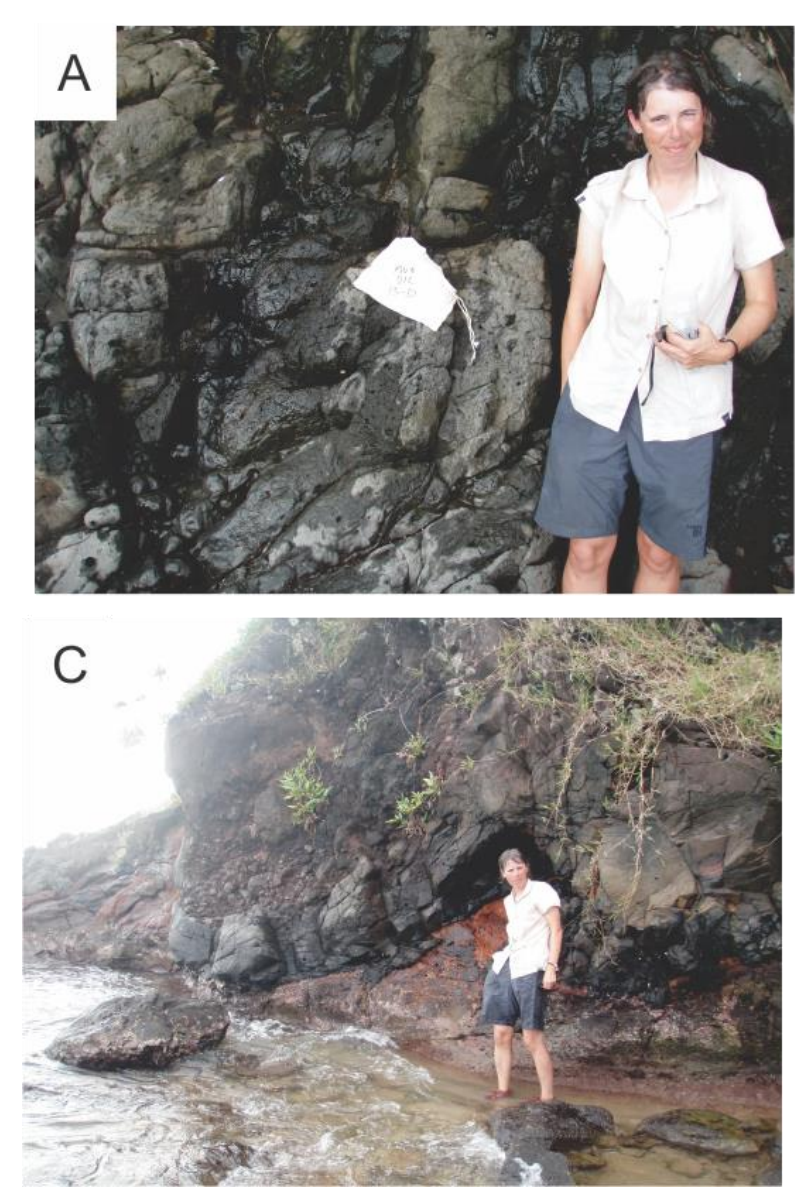

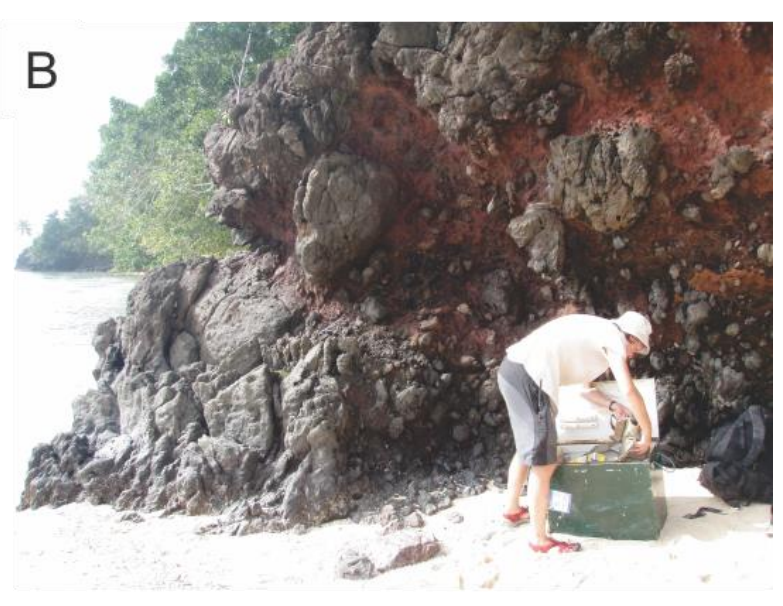

Figure 28. Field photographs (courtesy of T.A. Little) at sample sites PNG-12-13 to PNG-12-15. A) Massive andesite flow sampled at PNG-12-13. B) Megaclastic autobrecciated flow (or agglomerate) sampled at PNG-12-14. C) Massive flow overlying oxidised tuff at PNG-12-15

\subsubsection{PNG-12 016-019}

Sample sites PNG-12-16 to PNG-12-19 are located on the slopes of a north facing bay toward the south-east end of Kwatota Island (Fig. 27). Three flow units were sampled there (PNG-12-16 to PNG12-18), as well as one columnar-jointed dike (PNG-12-19) that intrudes oxidised agglomerate at sea level (Fig. 29). All four units are inferred to be undeformed, as is consistent with their sub-horizontal bench forming expression in the landscape, and the near vertical dip of an associated dike that was sampled at PNG-12-019. The orientation of that dike is $260 / \mathrm{NW} / 88^{\circ}$.

Sample sites PNG-12-16, PNG-12-17 and PNG-12-18 occupy benches at sea level, 20m and 30m elevation (Fig. 29), respectively, and in each of them oriented cores were retrieved from outcrops of massive andesitic flow deposits that are locally interlayered with autobreccia. Each inferred flow unit is separated from its neighbour by an appreciable break in slope, which I interpret as an eroded depositional contact. Furthermore, subtle textural and petrographic variations can be seen between the three inferred flow units. Moreover, the hypocrystallinity and approximately consistent grain size of microlites $(<0.2 \mathrm{~mm})$ in all three bench levels is inconsistent with a model where the benches are differentially exposed levels of one or two flow units that are $\geq 10-20 \mathrm{~m}$ thick.

The petrography of samples at PNG-12-016 to PNG-12-018 is similar, but each of the three inferred flow units has distinct characteristics that differentiate them from the other two. All of the rocks are characteristically porphyritic and have a groundmass that is dominated by plagioclase microlites and phenocrysts of orthopyroxene and minor clinopyroxene. Trachytic textures are commonly observed 
in thin section, as defined by the alignment of plagioclase microlites and elongate phenocrysts of orthopyroxene and rare amphibole (Fig. 30). Distinctive sub-equant vesicles are found in sample AM16A. These are characteristically $\sim 1 \mathrm{~mm}$ diameter and fragmented pyroxene often surrounds the vesicle walls (Fig. 30B). Core sample AM17B incorporates abundant xenoliths that have embayed grain boundaries. It also has the most vitreous groundmass of the three inferred flows, and contains elongate phenocrysts of amphibole not present in other samples (Fig. 30C). Core sample AM18B is highly vesicular, and contains the largest proportion of high birefringence clinopyroxene phenocrysts. Also, bands of what appears to be altered glass mineraloid (brown in plane polarised light, and isotropic) are found in the hypocrystalline groundmass of sample AM18B, but not in the other two flows (Fig. 30D, E).

Sample site PNG12-019 is a 3m thick columnar jointed dike that intrudes a country rock of hematite stained, oxidized autobreccia at sea level. The dike margins are near vertical at $267 / \mathrm{N} / 88^{\circ}$. This attitude is consistent with emplacement of the dike in a north-south extensional regime, and its vertical margins suggests a lack of any subsequent southward tectonic tilting towards the normal faults bounding Fergusson Island to the south. The dike sampled at PNG12-019 appeared to intrude upwards only a few metres into the surrounding country rock (Fig. 29). I infer from this that the flows sampled at higher elevation, namely at sites PNG-12-017 and PNG-12-018, post-date emplacement of this dike. Therefore, the overlying units are inferred to be similarly undeformed. 


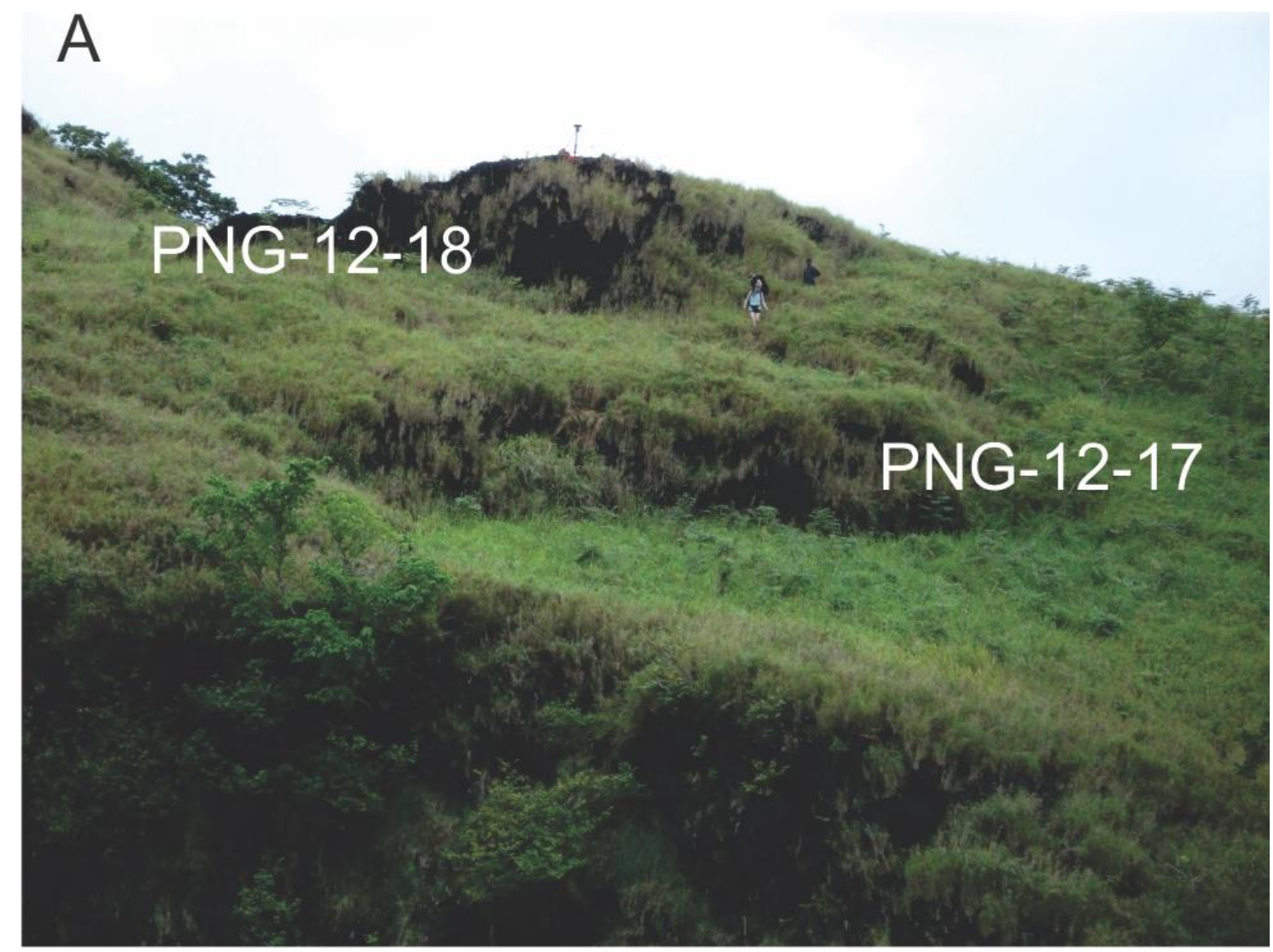

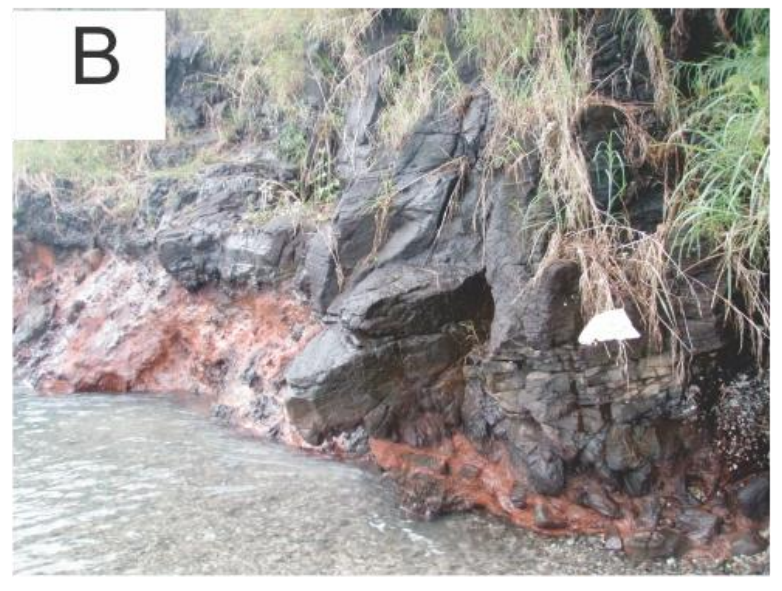

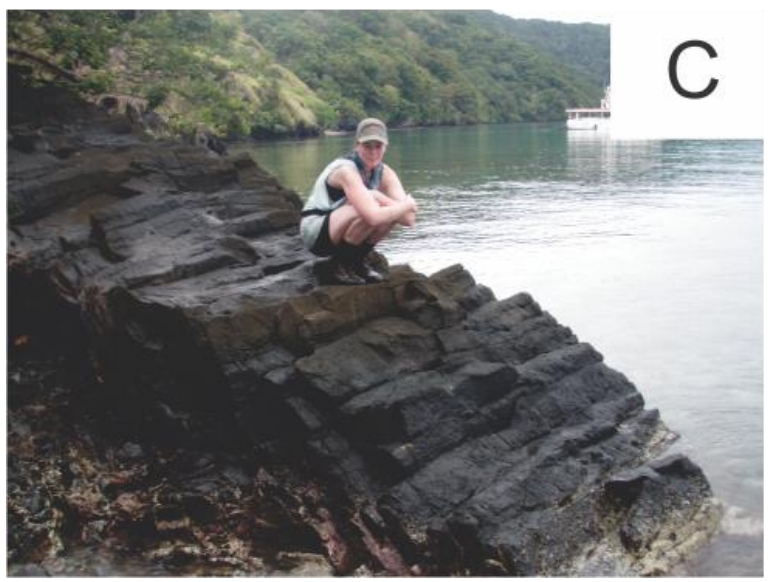

Figure 29. Field photographs (courtesy of T.A .Little) of sample locations PNG12-16 to PNG-12-19, on Kwatota Island. A) View from the boat towards the hillside on which sample sites PNG-1217 and PNG-12-18 are located. Note the step like topography that I infer is the expression of several layered lava flows. B) Sample site PNG-12-16 massive flow with autobrecciated base overlying oxidised tuff at sea level. C) Collumnar jointed dike sampled at PNG-12-19. Note the near vertical margins of the dike inferred to be undeformed by tectonic tilting. Also, the dike is not expressed on the landscape at any higher elevation than is shown in the photograph. I take this to mean that the dike was overlain by the above dikes rather than intruded them, and so the lava flows sampled at the above sites are also inferred to be undeformed. 

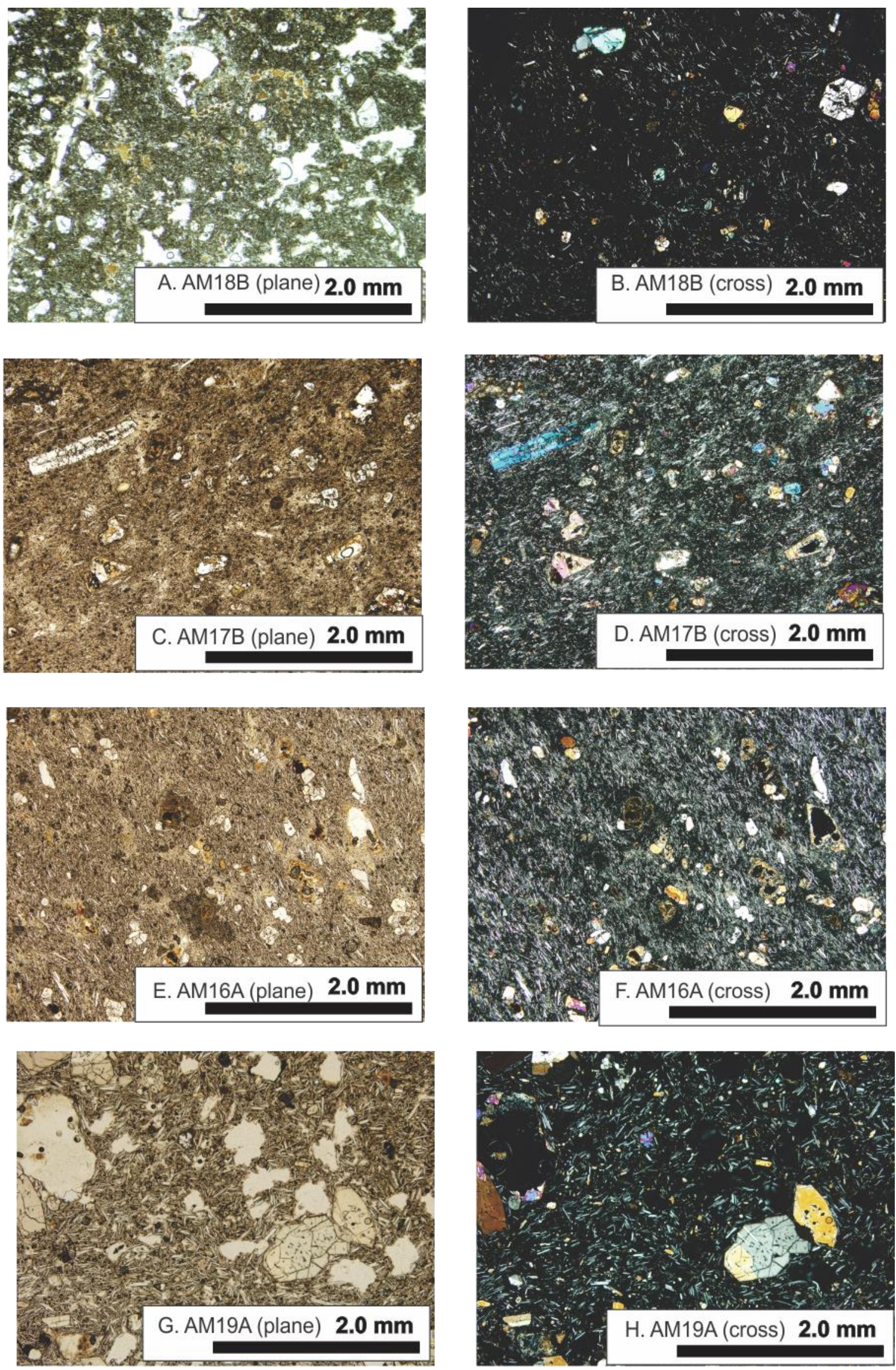
Figure 30 (previous page). Photomicrographs of samples from PNG-12-16 to PNG-12-19. All of these rocks are of andesitic composition, with trachytic textures in a vitreous groundmass. Sample AM18B (A-B) is the most vitreous of the samples, and ribbons of brown altered glass (seen under plane polarised light) distinguish this flow from the others. AM17B (C-D) has elongate amphibole phenocrysts that are not present in the other flows. AM16A (E-F) is the most vesicular, and vesicles often have fragmental orthopyroxene around their edges.

\subsubsection{PNG12 020-023}

Sample sites PNG-12-020 to PNG-12-023 are located to the SE of Kwatota Island, along a northeastsouthwest trending arrangement of islets at the south-western end of the Amphlett archipelago (Fig. 27). A fissile fabric was observed in outcrop at these sample sites, dipping between $10^{\circ}-40^{\circ}$ to the southeast. The flows sampled at these sites are lighter in colour, and less glassy than the other andesite flows we sampled in the Amphlett Islands. This probably indicates the flows that form these islands SW of Kwatota are thicker, and more devitrified due to slower cooling. I interpret the platy flow fabric in these flows as being joints that formed parallel to the contemporaneous topographic slope during flow (Jerram \& Petford, 2011) of the lavas down the southeast flanks of a now much eroded volcanic edifice.

PNG-12-020 is located on an islet to the SE of Kwatota Island. Here, three cores were obtained from an andesitic flow more than $3 \mathrm{~m}$ thick. This flow is autobrecciated at the base, and grades up into $>2 \mathrm{~m}$ thickness of massive flow material. A platy fabric is defined by the alignment of sub-elongate vesicles and orthopyroxene phenocrysts, as well as the trachytic texture of a microlitic groundmass. The platy flow fabric similar to that described above was measured in the field, and it has an attitude of $033 / \mathrm{SE} / 30^{\circ}$.

PNG-12-021 is located on Chalata Island, directly south of Kwatota Island. Here we sampled a massive to blocky flow, also more than $3 \mathrm{~m}$ thick, and with a platy flow fabric. Three cores were retrieved from the same horizon within a massive portion of an andesite flow that transitions laterally into autobrecciated material across a near vertical contact. That cross section in outcrop may represent a paleo flow front or levee. The sampled rocks exhibit a platy flow fabric, like that described previously, that has a strike and dip of $022 / \mathrm{SE} / 40^{\circ}$. This fabric is also defined by an alignment of vesicles and of elongate microphenocrysts of plagioclase and pyroxene.

PNG-12-022 and PNG-12-023 are located on north and southwest coasts respectively, of Gumata Island, which is located $\sim 4 \mathrm{~km}$ to the SW of Kwatota Island (Fig. 1). At site PNG-12-022, a several metres thick exposure of pale grey volcanics exhibits a fissile weathering pattern with an average strike and dip of $016 / \mathrm{SE} / 13^{\circ}(\mathrm{N}=3)$. Several dikes, each approximately $1 \mathrm{~m}$ thick, have fine grained quenched margins, and intrude the surrounding rocks at a high angle to the measured flow fabric (Fig. 6A). Core samples were retrieved both from the interior and margins of the dikes, as well as from the intruded volcanics at various distances from intrusion contacts. At site PNG-12-023, a platy fabric was also observed in outcrop of the pale grey andesitic flow material. This has an average attitude of $033 / \mathrm{SE} / 28^{\circ}(\mathrm{N}=5)$ and is interpreted as mentioned above.

The gently dipping flow fabrics that we observed could conceivably record primary dips, or they may indicate some tectonic tilting of an originally sub-horizontal flow fabric. Both options must be 
considered before applying any structural correction to paleomagnetic data. The elliptical arrangement of islets in the Amphlett Group was interpreted by Smith (1973) to represent the eroded remnants of a single, and once much larger and mostly emergent volcanic edifice. For sample sites PNG-12-020 to PNG-12-023, the interpretation of their SE dipping flow fabrics as reflecting untilted primary dips is consistent with the above inference as the sites would have been located on the SE dipping flank of the edifice.

The Mwadeia and Oitabu faults, which bound the north coast of Fergusson Island 10-25 km south of the Amphlett Islands, are moderately north dipping, active normal faults (Little et al. 2011). Any tectonic tilting in the hanging wall of these faults would thus be expected to be towards the south, rather than the southeast.

Because of the uncertain contributions of primary dip versus tectonic tilting to explain the gently southeast dipping flow fabrics, I have considered several approaches to applying a structural correction to paleomagnetic data. These are as follows:

1) Assume that the now southeast dipping fabrics were formed horizontally as compaction fabrics that have since been tilted to southeast dips by extensional tectonic deformation. This approach requires correcting all paleomagnetic data from sample sites PNG-12-020 to PNG-12-023, consistent with rotating SE dipping fabrics to horizontal.

2) Assume, once again, that the southeast dipping fabrics were formed horizontally and were later tectonically tilted to present southeast dips, but that this tilting took place prior to emplacement of the near vertical dikes which have not been tilted. This approach requires that paleomagnetic data from flow samples is corrected for the dip of measured fabrics, but that no correction is required for paleomagnetic data from dike samples.

3) Disregard the flow fabric orientation and assume that the dikes were emplaced vertically, and take the current deviation of the dikes from the vertical as being representative of the amount of subsequent tectonic tilting of the sample sites. This approach requires that all paleomagnetic data be corrected consistent with returning dikes to vertical orientation.

4) Assume that southeast dipping flow fabrics are primary and that the dikes were not necessarily emplaced vertically. In this scenario we assume that all the rocks of the Amphlett Islands are untilted and undeformed. This approach requires no structural correction to paleomagnetic data from the Amphlett Islands. 

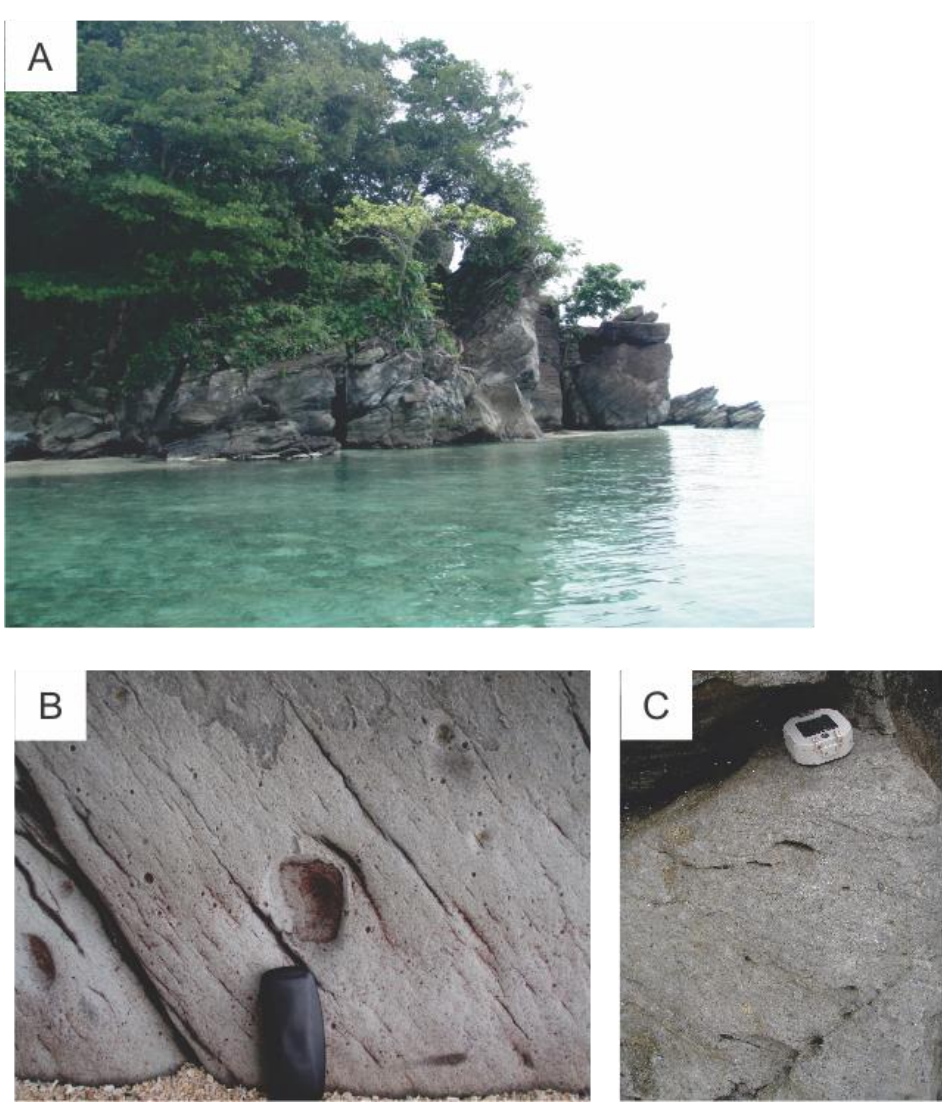

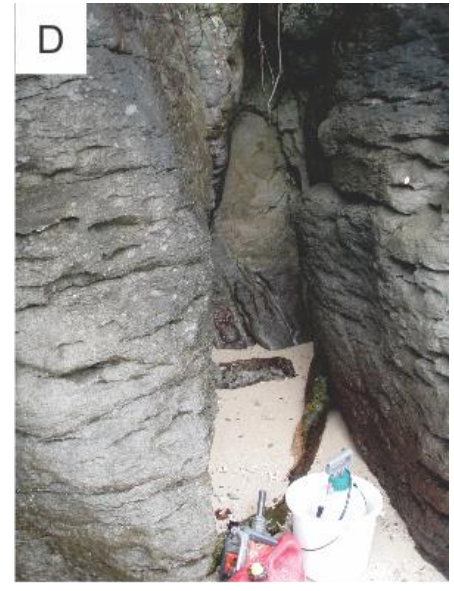

Figure 31. Field photographs (courtesy of T.A. Little) at sample sites PNG-12-22 and PNG-12-23, where a fissile flow fabric is well developed. A) View from boat towards dipping andesite flow lava at PNG-12-23. The flow here is at least $6 \mathrm{~m}$ thick. B) Close up of a mafic xenolith, which are commonly observed in outcrop at this location. C) Close up of fissile fabric at site PNG-12-22. D) Dikes intruding at high angle to the fissile fabric at PNG-12-22.

Figure 32 (next page). Photomicrographs of samples from PNG-12-20 to PNG-12-23 to the southeast of Kwatota Island. Textures vary between samples, but all have a microlite groundmass dominated by plagioclase. Note that $\mathrm{AM} 22 \mathrm{~B}(\mathrm{E}-\mathrm{F})$ has well developed trachytic texture, and also was sampled at a location where the measured fissile fabric is well developed on a fine scale. 

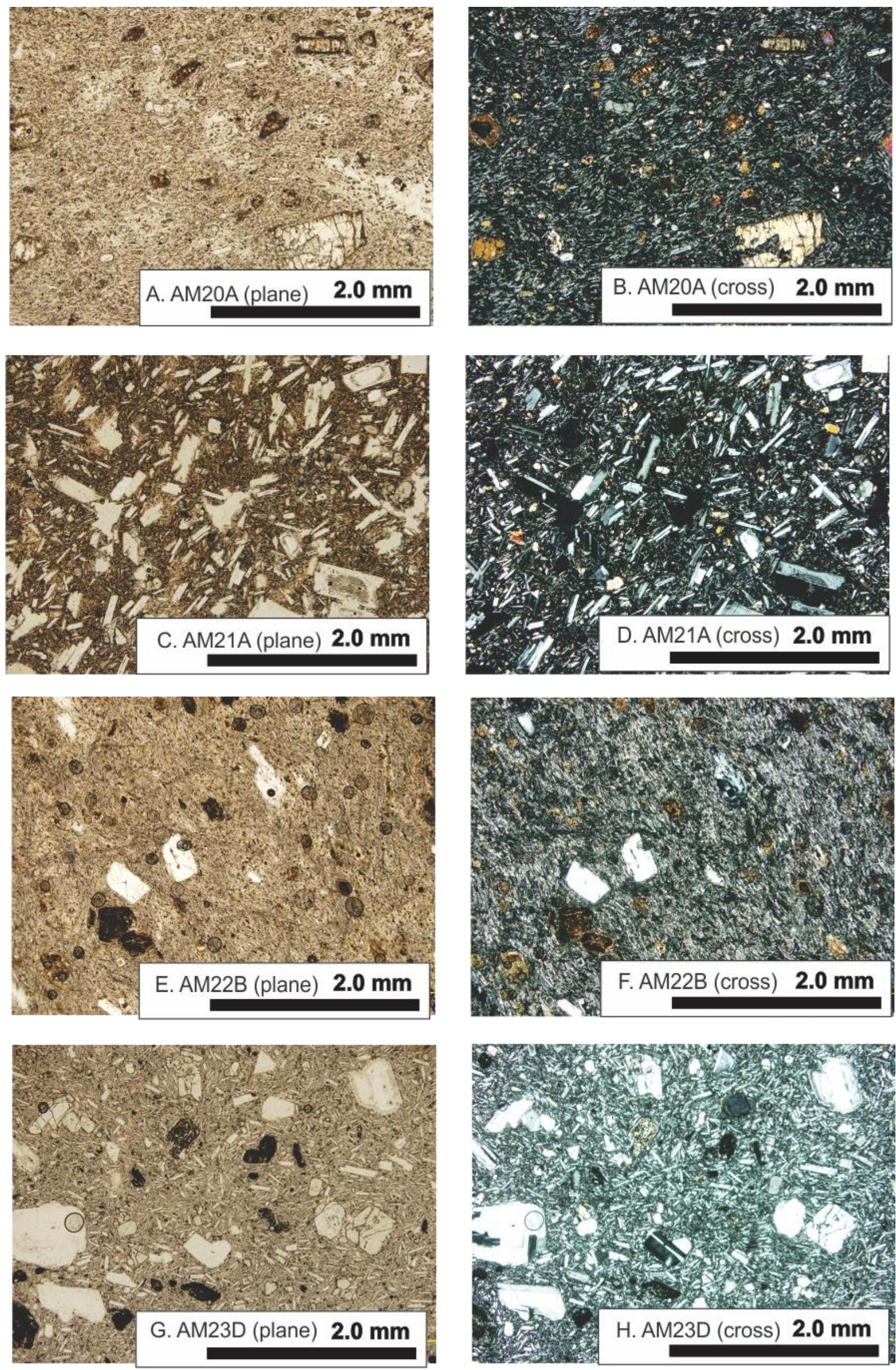


\subsection{Magnetic Susceptibilty Experiments and Inferred Magnetic Mineralogy}

Microcrystalline magnetite grains are inferred to be the dominant carriers of remanent magnetization in samples from the Amphlett Islands, based on demagnetization behaviour and temperature dependent magnetic susceptibility. Representative samples for each inferred depositional unit sampled were heated to $700^{\circ} \mathrm{C}$ and then cooled to room temperature while measuring magnetic susceptibility at $\sim 10^{\circ} \mathrm{C}$ intervals. Mass normalized magnetic susceptibility is plotted against temperature for each sample (Fig. 33).

Most samples exhibit the greatest loss of magnetic susceptibility on heating through $580^{\circ} \mathrm{C}$, or slightly below that, which corresponds to the Curie temperature of magnetite or Fe-rich titanomagnetite. The indicated dominance of magnetite as a ferromagnetic mineral phase lends confidence to my interpretation of the primary nature of remanence components, because magnetite is an expected primary magmogenic mineral in andesitic rocks. Because magnetic susceptibility experiments and the intensity of Natural Remanent Magnetization (NRM) in all samples provide strong evidence for the presence of magnetic mineral grains, but opaque mineral species were not identified in thin section of Amphlett Islands sample rocks, I infer that micro- to cryptocrystalline titano-magnetite grains are the carriers of remanent magnetization. The data show a consistent pattern characterised by lower magnetic susceptibility readings during cooling than at equivalent temperatures during heating. This is consistent with thermal alteration resulting in the loss of ferromagnetic mineral phases. A possible inference from these observations is that magnetic mineral phases occur as cryptocrystalline exsolution lamellae (e.g., Fe-Ti oxides exsolved from, and contained in Fe rich pyroxene phenocrysts), that may be diffusively resorbed into host phenocrysts on heating of samples (Feinberg et al., 2005). In any case, it is analytically advantageous that magnetic minerals are lost rather than grown through heating, as the likelihood of samples acquiring a partial Thermal Remanent Magnetization on cooling in a residual field is reduced.

While considerable alteration can be seen to have occurred during the heating process for several samples (Fig. 33C, E, F, G); most samples have a reversible temperature dependent magnetic susceptibility in the high blocking temperature range $\left(\sim 550-580^{\circ} \mathrm{C}\right)$. This observation lends confidence to the stability and dominance of magnetite grains, and that the most stable carriers of remanence are resistant to thermal alteration during demagnetization procedures. 
A. AM15B

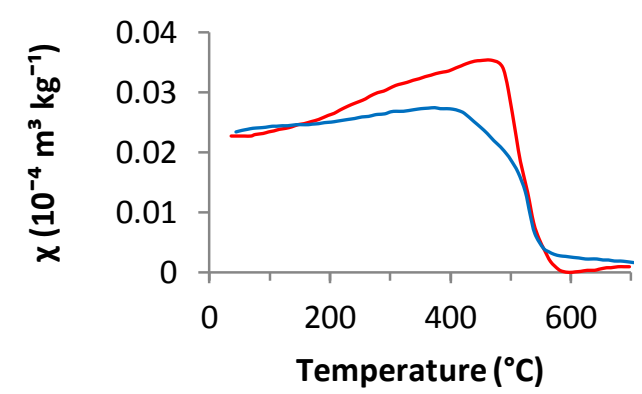

C. $\mathrm{AM} 17 \mathrm{C}$

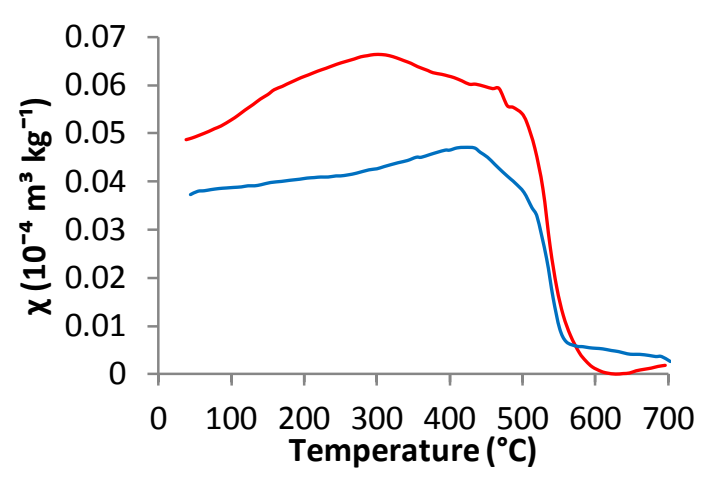

E. AM22D

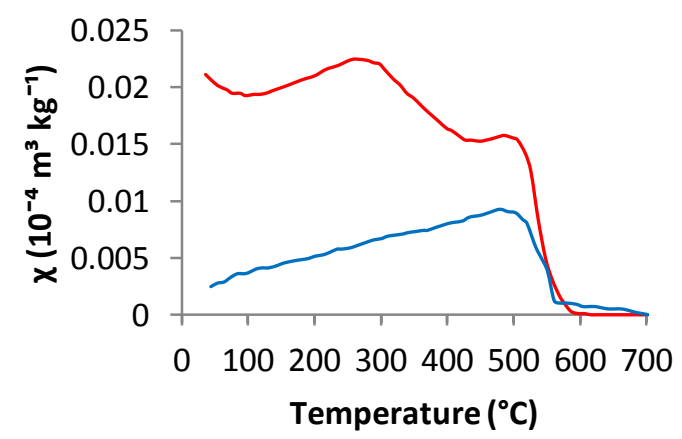

G. AM23A

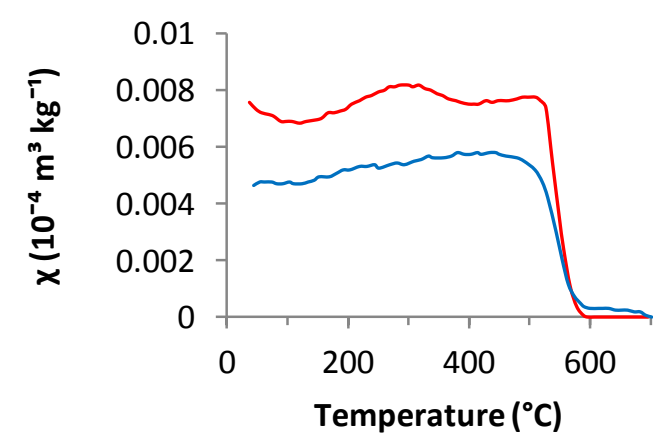

B. AM16C

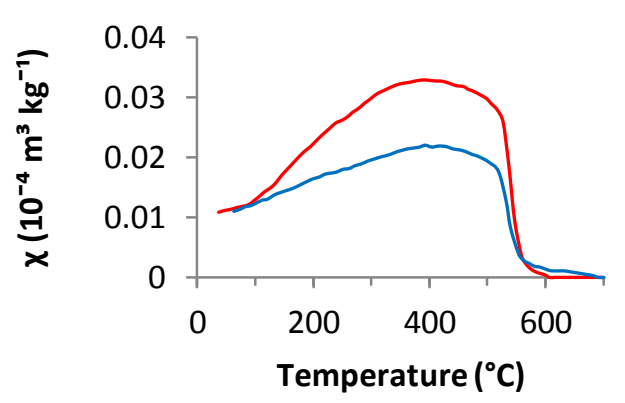

D. AM18A

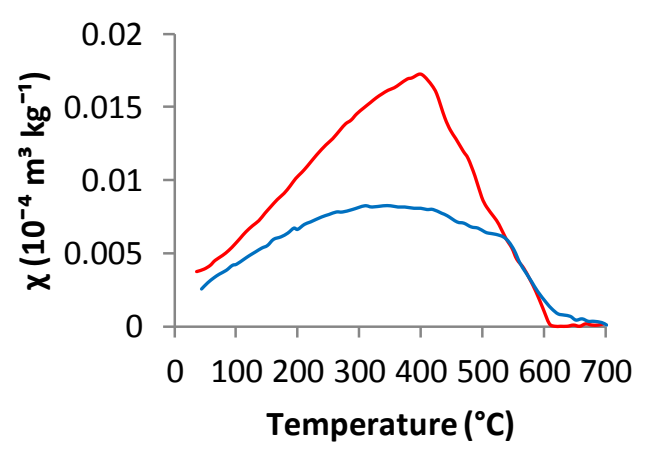

F. AM22H

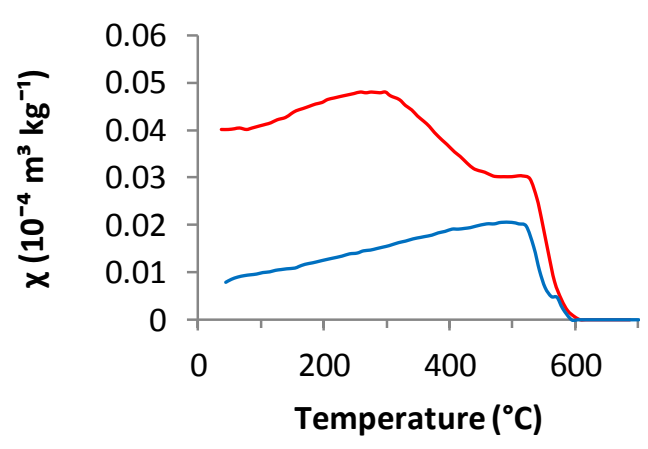

Figure 33. Temperature dependent magnetic susceptibility curves for samples from the Amphlett Islands. 


\subsection{Demagnetization Behaviour}

The Amphlett Islands samples are strongly magnetized, with NRMs between 0.1 and $5 \mathrm{~A} / \mathrm{m}$ (Table 12). While low blocking-temperature and low coercivity secondary magnetizations are evident in the demagnetization profiles of many specimens, these viscous components are consistently removed at low temperatures $\left(<250^{\circ} \mathrm{C}\right)$ and demagnetizing fields $(<20 \mathrm{mT})$ to reveal ChRM components of both normal and reverse polarity, and that have origin bound trajectories (Fig. 34). In many cases the secondary components are of uninterpretable directions, others can be interpreted as normal polarity overprints. These include specimens where secondary components differ slightly from the normal polarity ChRMs, and where they are almost opposite those of reverse polarity ChRMs carried by high blocking-temperature grains of the same specimen. This lends confidence to the interpretation that the directions determined from high temperature components are characteristic, and most likely represent primary magnetizations. There is generally good directional agreement between high temperature components in specimens from the same core, whether Thermal or Alternating-Field treated, which further affirms the interpretation of directions as characteristic, primary, and due to a single dominant mineralogy.

\subsection{Data selection and rejection}

ChRM data from the samples collected at site PNG-12-14 were collected from two metre scale blocks in a fine grained tuff or autobrecciated matrix in order to conduct a block test. Those samples are categorically rejected on the basis of the failure of that test. The poor directional agreement between core samples suggests that their magnetization was acquired prior to emplacement, and that it was differentially reoriented in the separate blocks during their later brecciation and/or transport in the deposit. Thus directions from that deposit cannot be reliably interpreted in terms of a GAD model field direction.

Specimens from sample site PNG-12-21 were rejected based on the likelihood of a significant contribution to remanence from multi domain grains. The presence of multi-domain grains is inferred from very low MDF (3.3mT) of AF treated specimens, and curvilinear trajectories in Zijdeveld plots of TH treated specimens (Fig. 34E \& F). Furthermore, the likelihood of multi-domain grains is consistent with the relatively coarse groundmass seen in thin section (Fig. 32C-D.

Additionally single cores are rejected from sample sites PNG-12-13 and PNG-12-18. Sample core AM18B was rejected on the basis of anomalous GAD inclination with respect to declination. A slight degree of autobrecciation in the vicinity of core sample AM18B was noted in the field, which may have resulted in the reorientation of the magnetization direction subsequent to TRM acquisition. Two specimens from sample core $\mathrm{AM} 13 \mathrm{C}$ were rejected due to poor directional agreement within a single core. ChRM directions determined for AM13C.1 and AM13C.2 both have northerly declinations, but the sign of their inclinations are in contrast. The angle between those directions is $17.3^{\circ}$, which I deem unacceptable given the relatively good inter-core directional agreement through the rest of this dataset. 

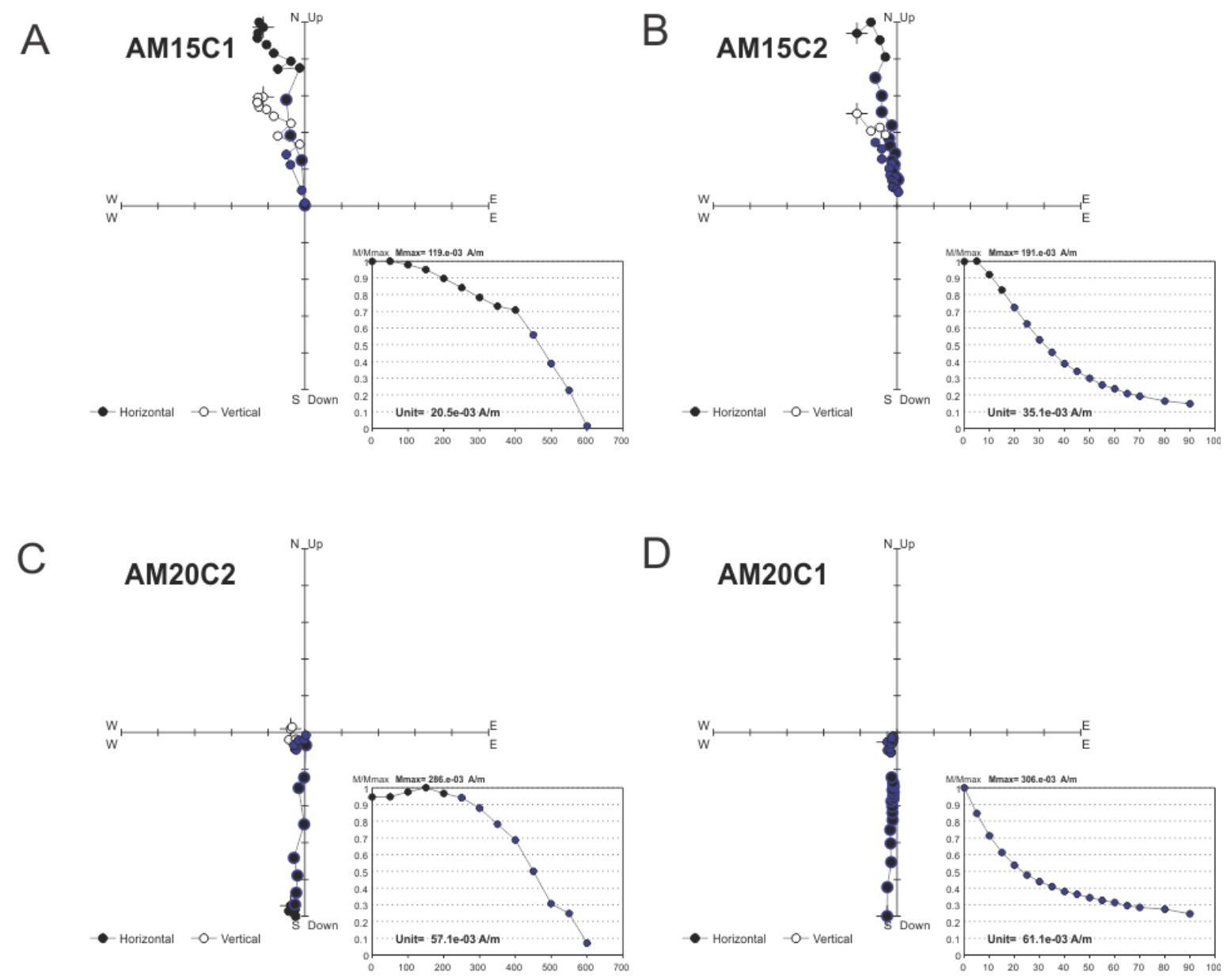

E

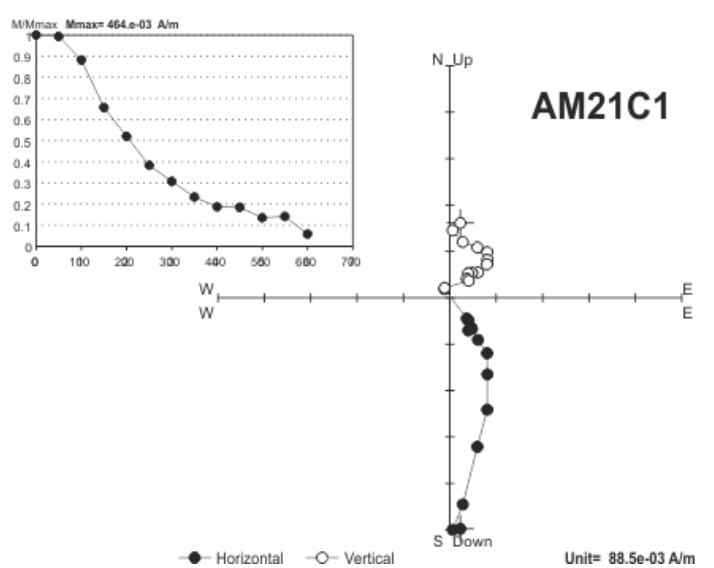

F

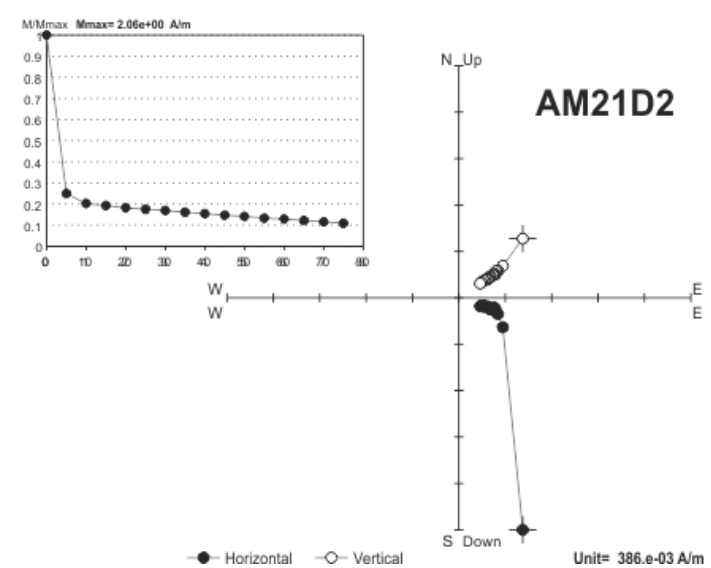

Figure 34. Demagnetization plots for selected specimens from the Amphlett Islands andesite to compare demagnetization behaviour through thermal (left) and alternating field (right) treatments. Specimens carry one component of either normal or reverse polarity, and plots agree well between AF and TH demagnetization experiments. AM2C.1 provides an example of multi-domain behaviour. NRM is readily removed at low coercivities and thermal demagnetization produces curvilinear plots. Samples from PNG-12-21 were rejected based on this inference of multi-domain grain behaviour. 


\subsection{Group Statistics and Interpretation of Woodlark Plate Vertical Axis Rotation}

ChRM components from specimens of the Amphlett Islands andesite cores are distributed in two clusters about antipodal mean directions, of normal and reverse polarity (Fig. 13). The calculated mean directions, from each directional cluster, are reasonably interpretable in terms of normal and reverse polarity GAD model field directions for the sample locality, having experienced an anticlockwise vertical axis rotation with respect to the Australian Plate.

Figure 35 shows the distribution of all ChRM directions for the Amphlett Islands, and two mean directions for clusters of normal and reverse polarity components. Those mean directions are antipodal within a $95 \%$ confidence interval, demonstrating a positive reversal test (Fig. 35). The transposed mean of those ChRM components (Fig. 35B; Dec: $352.6^{\circ}$, Inc: $-25.9^{\circ}, \alpha 95: 5.0 \mathrm{~N}=42$ ) is statistically improved with respect to each of the mean directions for clusters of opposing polarity.

The greatest directional scatter in the Amphlett Islands data is seen in the variable inclinations of ChRMs, while declinations are more consistent. This may be the result of some differential tilting and/or syn-depositional deformation of the sampled flows. The range of inclinations is especially evident in the distribution of reverse polarity ChRM directions (Fig. 35A). Inclination being the greatest source of scatter seems consistent with a certain small degree of tilting to the south that may result from normal sense motion on north dipping faults like those previously mentioned that bound the metamorphic domes of Fergusson Island (Fig. 27); However, there is insufficient evidence on the basis of the observations of this study to demonstrate or quantify any such regional tilting. The inclination anomaly $\left(-2.3 \pm 10.1^{\circ}\right)$ derived for the best mean ChRM direction for the Amphlett Islands is appreciably small, which also supports the inference that the Islands have not been significantly tilted since deposition of the Andesite sampled.

We interpret the southeast dipping flow fabrics at sample sites PNG12 020-023 to record primary dips of the lava flows (option 4 in section 5.2.3, above) based on 1) the consistency of those gentle dips, 2) their obliquity to the direction of tectonic tilt expected for slip on the major normal faults on Fergusson Island, 3 ) their location on the southeast flanks of the inferred volcanic edifice, as well as 4) the various effects of applying a structural correction to paleomagnetic data. In particular, application of a structural correction to paleomagnetic data (options 1, 2 and 3 in section X.2.3, above) results in 1) decreased statistical precision; 2) anomalous inclinations; i.e., ChRM directions become uninterpretable in terms of a Geocentric Axial Dipole; and 3) dikes dip steeply to the southeast, inconsistent with the sense of expected normal fault tilting. In summary, we infer that the gently southeast dipping flow fabrics are primary and formed parallel to the contemporary ground surface during extrusion and transport of flows down the SE dipping flanks of a now eroded volcano.

The dispersion of ChRM directions in the Amphlett Islands dataset $\left(\theta 63: 18.7^{\circ}\right)$ is sufficient to suggest the flows sampled were deposited over adequate time to sample and average out secular variation. Also, because there are clusters of reverse and normal directions that are spatially related, I suggest that reflects time variant localization of eruptive activity at different vents. The available isotopic ages for rocks from the Amphlett Islands coincide with Gauss-Matuyama chrons. Because there are mostly reverse directions in this data set, I suggest that eruptive activity in the Amphlett Islands mainly occurred during the late Gauss reverse polarity chron. 
Based on these results, I infer that the mean direction calculated from transposition of ChRM components from the Amphlett Islands sample suite is representative of a time averaged field direction at the sample locality and that the derived declination anomaly can be interpreted in terms of a tectonic vertical axis rotation with respect to the Australian Plate.

Confidence in time averaged field direction is gained from:

1) Sampling both reverse and normal polarity components of magnetization, with consistently origin bound trajectories.

2) The spatial distribution of sample sites that contribute to normal and reverse polarity mean directions.

3) A positive reversals test.

4) A sufficiently large $\theta 63$ to suggest secular variation has been averaged out.

For a locality on the Australian Plate, the mean direction derived from 3 Ma rocks is expected to lie between field directions that derive from VGP locations for the Australian Plate (Veevers \& Li, 1991; Turner et al, 2007) at $2 \mathrm{Ma}$ and $10 \mathrm{Ma}$, so a declination anomaly, derived from the comparison of a GAD model expected field direction for the Australian Plate with a calculated formation mean direction, can be interpreted in terms of a vertical-axis rotation with respect to the Australian Plate. At a location of $9.3^{\circ} \mathrm{S}, 150.8^{\circ} \mathrm{E}$ (representative of a mean Amphlett Group sample site location), the expected Australian Plate directions for $2 \mathrm{Ma}$ and 10Ma are shown below

Table 12. Australian Plate GAD field expected directions for the Amphlett Islands locality

\begin{tabular}{|c|c|c|}
\hline & Declination $\left(^{\circ}\right)$ & Inclination $\left(^{\circ}\right)$ \\
\hline $2 \mathrm{Ma}$ & $2.7 \pm 5.1$ & $-23.6 \pm 8.8$ \\
\hline $10 \mathrm{Ma}$ & $5.9 \pm 5.3$ & $-34.0 \pm 7.6$ \\
\hline
\end{tabular}

Comparison of the best mean direction of this study (Fig. 35B; Dec: $352.6^{\circ}$, Inc: $-25.9^{\circ}, \alpha 95: 5.0^{\circ}$ $\mathrm{N}=42$ ) with those expected directions for the Australian Plate at 2 and $10 \mathrm{Ma}$ yields anticlockwise declination anomalies of $10.1 \pm 7.6^{\circ}$ and $13.3 \pm 7.7^{\circ}$ respectively. These results lead to the conclusion that the Amphlett Islands have probably experienced an anticlockwise vertical axis rotation of $\sim 10$ $13^{\circ}$ with respect to the Australian Plate during the past 3 Myr.

When considered in relation to the published Euler poles describing Woodlark-Australia plate motion, derived from magnetic anomalies in the Woodlark Basin and from GPS plate motion vectors in the Woodlark Rift Zone, the declination anomalies calculated from Amphlett Islands paleomagnetic data indicate that this site is of Woodlark Plate affinity, and has experienced a vertical axis rotation comparable to that of the plate motion accommodated by the Woodlark Basin Spreading Centre. Luyendyk et al. (1973) proposed that the Woodlark Basin has opened $16^{\circ}$ in the past $3 \mathrm{Ma}$, based on restoring the Woodlark and Pocklington Rises to an inferred previously adjoined state. Their inferred pole of rotation is located on the eastern coast of Fergusson Island. More recently, Taylor et al. (1999) used sea floor spreading data from the Woodlark Basin to describe the Woodlark Basin opening between 3.6-0.52 Ma accomplishing an anticlockwise rotation about an 
Euler pole located at $9.3^{\circ} \mathrm{S}, 147^{\circ} \mathrm{E}$ at a rate of $4.2^{\circ}$ /Myr. Based on GPS data, the most recent Euler pole for Woodlark-Australia plate motion is located at $10.77^{\circ} \mathrm{S}, 147.92^{\circ} \mathrm{E}$ at a rate of $2.546^{\circ} / \mathrm{Myr}$ (Wallace et al., manuscript in review). The vertical-axis rotation inferred from the paleomagnetic results of this study is within error consistent with all three of these estimates, and indicates that the location occupied by the Amphlett Islands locality has been moving as part of the Woodlark Plate for at least the past $3 \mathrm{Ma}$.
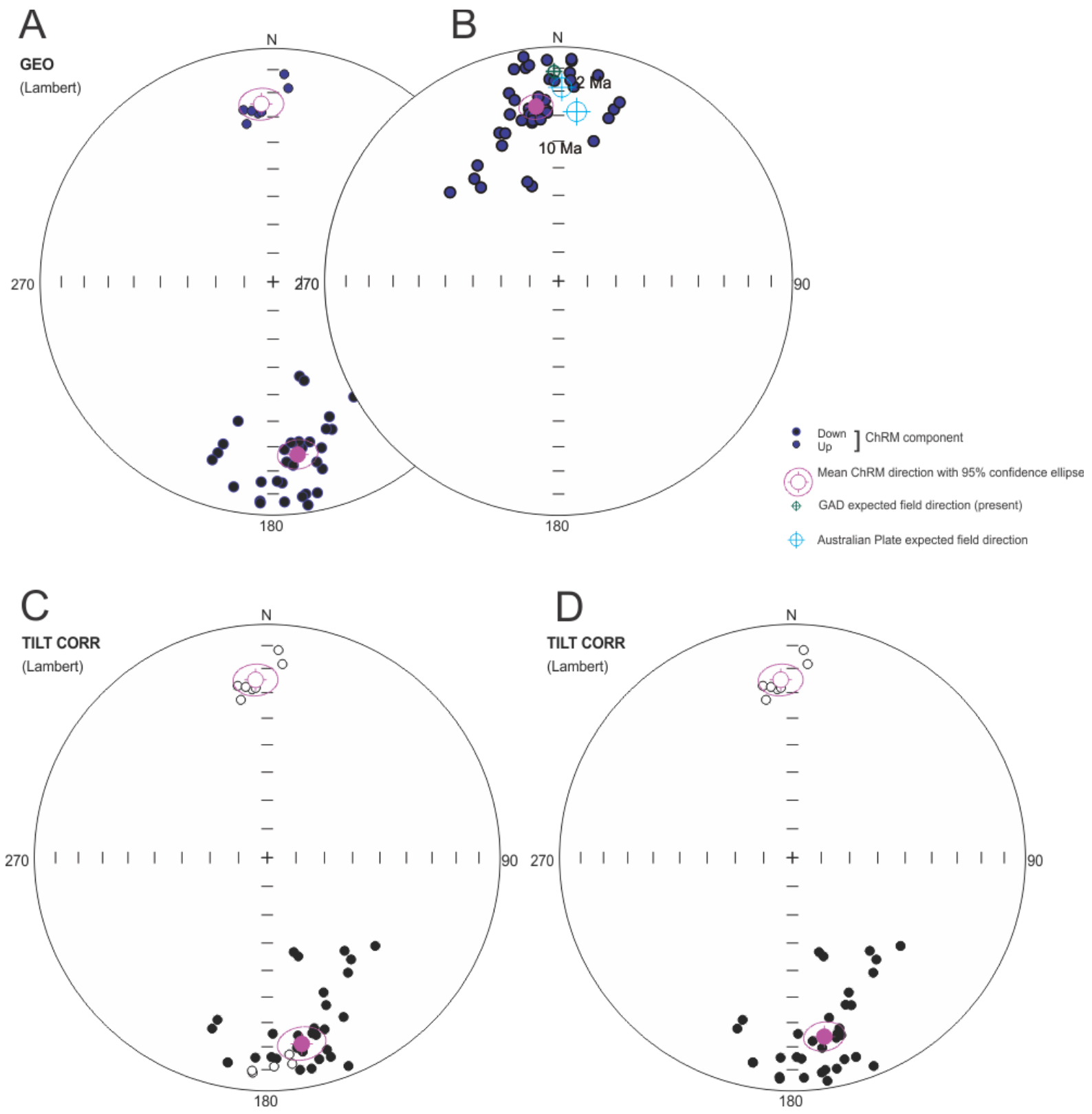

Figure 35. Equal area stereoplots to show distribution of ChRM components, and mean directions (with a95 ellipse) for clusters of normal and reverse directions, resulting from different approaches to structural correction for data from the Amphlett Islands. A) No structural correction applied (approach 4, section 5.2); normal mean: $356.2^{\circ} /-24.6^{\circ} \alpha 95=6.6^{\circ}$, reverse mean: $171.9^{\circ} / 26.1^{\circ} \alpha 95=6.0^{\circ}$. B) Transposed mean of data with no structural correction applied (preferred direction): $352.6^{\circ} /-25.9^{\circ} \alpha 95=5.0^{\circ}$. C) Corrected for SE tilting (approach 1, section 5.2); normal mean: 356.2 $/-24.6^{\circ} \alpha 95=6.6^{\circ}$, reverse mean: $169.5^{\circ} / 19.9^{\circ}$ $\alpha 95=7.0^{\circ}$. D) Corrected all but dike data for SE tiltng (approach 2, section 6.2); normal mean: $356.2^{\circ} /-24.6^{\circ}$ $\alpha 95=6.6^{\circ}$, reverse mean: $169.9^{\circ} / 23.1^{\circ} \alpha 95=6.0^{\circ} . \mathrm{N}=42$ 
Table 13. ChRM components retained for calculation of the Amphlett Islands locality mean direction.

\begin{tabular}{|c|c|c|c|c|c|c|c|}
\hline \multirow[t]{2}{*}{ Specimen ID } & \multirow{2}{*}{$\begin{array}{l}\text { NRM } \\
(\mathrm{A} / \mathrm{m}) \\
\end{array}$} & \multirow{2}{*}{\multicolumn{2}{|c|}{$\begin{array}{c}\text { MDF } \\
\left(\mathrm{mT} /{ }^{\circ} \mathrm{C}\right) \\
\end{array}$}} & \multicolumn{4}{|c|}{ ChRM calculated } \\
\hline & & & & PCA limits & $\operatorname{Dec}\left({ }^{\circ}\right)$ & $\operatorname{lnc}\left({ }^{\circ}\right)$ & $\operatorname{MAD}\left({ }^{\circ}\right)$ \\
\hline AM13A1 & 5.27 & & 436 & $450-600^{\circ} \mathrm{C}$ & 4.5 & -17.9 & 1.7 \\
\hline AM13B1 & 3.66 & & 430 & $450-600^{\circ} \mathrm{C}$ & 3.1 & -11.9 & 2.4 \\
\hline AM15A1 & 1.10 & $>90$ & & $5-90 m T$ & 354.9 & -28.4 & 1.5 \\
\hline AM15A2 & 1.35 & & 470 & $450-600^{\circ} \mathrm{C}$ & 356.1 & -27.9 & 2.9 \\
\hline AM15B1 & 2.02 & & 498 & $300-600^{\circ} \mathrm{C}$ & 350.5 & -32.0 & 1.4 \\
\hline AM15C1 & 1.19 E-1 & & 467 & $450-600^{\circ} \mathrm{C}$ & 350.2 & -26.2 & 3.8 \\
\hline AM15C2 & $1.91 \mathrm{E}-1$ & 32 & & $20-90 \mathrm{mT}$ & 352.8 & -27.1 & 2.6 \\
\hline AM19B1 & $2.95 \mathrm{E}-1$ & & 498 & $250-600^{\circ} \mathrm{C}$ & 168.1 & 8.4 & 5.4 \\
\hline AM19B2 & $3.59 \mathrm{E}-1$ & & 501 & $250-600^{\circ} \mathrm{C}$ & 171.2 & 8.8 & 4.9 \\
\hline AM19C1 & $5.23 \mathrm{E}-1$ & & 511 & $250-600^{\circ} \mathrm{C}$ & 177.4 & 14.8 & 3.6 \\
\hline AM19C2 & $6.14 \mathrm{E}-1$ & & 514 & $250-600^{\circ} \mathrm{C}$ & 178.8 & 15.6 & 3.3 \\
\hline AM19D1 & & & & & 183.4 & 15.2 & 2.6 \\
\hline AM19D2 & & & & & 190.9 & 11.5 & 2.6 \\
\hline AM20B1 & $2.35 \mathrm{E}-1$ & & 454 & $200-600^{\circ} \mathrm{C}$ & 172.2 & 7.8 & 1.7 \\
\hline AM20B2 & 1.74 E-1 & & 456 & $250-600^{\circ} \mathrm{C}$ & 171.1 & 3.6 & 1.9 \\
\hline AM20C1 & $3.06 \mathrm{E}-1$ & 23 & & 0-90mT & 183.4 & 6.5 & 2.5 \\
\hline AM20C2 & 2.70 E-1 & & 457 & $250-600^{\circ} \mathrm{C}$ & 183.3 & 5.7 & 1.5 \\
\hline AM20D1 & 2.47 E-1 & 43 & & 0-90mT & 177.0 & 6.2 & 2.4 \\
\hline AM22D1 & 1.21 & & 444 & $150-600^{\circ} \mathrm{C}$ & 160.1 & 33.4 & 1.3 \\
\hline AM22D2 & 1.04 & & 443 & $350-600^{\circ} \mathrm{C}$ & 167.1 & 30.3 & 3.1 \\
\hline AM22E1 & 1.15 & & 417 & $400-600^{\circ} \mathrm{C}$ & 165.2 & 18.2 & 1.3 \\
\hline AM22E2 & $9.36 \mathrm{E}-1$ & 87 & & $20-90 \mathrm{mT}$ & 175.7 & 23.6 & 1.7 \\
\hline AM22F1 & 1.80 & $>90$ & & $0-90 \mathrm{mT}$ & 170.1 & 28.5 & 1.6 \\
\hline AM22G2 & 1.69 & & 475 & $250-600^{\circ} \mathrm{C}$ & 171.3 & 29.3 & 0.9 \\
\hline $\mathrm{AM} 22 \mathrm{H} 1$ & 1.48 & & 462 & $250-600^{\circ} \mathrm{C}$ & 173.7 & 22.0 & 1.0 \\
\hline $\mathrm{AM} 22 \mathrm{H} 2$ & 2.10 & $>70$ & & 0-70mT & 166.3 & 21.6 & 1.3 \\
\hline AM22I1 & $7.66 \mathrm{E}-1$ & & 416 & $250-600^{\circ} \mathrm{C}$ & 170.8 & 31.2 & 2.1 \\
\hline AM22I2 & 1.08 & & 417 & $0-600^{\circ} \mathrm{C}$ & 176.1 & 28.7 & 1.0 \\
\hline
\end{tabular}

\begin{tabular}{|l|c|c|c|c|c|c|c|}
\hline AM16B1 & 1.44 & & 465 & $400-550^{\circ} \mathrm{C}$ & 129.2 & 39.9 & 1.6 \\
AM16C1 & 1.94 & & 513 & $200-600^{\circ} \mathrm{C}$ & 140.3 & 46.9 & 2.0 \\
AM16C2 & 1.63 & & 534 & $400-600^{\circ} \mathrm{C}$ & 140.5 & 42.8 & 1.6 \\
\hline AM17A1 & $4.17 \mathrm{E}-1$ & & $>350$ & $200-350^{\circ} \mathrm{C}$ & 144.9 & 39.5 & 0.6 \\
AM17B1 & $2.21 \mathrm{E}-1$ & 39 & & $5-90 \mathrm{mT}$ & 158.2 & 32.4 & 2.2 \\
AM17C1 & 1.19 & & $>350$ & $100-350^{\circ} \mathrm{C}$ & 157.3 & 37.4 & 1.0 \\
\hline AM18A1 & 1.61 & & 511 & $250-600^{\circ} \mathrm{C}$ & 164.3 & 55.4 & 1.9 \\
AM18A2 & 1.17 & & 495 & $400-600^{\circ} \mathrm{C}$ & 162.5 & 53.4 & 2.8 \\
AM18C1 & 1.53 & & 266 & $550-600^{\circ} \mathrm{C}$ & 197.9 & 24.0 & 0.4 \\
AM18C2 & 1.20 & & 264 & $550-600^{\circ} \mathrm{C}$ & 197.1 & 28.1 & 2.0 \\
\hline AM23A1 & 2.07 & & 383 & $250-600^{\circ} \mathrm{C}$ & 164.4 & 15.7 & 0.9 \\
AM23B1 & 1.56 & & 399 & $300-600^{\circ} \mathrm{C}$ & 179.9 & 21.8 & 3.7 \\
AM23C1 & 2.59 & & 382 & $400-600^{\circ} \mathrm{C}$ & 190.0 & 12.7 & 8.1 \\
AM23C2 & 1.87 & $>65$ & & $30-65 \mathrm{mT}$ & 158.0 & 4.2 & 3.6 \\
\hline
\end{tabular}




\section{NW Normanby Island Locality (3 Ma)}

\subsection{Geological Setting and Background}

Samples collected near the northwest tip of Normanby Island consist of intermediate composition intrusive rocks that are part of a Quaternary dike swarm in an especially active part of the Woodlark Rift. That dike swarm is part of a late stage of intrusion in the NW Normanby gneiss dome that exhumes eclogite facies rocks, less than $100 \mathrm{~km}$ west of the tip of active sea floor spreading in the Woodlark Basin (Fig. 1).

Dikes of intermediate composition occur near both east and west coasts of the NW tip of Normanby Island, in the D'Entrecasteaux Islands. These dikes occur as part of a swarm of metres-thick dikes that intrude Pliocene felsic orthogneiss and lesser paragneiss and mafic eclogite (Davies, 1971; DesOrmeau et al., 2013). For this study we sampled a dense swarm of dikes on the eastern side of NW Normanby Dome, south of Esa'ala (Fig. 36). Zircons from dikes of this swarm sampled at PNG09-075 and PNG-12-039, within the paleomagnetic sampling area for this study (Fig. 36), yielded CATIMS ages of $1.93 \pm 0.015 \mathrm{Ma}$ and 2.94 Ma respectively (J. DesOrmeau, pers. comm., 2013). U/Pb dating from one other dike sample from the west coast of NW Normanby Island yielded individual zircon ages range of ages between 4 and $2 \mathrm{Ma}$, with a cluster around 3.3 $\mathrm{Ma}$ (J. DesOrmeau, pers. comm., 2013). K/Ar dating (whole rock and K-feldspar) of a dolerite dike and a granodiorite body from the west coast of NW Normanby Island yielded ages of 1.8-1.9 Ma (Baldwin, 1993). I interpret these age data to suggest that these two centres were probably active coevally on either side of the island, and I take $3 \pm 0.5 \mathrm{Ma}$ as a representative age for the dikes sampled in this study.

The Dawson Strait area, surrounding the NW Normanby Island paleomagnetic sampling locality is subject to on-going crustal extension, as evidenced by onshore and offshore faulting, recent-active silicic volcanism, and GPS plate motion observations (Fig. 44). Numerous faults (both active and inactive) have been mapped onshore in the D'Entrecasteaux Islands (Hill, 1994; Little et al., 2007, 2011) and offshore in the Dawson Strait area (Little et al, 2007, 2011; Mutter et al., 1996; Taylor \& Huchon, 2002). Normal faults in the area generally strike E-W, consistent with N-S Pliocene extension in the Woodlark Rift. Active normal faults bound Goodenough, Mailolo and Oitabu Domes, on Goodenough and Fergusson Islands and dip to the north at shallow angles of 30-40 (Little et al., 2007, 2011). Other known structures of significance here, not necessarily active, include the northsouth striking Oredi Shear Zone, dipping to the east where it flanks Oitabu Dome in SE Fergusson Island (Hill, 1994), and the north-south striking Trobriand Transfer Fault (Little et al., 2007) that places upper plate Papuan Ultramafic Body (PUB) ophiolite to the west adjacent to greenschist facies metamorphics in SE Normanby Island to the east (Fig. 44). The seafloor of the north-eastern Woodlark Rift preserves ridges and swales that are likely the expression of east-west striking normal faults, including those in the Moresby Rift to the north of Moresby Seamount, mapped as imaged and drilled by ODP leg 180 (Taylor \& Huchon, 2002). The Dawson Strait area is also host to active volcanism and geothermal activity, associated with extension. Recently active silicic volcanic vents are located on Sanaroa, SE Fergusson, and Dobu Islands (Smith et al., 1977; Catalano, 2012) and active geothermal vents are found within kilometres of the paleomagnetic sampling area on NW Normanby Island. The geochemistry of young peralkaline rhyolite volcanism in the D'Entrecasteaux Islands is interpreted to represent rifting ahead of incipient sea floor spreading in the D'Entrecasteau Islands (Smith, 1982; Zirakparvar, 2012). 
The paleomagnetic sampling locality for this study is located 3km south of the Esa'ala GPS station (Fig. 44), which is estimated to be moving at a rate of $7.5 \mathrm{~mm} / \mathrm{yr}$, to the northeast with respect to the Australian Plate. This direction is anomalously clockwise deflected from the majority of surrounding GPS plate motion vectors, which form a regional pattern of anticlockwise vertical axis rotation with respect to the Australian Plate (Wallace, manuscript in review). 


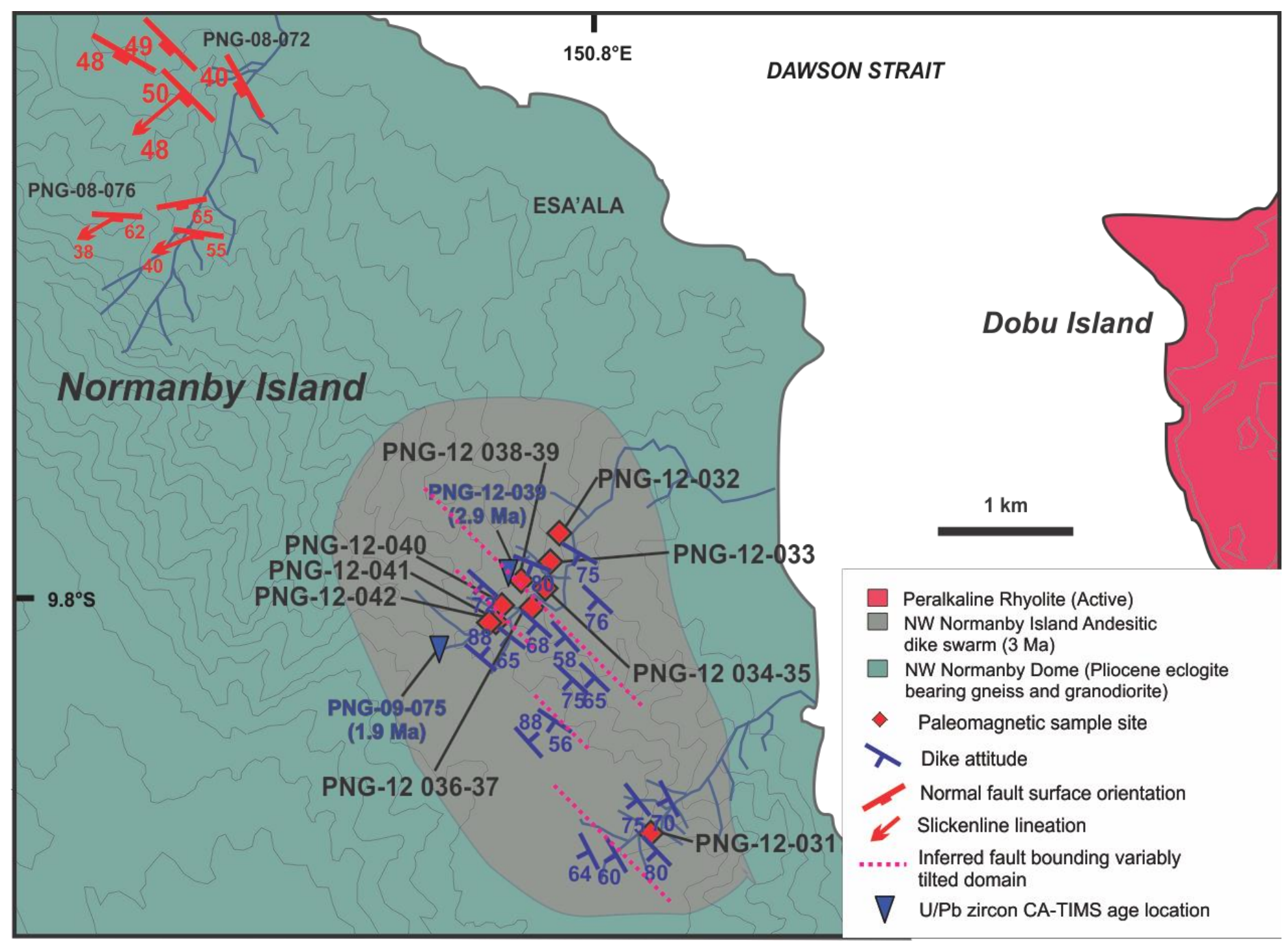

Figure 36. Map of the NW Normanby Island paleomagnetic locality, to show sample locations in the area of the NW Normanby Island dike swarm, as well as structural and age data used in the interpretation of paleomagnetic results. Attitudes of sampled dikes are shown in blue. Normal Faults and striations measured by Little et al (2011) are shown in red, ocated to the northwest of the paleomagnetic sampling area. Pink dashed lines indicate the inferred boundaries of domains interpreted to have undergone variable tilting the northeast, as a result of normal dip slip on southwest dipping faults. Blue inverted triangles show sample locations and are labelled with $\mathrm{U} / \mathrm{Pb}$ zircon age determinations of DesOrmeau et al. (2013). 


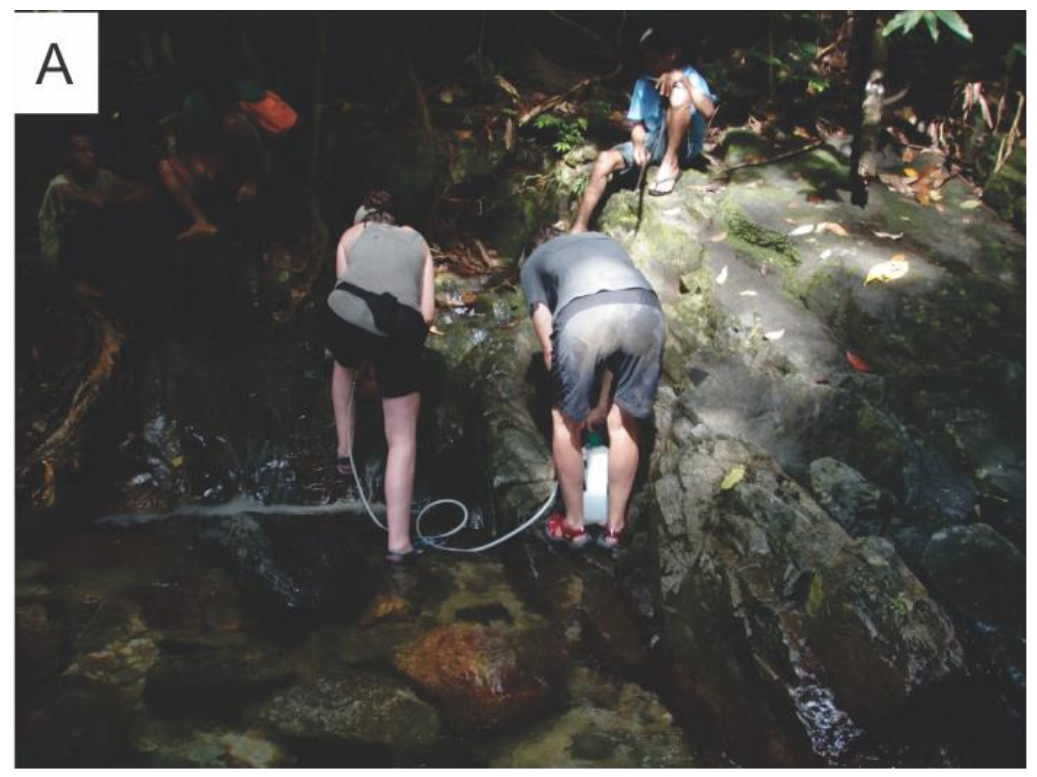

Figure 37. Field Photographs for the NW Normanby Island locality. A) Sample core drilling in progress at a location where one $\sim 5 \mathrm{~m}$ wide dike protrudes into the stream bed, and is intruded by other dikes. B, C, D) Photographs of normal fault surfaces measured at PNG-08-072 and PNG-08-076 to show wide zone of fault breccia indicating significant slip on these surfaces.
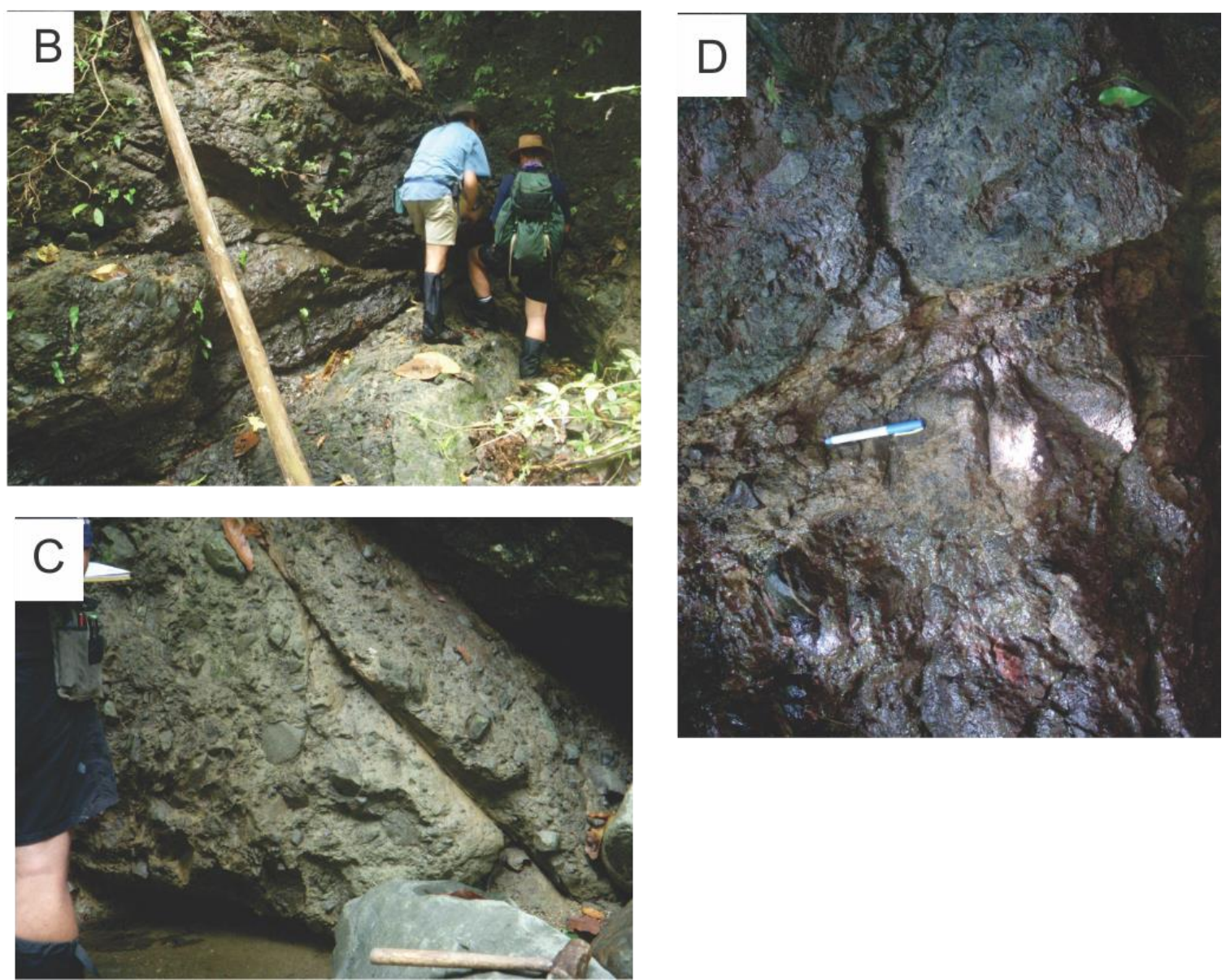

Figure 38. (next page) Photomicrographs of dike samples from NW Normanby Island. All samples are fine grained crystalline rocks. Some vesicles are evident in places. Common to all specimens is amphibole, both green and brown 

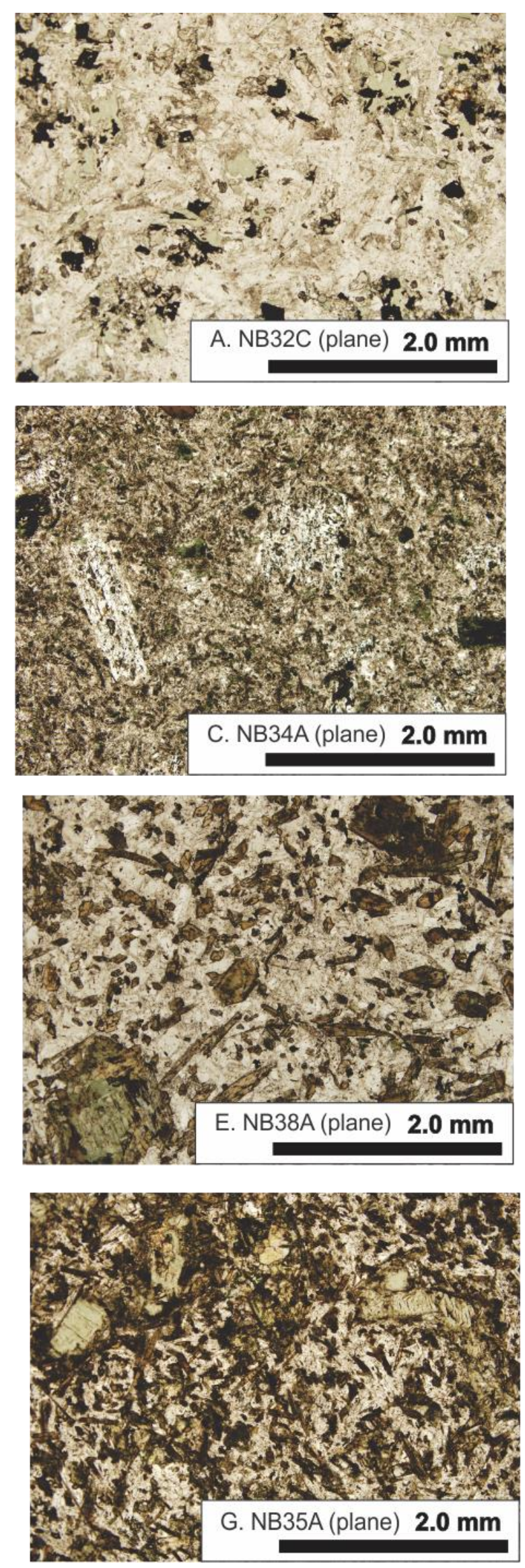
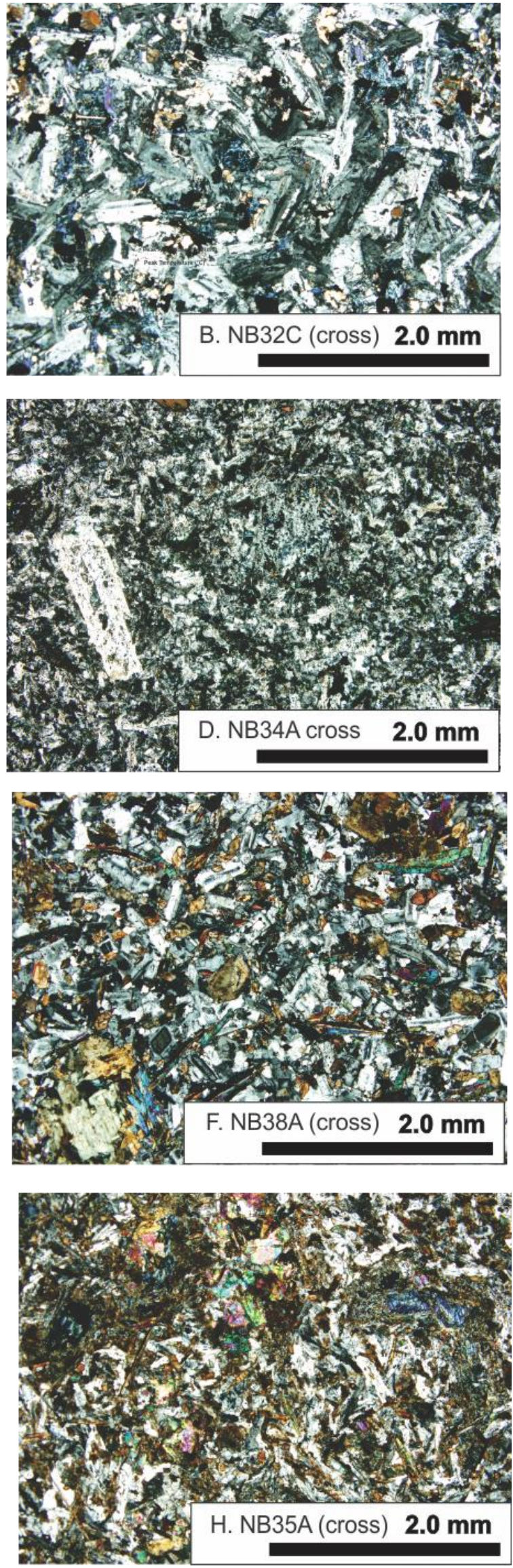


\subsection{Sample Rocks - field relationships, petrography, and inferred structural correction.}

The sample set for this locality consists of 28 oriented core samples that were drilled from 23 dikes of intermediate composition within an area of $3 \mathrm{~km}^{2}$ (Fig. 36). This region is intruded by a lit-par-lit swarm of generally $m$ scale thick dikes that I infer includes individual dikes that have been variably tilted to the northeast as a result of extension by slip on southwest dipping normal faults in this region (Little et al., 2011).

The dikes range in thickness from a few centimetres to several metres, and are found in close proximity to one another (generally within metres). They occur in a dense swarm and commonly intrude each other such that only few screens of original gneissic country rock are present. In several cases we were able to sample several generations of intrusion at one location (Fig. 37A). The dikes have sharp intrusive contacts and distinct chilled margins up to several $\mathrm{cm}$ thick.

The dikes consist of broadly andesitic mineralogy and they have hypabyssal textures (Fig. 38). All sample rocks have a fine grained holocrystalline groundmass dominated by intersertal feldspar. Amphibole, both green and brown, is abundant in all samples. Those grains occur as prismatic igneous phenocrysts or as a fibrous replacement to relict pyroxene (Fig. 38). Brown prismatic amphibole may be contact metamorphic hornblende related to reheating by the adjacent intrusion of younger dikes. Minor biotite can be found in some samples, and opaque mineral grains with diamond habit are inferred to be magnetite series.

The spatial pattern of dike orientations in and around the sample area provides the basis for application of a structural correction. These data suggest the area has been subject to a locally variable degree of tilting as a result of slip on co-existing southwest dipping normal faults (Fig. 36; Fig. 37B-D). There is a northeast-southwest repetition of domains in which some dikes dip as shallowly as $60^{\circ}$ ( $30^{\circ}$ deflected from vertical), and graduate southeast to orientations approaching vertical (Fig. 36). Accepting some natural variation in the orientation of dikes on emplacement, we utilize an assumption that dike $s$ intruded in the shallow crust are preferentially emplaced with vertical attitudes. The variable deviation of dike attitudes from vertical can then be attributed to tilting associated with slip on southwest dipping normal faults, resulting in the deflection of perhaps originally vertical dikes to shallower southwest dips. Figure 36 shows the spatial distribution of dike attitudes as measured in the field (T.A. Little unpub. data, 2003, 2009, 2012). The strike of the dikes is persistently near $130^{\circ}$ in all areas of the dike swarm. This strike is similar to the $135^{\circ}$ mean strike of a set of 4 well exposed fault surfaces measured (by T. A. Little) at site PNG-08-072, where one slickenline pitches at $87^{\circ}$ to the northwest (Fig. 36). Another set of 3 fault surface measurements at site PNG-08-076 have a mean strike of $120^{\circ}$, and they contain slickenlines that pitch at $\sim 50^{\circ}$ to the west (Fig. 36).

For the application of a structural correction to paleomagnetic data we have employed a simple model of variable tilting due to slip on normal faults that strike $135^{\circ}$ and dip to the southwest, using the mean attitude of the 4 measurements at PNG-08-072 as a representative orientation for predominantly dip slip normal faults. Those faults are inferred to bound domains of variable tilting, within which dike attitudes are $0-30^{\circ}$ deflected from vertical. Because measured slickenlines pitch at a high angle to the strike of those faults it is reasonable to infer tilting about a horizontal axis that strikes parallel to the mean fault surface orientation, consistent with rollover in the hanging wall of 
pure dip-slip normal faults. Furthermore, correcting for that inferred rotation would restore the observed fault dips to steeper angles of $54^{\circ}$ to $65^{\circ}$, more consistent with simple Andersonian normal faulting.

I propose three possible approaches to applying a structural correction to paleomagnetic data. Those three approaches are as follows:

1) Assume that the variability of dike dips in the sampled swarm is merely due to natural variability. This first approach represents a scenario involving minimum post-emplacement deformation of the sampled dike swarm, and involves no application of a structural correction to the paleomagnetic data from this site.

2) Assume that the observed normal faulting on NW Normanby Island post-dated intrusion of all sampled dikes, causing a rotation of naturally variable dike attitudes away from the vertical, and that this rotation did not vary from one sample site to another. This approach represents a maximum deformation scenario, where progressive slip on southwest dipping normal faults has resulted in uniform tilting of the sampled dike swarm, as well as the rotation of faults to shallow dips. This approach involves rotating all data about a horizontal axis trending $135^{\circ}$ (parallel to the mean strike of normal faults observed in outcrop) by $15^{\circ}$. That correction reflects both restoration of the mean deviation of all dikes from the vertical, as well as the deviation of fault dips from Andersonian orientations.

3) Assume that the shallowly emplaced dikes were originally vertical, but they have later been subject to a locally variable magnitude of tilting in the hanging walls of southwest dipping normal faults. This approach involves correcting paleomagnetic data by a spatially variable degree of rotation about the above cited horizontal axis $\left(135^{\circ}\right)$. The magnitude of that rotation depends on the mean deviation of dike dips from the vertical at a particular sampling site, or the inferred tilt at a particular sampling site based on its location relative to inferred domain boundaries. 


\subsection{Susceptibility Experiments and Inferred Magnetic Mineralogy}

One successful temperature dependant magnetic susceptibility plot indicates two populations of ferromagnetic grains (Fig. 39). One Curie temperature can be seen at $\sim 250^{\circ} \mathrm{C}$, another more dominant mineralogy is evident in the more significant loss of magnetic susceptibility within a small temperature range approaching $600^{\circ} \mathrm{C}$. This is indicative of a significant population of Fe rich titanomagnetite grains with high blocking temperatures, and lends confidence to the stability of remanent magnetization.
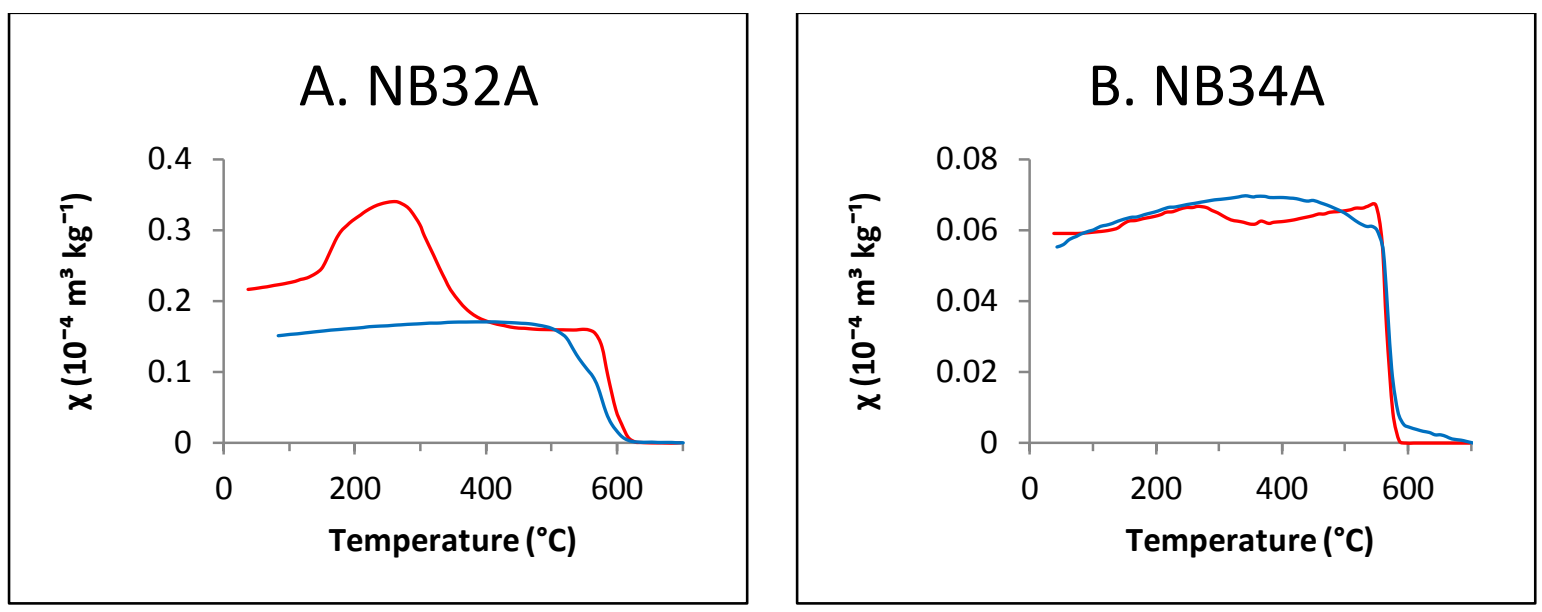

Figure 39. Temperature dependent magnetic susceptibility plots for samples from the NW Normanby Island dike swarm. 


\subsection{Demagnetization Behaviour}

A combination of thermal and alternating field demagnetization procedures were carried out on 34 specimens from the NW Normanby Island dike swarm. Those experiments yielded a range of demagnetization profiles which are largely indicative of between 1 and 3 stable components of thermally acquired ChRM.

The NW Normanby Island dike samples are generally strongly magnetized, with NRM on the order of $10^{-3}$ to $10^{-1} \mathrm{~A} / \mathrm{m}$. Generally the most significant loss of remanence occurs between $450-600^{\circ} \mathrm{C}$, while another less noteworthy blocking temperature population can be seen to demagnetize between $100-350^{\circ} \mathrm{C}$. Figure 40 presents selected demagnetization plots to show the range of demagnetization behaviour characteristic of NW Normanby Island dike samples.

In some samples a single component is removed through the full range of blocking temperatures and coercivities (Fig. 40A, B, G, H), while other samples record several components held in different portions of the blocking temperature spectrum. In several cases, three components can be determined from thermal demagnetization plots of a single sample (e.g. specimen NB31D.1; Fig. 42C). Two specimens from sample core NB31D retain a normal polarity component in the low blocking temperature range $\left(<250^{\circ} \mathrm{C}\right)$, another component of reverse polarity in the intermediate blocking temperature range $\left(250-450^{\circ} \mathrm{C}\right)$, and another normal polarity component at high blocking temperature $\left(450-580^{\circ} \mathrm{C}\right)$. Specimen NB31C.1, from an adjacent dike, also retains a normal polarity component in the low blocking temperature range $\left(<250^{\circ} \mathrm{C}\right)$, with reverse polarity remanence at higher temperature.

In some cases thermal and alternating field demagnetization plots correlate well, in other cases Zijdeveld plots are not compatible between treatments (Fig. 41). The comparison of those treatments illustrates a spectrum of behaviour with respect to low temperature and coercivity components. In some cases components of opposing polarity that are well defined in thermal demagnetization plots are not discernible in alternating field demagnetization plots (Fig. 41A-B); in other cases two components can be well correlated between treatments (Fig. 41C-D); or ChRM components can be seen to agree through high temperature and coercivity demagnetization steps, while early steps produce curvilinear trajectories in one or other treatment (Fig. 41E-F). This range of behaviour indicates that the ferromagnetic mineralogy is variable between dike samples, especially in the lower blocking temperature and coercivity ranges. Curvilinear trajectories in Zijdeveld plots indicate that ferromagnetic mineral grain populations overlap in either the blocking temperature or coercivity spectrum. Where curvilinear trajectories are seen in thermal demagnetization plots they may indicate secondary mineral alteration, given that dikes can be expected to acquire a primary TRM and so characteristic components should be well defined in the blocking temperature spectrum. Directions derived from PCA of low temperature and peak field demagnetization steps is often very near to the present day field direction, which may suggest that magnetically soft grains have been recently (re)magnetized or subject to viscous reorientation. Also, a few samples retain a small remanence that remains past the highest temperature or peak field amplitude demagnetization step undertaken (Fig. 40A, F, H). 

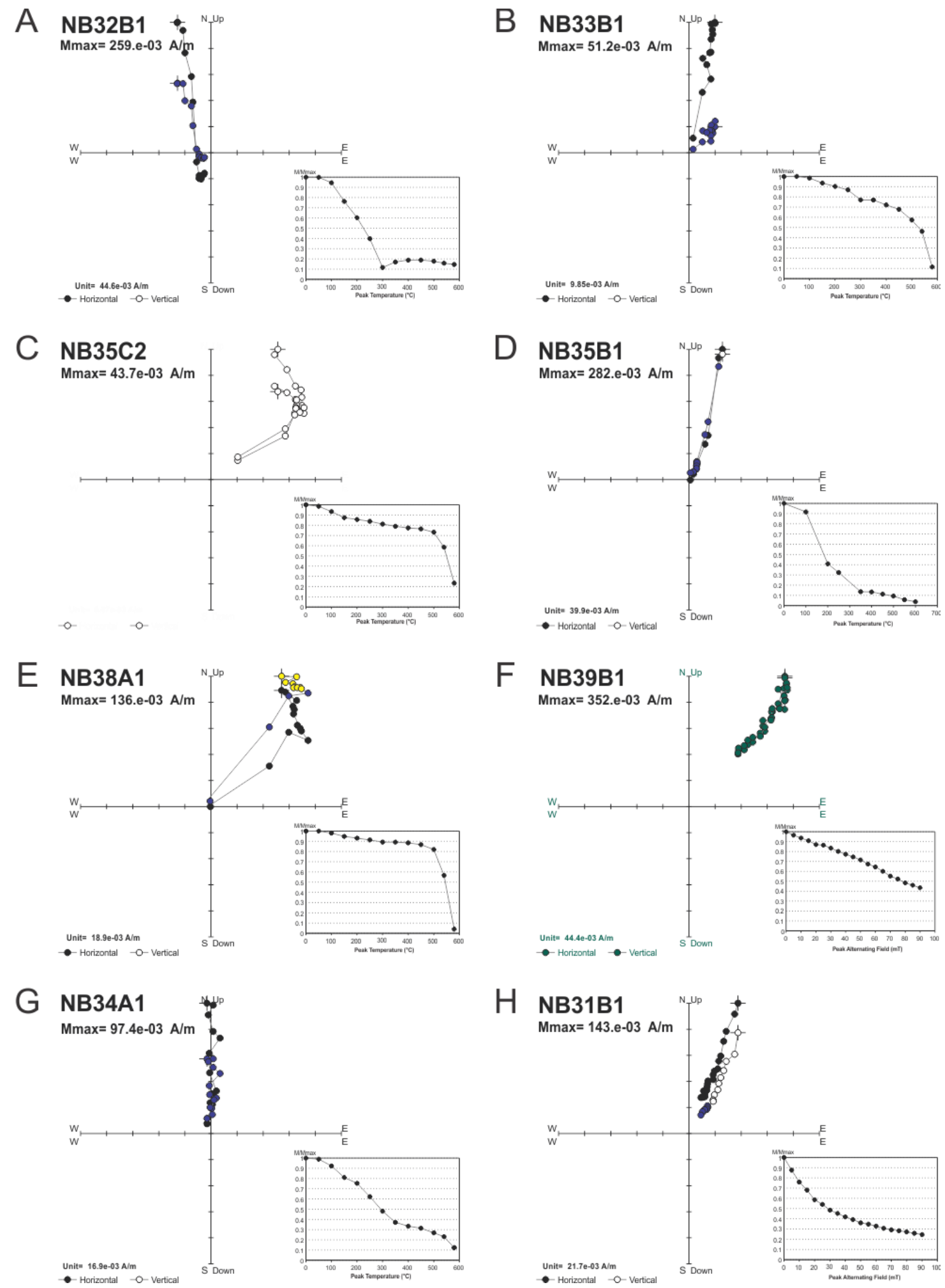

Figure 40. Zijdeveld and module plots for selected specimens to show a range of demagnetization behaviours exhibited by NW Normanby Island dike samples. The measurement points used in PCA calculation of ChRM directions are shown in blue, and measurement points prior to the removal of a secondary remanence are shown in yellow. 

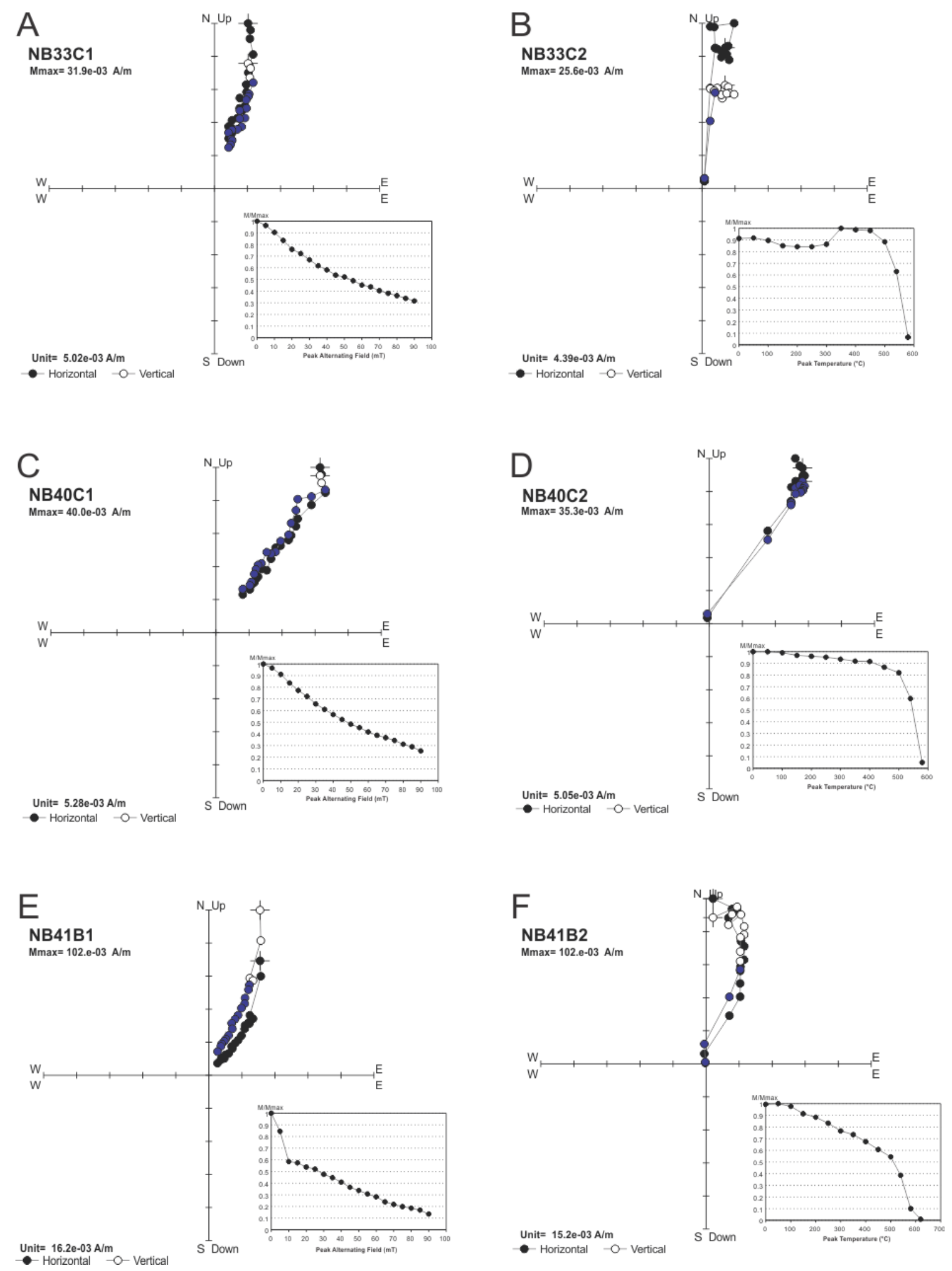

Figure 41. Selected Zijdeveld and module plots for pairs of duplicate specimens (from the same core), to show comparisons of Alternating Field (left) and Thermal (right) demagnetization treatments. The measurement points used in PCA calculation of ChRM directions are shown in blue. 
Mmax $=61.1 \mathrm{e}-03 \mathrm{~A} / \mathrm{m}$

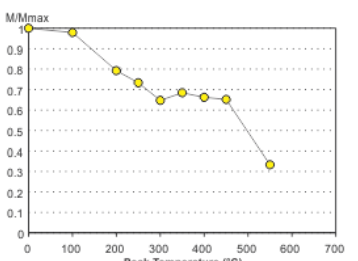

NB31C1 (dike 2)

$\underset{M \max =1.66 \mathrm{e}-03 \mathrm{~A}}{\mathrm{NB}}$

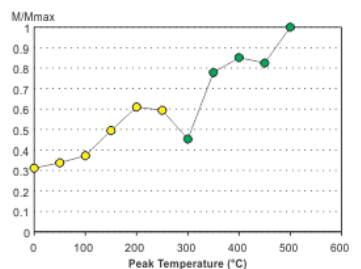

NB31D1 (dike 1)

Mmax $=16.6 \mathrm{e}-03 \mathrm{AIm}$

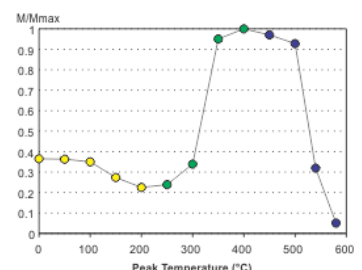

Unit 2970-03A Am
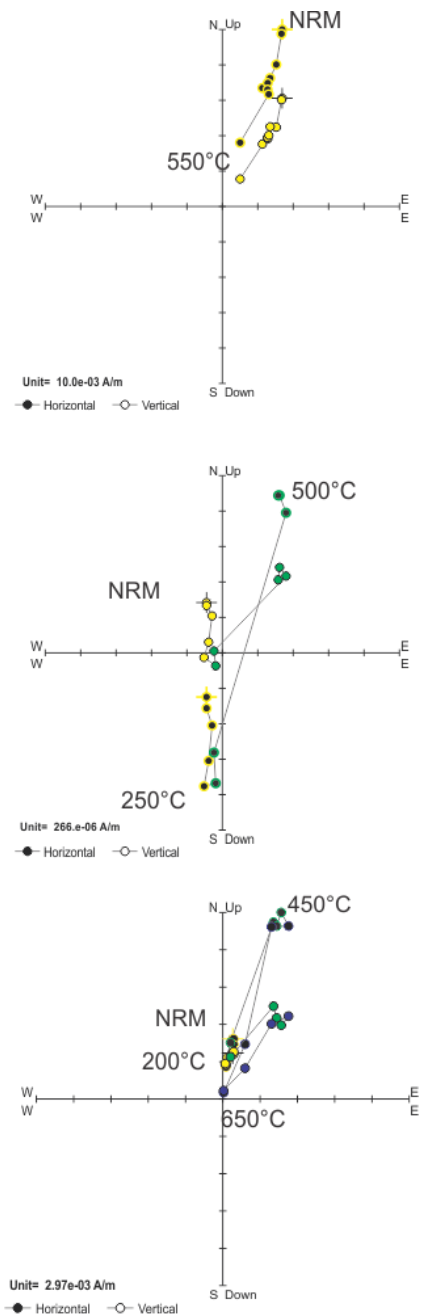

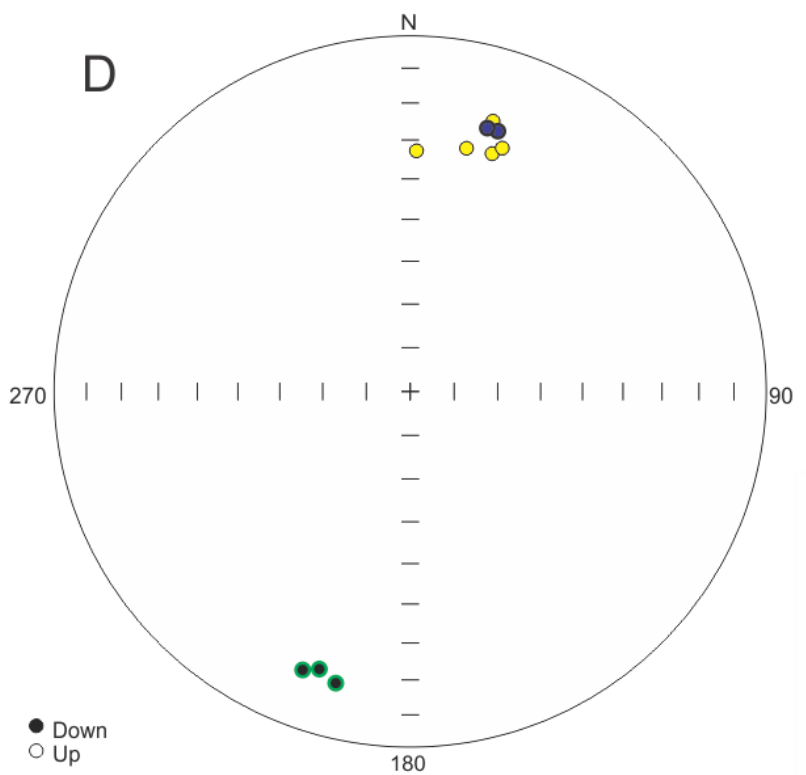

F

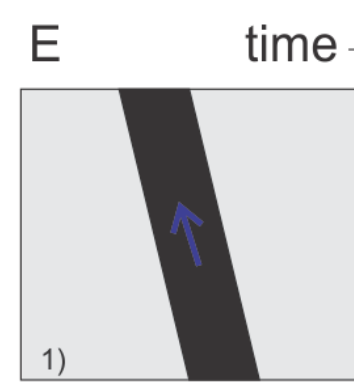

Figure 42. Demagnetization data from different dikes at sample site PNG-12-31, and cartoon to illustrate their interpretation demonstrating a positive baked contact test. A-C: Module and Zijdeveld plots for individual specimens from different dikes retaining between 1 and 3 components

magnetization shown in blue green and yellow. D: Equal area stereoplot to show all PCA components (tilt corrected coordinates) calculated from demagnetization plots of PNG-12-31 samples. Colours indicate correlation of GILBERT $4.18 \mathrm{Ma}$ components based on blocking temperature range.

E: Cartoon to show interpretation of data from sample site PNG-12-31. 1) Dike 1 emplaced at $>650^{\circ} \mathrm{C}$ and magnetized in normal polarity field. 2) Dike 2 emplaced after geomagnetic field reversal, reheating dike $450^{\circ} \mathrm{C}$ and cooling in reverse polarity field. 3) Dike 3 emplaced after another geomagnetic field reversal, reheating dikes $1 \& 2$ to $200-250^{\circ} \mathrm{C}$, and cooling in normal polarity field. F: Late Pliocene to recent geomagnetic polarity timescale after Pouliquen et al. (2001). 


\subsection{Group Statistics, Interpretation, and Tectonic Implications}

From a total of 33 demagnetization profiles 35 ChRM directions have been determined for the NW Normanby Island data set. The 35 intermediate and high temperature components interpreted as ChRM directions are distributed in two clusters of opposing normal and reverse polarity (Fig. 43), which together contribute to the calculation of the preferred paleomagnetic mean direction (Dec: $19.0^{\circ}$, Inc: $-37.7^{\circ}, \alpha 95: 6.3^{\circ} \mathrm{N}=35$ ). Those directions are determined for components that persist through demagnetization steps exceeding at least $200^{\circ} \mathrm{C}$ and up to a peak alternating field of $90 \mathrm{mT}$.

Several approaches have been considered for applying a structural correction to the data. We prefer the third approach outlined in section 6.2 (correction for the local deviation of dikes from the vertical, based on the mean dike attitude at a particular sample site, or its location within a variably tilted domain). Employing this approach to the structural correction of the paleomagnetic data results in the most directionally and statistically favourable mean direction. Prior to the application of any structural correction there are several individual components that are well defined (small $M A D$ ), but have GAD un-interpretable directions in geographic coordinates (positive inclinations corresponding to northerly declinations, or negative inclinations corresponding to southerly declinations). Those components are rotated to reasonable GAD field directions on application of a structural correction. Thus, the first approach to structural correction for this locality (assuming minimum deformation) is rejected in favour of correcting paleomagnetic data for some tectonic tilting. The mean paleomagnetic directions obtained on the basis of all three structural correction approaches have slightly high inclinations compared to the expected Australian Plate direction for this location, but that discrepancy is minimised by employing the third approach (variable southwest tilting of dikes) rather than correcting all data uniformly for $15^{\circ}$ of SW tilting (approach 2; section 6.2). ChRM directions after application of my preferred structural correction are distributed in two clusters of normal and reverse polarity (Fig. 43C) that are antipodal at $95 \%$ confidence, demonstrating a positive reversal test. Furthermore, while the statistical difference is minimal, of the three approaches my preferred structural correction yields the mean direction with the highest degree of precision (Dec: $19.0^{\circ}$, Inc: $-37.7^{\circ}, \alpha 95: 6.3^{\circ} \mathrm{N}=35$ ).

I interpret the paleomagnetic data for the NW Normanby Island locality to demonstrate baked contact magnetizations. Many demagnetization plots of individual Normanby Island dike specimens indicate several remanence components of alternating normal and reverse polarity retained in discrete blocking temperature ranges. I derive particular confidence in the primary thermoremanent nature of ChRM components in this data set, as well as the representative time-averaged nature of the NW Normanby Island paleomagnetic mean direction, from a set of data indicative of baked contacts at sample site PNG-12-31. Figure 42 presents the stepwise thermal demagnetization profiles of individual specimens from 3 different dikes sampled within metres of each other at sample site PNG-12-31. Specimens NB31D.1 and NB31D. 2 contain 3 components of alternating normal-reverse-normal polarity at high-, intermediate-, and low-temperatures respectively. The reverse polarity component that appears to be an intermediate temperature overprint in specimen NB31D.1 is directionally comparable with a reverse polarity remanence that is the most stable component defined in Zijdeveld plot for specimen NB31C.1. A normal polarity remanence removed through low temperature demagnetization of specimens NB31D.1, NB31D.2, and NB31C.1 is directionally comparable with the normal polarity ChRM of specimens NB31A.1 and NB31B.1 that are retained by high coercivity and blocking temperature grains. My preferred interpretation is that 
some dikes contain several generations of partial TRM (pTRM). In this scenario the most stable remanence component is a primary TRM acquired on initial emplacement, and successively lower temperature components represent the acquisition of a pTRM through reheating in the baked contact zone of younger dikes. Because the data from sample site PNG-12-31 records three generations of TRM of alternating normal-reverse-normal polarity, I suggest that emplacement of dikes in the NW Normanby Island swarm spanned at least two geomagnetic field reversals. There are several documented geomagnetic polarity reversals within the 4-2 Ma range of isotopic ages derived from NW Normanby dikes, which serve to support the age assignment and the representative time averaged nature of the paleomagnetic mean direction. The range of isotopic ages from NW Normanby dikes corresponds to the upper-Gauss to lower-Matuyama, normal and reverse polarity chrons (Gee \& Kent, 2007; Pouliquen et al., 2001). Within this time frame there are several candidate geomagnetic events that may be represented in the paleomagnetic data. Given that the majority of ChRM directions are of normal polarity, and reverse polarity components are interpreted as being of intermediate relative age (Fig. 10), it is likely that emplacement of these dikes occurred mainly during the upper-Gauss normal polarity chron. The Mammoth and Kaena reverse polarity events that interrupt the Gauss Chron are dated at 3.3-3.2 Ma, and 3.1-3.0 Ma respectively (Pouliquen et al., 2001). Attributing reverse polarity components to magnetization during either one of these events is consistent with the range of isotopic ages from intermediate dikes of the swarm and reinforces the aforementioned age assignment of $3 \pm 0.5 \mathrm{Ma}$ for the NW Normanby locality based on Zircon $\mathrm{U} / \mathrm{Pb}$ ages. Furthermore, if each of these events lasted 100 ka (Pouliquen et al., 2001), and NW Normanby Island dikes were emplaced either side of at least one of them, this affords sufficient time sampled to average out secular variation. This inference of the time averaged representative nature of the paleomagnetic mean direction for NW Normanby Island is further corroborated by a $\theta 63$ of 20.8 for the preferred mean direction (Fig. 43B).

Paleomagnetic directions derived from NW Normanby Island data yield results that are unequivocally indicative of a significant clockwise rotation with respect to the Australian Plate at this site, during the past 2-3 Ma. The latitude and longitude coordinates of the NW Normanby Island locality are $9.8^{\circ} \mathrm{S}, 150.8^{\circ} \mathrm{E}$. The Geocentric Axial Dipole field direction for those coordinates for the present day, and corresponding to Australian Plate paleomagnetic pole locations at $2 \mathrm{Ma}$ and $10 \mathrm{Ma}$ (Veevers \& Li, 1991) are shown below.

Table 14. Australian Plate GAD field expected directions for the NW Normanby Island Locality

\begin{tabular}{|c|c|c|}
\hline & Declination $\left({ }^{\circ}\right)$ & Inclination $\left(^{\circ}\right)$ \\
\hline Present & 0.0 & -19.1 \\
\hline $2 \mathrm{Ma}$ & $2.7 \pm 5.1$ & $-24.5 \pm 8.7$ \\
\hline $10 \mathrm{Ma}$ & $5.9 \pm 5.3$ & $-34.8 \pm 7.6$ \\
\hline
\end{tabular}




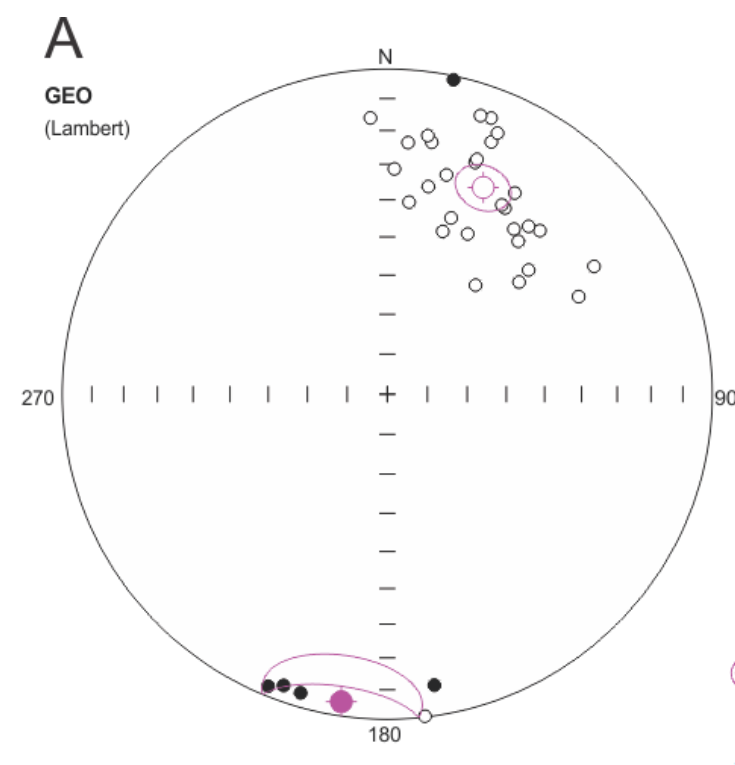

Figure 43. Equal area stereoplots to show distribution of ChRM components, and mean directions (with $\alpha 95$ ellipse) for clusters of normal and reverse directions, resulting from different approaches to structural correction for data from the NW Normanby Island dike swarm. A) No structural correction applied (approach 1, section 6.2); normal mean: $024.9^{\circ} /-30.6^{\circ} \alpha 95=6.3^{\circ}$, reverse mean: $188.5^{\circ} / 4.9^{\circ}$ $\alpha 95=14.9^{\circ}$. B) Corrected for uniform tilting (approach 2, section 6.2); normal mean: $020.5^{\circ} /-44.5^{\circ} \alpha 95=6.3^{\circ}$, reverse mean: $186.7^{\circ} / 16.8^{\circ} \alpha 95=14.9^{\circ}$. C) Corrected for variable tilting (approach 3, section 6.2); normal mean: $021.6^{\circ} /-41^{\circ} \alpha 95=6.2^{\circ}$, reverse mean: $186.9^{\circ} / 16.5^{\circ} \alpha 95=14.4^{\circ}$. D) Transposed mean of data corrected for variable tilting (preferred direction): $19.0^{\circ} /-37.7^{\circ} \alpha 95=6.3^{\circ} . \mathrm{N}=35$

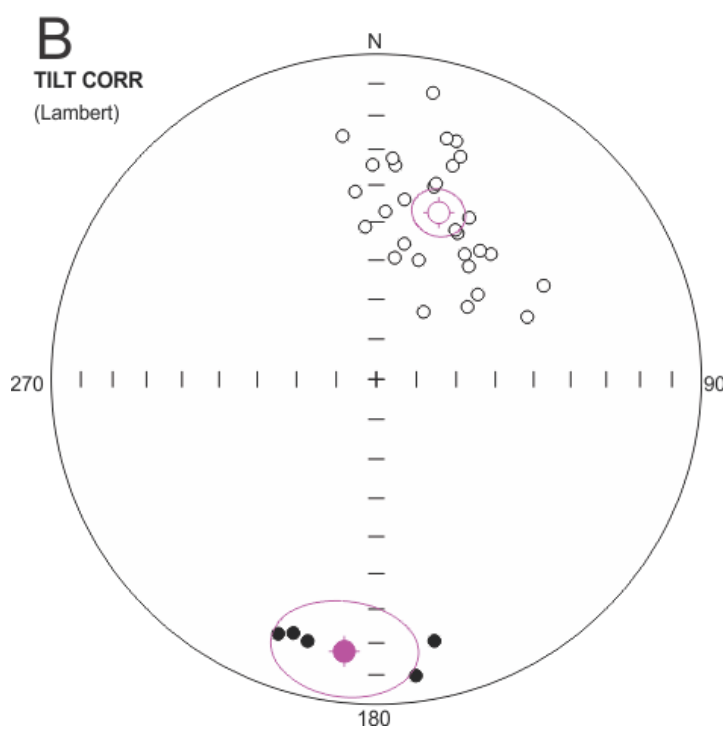

Uown ] ChRM component

(C) Mean ChRM direction with $95 \%$ confidence ellipse

GAD expected field direction (present)

$\oplus$ Australian Plate expected field direction

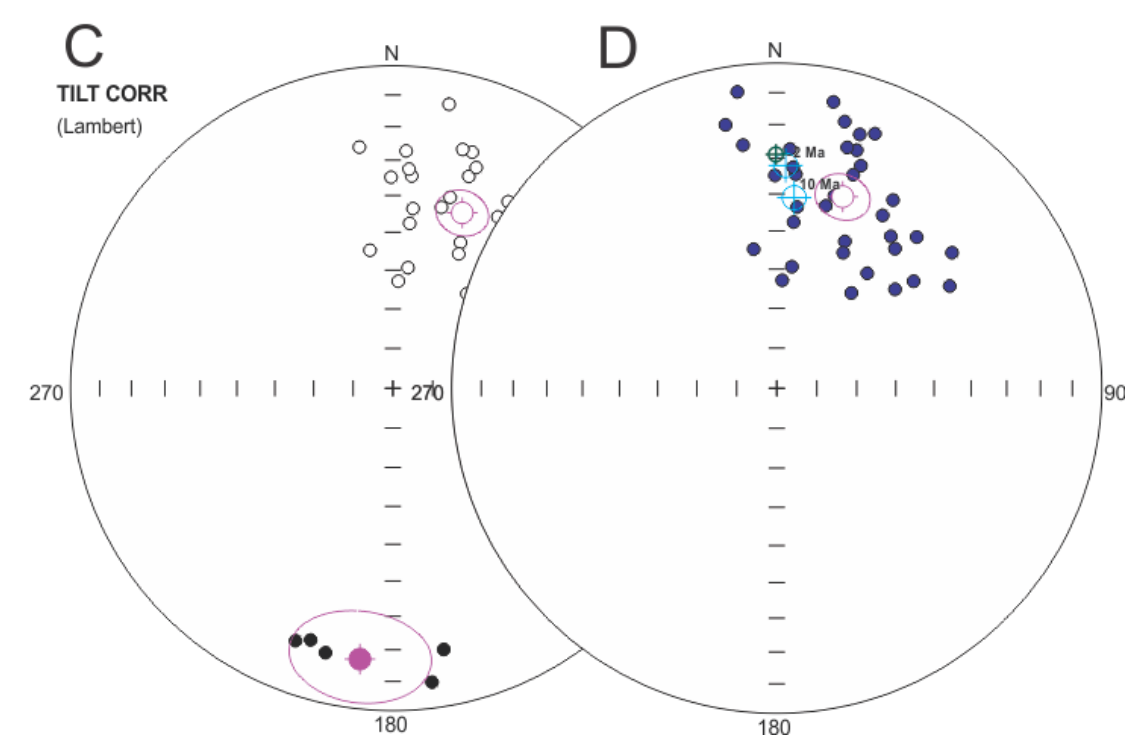


Table 15. ChRM components retained for calculation of the NW Normanby Island dike Swarm mean direction

\begin{tabular}{|c|c|c|c|c|c|c|c|}
\hline \multirow{3}{*}{$\begin{array}{l}\text { Specimen ID } \\
\text { NB31A1 }\end{array}$} & \multirow{3}{*}{$\begin{array}{c}\begin{array}{c}\mathrm{NRM} \\
\left(10^{-3} \mathrm{~A} / \mathrm{m}\right)\end{array} \\
61.1\end{array}$} & \multirow{2}{*}{\multicolumn{2}{|c|}{$\begin{array}{c}\mathrm{MDF} / \mathrm{MDT} \\
\left(\mathrm{mT} /{ }^{\circ} \mathrm{C}\right)\end{array}$}} & \multicolumn{4}{|c|}{ ChRM calculated } \\
\hline & & & & \multirow{2}{*}{$\begin{array}{l}\text { PCA limits } \\
\text { NRM }-450^{\circ} \mathrm{C}\end{array}$} & \multirow{2}{*}{$\frac{\operatorname{Dec}\left({ }^{\circ}\right)}{19.0}$} & \multirow{2}{*}{$\begin{array}{l}\operatorname{Inc}\left({ }^{\circ}\right) \\
-30.0\end{array}$} & \multirow{2}{*}{$\frac{\operatorname{MAD}\left({ }^{\circ}\right)}{4.6}$} \\
\hline & & & 498 & & & & \\
\hline NB31B1 & 143.0 & 28.6 & & $50-90 \mathrm{mT}$ & 20.7 & -27.7 & 2.1 \\
\hline NB31C1 & 0.52 & & & $200-450^{\circ} \mathrm{C}$ & 194.3 & 16.5 & 2.6 \\
\hline NB31D1 & 6.1 & & 560 & $450-580^{\circ} \mathrm{C}$ & 18.6 & -23.8 & 2.8 \\
\hline NB31D1 & 6.1 & & & $250-400^{\circ} \mathrm{C}$ & 201.1 & 17.2 & 5.6 \\
\hline NB31D2 & 11.9 & & & $450-580^{\circ} \mathrm{C}$ & 16.3 & -23.9 & 4.0 \\
\hline NB31D2 & 11.9 & & 554 & $250-450^{\circ} \mathrm{C}$ & 198.1 & 19.0 & 5.4 \\
\hline NB32A1 & 470 & & 216 & NRM $-550^{\circ} \mathrm{C}$ & 5.1 & -34.3 & 2.9 \\
\hline NB32B1 & 259 & & 225 & NRM $-580^{\circ} \mathrm{C}$ & 352.1 & -25.5 & 2.5 \\
\hline NB33A1 & 1.39 & & 566 & $200-450^{\circ} \mathrm{C}$ & 172.4 & 8.9 & 1.9 \\
\hline NB33B1 & 51.1 & & 527 & NRM $-580^{\circ} \mathrm{C}$ & 11.2 & -11.2 & 2.1 \\
\hline NB33C1 & 31.9 & 53.3 & & $15-90 \mathrm{mT}$ & 16.7 & -38.2 & 1.7 \\
\hline NB33C2 & 23.4 & & 552 & $400-580^{\circ} \mathrm{C}$ & 4.2 & -32.4 & 1.9 \\
\hline NB34A1 & 97.4 & & 293 & NRM $-580^{\circ} \mathrm{C}$ & 3.2 & -27.2 & 3.8 \\
\hline NB35A1 & 0.839 & & & $250-400^{\circ} \mathrm{C}$ & 169.0 & 18.6 & 8.6 \\
\hline NB35B1 & 282 & & 182 & $200-600^{\circ} \mathrm{C}$ & 24.9 & -48.8 & 3.9 \\
\hline NB35C1 & 58.5 & & 531 & $300-600^{\circ} \mathrm{C}$ & 59.4 & -38.2 & 2.1 \\
\hline NB35C2 & 43.7 & & 550 & $300-580^{\circ} \mathrm{C}$ & 52.3 & -32.3 & 3.1 \\
\hline NB36A1 & 21.2 & & 521 & $450-580^{\circ} \mathrm{C}$ & 7.1 & -59.1 & 2.3 \\
\hline NB37A1 & 53.8 & 29.8 & & NRM-90mT & 2.9 & -62.8 & 3.6 \\
\hline NB37B1 & 51.7 & & 518 & $450-580^{\circ} \mathrm{C}$ & 350.6 & -54.3 & 2.5 \\
\hline NB38A1 & 136 & & 545 & $450-580^{\circ} \mathrm{C}$ & 52.0 & -45.6 & 3.8 \\
\hline NB39A1 & 131 & & 553 & $500-600^{\circ} \mathrm{C}$ & 38.1 & -59.5 & 2.1 \\
\hline NB39B1 & 352 & 77.9 & & $35-90 \mathrm{mT}$ & 42.8 & -36.8 & 1.5 \\
\hline NB39C1 & 43.3 & & 525 & $400-600^{\circ} \mathrm{C}$ & 50.1 & -50.8 & 1.5 \\
\hline NB40A1 & 58.9 & & 525 & $\mathrm{NRM}-580^{\circ} \mathrm{C}$ & 31.7 & -32.5 & 2.0 \\
\hline NB40B1 & 1.7 & & 176 & $50-540^{\circ} \mathrm{C}$ & 359.5 & -34.9 & 7.6 \\
\hline NB40C1 & 40.0 & 48.0 & & $10-90 \mathrm{mT}$ & 36.9 & -41.2 & 2.1 \\
\hline NB40C2 & 35.3 & & 547 & NRM $-580^{\circ} \mathrm{C}$ & 31.5 & -37.7 & 1.6 \\
\hline NB40D1 & 32.4 & & 549 & NRM $-580^{\circ} \mathrm{C}$ & 40.3 & -43.1 & 2.4 \\
\hline NB41A1 & 43.8 & & 516 & $50-580^{\circ} \mathrm{C}$ & 5.8 & -47.4 & 3.9 \\
\hline NB41A2 & 93.0 & & 513 & $400-620^{\circ} \mathrm{C}$ & 15.0 & -41.5 & 2.4 \\
\hline NB41B1 & 102 & 27.3 & & $15-90 \mathrm{mT}$ & 38.2 & -52.9 & 1.6 \\
\hline NB41B2 & 101 & & 512 & $500-620^{\circ} \mathrm{C}$ & 26.1 & -51.7 & 3.3 \\
\hline NB42A1 & 30.7 & & 581 & $250-620^{\circ} \mathrm{C}$ & 6.4 & -43.3 & 1.5 \\
\hline
\end{tabular}


Comparison of the preferred mean direction (Dec: $19.0^{\circ}$, Inc: $-37.7^{\circ}, \alpha 95: 6.3^{\circ} \mathrm{N}=35$ ) with that expected for the Australian Plate at $2 \mathrm{Ma}$ yields a clockwise declination anomaly of $16.3 \pm 9.5^{\circ}$. While I do favour that direction, the distribution of ChRM directions that contribute to calculation of that mean may illustrate that some post emplacement reorientation has been left uncorrected by structural correction procedures. The steep inclination of corrected mean directions may be explained by a southward tilt $\left(<10^{\circ}\right)$ that has remained uncorrected. The inclination anomaly for the best mean direction is $-13.2 \pm 10.7^{\circ}$, which may also be indicative of southward tilting uncorrected. Also, the spread in the declinations of individual ChRM components appears to follow a small circle about a vertical axis (Fig. 43A), which may be explained by some syn-emplacement vertical-axis rotation. Accepting some uncertainty associated with the degree of southward tilt and synemplacement vertical-axis rotation, all three above mentioned structural correction scenarios similarly yield declination anomalies of $15-20^{\circ}$.

The clockwise rotation observed at this locality is anomalous to the regional pattern of anticlockwise rotation with respect to the Australian Plate in the Woodlark Rift. This demonstrates complexity in the rift structure. Given the known prevalence of E-W striking normal faults on and offshore in the continental rift zone, one possible explanation for the anomalous clockwise rotation that we observe at NW Normanby is the existence of a nearby dextral transfer fault that has caused a clockwise vertical axis rotation in the NW Normanby Island region. Figure 44 shows the proposed Dobu Transfer Fault, attempting to reconcile my interpretation of swath bathymetry with subaerial geology (Davies, 1976), the pattern of interseismic strain accumulation as seen in GPS plate motion vectors (Wallace, manuscript in review), as well as other mapped tectonic structures in the area (Hill, 1994; Little, 2007; Taylor \& Huchon, 2002). The interpretation of a local clockwise vertical-axis rotation of NW Normanby Island relative to Australia as reflecting deformation adjacent to an active dextral transfer fault is appealing for several reasons:

1) The proposed Dobu Transfer Fault follows a prominent N-S striking shelf, which links with the Trobriand Transfer Fault further north (Fig. 44).

2) E-W striking grabens and inferred submarine fault scarps to the north and south of Normanby Island appear dextrally offset by up to $7 \mathrm{~km}$ across the proposed transfer fault (Fig. 44).

3) The proposed fault runs parallel to the GPS vector from Esa'ala, and the velocity gradient between Esa'ala and Salamo GPS observation points is consistent with dextral shear on a N-S striking structure to their east (Fig. 44).

4) The proposed fault location runs near to recent volcanism and geothermal activity at Dobu Island (Fig. 44).

5) The proposed fault location provides a structure to account for the Papuan Ultramafic Body rocks located adjacent to the eclogite bearing NW Normanby Gneiss Dome (Fig. 44).

Clockwise rotation of a crustal block adjacent to a dextral transfer fault presents a space problem; however, in the proximity of rapidly exhumed bodies of partially molten (U)HP metamorphosed continental crust rising as diapirs (Ellis, 2011; Little et al., 2011) as well as active volcanism there is reason to assume sufficient heat flow and malleability to the crust in the Dawson Strait area to mitigate the space problem presented. Furthermore, extension in the Woodlark Rift is often attributed to accommodation by a mobile lower crust, with both elevated Moho and geotherm (Abers, 2002; Kington \& Goodliffe, 2008; Martinez et al., 2001). 
To define the extent of the NW Normanby Island crustal block (Fig. 45E) that is inferred based on these results is challenging. The structures that bound the rotating block should have a sense of slip consistent with the surrounding relative motions. This means that both the northern and southern extents of the block must be bound by extensional structures, and the western boundary must have a strike-slip component. There is a candidate graben to delineate a potential northern boundary of the block. A normal fault bounding the southern margin of the block may help to explain the aforementioned potentially uncorrected southward tilt. The western boundary may correspond to the east dipping Oredi shear zone (Hill, 1994), especially if that boundary curves around to truncate the southern end of the Olologea Shear zone (Fig. 44). Also, the extent of the NW Normanby Island block may be indicated by the spatial extent of volcanism in the Dawson Strait area.

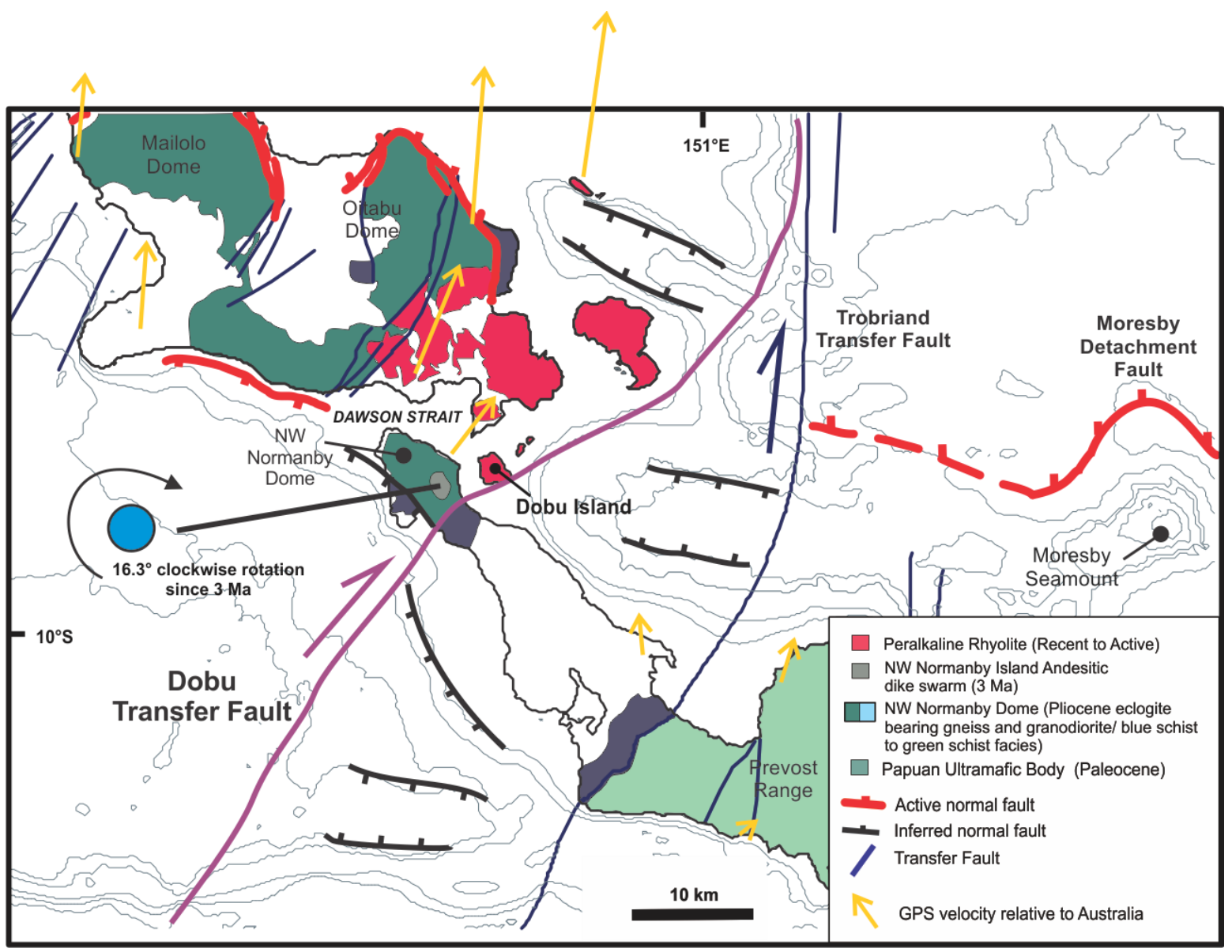

Figure 44. Interpreted map of the Dawson Strait area to show the location of the Proposed Dobu Transfer Fault (this study).Known active normal faults bounding Fergusson Island are after Hill et al. (1994) and Little et al. (2011), and the location of the Moresby Detachment Fault is interpreted from SWATH bathymetry to coincide with Moresby Seamount (after Abers et al., 2001; Taylor \& Huchon, 2002). Transfer faults on Fergusson Island after Hill et al. (1994), and those on Normanby Island, including the Trobriand Transfer Fault after Little et al. (2007). Submarine normal faults are inferred from SWATH bathymetry of Taylor et al. (1999). Bathymetric contours from SWATH are shown at 250m, $500 \mathrm{~m}, 1000 \mathrm{~m}, 1250 \mathrm{~m}$ depth. Contemporary GPS velocities shown are from Wallace et al. (manuscript in review). The $16^{\circ}$ clockwise rotation of NW Normanby Island indicated by 3 Ma paleomagnetic data (this study) informs the inferred location of the Dobu Transfer Fault, coincident with apparent offsets of inferred fault scarps expressed in the sea floor terrain. 


\section{Discussion \& Conclusions}

The tectonic implications of the ChRM directions observed at each of the four paleomagnetic localities in this study are discussed in the previous four chapters. This discussion aims to integrate those observations in the context of the entire Woodlark Rift; and argues that those observations contribute to the research objectives of this study.

As outlined in Chapter 1, the research objectives of this study are: 1) to constrain timing of the onset of extension in the Woodlark Rift, 2) to constrain the spatial extent of Woodlark Rifting through time, and 3) to constrain the sense and rate of vertical-axis rotations of crustal block motions in the Woodlark Rift during the Miocene to Recent.

I demagnetized samples from 40 sites across four paleomagnetic localities in the Woodlark Rift. From 288 demagnetization experiments undertaken, approximately $70 \%$ yielded interpretable results. The components interpreted as ChRM, and used to calculate formation mean directions are generally retained by grains with blocking temperatures and Curie temperatures indicative of magnetically stable titano-magnetite grains. Also, the temperature-dependent magnetic susceptibility is generally reversible in the upper range of grain blocking temperatures, which suggests that the high blocking temperature grains are hardy to thermal alteration. Some thermal alteration was induced in all of the temperature dependent magnetic susceptibility experiments conducted; however, the high temperature portions of heating and cooling curves are generally reversible. That suggests that thermal alteration did not generally affect grains of high blocking temperature $\left(500-600^{\circ} \mathrm{C}\right)$. These grains are inferred as likely to be primary to the sample rocks and sufficiently magnetically stable in order to carry a representative ChRM direction.

For all of the mean directions interpreted as ChRM, the data demonstrate positive fold tests, reversal tests, and/or baked contact tests. Field tests were conducted for all paleomagnetic data in order to test the primary nature of remanence components; and structural corrections also serve to return ChRM directions to their primary orientation. At some sample sites the rocks are poorly bedded, and the degree of tectonic tilting was difficult to ascertain. As a result there may be some degree of tectonic tilting that is left uncorrected; however, the structural corrections applied are generally correcting for shallow dips, and make little difference to the declination of the mean direction. So, directional errors resulting from uncorrected tectonic tilting of sample rocks are small.

All mean directions presented in this thesis are calculated for $95 \%$ confidence, as are the paleomagnetic poles used as an Australian Plate reference frame (Idnurm, 1985; Turner et al., 2007; Veevers \& Li, 1991). Those uncertainties propagate through the calculation of Australian Plate GAD expected field directions, and the calculation of declination anomalies. Thus, the inferred finite vertical-axis rotations presented in this thesis are also at $95 \%$ confidence.

Paleomagnetic data from the Woodlark Rift provide evidence for a Middle Miocene onset of rifting; this is circa 4-10 Myr earlier than has previously been inferred by other workers (Section 7.1). My new results for Early to Late Miocene rocks on the mainland Papuan Peninsula also suggest that the rift initially extended further south than it does now, and that it has since shifted north to where extension is predominantly localised on the Mai'iu Fault along the northern coast of the southeastern Papuan Peninsula (Section 7.2). I find evidence for the Woodlark Rift consisting of 
several blocks up to $200 \mathrm{~km}$ across, each of which has rotated differentially with respect to one another during the Pliocene to Recent (Section 7.3).

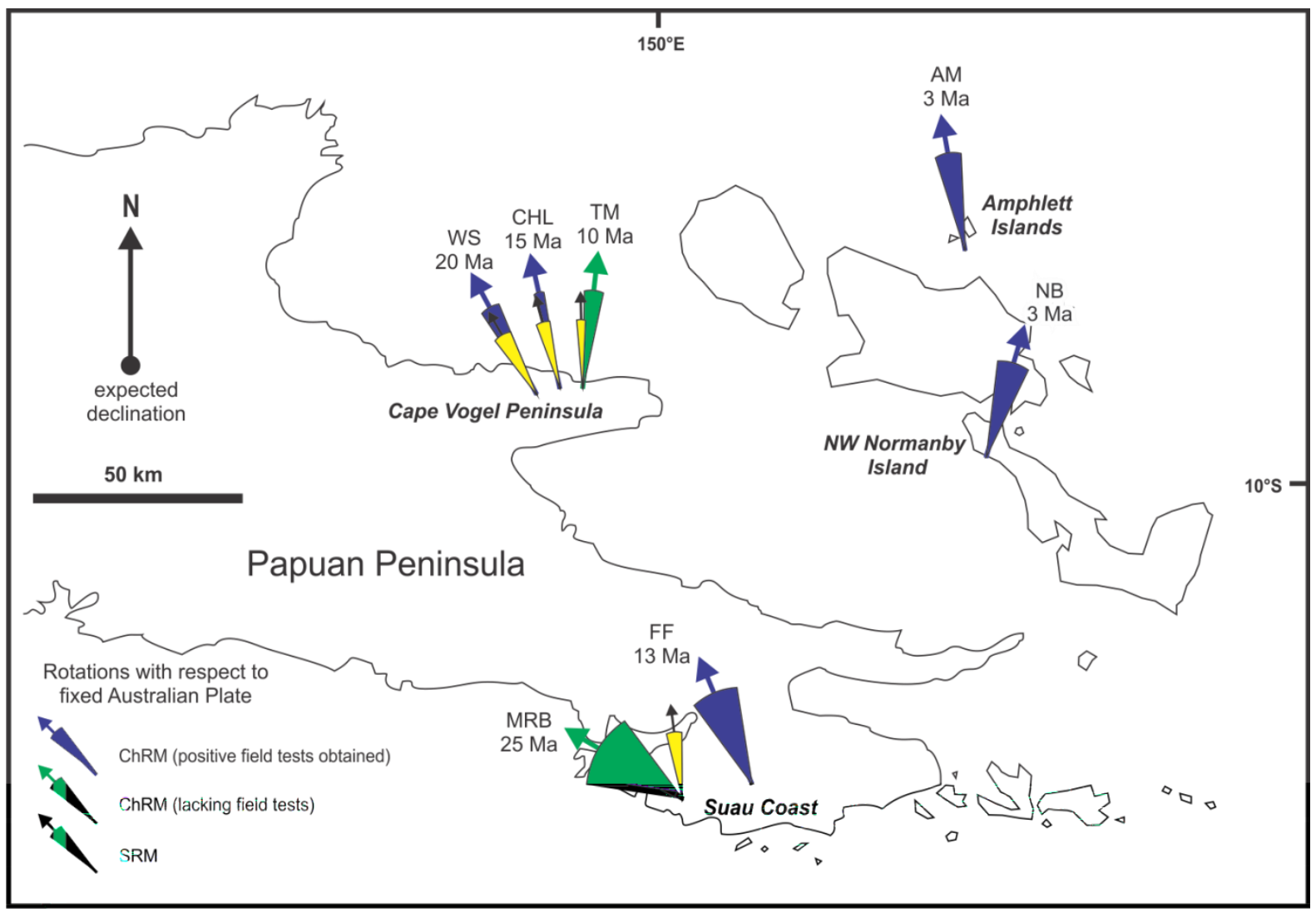

Figure 45. Summary map to show mean ChRM and SRM interpreted directions (Table 16), deflected from north corresponding to declination anomalies with respect to expected GAD field expected directions for the Australian Plate. Blue arrows (and $\triangle R$ wedges) indicate ChRM interpreted mean directions demonstrating one or more positive field test; green arrows (and $\Delta R$ wedges) indicate ChRM interpreted directions lacking positive field tests; yellow arrows (and $\Delta R$ wedges) indicate SRM interpreted mean directions. 
Table 16.Summary table of mean ChRM and SRM directions and corresponding anomalies (Fig. 45) with respect to Australian Plate GAD expected field directions.

\begin{tabular}{|c|c|c|c|c|c|c|c|c|c|c|c|c|c|c|}
\hline Formation/Locality & $\begin{array}{l}\text { Age } \\
\text { (Ma) }\end{array}$ & $\mathrm{N} /$ sites $^{12}$ & Component $^{1}$ & $D_{\text {geo }}{ }^{2}$ & $I_{\text {geo }}{ }^{2}$ & $\alpha_{95}{ }^{2}$ & $D_{\text {tilt }}^{3}$ & $\mathrm{I}_{\text {tilt }}{ }^{3}$ & $\alpha_{95}{ }^{3}$ & Tests $^{4}$ & $D_{\exp }{ }^{5}$ & $I_{\text {exp }} 5$ & $\begin{array}{l}D_{\text {anom }} \pm \Delta R^{6} \\
\text { (95\% confidence) }\end{array}$ & $\begin{array}{l}\mathrm{I}_{\text {anom }} \pm \Delta \mathrm{F}^{6} \\
\text { (95\% confidence) }\end{array}$ \\
\hline \multicolumn{15}{|l|}{ Cape Vogel Peninsula } \\
\hline \multirow[t]{2}{*}{ Woruka Siltstone (WS) } & $20 \pm 3$ & $31 / 4$ & ChRM (Table 4) & $354.6^{\circ}$ & $-16.6^{\circ}$ & $8.7^{\circ}$ & $341.7^{\circ}$ & $-25.2^{\circ}$ & $8.5^{\circ}$ & $F, R$ & $10.1 \pm 5.5^{\circ}$ & $-42.9 \pm 5.7^{\circ}$ & $-28.4 \pm 10.9^{\circ}$ & $17.7 \pm 10.2^{\circ}$ \\
\hline & & $10 / 4$ & SRM ( Table 3) & $349.3^{\circ}$ & $-14.4^{\circ}$ & $12.0^{\circ}$ & $339.8^{\circ}$ & $-19.6^{\circ}$ & $13.0^{\circ}$ & & & & $-30.3 \pm 14.9^{\circ}$ & $23.3 \pm 14.2^{\circ}$ \\
\hline \multirow{2}{*}{$\begin{array}{l}\text { Castle Hill Limestone } \\
(\mathrm{CHL})\end{array}$} & $15 \pm 3$ & $27 / 2$ & ChRM (Table 6) & $359.4^{\circ}$ & $-22.1^{\circ}$ & $4.7^{\circ}$ & $356.4^{\circ}$ & $-20.4^{\circ}$ & $4.5^{\circ}$ & $\mathrm{F}$ & $8.8 \pm 2.6^{\circ}$ & $-32.2 \pm 3.9^{\circ}$ & $-12.4 \pm 5.5^{\circ}$ & $11.8 \pm 6.0^{\circ}$ \\
\hline & & $11 / 2$ & SRM (Table 5) & $359.3^{\circ}$ & $-29.8^{\circ}$ & $9.5^{\circ}$ & $354.1^{\circ}$ & $-22.7^{\circ}$ & $10.5^{\circ}$ & & & & $-14.7 \pm 11.7^{\circ}$ & $9.5 \pm 11.2^{\circ}$ \\
\hline \multirow[t]{2}{*}{ Tapio Marl (TM) } & $10 \pm 3$ & $14 / 3$ & ChRM (Table 8) & $12.3^{\circ}$ & $-31.8^{\circ}$ & $8.4^{\circ}$ & $9.3^{\circ}$ & $-28.5^{\circ}$ & $9.6^{\circ}$ & $\mathrm{R}$ & $5.8 \pm 5.3^{\circ}$ & $-34.8 \pm 7.6^{\circ}$ & $6.5 \pm 11.2^{\circ}$ & $3.0 \pm 11.3^{\circ}$ \\
\hline & & $29 / 3$ & SRM (Table 7) & $4.5^{\circ}$ & $-32.1^{\circ}$ & $4.4^{\circ}$ & $1.8^{\circ}$ & $-26.9^{\circ}$ & $5.7^{\circ}$ & & & & $-1.3 \pm 7.4^{\circ}$ & $2.7 \pm 8.8^{\circ}$ \\
\hline \multicolumn{15}{|l|}{ Suau Coast } \\
\hline \multirow{2}{*}{$\begin{array}{l}\text { Modewa River Beds } \\
\text { (MRB) }\end{array}$} & $25 \pm 5$ & $12 / 2$ & SRM (Table 10) & $3.1^{\circ}$ & $-31.4^{\circ}$ & $4.0^{\circ}$ & $352.9^{\circ}$ & $-17.4^{\circ}$ & $7.1^{\circ}$ & & $10.2 \pm 5.6^{\circ}$ & $-44.0 \pm 6.4^{\circ}$ & $-7.1 \pm 6.7^{\circ}$ & $12.6 \pm 7.5^{\circ}$ \\
\hline & & $7 / 2$ & $\mathrm{ChRM}^{11}$ & $311.0^{\circ}$ & $-52.0^{\circ}$ & $13.2^{\circ}$ & $304.6^{\circ}$ & $-30.9^{\circ}$ & $17.3^{\circ}$ & $\mathrm{R}$ & & & $-59.2 \pm 22.4^{\circ}$ & $8.0 \pm 14.7^{\circ}$ \\
\hline Fife Bay Volcanics (FF) & 12.6 & $18 / 6$ & ChRM (Table 11) & $343.7^{\circ}$ & $-9.1^{\circ}$ & $12.8^{\circ}$ & $343.5^{\circ}$ & $-12.2^{\circ}$ & $12.2^{\circ}$ & $\mathrm{F}$ & $5.8 \pm 5.3^{\circ}$ & $-36.1 \pm 7.4^{\circ}$ & $-22.7 \pm 13.3^{\circ}$ & $23.9 \pm 14.2^{\circ}$ \\
\hline Amphlett Islands (AM) & $3 \pm 0.5$ & $42 / 9$ & ChRM (Table 13) & $352.6^{\circ}$ & $-25.9^{\circ}$ & $5.0^{\circ}$ & $\begin{array}{l}{ }^{\prime} 350.6^{\circ} \\
851.0^{\circ}\end{array}$ & $\begin{array}{l}-20.7^{\circ} \\
-23.4^{\circ}\end{array}$ & $\begin{array}{l}5.9^{\circ} \\
5.1^{\circ}\end{array}$ & $\mathrm{R}$ & $2.7 \pm 5.1^{\circ}$ & $-23.6 \pm 8.8^{\circ}$ & $-10.1 \pm 7.6^{\circ}$ & $-2.3 \pm 10.1^{\circ}$ \\
\hline $\begin{array}{l}\text { NW Normanby Island } \\
\text { (NB) }\end{array}$ & $3 \pm 0.5$ & $35 / 12$ & ChRM (Table 15) & $22.2^{\circ}$ & $-27.0^{\circ}$ & $6.5^{\circ}$ & $\begin{array}{l}{ }^{9} 18.0^{\circ} \\
10 \quad 19.0^{\circ}\end{array}$ & $\begin{array}{l}-40.7^{\circ} \\
-37.7^{\circ}\end{array}$ & $\begin{array}{l}6.5^{\circ} \\
6.3^{\circ}\end{array}$ & $\begin{array}{l}R, B \\
F, R, B\end{array}$ & $2.7 \pm 5.1^{\circ}$ & $-24.5 \pm 8.7^{\circ}$ & $\begin{array}{l}15.3 \pm 10.0^{\circ} \\
16.3 \pm 9.5^{\circ}\end{array}$ & $\begin{array}{l}-16.2 \pm 10.9^{\circ} \\
-13.2 \pm 10.7^{\circ}\end{array}$ \\
\hline
\end{tabular}

Notes: 1) Characteristic Remanent Magnetization (CHRM) interpreted as primary (shown in bold italics), or Secondary Remanent Magnetization (SRM) interpreted as overprint; 2) Mean direction calculated from PCA components prior to structural correction; 3) Mean direction calculated from PCA components corrected for bedding tilt; 4) Positive field tests obtained for ChRM mean directions (F: informal fold test meaning $\alpha 95$ is reduced on application of structural correction, R:reversal test, B: baked contact test); 5) Expected GAD field direction for sample location corresponding to Australian Plate paleomagnetic pole positions (Veevers \& Li, 1991, Turner et al., 2007) at time of rock formation; 6) Declination and Inclination anomalies (observed- expected) with $\triangle R$ and $\Delta F$ (Butler, 1992) for preferred directions (shown in bold italics), calculated with respect to Australian Plate GAD expected field directions; 7) structural correction approach 1, section 5.2, 8) structural correction approach 2, section 5.2, 9) structural correction approach 2, section 6.2, 10) structural correction approach 3, section 6.3; 11) Components tentatively interpreted as ChRM, as distinct from secondary overprint; 12) N/sites: Number of components included in calculation of mean direction, across number of sample sites (pertaining to application of structural correction). 


\subsection{An Early Stage of Rifting}

The onset of rifting in the Woodlark Rift is generally thought to be marked by a regionally extensive erosion surface that was inundated at $8.4 \mathrm{Ma}$ (Taylor \& Huchon, 2002). Paleomagnetic data from Early to Late Miocene rocks sampled at Cape Vogel Peninsula and the Suau Coast, on the Papuan Peninsula, indicate that an anticlockwise vertical-axis rotation began there at some time between the Early and Middle Miocene. Based on these data, rift onset is inferred to have taken place at $15 \pm$ $3 \mathrm{Ma}$, circa $7 \mathrm{Myr}$ earlier than has generally been inferred by other workers. The Early Miocene Woruka Siltstone and Middle Miocene Castle Hill Limestone at Cape Vogel Peninsula yield declination anomalies relative to Australia of $28.8 \pm 14.0^{\circ}$ and $12.4 \pm 7.1^{\circ}$, respectively. The difference between those declination anomalies indicates that an anticlockwise vertical-axis rotation of these Cape Vogel Peninsula sites with respect to the Australian Plate began by the Middle Miocene. This rotation may be attributed to the onset of rifting of the Papuan Peninsula away from the Australian Plate along a plate boundary zone (rift margin) located further south. The relative declination anomalies of the above two formations at Cape Vogel Peninsula indicates an incremental anticlockwise vertical-axis rotation of $16.4 \pm 21.1^{\circ}$ relative to the Australian Plate took place between the Early and Middle Miocene, between deposition of the Woruka siltstone and the Castle Hill Limestone. Tentatively interpreted results for the Modewa River Beds and Fife Bay Volcanics at the Suau Coast on the opposite side of the Papuan Peninsula also suggest an anticlockwise verticalaxis rotation with respect to the Australian Plate between the Early and Middle to Late Miocene. The similarity in the magnitude of these rotations may reflect an early phase of Woodlark Rifting that encompassed the entire N-S width of the Papuan Peninsula (Fig. 45D), or was localised entirely south of it.

At the same time, the pattern of subsidence to the north and south of the uplifting Papuan Peninsula seems consistent with thermal expansion in an E-W striking rift (Fig. 45D). To the south of the Papuan Peninsula during the Middle to Late Miocene, the Coral Sea Basin as well as the Queensland and Marion Plateaux experienced elevated rates of subsidence (DiCaprio et al., 2010; Mutter, 1977; Wang \& Stein, 1992; Wilson \& Hall, 2010); and the Coral Sea Basin received an influx of terrigenous sediment from a Papua New Guinea source (Mutter, 1977). To the north of the Papuan Peninsula, the Trobriand Basin was also subsiding and accumulating sediment eroded from a terrigenous source (Fitz \& Mann, 2013). Late Miocene volcanism on the Papuan Peninsula became increasingly subaerial with uplift and exposure (Smith, 1982). Those Late Miocene volcanic rocks in southeast Papua New Guinea have trace element compositions that are suggestive of subduction related volcanism, but may also be explained by the interaction of melts with continental rocks (Catalano, 2012; Smith, 1982; Taylor et al., 1995).

The Cape Vogel Peninsula is inferred to have undergone $16^{\circ}$ of anticlockwise vertical-axis rotation relative to Australia, between the Early and Middle Miocene. The Cape Vogel Peninsula is located $300 \mathrm{~km}$ to the east of the 3.6-0.5 Ma Euler pole location of Taylor et al. (1999) for WoodlarkAustralia Plate motion (Fig. 2). If the Middle to Late Miocene phase of extension was governed by the same Euler Pole rotation that has resulted in Pliocene to Recent sea floor spreading in the Woodlark Basin (Taylor et al., 1999, see Fig. 2), the amount of N-S crustal extension necessary to account for the above-mentioned Early to Middle Miocene vertical-axis rotation would be approximately $80 \mathrm{~km}$. 


\subsection{Reorganisation of the Rift to the Pliocene Configuration}

Prior to the Late Miocene, Woodlark-Australia Plate motion may have been accommodated across a relatively large and unbroken zone of diffuse N-S extension. Since that time, this zone has localized north of the Papuan Peninsula and fragmented into several blocks that rotate differentially with respect to one another within the Woodlark Rift. Paleomagnetic results for Miocene rocks at the Cape Vogel Peninsula and the Suau Coast suggest that relatively uniform anticlockwise vertical-axis rotations with respect to the Australian Plate affected the entire Papuan Peninsula between the Early and Late Miocene. Subsequent to that time, clockwise vertical-axis rotations relative to Australia of $11.8 \pm 8.4^{\circ}$, for the Late Miocene Tapio Marl at Cape Vogel Peninsula, and $16.3 \pm 11.4^{\circ}$ for the $3 \mathrm{Ma}$ dike swarm at NW Normanby Island, have occurred within the Woodlark Rift. Those younger rotations are in stark contrast to the $4.2^{\circ} \mathrm{Myr}$ anticlockwise rotation of the Woodlark Plate relative to Australia derived from magnetic anomalies in the Woodlark Basin (Taylor et al., 1999). This means that the Pliocene Euler pole kinematics that describe oceanic spreading in the Woodlark Basin since $6 \mathrm{Ma}$ are not valid to extend into the zone of continental extension in the Pliocene Woodlark Rift ahead of the western tip of active sea floor spreading. I speculate that an early stage of rifting, during the Middle to Late Miocene, was characterised by a wide zone of diffuse extension where vertical-axis rotations were more akin to the current Euler pole kinematics of the Woodlark Basin Sea Floor spreading centre since $6 \mathrm{Ma}$, and a shift towards the current organisation of differentially rotating crustal blocks occurred around the Late Miocene to Early Pliocene.

The Late Miocene to Early Pliocene was certainly a time of reorganisation in the Woodlark Rift. The 8.4 Ma inundation surface that has generally been ascribed to the onset of extension in the Woodlark Rift was formed over a large area (Fitz \& Mann, 2013; Taylor \& Huchon, 2002). Fitz and Mann (2013) suggest that a short phase of compression in the Late Miocene resulted in the dip-slip inversion of normal faults in the Trobriand Basin; and preceded the initiation of the Mai'iu Normal Fault, which resulted in rapid hanging wall subsidence of the Goodenough Basin during the Pliocene (Fitz \& Mann, 2013). At some time around the Late Miocene, the anticlockwise vertical-axis rotation relative to Australia that was underway at Cape Vogel Peninsula changed sense, resulting in a clockwise deflected declination anomaly for the Tapio Marl. That change may be associated with a northward jump of the southern margin of the rift to its current position near the Mai'iu Fault. It may date the onset of rapid slip on the Mai'iu Normal Fault. A clockwise sense of rotation of that fault's hanging wall is expectable because it has an along-strike gradient in slip rate (increasing the NW), as documented by Mann \& Taylor (2002). Prior to that Late Miocene change, the correlation of Early to Middle Miocene paleomagnetic data from the Suau Coast and Cape Vogel Peninsula suggest that the Woodlark Rift encompassed the entire width of the current Papuan Peninsula; and that a reorganisation in the Late Miocene involved a recapture of the Suau Coast by the Australian Plate.

\subsection{Pliocene to Recent Rotations of Crustal Blocks in the Woodlark Rift}

A $10.1 \pm 7.6^{\circ}$ anticlockwise vertical-axis rotation of the Amphlett Islands with respect to Australia, since $3 \mathrm{Ma}$, is consistent with the rates of sea floor spreading in the Woodlark Basin since the Late Pliocene (Taylor et al., 1999). This indicates that the Amphlett Islands are situated on a stable part of the Woodlark Plate (Fig. 45E). Given that inference, and the presence of active north-dipping normal faults that bound the northern D'Entrecasteaux Islands (Hill, 1994; Little et al, 2011), the current northern margin of the Woodlark Rift is probably near the northern coasts of the D'Entrecasteaux Islands, and may be coincident with the north dipping normal faults that bound gneiss domes. 
Paleomagnetic data indicate there has not been significant southward tilting of volcanic strata on the Amphlett Islands, towards those north dipping normal faults. Similarly, Formation Micro-Scanner (FMS) analysis of cores from the northern drill sites of ODP leg 180 also find no evidence for tectonic tilt since $3 \mathrm{Ma}$, at a location north of the rift (Celerier et al., 2002). So, a lack of southward tilting at the Amphlett Islands, correlated with other flat lying strata north of the rift, is additional evidence to support the inference of the Amphlett Islands being located on a stable part of the Woodlark Plate.

The clockwise vertical-axis rotations with respect to Australia that are observed for the Late Miocene rocks at Cape Vogel Peninsula, and for 3 Ma dikes at NW Normanby Island, inform my interpretation of Pliocene to Recent crustal block rotations within the Woodlark Rift. The inferred clockwise vertical-axis rotations relative to Australia of $11.8 \pm 8.4^{\circ}$ for the Cape Vogel Peninsula (since Late Miocene) and $16.3 \pm 11.4^{\circ}$ at NW Normanby Island (since $3 \mathrm{Ma}$ ), are consistent with these localities occupying the hanging wall block of the Mai'iu Fault, which has an along strike gradient in slip rate to result in a clockwise vertical-axis rotation of the Goodenough Bay Block (Fig. 45E) in its hanging wall. The rapid rotation at NW Normanby Island has led me to propose the existence of a previously unmapped dextral transfer fault running northeast-southwest through the narrowest part of NW Normanby Island (Fig. 44), that has superimposed a further clockwise vertical axis rotation relative to Australia on the NW Normanby Island Block (Fig. 45E), to the NE of Goodenough Bay. Named the Dobu Transfer Fault, this structure may extend south onto the mainland Papuan Peninsula. The southward trajectory of the proposed Dobu Transfer Fault trace (Fig. 45E) coincides with where the Mai'iu Normal Fault trace intersects the north coast of the Papuan Peninsula. It may also continue further inland to coincide with the western edge of the Milne Bay graben (Fig. 45E). To the north of the Woodlark Rift, the fault scarp is inferred to follow a steep N-S striking shelf edge that extends between approximately $8.5^{\circ} \mathrm{S}$ and $9.5^{\circ} \mathrm{S}$. This same bathymetric feature has previously been interpreted as delineating the trace of the Trobriand Transfer Fault of Little et al. (2007). It is possible that the Dobu Transfer Fault is another incarnation of the same accommodation of differential extension in the eastern Woodlark Rif as the Trobriand Transfer Fault.

The pattern of GPS velocities in the Woodlark Rift (Wallace et al., manuscript in review) suggests the same sense of apparent vertical-axis rotation with respect to Australia at Cape Vogel and NW Normanby Island as Late Miocene and Pliocene (3 Ma) paleomagnetic data. Wallace et al. (manuscript in review) find the GPS velocity field in the Woodlark Rift is indicative of block rotations; and they derive elastic block boundary locations similar to the crustal block boundaries inferred based on Late Miocene and Pliocene paleomagnetic data (Fig. 45E). GPS data generally cannot be interpreted in a simple way as being indicative of long term plate motions due to elastic effects; however, my paleomagnetic data indicate vertical-axis rotations relative to Australia that are consistent with the pattern of GPS velocities. This suggests that the contemporary motions currently observed in the Woodlark Rift are expressive of the longer term motions of crustal blocks that have been taking place since $3 \mathrm{Ma}$. 


\section{A. Paleogene arc-continent collision}

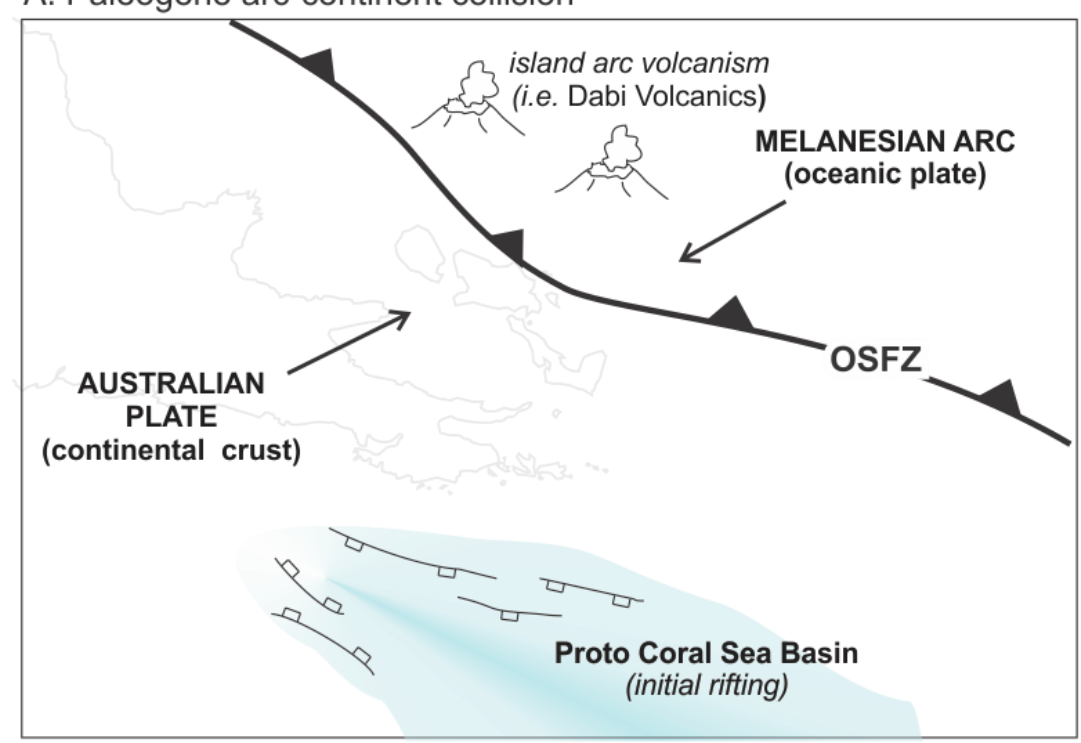

\section{Early Miocene forearc extension}

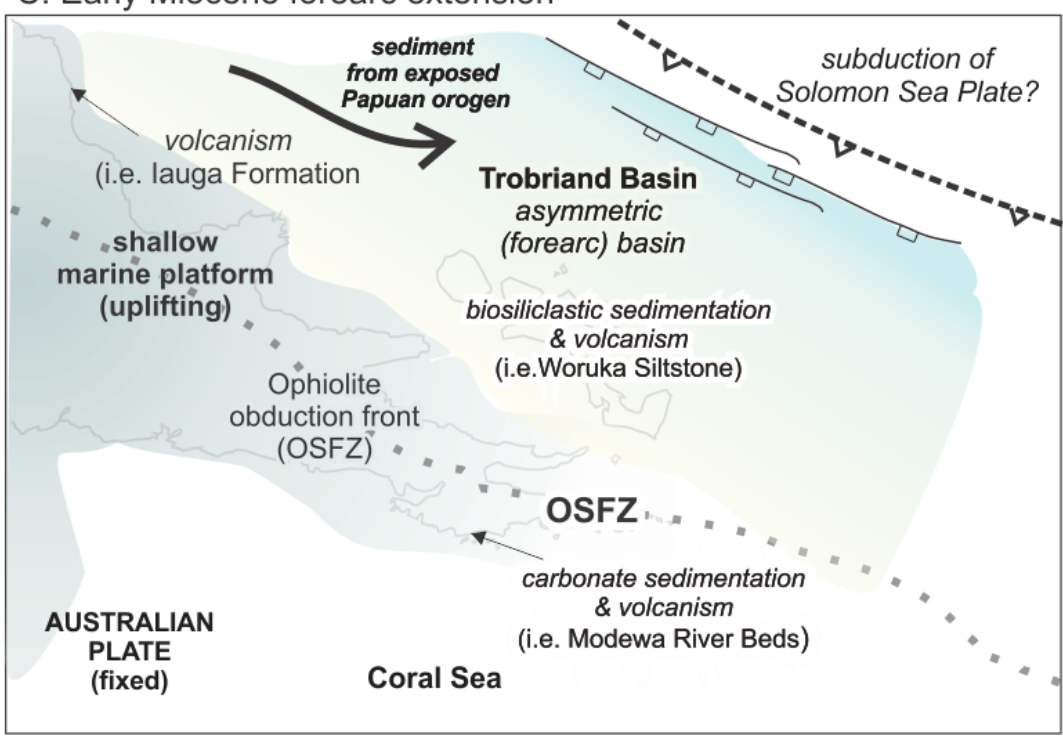

B. Eocene fold thrust belt development north of sea floor spreading.

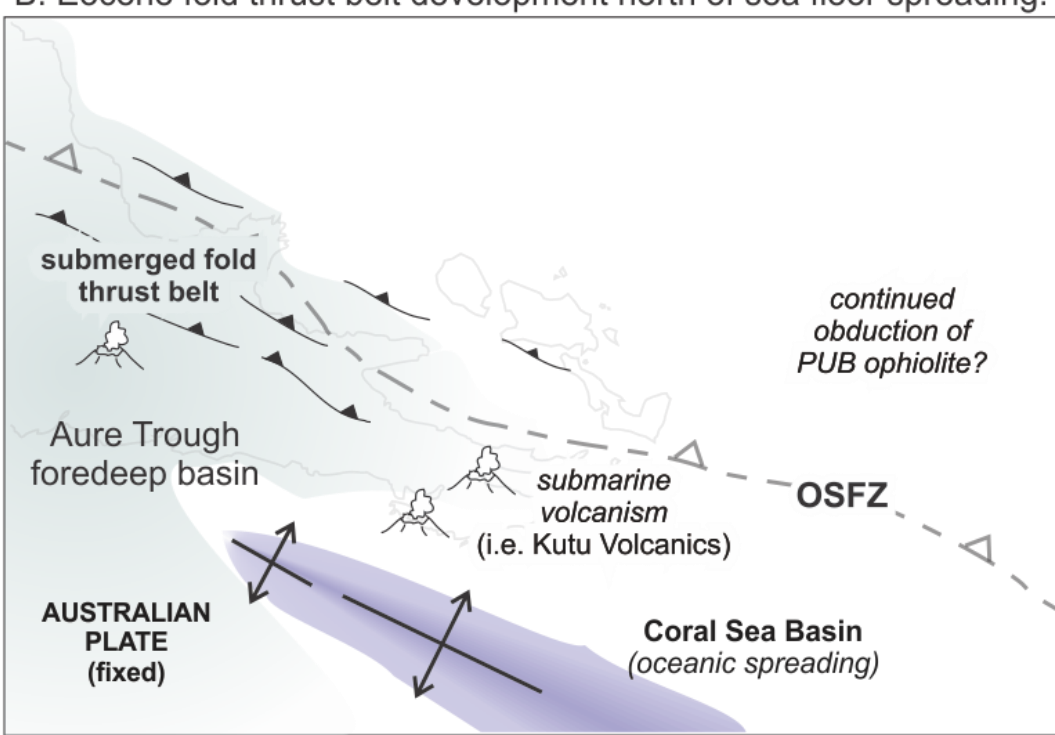

D. Middle to Late Miocene early stage of the Woodlark Rift

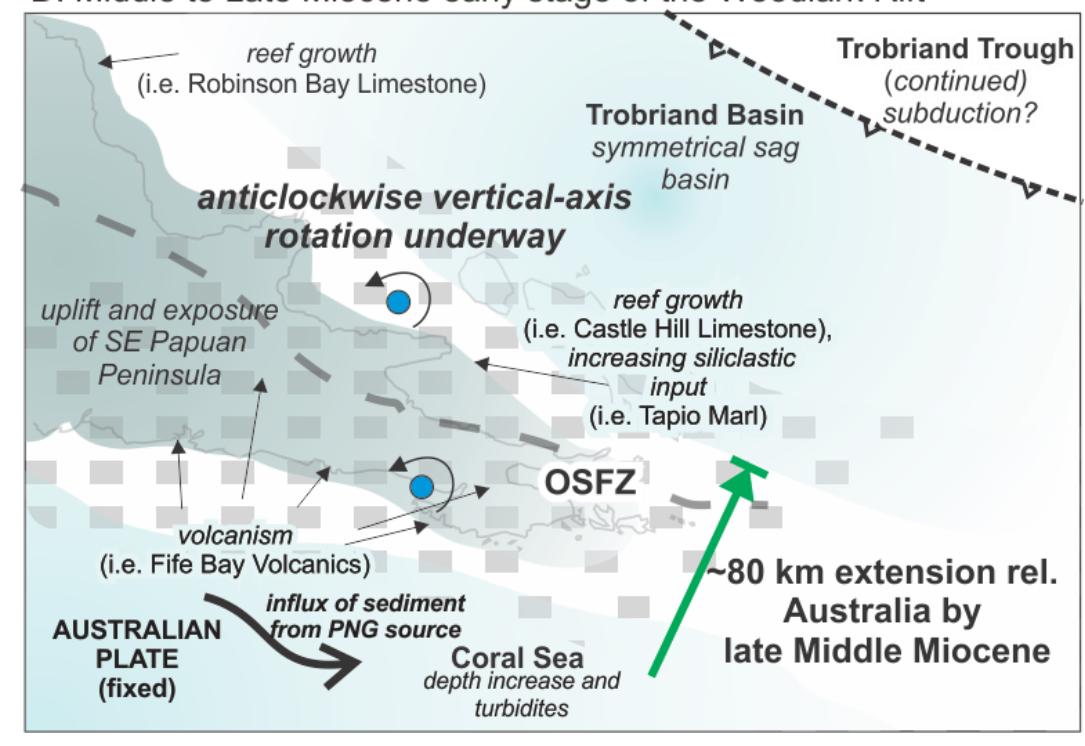


E. Pliocene to Recent crustal block rotations

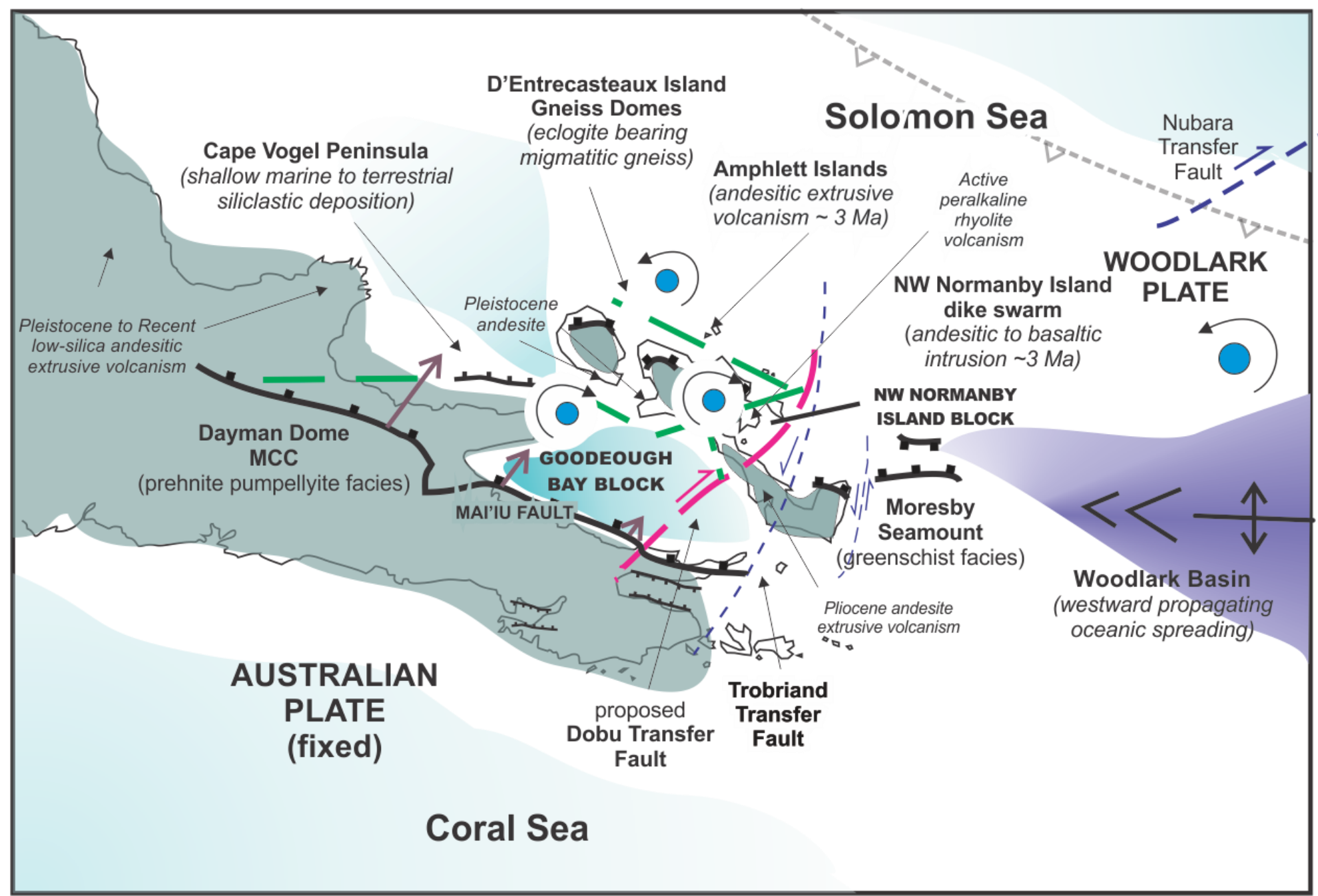

Figure 45. Schematic map representation of SE Papua New Guinea tectonics during the Cenozoic, and my interpretation of Woodlark Rift development since the Middle Miocene. A) arccontinent collision of Australian Plate with the Melanesian arc resulting in subduction to the north, coeval with arc volcanism and initial rifting of the Coral Sea Basin. B) Development of a submerged fold thrust belt and foredeep basin to the north of sea floor spreading in the Coral Sea Basin. C) Possible southward subduction at Trobriand Trough, accompanied by forearc extension to the north of volcanism and sediment starved marine deposition on a shallow platform. D) Early stage of Woodlark Rifting resulting in anticlockwise rotation of Papuan Peninsula sites relative to Australia. E) Pliocene to Recent crustal block rotations in the Woodlark Rift. Extension shifted to localise north of the Papuan Peninsula. Clockwise rotation of Goodenough Bay Block as an expression of NW-SE gradient in slip rate on the Mai'iu normal Fault. Further clockwise rotation of NW Normanby Island block, indicative of dextral transfer fault. Amphlett Islands moving as part of the Woodlark Plate 


\subsection{Possible avenues for further study.}

My interpretation of an anticlockwise vertical-axis rotation of the Papuan Peninsula relative to the Australian Plate during the Miocene, as due to an early phase of extension in the Woodlark Rift, during the Middle to Late Miocene is new. That interpretation is non-unique; and further study is needed to obtain further constraints on the timing of rift onset, and better resolution of the spatial pattern of vertical-axis rotations relative to Australia during the Miocene.

The Middle to Late Miocene phase of extensional rifting that I infer from my new paleomagnetic data is in incompatible with a model of southward convergence and subduction of the Solomon Sea Plate at the Trobriand Trough during the Miocene. Further work to reconcile the inconsistency of those models may benefit from determining paleomagnetic rotations for other Miocene rocks on the Papuan Peninsula. There are several exposures of volcanic and sedimentary rocks (Fig. 1) dated as Miocene on the Papuan Peninsula (Smith \& Davies, 1976; Smith \& Milsom, 1984) that represent potential sample targets. Paleomagnetic sampling of those rocks may contribute to greater spatial and temporal resolution on the inferred vertical-axis rotation of the Papuan Peninsula relative to the Australian Plate during the Miocene.

My inference of the Middle to Late Miocene Woodlark Rift being characterised by a wide zone of extension raises further questions about the origins of some known structures in the current Woodlark Rift (e.g., could the Trobriand Trough be an extensional structure rather than a subduction trench?; does the Nubara Transfer Fault exploit a structural weakness inherited from what was once the northern extent of an early stage of rifting?

Pliocene volcanic rocks in the D'Entrecasteaux Islands also hold potential for paleomagnetic studies; e.g., andesites on Fergusson Island, Goodenough Island, and Normanby Island. The Papuan Peninsula also hosts potential Pliocene volcanic targets in the Musa Valley and Mangalese Plateau high-K basalts.

Further studies of the rotational history of the rift should also focus on further constraining and explaining the reorganisation of the Woodlark Rift around the Late Miocene to Early Pliocene. Based on my paleomagnetic data, that time appears to mark a transition from relatively widespread and uniform anticlockwise vertical-axis rotation relative to Australia, of a zone at least as wide as the current Papuan Peninsula, to the current organisation of crustal blocks that rotate rapidly with respect to one another. Further work is needed to understand how and why that Late Miocene reorganisation of rift kinematics took place. The regional unconformity dated at $8.4 \mathrm{Ma}$ (Taylor \& Huchon, 2002) is certainly conspicuous; does it represent the timing of maximum regional uplift due to thermal expansion in the early stages of rifting?

My inference of a previously unmapped dextral transfer fault that runs through NW Normanby Island (my Dobu Transfer Fault) raises questions about the transfer structures in the eastern Woodlark Rift and western Woodlark Basin. What is the relationship of the Dobu Transfer Fault to the Trobriand Transfer Fault of Little et al. (2007)? Is one fault a younger expression of the other, that initiated to accommodate a change in Woodlark Plate motion? Are both the Trobriand Transfer Fault and the Dobu Transfer Fault active dextral strike slip faults, both contributing to accommodation of the same Woodlark Plate motion? 


\subsection{Conclusions}

I determined characteristic paleomagnetic directions for six Miocene to Pliocene age formations at four localities in the current Woodlark Rift. The declination anomalies of those directions, relative to expected GAD expected field directions for the Australian Plate, are interpreted as reflecting vertical-axis rotations, and provide the basis for my new interpretation of the Woodlark Rift history.

At Cape Vogel Peninsula, on the mainland Papuan Peninsula, I determined anticlockwise declination anomalies of $28.8 \pm 14.0^{\circ}$ and $12.4 \pm 7.1^{\circ}$ for the Early Miocene Woruka Siltstone and Middle Miocene Castle Hill Limestone, respectively, as well as a clockwise declination anomaly of $11.8 \pm 8.4^{\circ}$ for the Late Miocene Tapio Marl.

At the Suau Coast, Late Miocene dikes and flows of the Fife Bay Volcanics yield a declination anomaly of $22.3 \pm 17.5^{\circ}$. At the Suau Coast locality I also observe that directions from the Early Miocene Modewa River Beds are further anticlockwise deflected from Australian Plate expected directions, which correlates with the differential finite vertical-axis rotations relative to Australia observed at Cape Vogel Peninsula.

At the Amphlett Islands, from andesite flows and dikes I determined an anticlockwise vertical-axis rotation of $10.1 \pm 10.1^{\circ}$ relative to the Australian Plate since $3 \mathrm{Ma}$.

At NW Normanby Island, from a swarm of basaltic-andesite dikes, I determined a clockwise declination anomaly of $16.3 \pm 11.4^{\circ}$ relative to Australia since $3 \mathrm{Ma}$

From these data I infer that: 1) Extension in the Woodlark Rift resulted in an anticlockwise verticalaxis rotation of the entire south-eastern part Papuan Peninsula relative to Australia beginning by the Middle Miocene; 2) Around the Late Miocene there was a reorganisation of the rift, which marks the beginning of localization of extensional strain on the Mai'iu fault and onset of complex, differential vertical-axis rotations of crustal blocks farther north within the Woodlark Rift; 3) The vertical-axis rotation of the Amphlett Islands relative to Australia is consistent with the rate of Pliocene sea floor spreading in the Woodlark Basin, and indicates that the area directly north of the D'Entrecasteau Islands is part of the stable Woodlark Plate, which means that the active normal faults that bound the northern coasts of Fergusson and Goodenough Island probably delineate the northern extent of the Woodlark Rift; 4) NW Normanby Island is located on a crustal block that has rapidly been rotating clockwise with respect to Australia, to the west of the newly proposed Dobu Transfer Fault; and 5) The sense of vertical-axis rotations of Pliocene rocks relative to Australia that are determined from my new paleomagnetic data correlates with the pattern of present day GPS observations, and suggest that the current kinematics of the continental Woodlark Rift were established by at least 3 Ma. 


\section{References}

Abers, G. A., 2001, Evidence for seismogenic normal faults at shallow depths in continental rifts, in Wilson, R. C. L., Whitmarsh, R. B., Taylor, B., and Froitzham, N., eds., Non-volcanic Rifting of Continental Margins, Volume 187: London, The Geological Society of London, p. 305-318.

Abers, G.A., Ferris, A., Craig, M., Davies, H., Lerner-Lam, A.L., Mutter, J.C., and Taylor, B., 2002, Mantle compensation of active metamorphic core complexes at Woodlark rift in Papua New Guinea: Nature, v. 418, p. $862-865$.

Abers, G.A., Roecker, S.W., 1991. Deep structure of an arc-continent collision: Earthquake relocation and inversion for upper mantle P and S wave velocities beneath Papua New Guinea. Journal of Geophysical Research 96, 6379-6401.

Ashley, P.M., and Flood, R.H., 1981, Low-K tholeiites and high-K igneous rocks from Woodlark Island, Papua New Guinea: Journal of the Geological Society of Australia, v. 28, p. 227-240.

Baldwin, S.L., Fitzgerald, P.G., and Webb, L.E., 2012, Tectonics of the New Guinea Region: Annual Review of Earth and Planetary Sciences, v. 40, p. null.

Baldwin, S.L., Ireland, T.R., 1995. A tale of two eras: Plio-Pliestocene unroofing of Cenozoic and late Archean zircons from active metamorphic core complexes, Solomon Sea, Papua New Guinea. Geology 23, 1023-1026.

Baldwin, S.L., Lister, G.S., Hill, E.J., Foster, D.A., and McDougall, I., 1993, Thermochronologic constraints on the tectonic evolution of active metamorphic core complexes, D'Entrecasteaux Islands, Papua New Guinea: Tectonics, v. 12, p. 611-628.

Baldwin, S.L., Monteleone, B.B., Webb, L.E., Fitzgerald, P.G., Grove, M., and Hill, E.J., 2004, Pliocene eclogite exhumation at plate tectonic rates in eastern Papua New Guinea: Nature, v. 431, p. 263-267.

Baldwin, S. L., Webb, L. E., and Monteleone, B. D., 2008, Late Miocene coesite-eclogite exhumed in the Woodlark Rift: Geology, v. 36, p. 735-738.

Benes, V., Scott, S. D., and Binns, R. A., 1994, Tectonics of rift propagation into a continental margin: Western Woodlark Basin, Papua New Guinea: Journal of Geophysical Research, v. 99 (no. B3), p. 4439-4455.

Burns, R. E., Andrews, j. E., et al., 1973 - Initial Reports of the Deep Sea Drilling Project, vol. 21. Washington, U.S. govt. Printing office.

Catalano, J P, 2012, Geochemical and 40Ar/39Ar constraints on the evolution of volcanism in the Woodlark Rift, Papua New Guinea, Earth Sciences - Theses.

Célérier, B., Louvel, V., Le Gall, B., Gardien, V., and Huchon, P., 2002, Presentation and structural analysis of FMS electrical images in the western Woodlark Basin. In Huchon, P., Taylor, B., and Klaus, A. (Eds.), Proc. ODP, Sci. Results, 180

Chadima, M., Hrouda, F. 2006. Remasoft 3.0 a user-friendly paleomagnetic data browser and analyzer. Travaux Géophysiques, XXVII, 20-21

Coffin, M.F., Sawyer, D.S., Reston, T.J., and Stock, J.M., 2006. Continental breakup and sedimentary basin formation. Eos Trans. AGU, 87:528, doi:10.1029/2006E0470006

Colletini, C., 2011, The mechanical paradox of low-angle normal faults: Current understanding and open questions: Tectonophysics, v. 510, p. 253-268. 
Daczkco, N., Caffi, P., Halpin, J.L., Mann, P., 2009. Exhumation of the Dayman dome metamorphic core complex, eastern Papua New Guinea. Journal of Metamorphic Geology 27, 405-422.

Daczko, N. R., Caffi, P., and Mann, P. R., 2011, Structural evolution of the Dayman dome metamorphic core complex, eastern Papua New Guinea: Geological Society of America Bulletin, v. 123, p. 2335-2351.

Dallwitz, W.B., Green, D.H., and Thompson, J.E., 1966, Clinoenstatite in a volcanic rock from the cape vogel area, papua: Journal of Petrology, v. 7, p. 375-403.

Davies, H., 1971, Peridotite-gabbro-basalt complex in eastern Papua: an overthrust plate of oceanic mantle and crust: Australian Bur: Mineral Resources Bull, v. 128, p. 48.

Davies, H.L., 1980a. Folded thrust fault and associated metamorphics in the Suckling-Daymon massif, Papua New Guinea. American Journal of Science 280A, 171-191.

Davies, H., 1980b, Crustal Structure And Emplacement Of Ophiolite In Southeastern Papua New Guinea, Colloques Internationaux du Centre 117 National de la Recherche Scientifique, Volume 5: Grenoble, France, Centre National dela Recherche Scientifique, p. 17 - 33.

Davies, H., and Jaques, A., 1984, Emplacement of ophiolite in Papua New Guinea: Geological Society, London, Special Publications, v. 13, p. 341.

Davies, H.L., and Ives, D.J., 1965, The Geology of Fergusson and Goodenough Islands, Papua, Bureau of Mineral Resources, Geology and Geophysics, p. 64.

Davies, H., Warren, R.G., 1988. Origin of eclogite-bearing, domed, layered metamorphic complexes ("core complexes") in the D'Entrecasteaux islands, Papua New Guinea. Tectonics 7, 1-21.

Davies, H. L., and Warren, R. G., 1992, Eclogites of the D'Entrecasteaux Islands: Contributions to Mineralogy and Petrology, v. 112, p. 463-474.

Davies, H.L., Williamson, A.N., 1998. Buna, Papua New Guinea, 1:250,000 Geological Series. Geol. Survey Papua New Guinea Explanatory Notes SC/55-3, Port Moresby, Papua New Guinea.

Timescales of Partial Melting and UHP Exhumation: Ca-Tims Results From Melt Fractions Exposed In the D’Entrecasteaux Islands, Papua New Guinea Desormeau, J. W., Gordon, Stacia, Little, Timothy A., Bowring, Samuel A., Earth, Atmospheric, and Planetary Sciences, Massachusetts Institute of Technology, 77 Massachusetts Avenue, Cambridge, MA 02139

DiCaprio, L., Müller, R.D., and Gurnis, M., 2010, A dynamic process for drowning carbonate reefs on the northeastern Australian margin: Geology, v. 38, no. 1, p. 11-14,

Dow, D.G., 1977. A geological synthesis of Papua New Guinea. Australian Bureau of Mineral Resources, Geology and Geophysics Bulletin 201, p.41

Ellis, S.M., Little, T.A., Wallace, L.M., Hacker, B.R., and Buiter, S.J.H., 2011, Feedback between rifting and diapirism can exhume ultrahigh-pressure rocks: Earth and Planetary Science Letters, v. 311, p. 427-438.

Feinberg, J. M., G. R. Scott, P. R. Renne, and H.-R. Wenk , 2005, Exsolved magnetite inclusions in silicates: Features determining their remanence behavior, Geology, 33, 513 - 516.

Ferris, A., Abers, G.A., Zelt, B., Taylor, B., and Roecker, S., 2006, Crustal structure across the transition from rifting to spreading: The Woodlark rift system of Papua New Guinea: Geophysical Journal International, v. 166, 
p. 622-634.Fisher, R. A., 1953. Dispersion on a sphere. Proceeds of the Royal Society of London, Series A(217), pp. 295-305.

G. Fitz, P. Mann, 2013, Tectonic uplift mechanism of the Goodenough and Fergusson Island gneiss domes, eastern Papua New Guinea: Constraints from seismic reflection and well data Geochemistry Geophysics Geosystems, 14, pp. 3969, pp.

Francis, G., Lock, G., Okuda, Y., 1987. Seismic stratigraphy and structure of the area to the southeast of the Trobriand Platform. Geo-Mar Lett. 7, 121-128.

Gaina, C., Müller, R.D., Royer, J.Y., and Symonds, P., 1999, Evolution of the Louisiade triple junction: Journal of Geophysical Research, v. 104, p. 12,927-12,939.

Gee, J. S. \& Kent, D. V. (2007). Source of oceanic magnetic anomalies and the geomagnetic polarity timescale. In M. Kono (Ed.), Geomagnetism, volume 5 of Treatise on Geophysics (pp. 455-507). Elsevier.

Goodliffe, A., Taylor, B., Martinez, F., Hey, R., Maeda, K., Ohno, K., 1997. Synchronous reorientation of the Woodlark basin spreading center. Earth and Planetary Science Letters 146, 233-242.

Gordon, S. M., Little, T. A., Hacker, B. R., Bowring, S. A., Korchinski, M., Baldwin, S. L., Kylander-Clark, A. R. C., and Millet, M.-A., 2012, Multi-stage exhumation of young UHP-HP rocks: timescales of melt crystallization in the D'Entrecasteaux Islands, southeastern Papua New Guinea: Earth and Planetary Science Letters, v. 351-352, p. 237-246.

Hegner, E., and Smith, I.E.M., 1992, Isotopic compositions of late Cenozoic volcanics from southeast Papua New Guinea: evidence for multi-component sources in arc and rift environments: Chemical geology, v. 97, p. 233-249.

Hill, E. J., 1994, Geometry and kinematics of shear zones formed during continental extension in eastern Papua New Guinea: Journal of Structural Geology, v. 16, p. 1093-1105.

Hill, E.J., and Baldwin, S.L., 1993, Exhumation of high-pressure metamorphic rocks during crustal extension in the D'Entrecasteaux region, Papua New Guinea: Journal of Metamorphic Geology, v. 11, p. 261-277.

Hill, E.J., Baldwin, S.L., Lister, G.S., 1995. Magmatism as an essential driving force for formation of active metamorphic core complexes in eastern Papua New Guinea. Journal of Geophysical Research 100, 1044110451.

Hill, K., and Hall, R., 2003, Mesozoic-Cenozoic evolution of Australia's New Guinea margin in a west Pacific context: Evolution and dynamics of the Australian plate, v. 22, p. 265-290.

Hill, K.C., and Raza, A., 1999, Arc-continent collision in Papua Guinea: Constraints from fission track thermochronology: Tectonics, v. 18, p. 950-966.

Honza, E., Davies, H., Keene, J., and Tiffin, D., 1987, Plate boundaries and evolution of the Solomon Sea region: Geo-Marine Letters, v. 7, p. 161-168.

Jerram, D., Petford, N., 2011, The Field Description of Igneous Rocks: Second Edition, The Geological Field Guide Series, Wiley-Blackwell, West Sussex, U.K. 256 pp

Johnson, R.W., Mackenzie, D.E., and Smith, I.E., 1971, Seismicity and late Cenozoic volcanism in parts of PapuaNew Guinea: Tectonophysics, v. 12, p. 15-22. 
Johnson, R.W., Mackenzie, D.E., and Smith, I.E.M., 1978, Delayed partial melting of subduction-modified mantle in Papua New Guinea: Tectonophysics, v. 46, p. 197-216.

Johnson, T., and Molnar, P., 1972, Focal Mechanisms and Plate Tectonics of the Southwest Pacific: Journal of Geophysics. Res., v. 77, p. 5000-5032.

Joshima, M., Okuda, Y., Murakami, F., Kishimoto, K., and Honza, E., 1986, Age of the Solomon Sea Basin from magnetic lineations: Geo-Marine Letters, v. 6, p. 229-234.

Kington, J. D., and Goodliffe, A. M., 2008, Plate motions and continental extension at the rifting to spreading transition in Woodlark Basin, Papua New Guinea: Can oceanic plate kinematics be extended into continental rifts?: Tectonophysics v. 458, p. 82-95

Kirschvink, J.L., 1980. The least-squares line and plane and the analysis of paleomagnetic data, Geophys. J. R. Astron. Soc., 62, 699-718

Little, T.A., Baldwin, S.L., Fitzgerald, P.G., Monteleone, B., 2007. Continental rifting and metamorphic core complex formation ahead of the Woodlark Spreading Ridge, D'Entrecasteaux Islands, Papua New Guinea. Tectonics 26, TC1002, doi:1010.1029/2005TC001911.

Little, T.A., Hacker, B.R., Gordon, S.M., Baldwin, S.L., Fitzgerald, P.G., Ellis, S., and Korchinski, M., 2011, Diapiric exhumation of Earth's youngest (UHP) eclogites in the gneiss domes of the D'Entrecasteaux Islands, Papua New Guinea: Tectonophysics, v. 510, p. 39-68.

Little, T. A, Hacker, B. R., Brownlee, S. and Seward, G., 2013, Microstructures and quartz lattice preferred orientations in the eclogite-bearing migmatitic gneisses of the D'Entrecasteaux Islands, Papua New Guinea: Geochemistry, Geophysics, Geosystems (G3), v. 14, doi:10.1002/ggge.20132.

Little, T. A., Hacker, B. R., Gordon, S. M., Baldwin, S. L. and Fitzgerald, P. G., Ellis, S., and Korchinski, M., 2011, Diapiric exhumation of the world's youngest (UHP) eclogites in the gneiss domes of the D'Entrecasteaux Islands Papua New Guinea: Tectonophysics, Paper TECTO-125157, 30 pp, doi:10.1016/j.tecto.2011.06.006.

Lus, W.Y., McDougall, I., and Davies, H.L., 2004, Age of the metamorphic sole of the Papuan Ultramafic Belt ophiolite, Papua New Guinea: Tectonophysics, v. 392, p. 85-101.

Luyendyk, B.P., MacDonald, K.C., and Bryan, W.B., 1973. Rifting history of the Woodlark Basin in the southwest Pacific: Geol. Soc. Am. Bull., v. 84, p. 1125.

Mann, P., And F.W. Taylor (2002), Emergent late Quaternary coral reefs of eastern Papua New Guinea constrain the regional pattern of oceanic ridge propagation, Eos Trans. AGU, Fall Meeting Suppl., Abstract T52C-1206.

Martinez, F., Goodliffe, A.M., and Taylor, B., 2001, Metamorphic core complex formation by density inversion and lower-crust extrusion: Nature, v. 411, p. 930-934.

Martinez, F., and Taylor, B., 2002, Mantle wedge control on back-arc crustal accretion: Nature, v. 416, p. 417420.

Martinez, F., Taylor, B. \& Goodliffe, A., 1999. Contrasting styles of seafloor spreading in the Woodlark Basin: Indications of rift induced secondary mantle convection. Journal of Geophysical Research, pp. 12909-12926.

Merrill, R. T. and McElhinny, M. W., 1983, The Earth's Magnetic Field: Its history, origin, and planetary perspective, Academic Press, London. 
Monteleone, B., 2007, Timing and conditions of formation of the D'Entrecasteaux Islands, Papua New Guinea: Syracuse, NY, Syracuse University. 121

Monteleone, B.D., Baldwin, S.L., Ireland, T.R., and Fitzgerald, P.G., 2001, Thermochronologic constraints for the tectonic evolution of the Moresby Seamount, Woodlark Basin, Papua New Guinea, Proceeding of the oceanic drilling program, scientific results, Volume 180, p. 35.

Mutter, J.C., 1977. The Queensland Plateau, Bur. Miner. Res. Aust. Bulletin, p. 179.

Mutter, J. C., Mutter, C. Z., and Fang, J., 1996, Analogies to oceanic behaviour in the continental breakup of the western Woodlark basin: Nature, v. 380, p. 333-336.

Mutter, J.C., J.S. Floyd, A. Lerner-Lam, B. Taylor, G. Abers, and A. Ferris, 2000, Active and natural seismicity investigation of continental breakup in the western Woodlark Basin, Eos, Transactions AGU, S414,.

Neel, L. (1955). Some Theoretical Aspects of Rock-magnetism in: Advances in Physics 4, 191-243.

Pouliquen, G., Gallet, Y., Dyment, J., Patriat, P. and Tamura, C. (2001), A geomagnetic record over the last 3.5 million years from deep-tow magnetic anomaly profiles across the Central Indian Ridge, Journal of Geophysical Research v. 106, p. 10941-10960.

Quarles van Ufford, A.Q., and Cloos, M., 2005, Cenozoic tectonics of New Guinea: AAPG bulletin, v. 89, p. 119.

Robertson, A.H.F., Awadallah, S.A.M., Gerbaudo, S., Lackschewitz, K.S., Monteleone, B.D., Sharp, T.R., and the ODP Leg 180 Shipboard Scientific Party, 2001. Evolution of the Miocene-Recent Woodlark Rift Basin, SW Pacific, inferred from sediments drilled during Ocean Drilling Program Leg 180. In Wilson, R.C.L., Froitzheim, N., Taylor, B., and Whitmarsh, R.B. (Eds.), Non-Volcanic Rifting of Continental Margins: A Comparison of Evidence from Land and Sea. Spec. Publ.-Geol. Soc. London, 187:335-372.

Rogerson, R., 1991, New stratigraphic and whole-rock geochemical data from the Waria River area, northern Papuan Peninsula, Geological Survey of Papua New Guinea.

Rogerson, R., and Hilyard, D.B., 1989, Scrapland: a suspect composite terrane in Papua New Guinea, Geological Survey of Papua New Guinea.

Sawyer D.S., Coffin M.F., Reslen T.J., Stock J.M., Hopper J.R., 2007, COBBOOM, The Continental Breakup and Birth of Oceans Mission, Scientific Drilling, 5, 13-25.

Shillington, D. J., Scott, C. L., Minshull, T. A., Edwards, R. A., Brown, P. J. \& White, N. Abrupt transition from magma-starved to magma-rich rifting in the eastern Black Sea. Geology 37, 7-10 (2009).

Smith, I. E., 1973-Late Cainozoic volcanism in the southeast Papuan islands. Bur. Miner. Resour. Aust. Rec. 1973/67 (unpubl.).

Smith, I.E., 1976a, Geology of the southeast Papuan mainland, Australian Bureau of Mineral Resources. 122

Smith, I.E.M., 1976b, Volcanic rocks from southeastern Papua: The evolution of volcanism at a plate boundary, Australian National University.

Smith, I.E.M., 1976c. Peralkaline rhyolites of the D'Entrecasteaux Islands, Papua New Guinea, in: Johnson, R.W. (Ed.), Volcanism in Australasia. Elsevier, Amsterdam, pp. 275-285.

Smith, I.E.M., 1982, Volcanic evolution in eastern Papua: Tectonophysics, v. 87, p. 315-333. 
Smith, I.E.M., Chappell, B.W., Ward, G.K., and Freeman, R.S., 1977, Peralkaline rhyolites associated with andesitic arcs of the southwest Pacific: Earth and Planetary Science Letters, v. 37, p. 230-236.

Smith, I.E.M., Compston, W., 1982. Strontium isotopes in Cenozoic volcanic rocks from southeastern Papua New Guinea. Lithos 15, 200-206.

Smith, I.E.M., Milsom, J.S., 1984. Late Cenozoic volcanism and extension in the eastern Papua, in: Kokelaar, B.P., Howells, M.F. (Eds.), Marginal Basin Geology, pp. 163-171.

Smith, I.E., 1972, High-potassium intrusives from southeastern Papua: Contributions to Mineralogy and Petrology, v. 34, p. 167-176.

Smith, I.E.M., Taylor, S.R., and Johnson, R.W., 1979, REE-fractionated trachytes and dacites from Papua New Guinea and their relationship to andesite petrogenesis: Contributions to Mineralogy and Petrology, v. 69, p. 227-233.

Spencer, J. E., 2010, Structural analysis of three extensional detachment faults with data from the 2000 SpaceShuttle Radar Topography Mission: GSA Today, v. 20 (no. 8), p. 1-10.

Stolz, A.J., Davies, G.R., Crawford, A.J., and Smith, I.E.M., 1992, Sr, Nd and Pb isotopic compositions of calcalkaline and peralkaline silicic volcanics from the D'Entrecasteaux Islands, Papua New Guinea, and their tectonic significance: Mineralogy and Petrology, v. 47, p. 103-126.

Tauxe, 2010. Essentials of Paleomagnetism. s.I.:s.n.

Taylor, B., 1999. Background and regional setting, in: Taylor, B., al., e. (Eds.). Ocean Drilling Program, Texas A \& M University, College Station, pp. 1-20.

Taylor, B., Goodliffe, A.M., Martinez, F., 1999. How Continents break-up: Insights from Papua New Guinea. Journal of Geophysical Research 104, 7497-7512.

Taylor, B., Huchon, P., 2002. Active continental extension in the western Woodlark basin: A synthesis of Leg 180 results, in: Huchon, P., Taylor, B., Klaus, A. (Eds.), Proceedings of the Ocean Drilling Program, Scientific Results Volume 180. Ocean Drilling Program, Texas A \& M University, College Station, Texas, pp. 1-36 (CD ROM).

Taylor, B., Goodliffe, A., Martinez, F., and Hey, R., 1995, Continental rifting and initial seafloor spreading in the Woodlark basin: Nature, v. 374, p. 534-537.

Trail, D.S., 1967, Geology of Woodlark Island, Papua, by D. S. Trail: (Canberra), Bureau of Mineral Resources, Geology and Geophysics.

Turner, G. M., D. M. Michalk, H. E. G. Morgans, and J. O. Walbrecker (2007), Early Miocene Magnetostratigraphy and a new palaeomagnetic pole position from New Zealand, Earth Planets Space, 59, 841-851.

Van Wijk, J.W., Blackman, D.K., 2005, Dynamics of continental rift propagation: the endmember modes. Earth and Planetary Science Letters 229, 247-258.Walker, D.A., and McDougall, I., 1982, 40Ar/39Ar and K/Ar dating of altered glassy volcanic rocks: the Dabi Volcanics, P.N.G: Geochimica et Cosmochimica Acta, v. 46, p. 21812190.

Veevers, J. J., and Z. X. Li (1991), Review of seafloor spreading around Australia. Marine magnetic anomaly modelling, Aust. J. Earth Sci., 38, 
391-408,

Verosub, K.L., 1977, Depositional and post-depositional processes in the magnetization of sediments, Rev. Geophys. Space Phys., v. 15, 129-143

Wallace, L.M., Stevens, C., Silver, E., McCaffrey, R., Loratung, W., Hasiata, S., Stanaway, R., Curley, R., Rosa, R., and Taugaloidi, J., 2004, GPS and seismological constraints on active tectonics and arc-continent collision in Papua New Guinea: Implications for mechanics of microplate rotations in a plate boundary zone: J. geophys. Res, v. 109.

Walker, D. I., McDougall, I., 1982, ${ }^{40} \mathrm{Ar} /{ }^{39} \mathrm{Ar}$ and K-Ar dating of altered glassy volcanic rocks: the Dabi Volcanics, PNG, Geochemica et Cosmochemica Acta, 46, 2181-2190.

Wang, Z., Stein, C.A., 1992, Subsidence of the Gulf of Papua in the Cenozoic, Tectonophysics, 205, p 409-426.

Webb, L.E., Baldwin, S.L., Fitzgerald, P.G., Castellani, L., and Zirakparvar, N.A., 2009, Structural Analysis of the Louisiade Archipelago, southeastern Papua New Guinea, American Geophysical Union, Fall Meeting.

Webb, L.E., Baldwin, S.L., Little, T.A., and Fitzgerald, P.G., 2008, Can microplate rotation drive subduction inversion?, Geology, v. 36, p. 823-826.

Weissel, J.K., and Watts, A.B., 1979, Tectonic evolution of the Coral Sea basin: Journal of Geophysical Research, v. 84, p. $4572-4582$.

Weissel, J.K., Taylor, B., Karner, G.D., 1982. The opening of the Woodlark Basin, subduction of the Woodlark spreading system, and the evolution of northern Melanesia since mid-Pliocene time. Tectonophysics 87, 253277.

Westaway, R., 2005. Active low-angle normal faulting in the Woodlark extensional province, Papua New Guinea: A physical model. Tectonics 24, TC6003, doi:6010.1029/2004TC001744.

Westaway, R., 2007. Correction to "Active low-angle normal faulting in the Woodlark extensional province, Papua New Guinea: A physical model". Tectonics 26, TC1003.

Wilson, M.E.J. \& Hall, R. 2010. Tectonic influences on SE Asian carbonates and their reservoir development. In: Morgan, W.A., George, A.D., Harris, P. M., Kupecz, J.A. \& Sarg, J.F. (Eds.) Cenozoic Carbonate Systems of Australasia. SEPM Special Publication, 95, 122-149

Worthing, M.A., 1988, Petrology and tectonic setting of blueschist facies metabasites from the Emo Metamorphics of Papua New Guinea: Australian Journal of Earth Sciences, v. 35, p. 159-168.

Worthing, M.A., and Crawford, A.J., 1996, The igneous geochemistry and tectonic setting of metabasites from the emo metamorphics, Papua New Guinea; A record of the evolution and destruction of a backarc basin: Mineralogy and Petrology, v. 58, p. 79-100.

Yan, C., and Kroenke, L., 1993, A plate tectonic reconstruction of the Southwest Pacific, 0-100 Ma, Volume 130, College Station Texas, p. 697-709.

Zirakparvar, N., Baldwin, S., and Vervoort, J., 2011, Lu-Hf garnet geochronology applied to plate boundary zones: Insights from the (U) HP terrane exhumed within the Woodlark Rift: Earth and Planetary Science Letters.

Zirakparvar, N.A., 2012, Geochemical and Geochronological Constraints on the Origin and Evolution of Rocks in the Active Woodlark Rift of Papua New Guinea: Syracuse, Syracuse University.

Zirakparvar, N. A., Baldwin, S. L., and Vervoort, J. D., 2013 The origin and geochemical evolution of the Woodlark Rift of Papua New Guinea: Gondwana Research, v. 23, p. 931-943. 
Zijderveld, J. D. A. (1967). A.C. demagnetization of rocks: analysis of results. In Methods in Paleomagnetism. D. Collinson, K. Creer and S. Runcorn. Amsterdam, Elsevier: 254-286. 
APPENDIX A: Demagnetization Data

APPENDIX B: Sample Catalogue

Appended to disc below 


\section{APPENDIX C: Orientation Conventions}

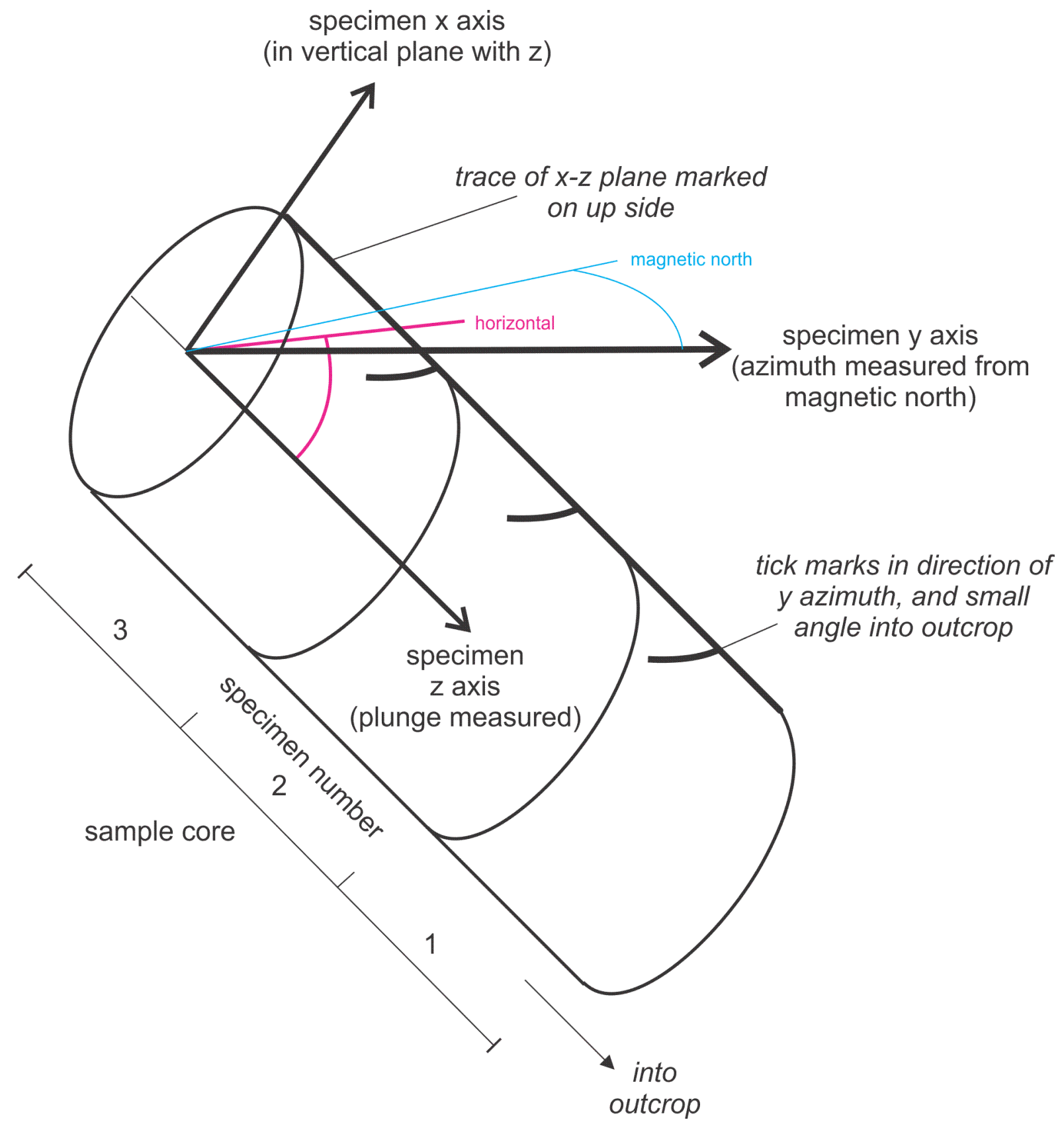




\section{APPENDIX D: Equations}

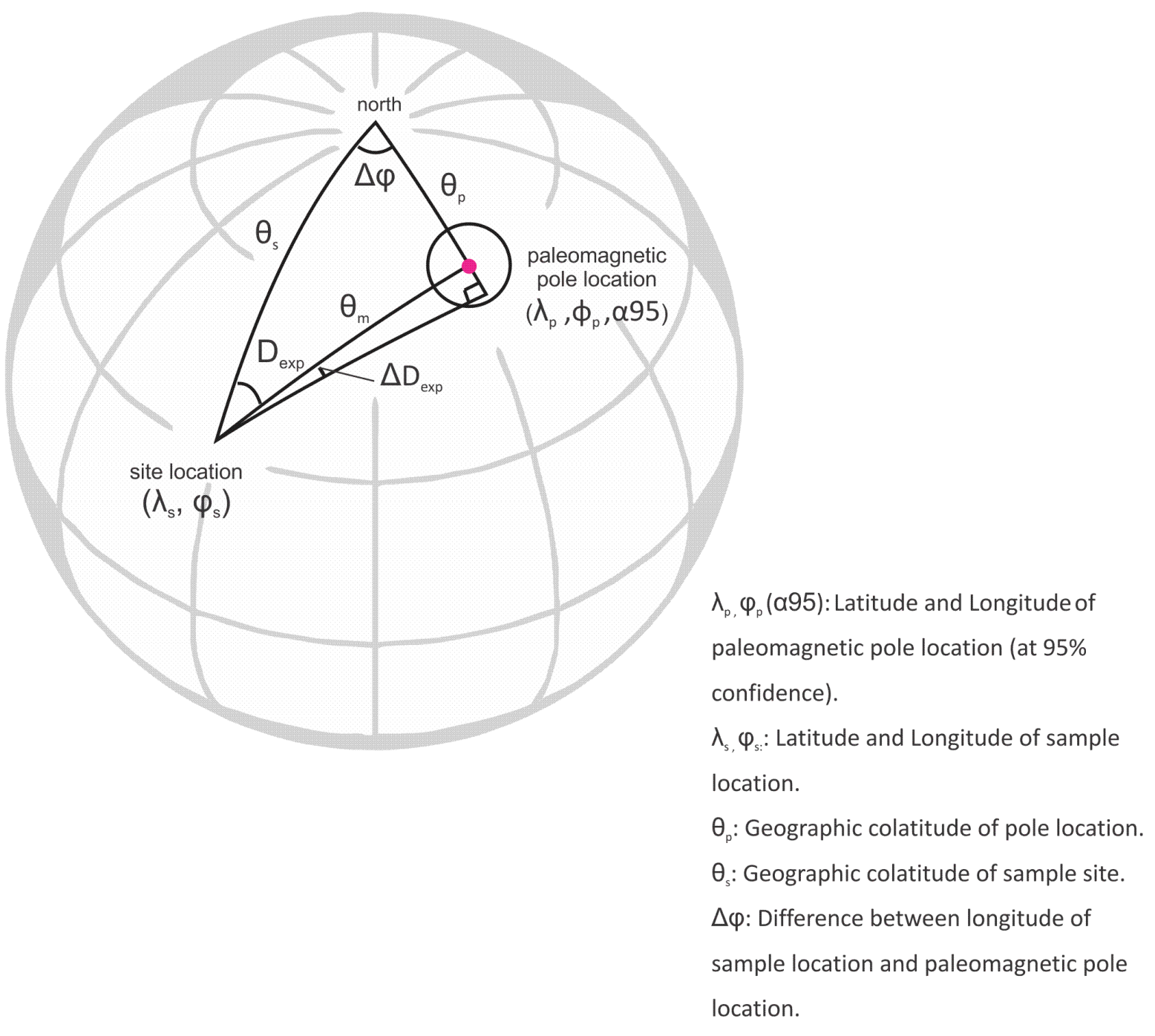

The magnetic colatitude of the sample site $\left(\theta_{\mathrm{m}}\right)$ is calculated by: $\cos \theta_{m}=\cos \theta_{p} \cdot \cos \theta_{s}+\sin \theta_{p} \cdot \sin \theta_{s} \cdot \cos \Delta \varphi$

The expected declination follows from this by:

$$
I_{\text {exp }}=\tan ^{-1}\left(2 \cot \theta_{m}\right)
$$

And the Expected declination $\left(D_{\text {exp }}\right)$ corresponding to the paleomagnetic pole location is calculated by:

$$
\cos D_{\text {exp }}=\left(\sin \lambda_{p}-\sin \lambda_{s} \cdot \cos \theta_{m}\right) /\left(\cos \lambda_{s} \cdot \sin \theta_{m}\right)
$$

Uncertainty in the expected declination $\left(\Delta \mathrm{D}_{\text {exp }}\right)$ is calculated by:

$$
\Delta D_{\text {exp }}=\sin ^{-1}\left(\sin \alpha 95 / \sin _{\text {exp }} \theta_{m}\right)
$$

